MONOGRAPHIAE BOTANICAE

Vol. 99, 2009

IZABELA KAŁUCKA

\title{
MACROFUNGI IN THE SECONDARY SUCCESSION ON THE ABANDONED FARMLAND NEAR THE BIAŁOWIEŻA OLD-GROWTH FOREST
}

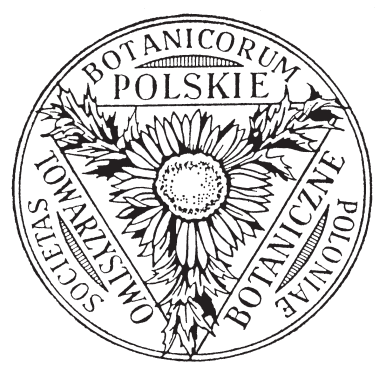


Edited with financial support of the Ministry of Science and Higher Education

\author{
EDITORIAL BOARD \\ Krystyna CZYŻEwSKA (Editor-in-Chief) \\ Małgorzata RUSZKIEWICZ-MiCHALSKA (Editorial Assistant)
}

\title{
EDITORIAL COUNCIL
}

Jacek HeRBICH (Gdańsk), Bogdan JACKOWIAK (Poznań), Stefania LOSTER (Kraków), Zbigniew MireK (Kraków), Romuald OlaCZeK (Łódź) - president, Agnieszka PoPIELA (Szczecin), Valerijus RAŠOMAVIČIUS (Vilnius), Krzysztof RosTAŃSKI (Katowice), Máría ZALIBERovÁ (Bratislava), Waldemar ŻUKOWSKI (Poznań)

\section{EDITORIAL OFFICE}

Department of Algology and Mycology

University of Łódź

12/16 Banacha Str.

PL-90-237 Łódź

\section{COVER DESIGN BY}

Zdzisław WALTER \& Janusz B. FALIŃSKI

(C) Copyright by the Polish Botanical Society, Warszawa 2009 


\section{CONTENTS}

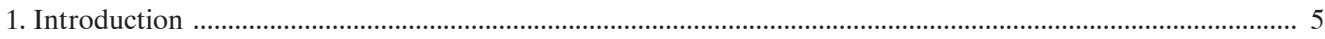

1.1. Fungal succession and old-fields ........................................................................................................ 5

1.2. Scheme of spontaneous secondary succession on abandoned fields near the Białowieża

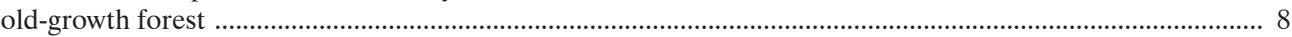

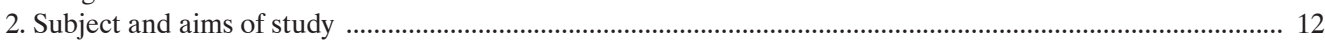

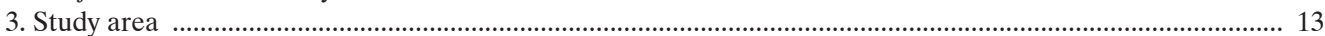

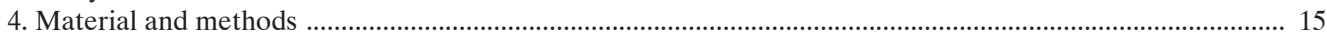

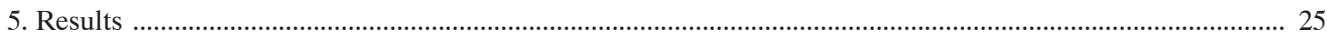

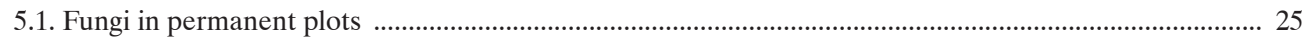

5.2. Changes in species and sporocarp distribution along successional gradient ........................................... 34

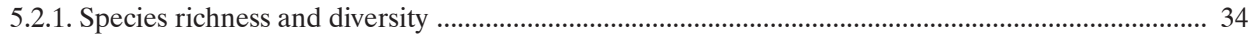

5.2.2. Species abundance patterns ......................................................................................................... 39

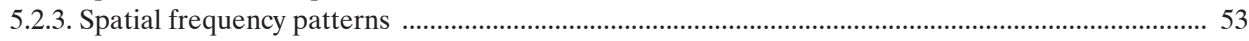

5.2.4. Ectomycorrhizal carpophore production ........................................................................................ 53

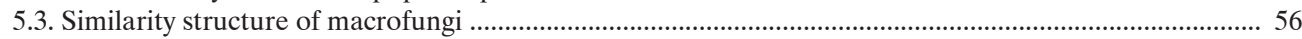

5.4. Quantitative changes in ectomycorrhizal roots along successional gradient .............................................. 60

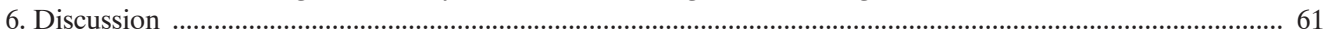

6.1. Macrofungi in the scheme of spontaneous secondary succession on the abandoned fields

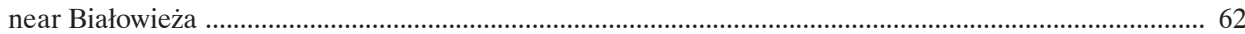

6.2. Patterns of fungal succession in post-agricultural land ........................................................................... 66

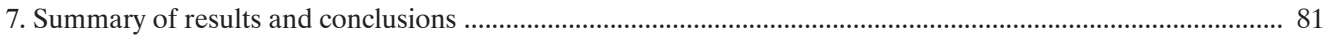

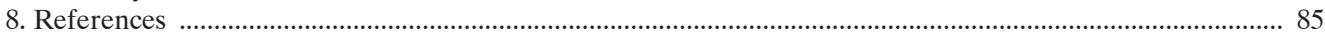

Appendix 1. Soil analysis in the permanent plots ........................................................................................... 95

Appendix 2. Vegetation description in the permanent plots ........................................................................... 101

Appendix 3. Macrofungi in the plots representing subsequent phases of vegetation succession in the old-fields near the Białowieża old-growth forest ............................................................. 115

Appendix 4. Results of k-mean analysis of fungi ............................................................................................ 141

Appendix 5. List of Basidiomycota in the old-field successional series near the Białowieża old-growth forest (Jelonka reserve and Czechy Orlańskie reserve) with notes on distribution and substrates 


\begin{abstract}
Izabela KaŁucKa. Macrofungi in the secondary succession on the abandoned farmland near the Biatowieza oldgrowth forest. Monogr. Bot., Vol. 99, 155 pp., 2009.

The paper deals with the succession of basidiomycete macrofungi on abandoned farmland. The research was carried out in the unique complex of old fields of different age located on the southwest edge of the Białowieża old-growth forest (NE Poland). These lands undergo spontaneous secondary succession leading to formation of a continental fresh pine forest. Regular observations of basidiomata in 16 permanent plots $\left(11\right.$ plots of $1000 \mathrm{~m}^{2}$, 5 plots of $400 \mathrm{~m}^{2}$ ) representing initial, optimal and terminal stage of vegetation development from psammophilous grassland to a pine forest with 100-year-old tree stand were conducted for three years. Soil and vegetation analyses were also carried out as well as quantitative examination of ectomycorrhizae in root samples.

The series yielded 300 species of macromycetes (including 6 collective taxa) found in permanent plots plus 18 species outside the plots. The species composition, spatial distribution of sporocarps, and quantitative structure of fungal communities changed along the successional gradient. Increasing diversity of fungi resulted from persistence of species typical of open areas and species associated with younger trees, as well as accumulation of species associated with older trees and more developed stands. Some species typical of younger phases were replaced with species arriving later in the chronosequence. Species usually occurred long before and after attaining maximum abundance and frequency. Species associated with certain periods of vegetation development could be distinguished, as well as species accompanying the phytocoenoses regardless of their developmental stage. Patterns in structural changes of the fungal community, e.g., in number of species, abundance, frequency and production of carpophores, could also be recognised. They were different in ectomycorrhizal and in saprotrophic fungi. The occurrence of the former was influenced mainly by the presence of symbiotic trees and their age, stand structure and soil properties, while occurrence of the latter was affected by microclimatic factors and by diversity of accessible substrates. Changes in fungal communities were consistent with vegetation changes, but were also specific to this group of organisms.
\end{abstract}

Key words: old-field succession, fungal succession, ectomycorrhizal fungi, saprotrophic fungi, sporocarp production, NE Poland 


\section{INTRODUCTION}

The influence of fungi on the formation and functioning of ecosystems is more complex and diverse than usually appreciated. Fungi take part in all major ecological processes, either in direct or indirect ways, and the existence of a great variety of other organisms and whole ecosystems depends on their activity. As decomposers, they drive the global carbon cycle by preventing an excessive accumulation of organic matter and its breakdown into the compounds which can be utilized by other organisms. As mycorrhizal partners fungi enhance plants water uptake and mineral nutrition, they supply regulatory substances and protect against pathogens and environmental stress. They interconnect individual plants via common mycorrhizal networks and build extensive sink-source relationships affecting the process of primary production as well as the composition and dynamics of vegetation. Fungal endophytes inhabiting tissues of most plants can considerably influence their condition and alter adaptation capabilities. As lichen compounds, fungi contribute to the colonization of most pioneer habitats on earth and they provide a shelter for the important nitrogen-fixing organisms - cyanobacteria. As parasites they strongly influence populations of their hosts and act as biological control. Also, fungi serve as a habitat or food for different organisms including bacteria, other fungi, nematodes, insects and mammals (RAyner 1992; Trappe \& LuOma 1992; Dighton 2003). According to Rayner (1992) In short, fungi demand the attention of anyone eager to understand the complex interactions and feedback governing life processes in the biosphere.

\subsection{Fungal succession and old-fields}

One of the key life processes is succession. It is a process of initiation and development of a community (and whole biocoenosis) within the confines of a potential biochore and relatively uniform environmental conditions (FALIŃSKi 1998). Succession of both plants and fungi can be defined as a directional change in the composition, relative abundance and spatial pattern of species comprising communities (FrANKLAND 1992, 1998). In strict mycological sense it is a sequential occupation of the same site by thalli (normally mycelia), either of different fungi, or of different associations of fungi (RAYNER \& TODD 1979). The term fungal community is frequently used in this context meaning assemblage of fungi living together in the same time and space (BEGON et al. 1996) or occurring within a certain uniform habitat (ARNOLDS 1992a).

Two different types of fungal succession can be distinguished depending on the type of resource used (PARK 1968; FRANKLAND 1992): substratum succession and seral succession. The former means time-related changes in the community structure of fungi bound to the substrate usually limited in space which offers unrenewable resource, such as fungi inhabiting litter or wood (e.g., Dickinson \& PugH 1974; RAYner \& Todd 1979). The latter refers to a series of fungal assemblages following successional changes in vegetation where the resource in the short-term is renewable, for example mycorrhizal fungi associated 
with their host plants (e.g., Allen E.B. \& Allen M.F. 1990; Helm et al. 1996; Nara et al. 2003a).

Chronosequences of fungal communities occur both in primary and secondary successional systems. Primary succession involves the colonization and establishment of vegetation on newly exposed substrates, usually scarce in nutrients, barren and devoid of autochtonous organic matter, in natural as well as anthropogenic sites. Successional series of ectomycorrhizal (ECM) fungi have been described in glacier forefronts (e.g., Helm et al. 1996; CÁzares et al. 2005; Mühlmann \& Peintner 2008), volcanic deserts (e.g., Allen M.F. et al. 1992; NARA et al. 2003a, b; OBASE et al. 2007), in coastal dunes (e.g., DOMINIK 1951; Dominik \& Pachlewski 1955; Allen M.F. \& Allen E.B. 1992; van der Heidden et al.1999; VAn Der Heijden \& Vosatka 1999; AshKannejhad \& Horton 2006), coal mine spoil (e.g., LisiewSKA \& SiedlaczeK 1982; Danielson 1991; GEBHARdt et al. 2007), ski slopes and road construction sites (e.g., Hashimoto \& Hyakumachi 2000). Secondary succession involves the replacement of pre-existing vegetation on developed soil containing the residues left by the previous community as a result of disturbance, for instance burned areas or on abandoned fields. Changes in fungal communities in different post-fire ecosystems have been described, e.g., by Visser (1995), Horton et al. (1998), Friedrich (2001), Sumorok (2001). Fungal dynamics in post-agricultural areas have also been extensively studied, however most of the research deals with soil microfungi or arbuscular mycorrhizae (AM) (Johnson et al. 1991; Boerner et al. 1996; Barni \& Siniscalco 2000; Hedlund 2002; HedLund \& Gormsen 2002; Richter et al. 2002; Klamer \& Hedlund 2004). It has been shown that agricultural management can reduce the abundance and diversity of these organisms, hence the rate of recovery of the vegetation and post-disturbance plant species composition can be affected (REeves et al. 1979; vAN DER HEIJDEN et al. 1998).

The ECM inoculum potential and colonization in post-arable fields have been less studied, despite being crucial for afforestation practices (PERRY et al. 1987; KROPP \& LANGLOIS 1990; Le TACON et al. 1994). BOERnER et al. (1996) compared an active agricultural field, 5- and 10-year-old fields, and undisturbed mature forest. They found that in the active field, ECM inoculum was sparse and patchily distributed, surrounded by large areas without ECM inoculum, and correlated with the ploughing pattern, so the chance of any seeds of ECM-dependent plants to find mycorrhizal partners (and thus effectively colonize the site) was very low. Both the ECM infectiveness and its homogeneity, and the ECM diversity increased with time since last disturbance, reaching the state of $a$ virtually unbroken matrix of high ECM infectiveness in mature forest. However, the data suggested that the pre-disturbance ECM fungi level could not be re-established in less than 25-30 years following agriculture cessation.

HEDLUND \& GORMSEN (2002) revealed that ECM colonization and the survival of tree seedlings in abandoned fields were higher in areas that were naturally colonized by plants and not managed by sowing additional species. The effect of artificial inoculation of pine and spruce seedlings outplanted into a field abandoned for more than 10 years has been studied by MenKIs et al. (2007). It appeared that even after the first year natural mycorrhizal colonization prevailed in the preinoculated root systems and introduced mycorrhizas were seldom found. The impact of inoculation on subsequent ECM communities was low and after two growing seasons extensive natural mycorrhization took place resulting in quite diverse fungal communities. This indicated that ECM formation in root systems is governed mainly by environmental factors, at least in not harsh conditions, and after sufficient passage of time from abandonment. However, the tree seedlings inoculated 
with Cenococcum geophilum and Piceirhiza bicolorata (but not Hebeloma crustuliniforme) showed significantly higher survival and growth when compared with controls over a longer period.

An interesting field experiment examining the influence of distance from established vegetation on the presence, abundance, diversity and community composition of ECM fungi in abandoned agricultural fields has been carried out by Dickie \& REICH (2005). Distinct spatial complexity of these fungi can strongly influence the establishment of tree seedlings and thus development of forest-type vegetation. The ECM fungal community varied considerably with distance from the forest edge. The abundance of mycorrhizae, uniformly high near trees, declined rapidly around $15 \mathrm{~m}$ from the base of trees. Similar decrease was observed in ECM species richness.

This kind of research focused on anthropogenic as well as natural factors influencing plant colonization patterns of post-agricultural land, especially those leading to successful establishment of trees and forest development, is of particular importance. This is particularly true when serious difficulties arise, as frequently happens (DOMINIK 1961; PerRY et al. 1987; Lepš \& RejmaneK 1991; Sobczak 1990; Szujecki 1990; Sierota 1996). Also, the rates of secondary succession of such habitats and recovery to late successional woody vegetation vary considerably, from 10-40 years (KEEVER 1983) to 140 years (European mesophilous pine forest) and 350 years (European mixed hardwood forest) (FALIŃSKI 1986a). In the Alps, 100 years after pasture abandonment, some areas are still in an early stage of transition from grassland to savannah-like community (WIEMKEN \& BOLLER 2006) and delayed succession is ascribed to the limitations connected with formation of ectomycorrhizae.

Post-agricultural areas proved to be good model systems for the studies of ECM fungal chronosequences following disturbance and for general fungal ecology.

The examination of ECM fungi sequences in young plantations of birch, Betula pendula and B. pubescens (MASON et al. 1982, 1983) on post-agricultural land gave rise to the successional concept of 'early- and late-stage fungi'. The results, confirmed in other types of forests (Chu-Chou \& Grace 1981, 1988; Dighton et al. 1986; NAtarajan et al. 1992; RichTER \& BRUHN 1993) showed that species of fungi occurring at the early stages of woodland development ('early-stage fungi', e.g., species of Hebeloma, Inocybe, Laccaria, Suillus and Rhizopogon) are, in due course, superseded or joined by others ('late-stage fungi', e.g., species of Russula, Cortinarius, Amanita, Lactarius, Leccinum). The concept was also discussed in the context of life histories of the species (Dighton \& MASOn 1985; Andrews 1992). The composition of the ECM fungal community is determined by r-selection at the beginning of the successional process, while K-selection prevails when trees age and organic matter accumulates. The early-stage fungi, colonizing seedlings, have a low carbohydrate demand (supplied by the host tree), they exploit nutrients contained in the inorganic pool, are capable of rapid mycelial growth and spread mainly by spores. The late-stage fungi are associated with older/larger trees or older forests, have a high carbohydrate demand, derive nutrients mainly from the organic pool, exhibit high competitive abilities due to the production of mycelial strands, and spread mainly via vegetative mycelium.

An ordered chronosequence of the ECM fungi was first ascribed to the age of host trees and the temporal stage of woodland development, and to changes in host physiology, photosynthate allocation in particular, as a result of aging (Dighton \& MASON 1985). However, it was also found that soil conditions, accumulation of litter, development of humus layer and content of organic matter are of great importance, as well as the stand structure (e.g., LAST et al. 1987; Blasius \& OBerWinkLer 1989; De VRies et al. 1995; JuMPPONEN et al. 1999). 


\subsection{Scheme of spontaneous secondary succession on abandoned fields near the Białowieża old-growth forest}

Successional processes in nature are usually long-lasting and slow, thus the examinations of the successional series developing in one place are usually carried out, with caution in the interpretation of the results, with the method of "time for space replacement" (Johnson \& MiYanishi 2008). A rare example of a site which is suitable for this kind of research is a complex of old fields situated near the southwest peripheries of the Białowieża National Park in the Białowieża old-growth forest (Fig.1), one of the best preserved primeval forests in Europe, which is listed by UNESCO as a World Heritage Site. In the past, this area lay in the borderland between two huge forest complexes Białowieża and Bielsk old-growth forest, the latter not having existed for five hundred

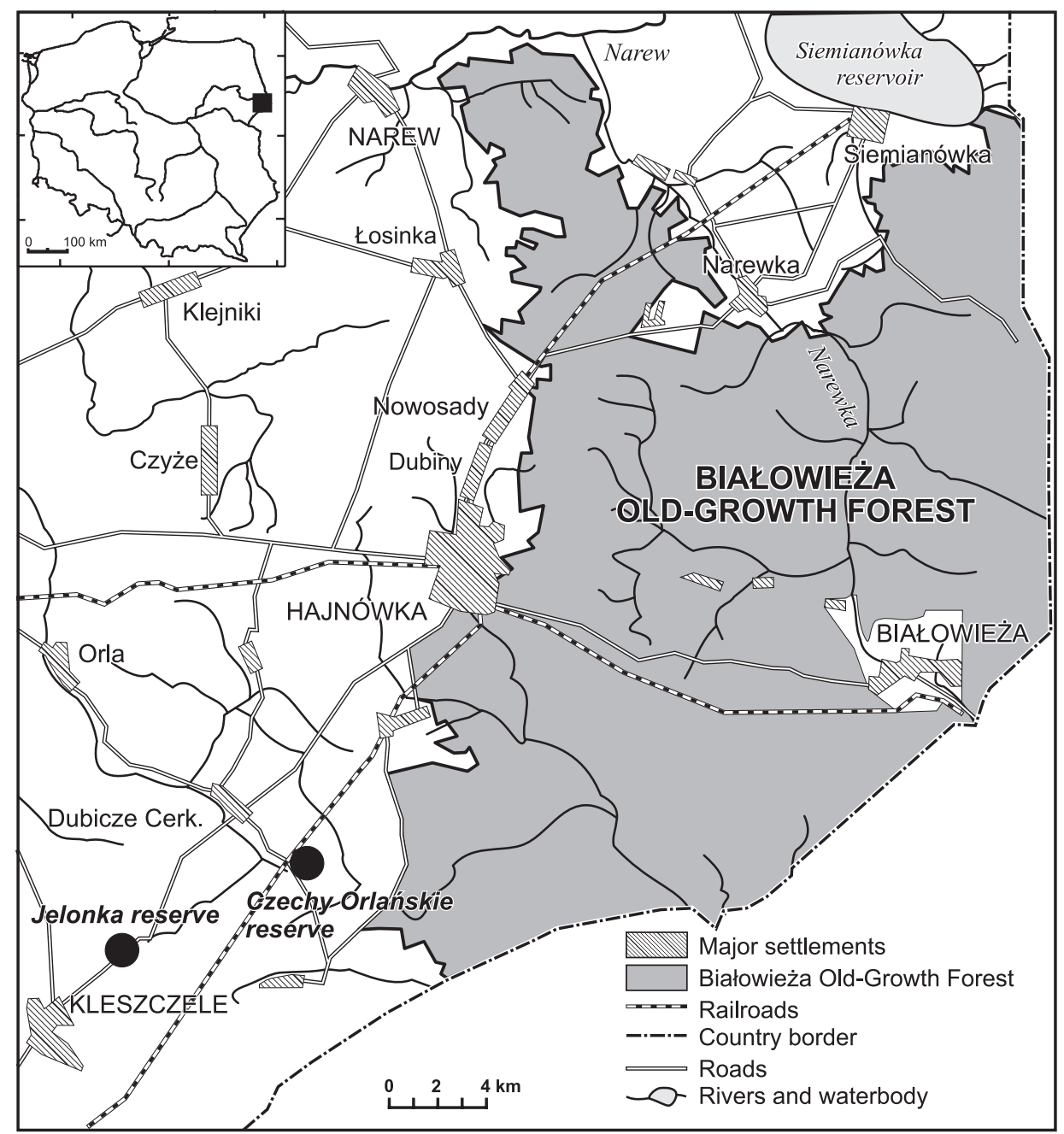

Fig. 1. The study area - Jelonka and Czechy Orlańskie reserves. 
years (FALIŃSKi 1986b). As a result of growing settlement and farming it became devoid of forest cover in the XVI century (AlEXANDROwicZ 1964; Wiśniewski 1964). However, as the soil here is poor and was soon depleted of its nutrients, part of the area was gradually left aside and spontaneously afforested again (KONDRATIUK 1974). The process intensified following the I and II World Wars. The main body of the abandoned fields arose as a result of demographic changes and the changes in agrarian policy in the last 50-60 years on rather dry and sandy soils which potentially are the habitat of mesophilous (fresh) pine forest. The area was subject to the government programme of land reclamation (up to 1992 ca 12,000 ha were afforested; FALIŃSKI et al. 1993). The most valuable part was excluded from management and secured for ecological studies as a nature reserve, which makes it unique on a European scale.

There occur side by side strips of old fields with vegetation communities representing initial, optimal and terminal stage of succession series from psammophilous grassland to continental fresh pine forest Peucedano-Pinetum. As a result of long-term studies initiated in 1970, ten phases of vegetation development were distinguished, as well as their duration (based on dendrochronometric studies) and dynamics of main components - vascular plants, bryophytes and lichens (Fig. 2) (FAliŃsKi et al. 1993; FALIŃSKi 1998, 2002). The syndynamic research was carried out mainly in the Jelonka reserve; the pine forest representing nearly mature final vegetation community, growing in the Czechy Orlańskie reserve, was included. A detailed description of the process of secondary succession, with diagnoses of consecutive phases of vegetation development, was published by FALIŃSKI (1986b, 1998) and FALIŃsKI et al. (1993). In brief, they are as follows:

Phase 0. A segetal community. Teesdaleo-Arnoseridetum Malc. 1929 R. Tx. 1937 [= Arnoserido-Scleranthetum (Chouard 1925) R. Tx. 1937] - a weed association poor in species, accompanying the crops of rye, oats, potato, yellow lupine and buckwheat. Among frequent species are Rumex acetosella, Scleranthus annuus, S. perennis, Convolvulus arvensis, Viola arvensis, Sinapis arvensis, Arabidopsis thaliana, Festuca rubra, Anthemis arvensis, Stachys annua and Galeopsis ladanum. Some strongly invasive pioneer species of mosses can appear, like Ceratodon purpureus and Brachythecium albicans.

Phase 1. The pioneer phase of a psammophilous herb-grassland on a new fallow. Duration 1-2 years after the field abandonment. Some typical weeds still occur, Galeopsis ladanum, Stachys annua, Digitaria ischaemum, Spergula arvensis and Gypsophila muralis. They are accompanied by herbaceous perennials, among which typical psammophytes prevail: Jasione montana, Helichrysum arenarium, Artemisia campestris, Hypericum perforatum, Solidago virgaurea, Hypochoeris radicata, Rumex acetosella, Hieracium pilosella, Knautia arvensis and Achillea millefolium. The occurrence of psammophilous grass Corynephorus canescens as well as therophytes like Filago minima, Gnaphalium sylvaticum and Scleranthus annuus is also characteristic. The vegetation community is a psammophilous herb-grassland belonging to the class Koelerietea, and the order of Festuco-Sedetalia. It represents a type of inland grassland of continental character, belonging to the alliance Koelerion glaucae (Volk 1931) Klika 1935 and the community Koelerio-Astragaletum arenariae described by GŁOWACKI (1988). The optimum of this community occurs in phases 4-6. As early as during phase 1 pioneer species of mosses can appear, Polytrichum piliferum and Niphotrichum canescens.

Phases 2,3 and 4. A psammophilous herb-grassland with lichen communities. Duration 2-15 years after the field abandonment. Thymus serpyllum and Astragalus arenarius appear 


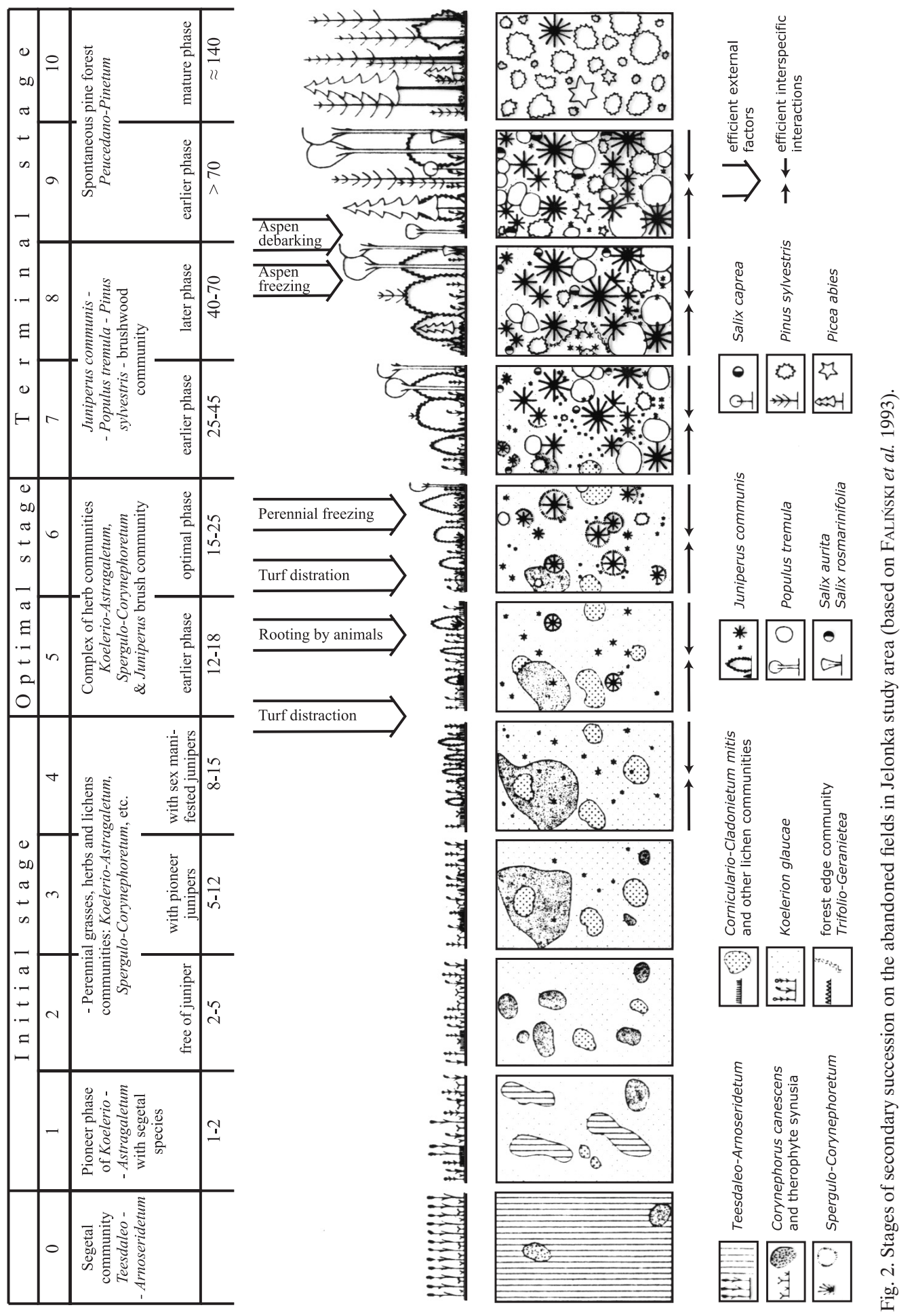


and, similarly to the species known from the previous phase, they will be present till the phase of juniper-aspen brushwood (7-8). The proportion of psammophilous bryophytes, as well as lichens (mainly Cladonia spp.) increases. The mosaic of vegetation patches representing subatlantic pioneer psammophilous grassland with domination of therophytes (Spergulo-Corynephoretum R. Tx. ex K. Czyżewska subass. typicum) or lichens (S.-C. subass. cladinetosum mitis) and with considerable participation of bryophytes (S.-C. cladinetosum var. with Polytrichum piliferum) (CzYŻEwSKA 1992), as well as patches of subcontinental psammophilous grassland of a Koelerion glaucae type is formed. Seedlings of juniper, pine and sometimes of aspen appear in greater quantities. At the end of the phase 4 , which closes the initial stage of psammophilous grassland succession, forest mosses start to occur, e.g., Sciuro-hypnum oedipodium, Hypnum cupressiforme and Dicranum scoparium.

Phases 5 and 6. A psammophilous herb-grassland and lichen communities in a complex including juniper shrub. Duration 12-25 years after the field abandonment. An increase in the number of juniper as well as the growth in height and breadth of the juniper shrubs result in breakup of the lichen-moss sward and the formation of edge-strip aggregations of psammophilous therophytes around, comprising, e.g., Teesdalea nudicaulis, Cerastium semidecandrum, Myosotis stricta, Spergula morisonii as well as Corynephorus canescens. An increase in the projection cover of junipers and pines causes permanent shading of the ground, accumulation of needles and xeric relations in the soil, because of an almost complete interception of precipitation. A decrease in the number of species and frequency of mosses can be seen, as well as an intensive development of diverse lichen mats. In phase 6 , several perennial species which attain their optimum in the brushwood phases, already occur, like Peucedanum oreoselinum and Chamaecytisus ruthenicus. Typical forest mosses appear around growing junipers and pine, aspen and spruce trees: Dicranum polysetum and Hylocomium splendens.

Phase 7 and 8. A juniper-aspen brushwood with pine. Duration 25-70 years after the field abandonment. Parallel processes of forming large juniper shrub aggregations, tree canopy closure, gradual disappearance of psammophilous communities and therophytes, as well as arrival of forest-edge perennials and willows take place. The brushwood becomes very dense and vertically complex, light and humidity conditions change, and there is an intensification of litter accumulation. The aspen and pine, accompanied by solitary birches and spruce, begin to form the tree stand. In the field layer, grassland species disappear and typical components of coniferous forests begin to occur, like Melampyrum pratense, Vaccinium myrtillus, V. vitis-idaea, Pleurozium schreberi, Dicranum polysetum, and Hylocomium splendens. Similarly, lichens typical of open vegetation are replaced by forest species. Temporal presence of, e.g., Climacium dendroides, Brachythecium rutabulum, Plagiomnium affine, the higro-hydrophilous bryophytes which have an ecological optimum in humid and wet sites, is characteristic of these phases. The juniper-aspen brushwood in the age of 60-70 years already attains stratification similar to that of a forest community in some places.

Phase 9 and 10. Early and mature phase of stable pine forest. Duration over 70 and about 140 years after the field abandonment, respectively. It is a subcontinental, mesophilous forest of Peucedano-Pinetum Mat. (1962) 1973 type with some subboreal components. The closest station of such forest, representing undisturbed final community of the chronosequence described from the Jelonka reserve, is situated ca $8 \mathrm{~km}$ to the northeast, in the Czechy Orlańskie reserve. 


\section{SUBJECT AND AIMS OF STUDY}

Conversion of vast areas of natural forests into agriculture and subsequent abandonment resulting from a loss of productivity or socioeconomic and demographic reasons is one of the main causes leading to the decrease of biodiversity worldwide (Dobson et al. 1997; StOATE et al. 2009). According to the afore mentioned authors, the European Union predictions are that up to 2030, land taken out of agricultural production will be one of the most striking features of the European landscape. The management of abandoned fields is one of the major problems which has to be urgently resolved in many countries in Europe, America and Asia (Smykata 1990; Sobczak 1990; Szujecki 1990; Johnston \& Crossley 2002; Du et al. 2007; StOATE et al. 2009).

The main management policy to cope with abandoned farmland, especially on poor soils, is afforestation; this has positive impact for water, soil and air protection, enhances carbon sequestration thereby reducing atmospheric concentrations of carbon dioxide and leads to the increase of overall diversity (StOATE et al. 2009). However, it frequently meets serious difficulties and gives unsatisfactory results. The establishment and performance of outplanted seedlings has often been reported to depend on ectomycorrhizal fungi (PERRY et al. 1987; Kropp \& Langlois 1990; Grove \& Le Tacon 1993; Marx et al. 2002; DunaBEITIA et al. 2004; RINCón et al. 2007), which may enhance uptake of water and nutrients (SMITH \& READ 2008) and protect them against drought, pathogens and heavy metal pollution (Morin et al. 1999; van Trichelen et al. 2001; Ortega et al. 2004). The soil cultivated for tens or even hundreds of years usually lacks a natural ECM inoculum (JoHNSON et al. 1991), thus the tree seedlings, either planted or regenerating spontaneously, may not find proper symbiotic partners. Without mycorrhizae on their roots, pine seedlings cannot survive on poor post-arable soil for more than 2 years (DominIK 1961).

It is well known that, apart from abiotic environmental conditions and the host plant presence, one of the most important causal factors affecting the onset and the subsequent process of fungal succession is the availability of species, either in form of spores, sclerotia, or mycelia (BRundrett 1991; FrankLAND 1992; TRAPPe \& LuOMa 1992; JumpPonen $e t$ al. 2002; AsHKANNEJHAD \& HORTON 2006; NARA 2006). This applies both to primary and secondary successional sites. In the absence of ECM inoculum, the development or recovery of ECM-dependent vegetation is possible only after the arrival of air-born or animaltransported propagules from the 'outside', which depends on the inoculum source distance (site size) (Dickie \& ReIch 2005) and time since disturbance (HeLm et al. 1999; JumpPonEN et al. 2002; JuMPPONEN 2003).

There is growing evidence from field studies, both in experimental and natural systems, that mycorrhizal symbionts can play a crucial role in successions of vegetation and vice versa (SMITH \& READ 2008). Although there are a few studies of chronosequences of fungi in post-agricultural land developing after cultivation cessation (first generation or first rotation forests), almost all of them concern managed plantations of trees (MASON et al. 1982); some encounter such stands among others of different origin, e.g., together with primary stands or 2- and 3-rotation stands (TERMORSHUIZEN 1991). None of these studies include non-ECM fungi.

Fungal communities, both ECM and saprobic, associated with spontaneous and entirely natural and man-unaffected return of the forest onto the old-fields, forming a hundred years long chronosequence, have been examined in the present study for the first time. 
The subject of the study is the succession of macrofungi on abandoned farmland and its relationship with the process of spontaneous, secondary succession of vegetation liberated from anthropogenic impact, leading to the restoration of the forest. The research comprised the observations of fungal carpophores as well as quantitative examination of ectomycorrhizal roots. The term macrofungi or macromycetes is used in accordance with ARNOLDS $(1981,1992 \mathrm{a})$ and means all the fungi producing sporocarps visible by naked eye (usually larger than $1 \mathrm{~mm}$ ).

It has been assumed that fungi, similarly to vascular plants, mosses and lichens, are permanent participants of the succession process studied. The aim of the research is to reveal the temporal patterns of macrofungal dynamics in abandoned fields and to relate them to the vegetation development. Thus, qualitative and quantitative examination of macromycetes in the range of successional phases of the series psammophilous grassland to mature pine forest was carried out, as well as basic quantitative analysis of ectomycorrhizal roots. Further the dynamics of fungal communities were related to changes in the composition and structure of phytocoenoses and habitat features; this allowed the addition of macrofungi to the model of old-field succession based on vegetation changes and lichen biota described above.

\section{STUDY AREA}

The research was carried out in two nature reserves, Jelonka and Czechy Orlańskie, situated near the southwest peripheries of the Białowieża old-growth forest (Fig. 1) in the complex of abandoned arable fields undergoing spontaneous secondary succession (Fig. 2).

Geographical location, geological substrate and land surface features. The study area is situated in mid-south part of the Równina Bielska plain (Nizina Północnopodlaska lowland, NE Poland), on the Precambrian East European platform, in the area of ground moraine plateau of the Middle Poland (Riss) glaciation. The most characteristic surface features are postglacial basins, hills of terminal moraine usually not exceeding $10 \mathrm{~m}$, and a lot of big sandrs situated along the moraine, with some distinct cones usually over 180 m a.s.l. high (MoJski 1972). The Pleistocene deposits are mainly sands, gravels and glacial boulders. Among the Holocene deposits are sands forming indistinct ridges and organic sediments in the basins floor (FALIŃSKI et al. 1993).

Climate. The climate is determined by the situation of the area in NE Poland where the influence of the continental air is usually stronger than the influence of the maritime one. This results in big annual temperature amplitudes $\left(22-23^{\circ} \mathrm{C}\right)$, long summers (over 90-100 days) and long cold winters (100-110 days). The vegetation season lasts ca 190 days. For about 140 days the minimal temperature drops below $0^{\circ} \mathrm{C}$ (ground frosts) (MARTYN 1995). The autumn ground frosts frequently repeating for several days cease vegetation many days prior to the average daily temperature attaining the $5^{\circ} \mathrm{C}$ threshold. The snow cover lasts over 90 days (Pı́́Ro 1973). The mean annual temperature is about $7^{\circ} \mathrm{C}$. The temperature extremes registered in Białowieża $(1949-2001)$ are $+34.5^{\circ} \mathrm{C}$ and $-38.7^{\circ} \mathrm{C}$ (FALIŃSKI 2002). The mean annual precipitation is $550-600 \mathrm{~mm}$; the spring rainfall is usually more 
abundant than the autumn one, which is also a feature of the continental climate (MARTYN 1995).

Jelonka reserve. The Jelonka reserve (N52.595; E23.364; alt. 178-185 m) is situated in the Kleszczów commune on either sides of the Hajnówka-Kleszczele road, about $1.2 \mathrm{~km}$ from the Jelonka village (see Fig.1). It remains under the administration of the Bielsk Podlaski Forest Inspectorate and comprises a compact area of 227 ha.

The reserve is situated in the catchments area of the Nurzec river (a tributary of the Bug river), but lacks any larger water courses. Two water-head areas - Trubianka Przednia and Trubianka Tylna lie to the south of the reserve. Within the reserve borders, three natural basins of probably ground-ice thawing origin are situated: Duży Ług (12 ha), Średni Ług (1.5 ha) and Mały $\operatorname{Lug}$ (0.3 ha). They form astatic water reservoirs with flat floors, filled with transitional peat bogs. They are part of the system of numerous drainageless basins occurring near the upper part of the Nurzec river (FALIŃsKi et al. 1993).

The reserve principally comprises former arable fields on poor mineral soils formed mainly from loamy sands. They are occupied with a complex of psammophilous grasslands, juniper shrubs, pine thickets and brushwood of juniper, aspen and pine (FALIŃSKI 1986b, 1998; FALIŃSKi et al. 1993). The occurrence and spatial distribution of these communities reflect the old ownership relations and time after abandonment. The peculiar landscape is made of narrow field-beds (5-20 m broad and 1-2 km long) set aside at different times beginning from World War I, representing different stages of secondary succession. However, as the habitat potential and environmental conditions show great homogeneity, they belong to the same successional series leading to the restoration of fresh pine forest Peucedano-Pinetum. In 1992, an area of about 70 ha was burned by an accidental fire and is now spontaneously regenerating.

The Jelonka reserve was established in 1989 for the strict protection of the vegetation complex formed on poor post-arable fields, which creates this unique landscape reflecting an old and traditional land use. The conservation extends throughout the whole ecological process shaping this landscape - the spontaneous secondary succession leading to natural forest return after centuries of deforestation and agricultural management (FALIŃSKI et al. 1993).

The area has been used for scientific research and education purposes mainly by the Białowieża Geobotanical Station of the Warsaw University (BSG UW). The monitoring of the succession process and studies on the ecology of pioneer species have been permanently carried out since 1971 (FALIŃsKi 1986a, b, 1998, 2002; set of plots no. 66) resulting, among other things, in the Faliński's model of the old-field secondary succession based on dynamics of vascular plants, supplemented with bryophytes and lichens by Czyżewska \& Cieśliński (FALIŃsKi et al. 1993). After the fire in 1992, research on the spontaneous regeneration has also been undertaken (FALIŃSKI 1996, 2002; set of plots no. 79). Participation of macrofungi in this process was also examined (KAŁUCKA \& SuMOroK 1996; SumOroK 2001).

In the area of the present reserve, preliminary research on fungi accompanying Juniperus communis was performed by J.J. Barkman; after his untimely death a provisional list of the collected fungal species was published (BARKMAN \& DE VRIES 1993).

Czechy Orlańskie reserve. The Czechy Orlańskie forest reserve (N52.631; E23.478; alt. $175 \mathrm{~m}$ ) is situated $8 \mathrm{~km}$ to the northeast from the Jelonka reserve, in the neighbourhood of the Białowieża old-growth forest (see Fig. 1). It belongs to the Dubicze Cerkiewne 
commune and is under the administration of the Bielsk Podlaski Forest Inspectorate. It occupies an area of 77.95 ha.

The reserve is situated on the flat plain between the Orlanka and Orla rivers in the catchments area of the river Narew.

It comprises a well preserved, compact fragment of pine and pine-spruce forests with a 100-year-old stand growing on post-arable land (FALIŃSKI 1992) probably as a result of semi-natural secondary succession (stimulated by leaving pine branches with cones on fresh fallow; Forestry Service, pers. comm., 1996). The following forest types can be distinguished:

- subcontinental mesophilous (fresh) pine forest Peucedano-Pinetum Mat. (1962) 1973 with subboreal features (the presence of Goodyera repens and a considerable amount of Ptilium crista-castrensis). A high proportion of Chamaecytisus ratisbonensis and Lembotropis nigricans provides evidence for the influence of subatlantic climate. Mainly the association of P.-P. typicum is represented but some patches of drier P.-P. pulsatilletosum can also be found;

- wet pine forest of Molinio-Pinetum Mat. 1973 type, which occupies small flat depressions. Oak trees as well as Molinia caerulea and Vaccinium uliginosum are present while spruce is almost lacking;

- spruce-pine forest representing the class and alliance of coniferous communities (Vaccinio-Piceetea, Vaccinio-Piceetalia), identified by FALIŃSKI (1992) as the Querco-Piceetum (Mat. 1952) Mat. et Pol. 1955. These are rather transitional phytocoenoses as oak is completely lacking and the species typical of lowland spruce forests, like Lycopodium annotinum, Goodyera repens, Moneses uniflora, and Plagiochila asplenioides are very sparse.

In the area of the present reserve the stands were permanently but not intensively managed and harvested at places but never clear-felled (Plan Urządzenia Gospodarstwa... no date).

The reserve was established in 1995 for the conservation of the forests growing in between the Białowieża old-growth forest and historical Bielsk old-growth forest, as well as for permanent documentation of the processes shaping the forest communities in transitional phytogeographical location (FALIŃSKi 1992).

The Czechy Orlańskie forest reserve is an important element of the successional changes in the old-fields, documenting the final phase of the process of forest recovery (compare FALIŃSKI 1986a, b, 1998; FALIŃSKi et al. 1993). The BSG UW carried out long-term studies here using permanent plots (set of plots no. 128). In the 80ties of the last century, a series of experiments on accelerating and slowing down the successional processes were performed (FALIŃSKI 1992).

\section{MATERIAL AND METHODS}

The research on the fungal succession was carried out during the years 1994-1998. The sporocarps of macromycetes were subject to qualitative and quantitative analysis in three consecutive seasons; the study focused on basidiomycetes as the proportion of ascomycetes fruit bodies was negligible. The ECM roots were also examined in two seasons. A series of soil analyses, as well as vegetation examination, were performed to document concurrent habitat features. Statistical analysis of the habitat-fungi relationships will be published separately. 


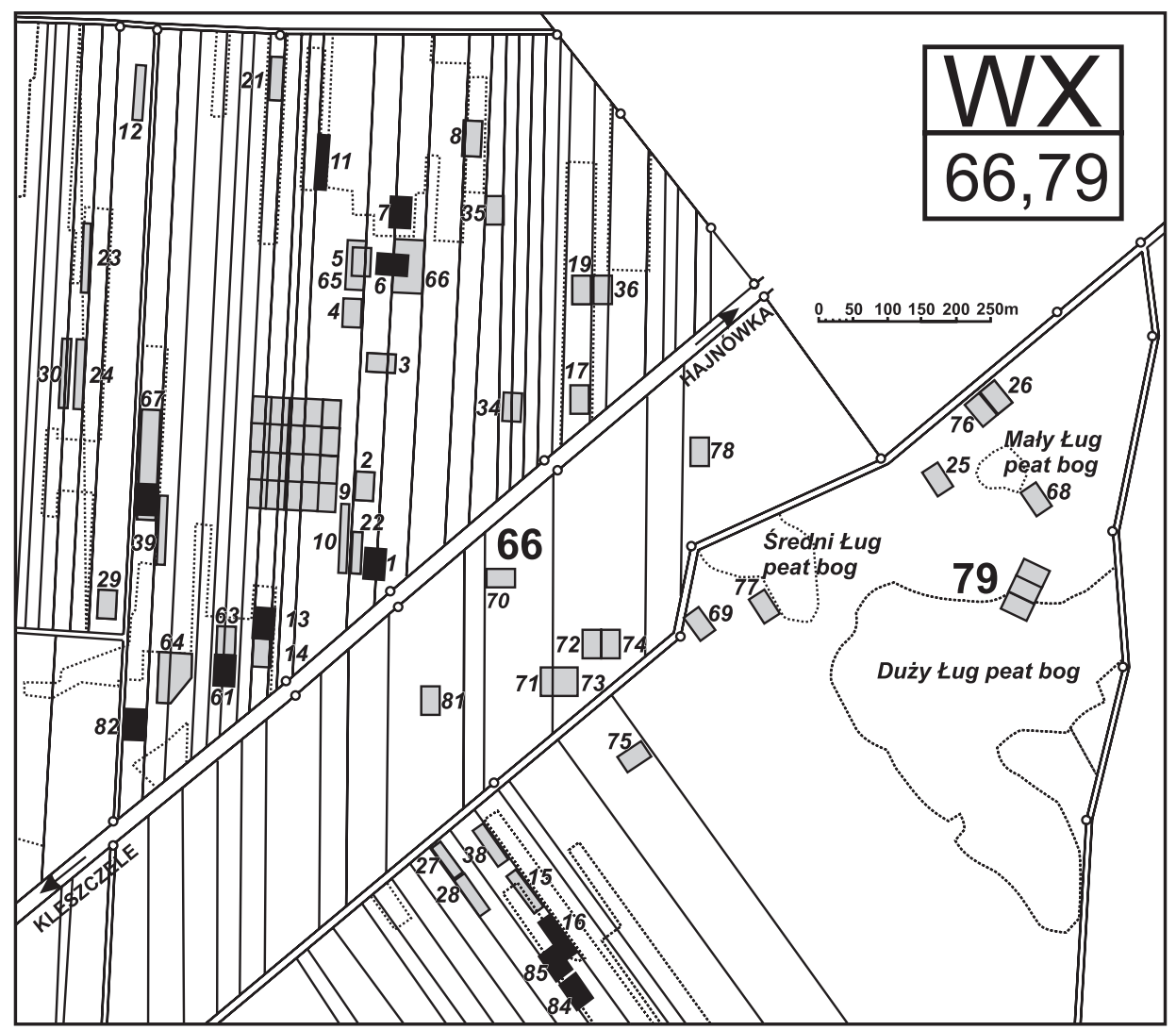

Fig. 3. Permanent plots within the Jelonka reserve and used in the studies of succession (based on FALIŃSKI 1998, augmented); the plots used in the present study are marked in black.

Selection and distribution of observation plots. The field observations were performed in permanent plots used by BSG UW for floristic-syndynamic research (FALIŃSKI 1977, 1980a, b, 1986a, b, 1998, 2002; FALIŃSKi et al. 1993). Most of them were set in the 1970s; some were established especially for the present research (nos 82, 84, 85). Each plot is marked with concrete posts at the corners, with BSG inscription and plot number, and is divided into subplots marked with wood stakes (see FALIŃsKI 1998, 2002).

The research was conducted in the Jelonka reserve, in 11 permanent plots, $1000 \mathrm{~m}^{2}$ each (Fig. 3). They represent 6 phases of secondary succession (Fig. 4), and correspond to the initial, optimal and early terminal stage of vegetation development (according to the interpretation of aerial photographs by FALIŃSKI 1986a, b, reprinted in FALIŃsKI et al. 1993, and to the map by FALIŃSKi 1990 (1991), reprinted in FALIŃSKI 1998; updated by Faliński, pers. comm., 1994).

Five plots representing the phase of nearly mature pine forest of Peucedano-Pinetum type, situated in the Czechy Orlańskie reserve were also included, each of them of $400 \mathrm{~m}^{2}$ (Figs 5, 6).

Each succession phase studied was represented by a total area of $2000 \mathrm{~m}^{2}$, with the exception of the earliest phase 2, for which only one $1000 \mathrm{~m}^{2}$ plot could be found. Successional 

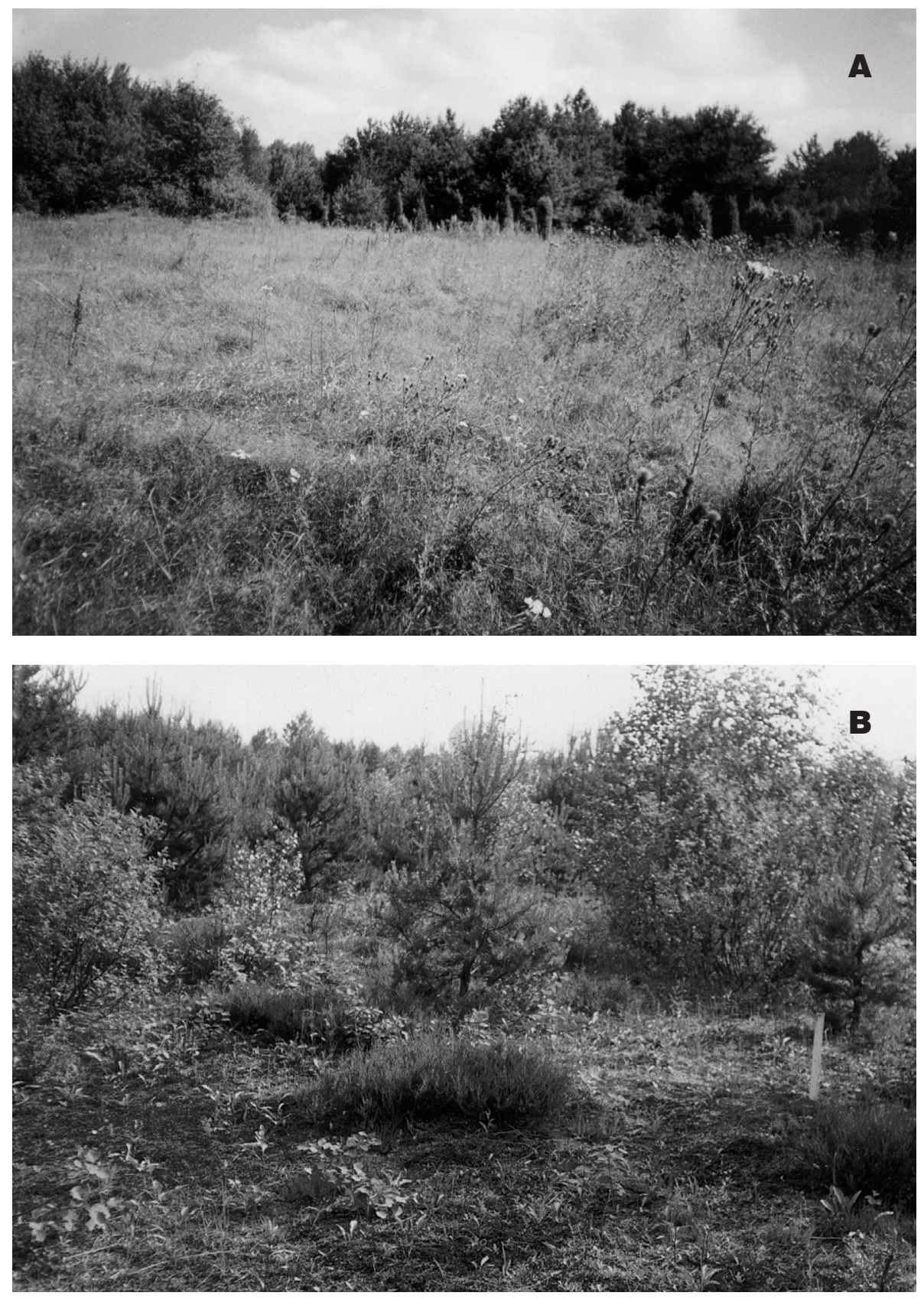

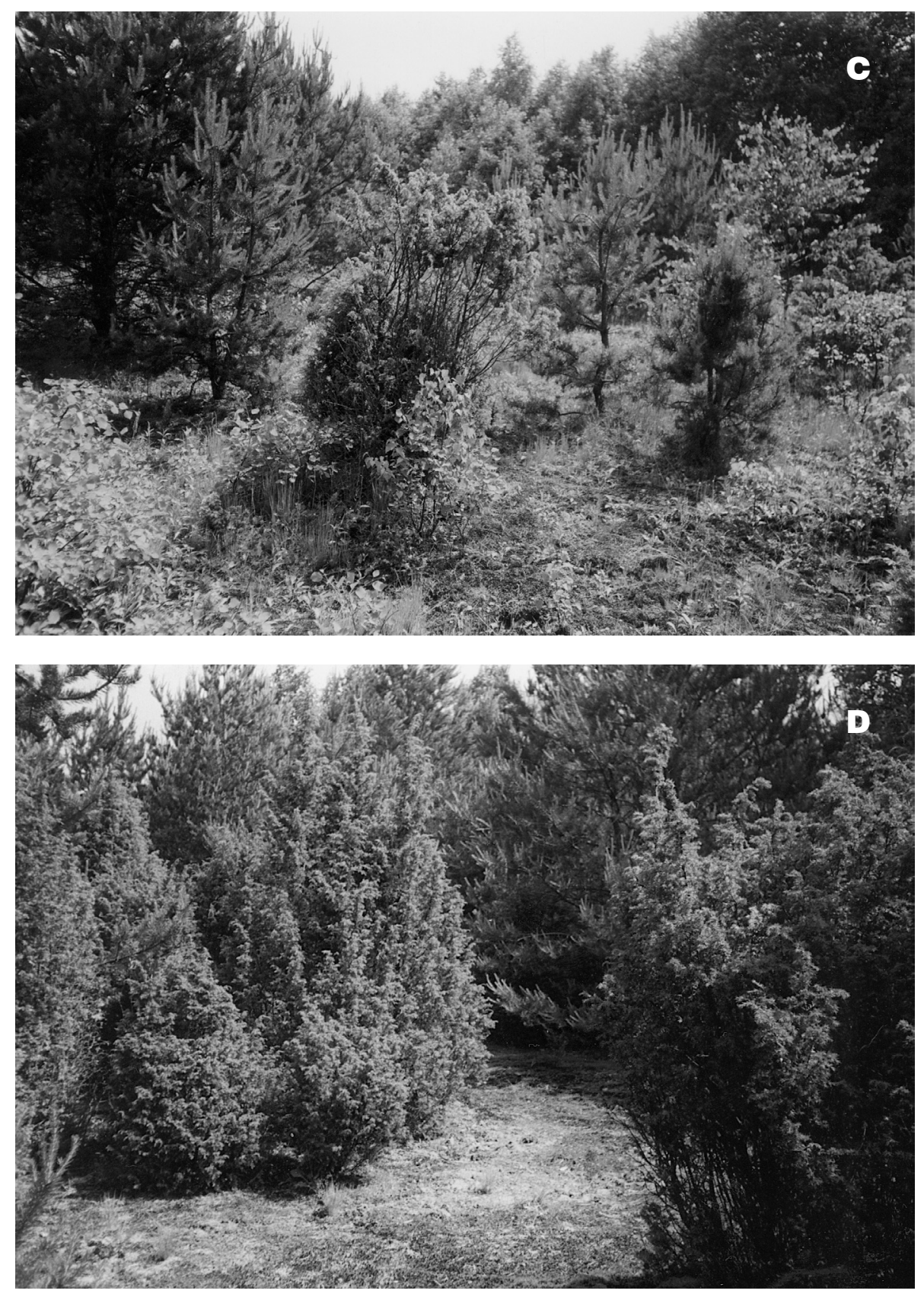

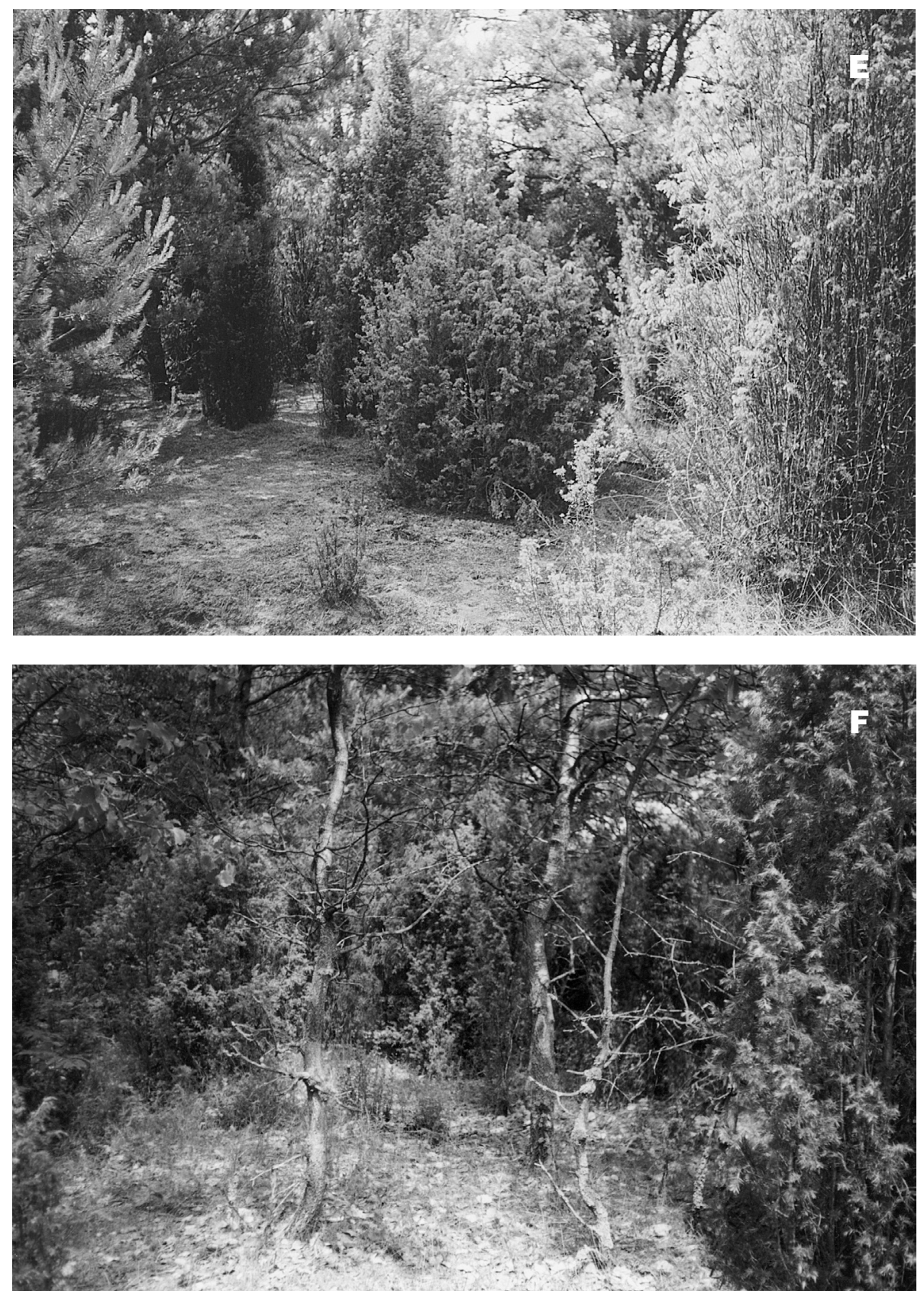

Fig. 4. Permanent plots in the Jelonka reserve: plot 82 - phase 2 (A), plot 67 - phase 4 (B), plot 85 - phase 5 (C), plot 13 - phase $6(\mathrm{D})$, plot 1 - phase 6/7 (E), plot 11 - phase $8(\mathrm{~F})$. 


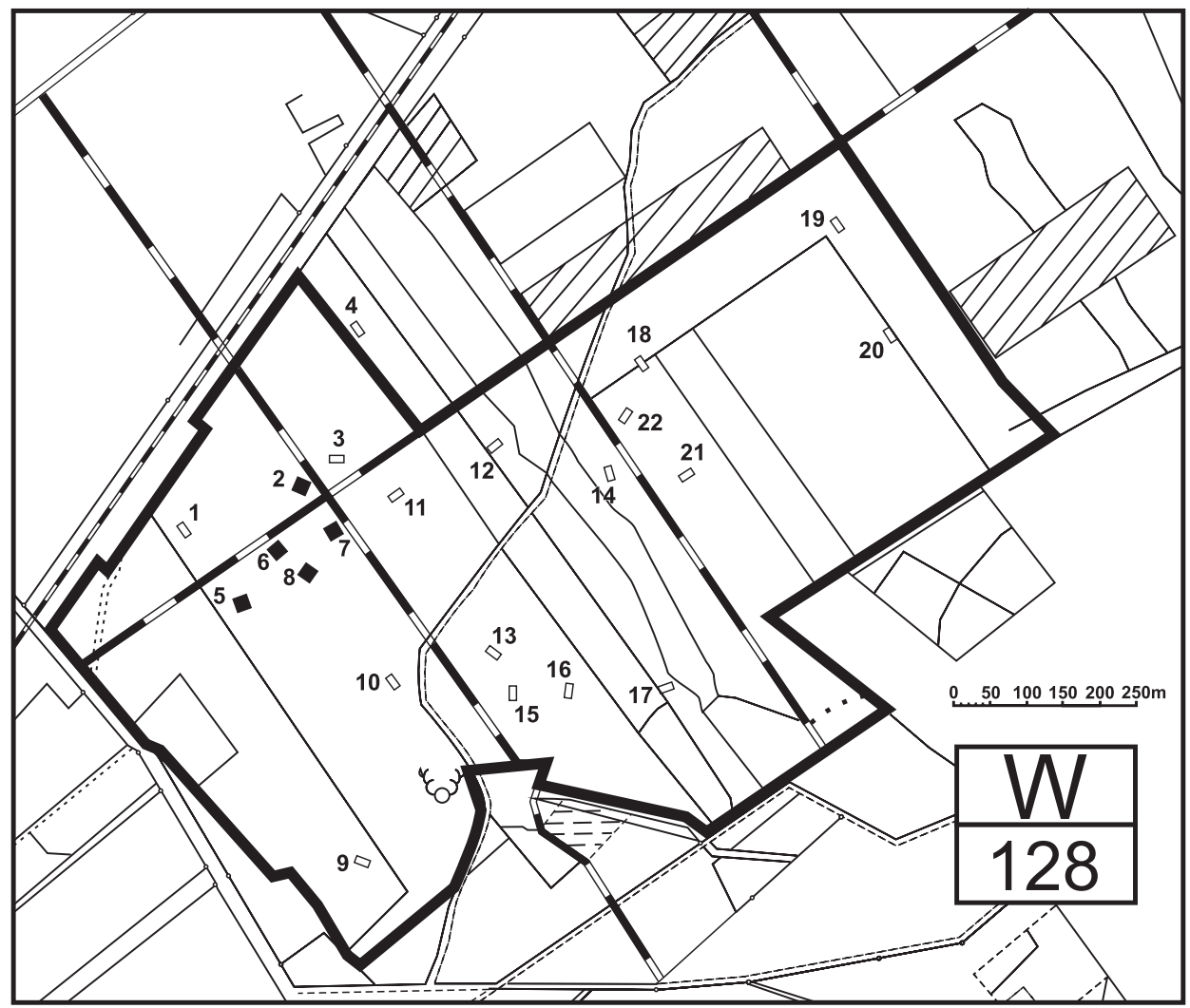

Fig. 5. Permanent plots in the Czechy Orlańskie reserve and used in the studies of succession (based on FALIŃSKI 1992, augmented); the plots used in the present study are marked in black.

status, size and shape, as well as internal division (subplots) of each plot are presented in Figure 7. In the present study, the original numbering of permanent plots is used.

Soil description and analysis. The examination of soil morphology was limited to the surface horizons as descriptions of full soil profiles were made in some plots of the Jelonka reserve in 1970s (FALIŃSKI 1987), as well as the analyses for forestry service purposes (Plan Urządzania Rezerwatu... no date). In all the profiles, the presence of plough humous horizon isolating deeper layers was clearly visible (Appendix 1).

In each succession phase, one plot was chosen for the description of soil morphology up to a depth of 50-60 cm. Samples for laboratory analyses were taken from each of the excavated horizons. The litter was sampled from the profile or from some place nearby, as in most plots it occurred patchily. The litter cover is included in the vegetation description (Appendix 2).

Additionally, ten samples of plough humous horizon (10-15 cm deep) were collected in each plot including a variety of sampling points differing in vegetation and litter. The samples originating from the same plot were mixed to obtain a bulk sample for the whole plot. In the pine forest of phase 9/10, ten samples were collected from all the 5 plots - two in each, and they were mixed together. 

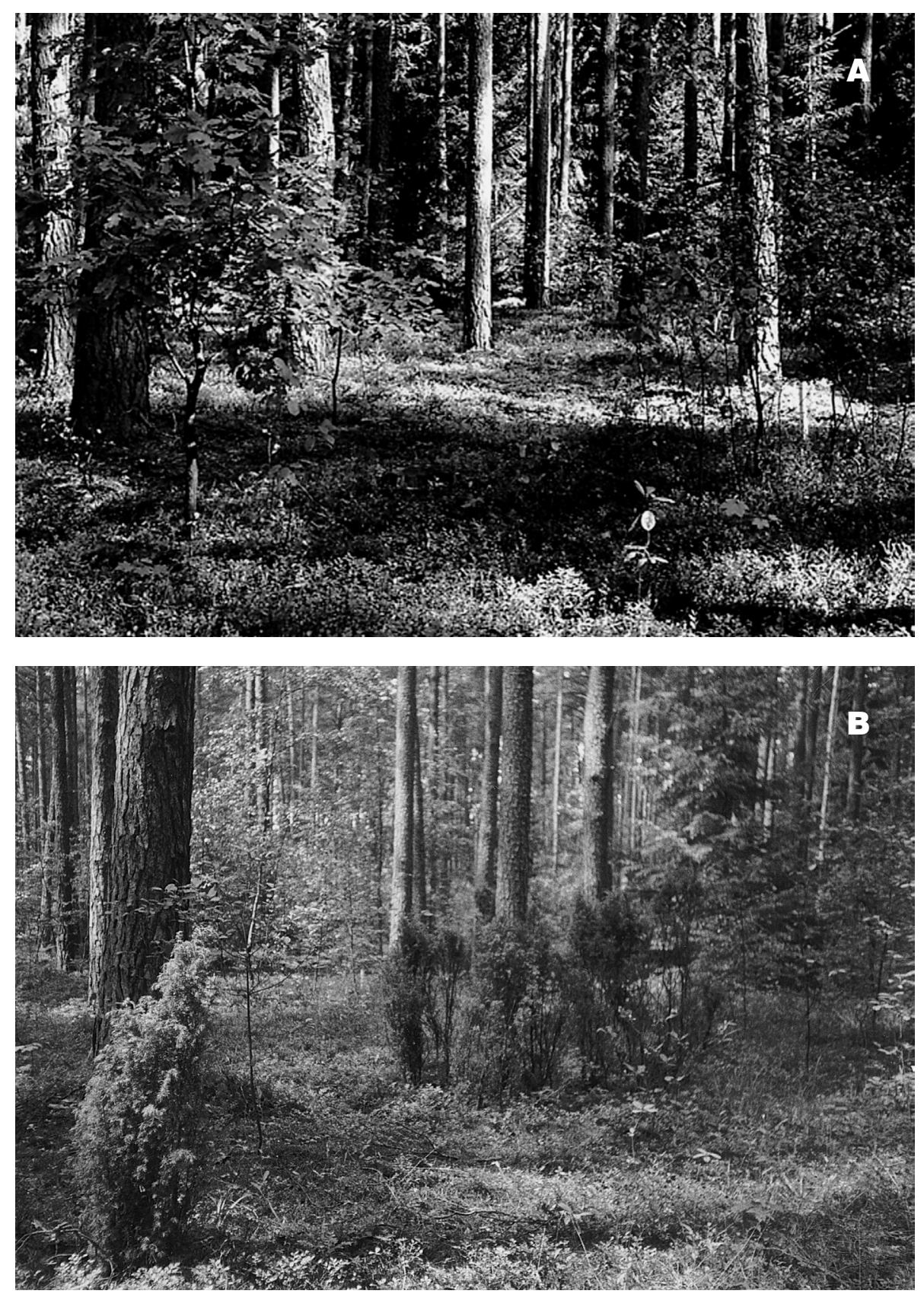

Fig. 6. Permanent plots in the Czechy Orlańskie reserve: plot 5 (A) and plot 6 (B), both representing phase $9 / 10$. 

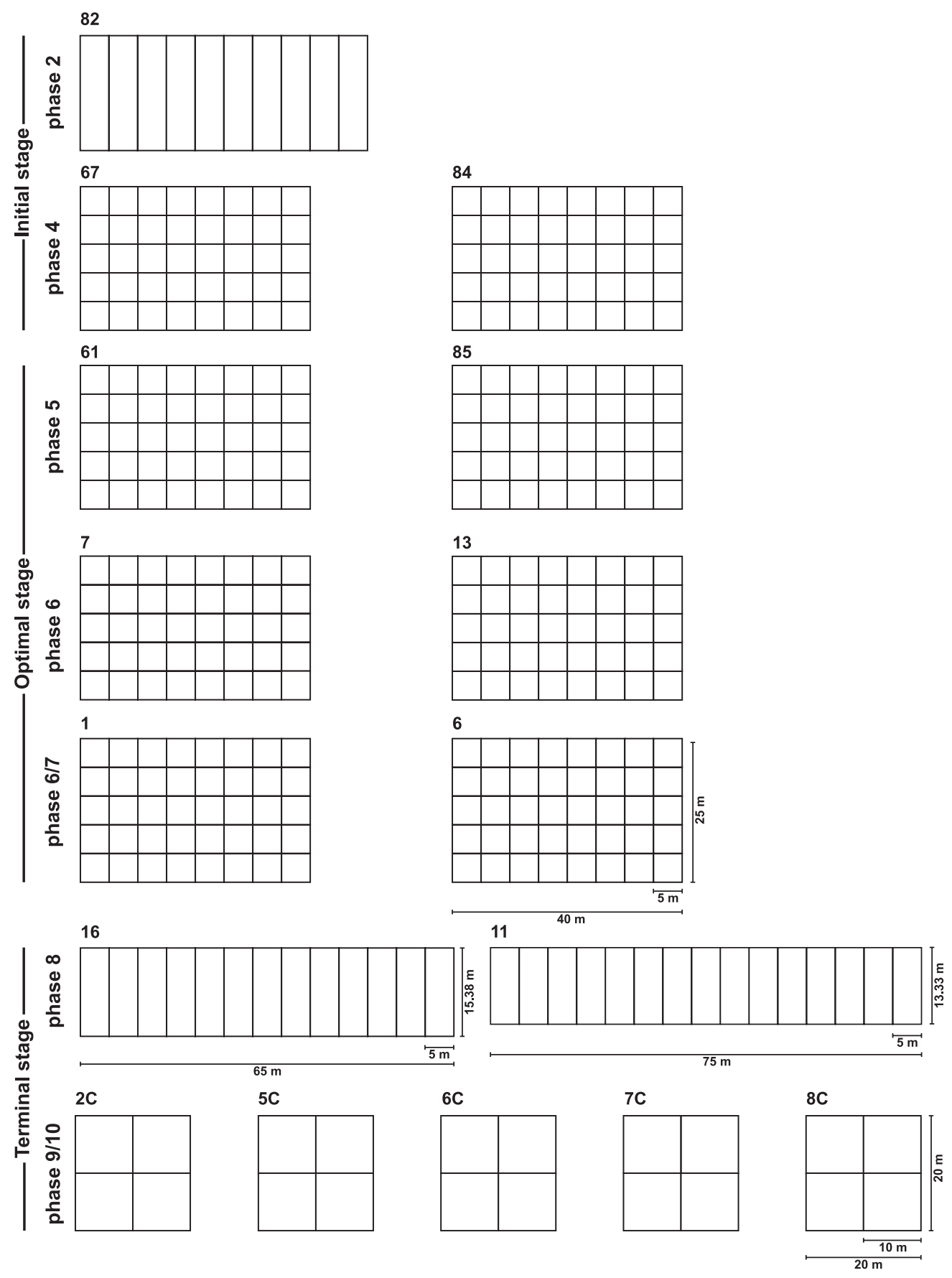

Fig. 7. Observation plots, showing numbering, internal division (subplots), and assignment to the succession phases and stages. 
The soil analysis includes: (a) grain-size distribution in the samples from the soil profiles (according to the method by Cassagrande modified by Prószyński), (b) organic $\mathrm{C}$ content (lost-on-ignition method), (c) total $\mathrm{N}$ content (Kiejdahl's method), (d) $\mathrm{pH}$ in $\mathrm{H}_{2} \mathrm{O}$ and in $\mathrm{KCl}(1 \mathrm{M})$.

Soil moisture was also analyzed in all the plots in 1997. Soil samples were collected in 5 terms (from July to November), at least 5 replicates in the $1000 \mathrm{~m}^{2}$ plots and 2 replicates in $400 \mathrm{~m}^{2}$ plots in each term.

Vegetation description. In the Jelonka reserve, the vegetation occupying the plots studied was described in June 1997, including the abundance of species according to the scale by Londo (1975) (Appendix 2 - Tab. A2.1). The localization of relevés corresponds with the squares used for long-term phytosociological monitoring (see FALIŃSKI 1998, 2002).

The vegetation descriptions in the plots in the Czechy Orlańskie reserve are cited after FALIŃSKi (1992) (Appendix 2 - Tab. A2.2).

The nomenclature of vascular plants follows the work by MiREK et al. (2002), bryophytes - the work by OCHYRA et al. (2003), lichens - the work by SANTESSON et al. (2004).

Each plot was examined for the presence of coniferous and deciduous tree species. All the pines exceeding a height of $20 \mathrm{~cm}$ were counted and their age was estimated based on the number of branching points on the main stem. The age ranges of trees in plot descriptions refer to the third year of observations (1996).

Mycological data - carpophores. Systematic observations of fungal carpophores were carried out during three vegetative seasons (1994-1996), once a month on average, from May to November, depending on the weather conditions and intensity of sporocarp production. In the Jelonka reserve, each plot was visited 17 times, except for plot 82, which was established in 1995 and visited 13 times. In the Czechy Orlańskie reserve, 16 visits were performed for each plot. One by one, all the subplots in each plot were searched for macromycete carpophores during each visit; all the species were recorded and all the carpophores were counted.

Qualitative analysis. The carpophores collected were identified either fresh or dried according to the generally accepted macro- and microscopic methods using a NIKON SMZU binocular and NIKON E-400 light microscope.

The nomenclature of fungi follows KNUDSEN \& VeSTERHOLt (2008) for agaricoid and boletoid species, and LEGON et al. (2009) - for the other species. In case of species not included in the above mentioned sources, the nomenclature follows WoJEwODA (2003) and Index Fungorum (http://www.indexfungorum.org). The systematics of species is in accordance with KIRK et al. (2008).

All exsiccata have been deposited in the Herbarium Universitatis Lodziensis (LOD).

In the field observations of fungal carpophores, taxonomical difficulties can cause problems with recording species and counting carpophores. In the present study, this was particularly true in case of the genera Entoloma, Galerina and Cortinarius. As these fungi occurred with high abundance and frequency, collective taxa were distinguished: Entoloma spp., Galerina spp. and Cortinarius spp. (see ARNOLDS 1992a, b). The latter genus was additionally divided into four groups of species based on the average dry weight of the carpophores:
Cortinarius spp. I
$<0.2 \mathrm{~g}$
Cortinarius spp. III
0.5-1.0 g
Cortinarius spp. II
$0.2-0.5 \mathrm{~g}$
Cortinarius spp. IV
$>1.0 \mathrm{~g}$ 
In the case of Psilocybe montana, part of the data refers to the rarer and less abundant species $P$. phyllogena; both species occurred in the same plots, their carpophores grew mixed together and clear distinction of the species in the field during dry weather conditions was impossible.

Forms and varieties were treated the same way as species in all quantitative analyses.

Quantitative analyses. The data on carpophore occurrence were analyzed using the following parameters (compare ARNOLDS 1981; KAŁUCKA 2008):

- abundance of carpophores of a species found in a plot during one observation season (year) (ACy);

- abundance of carpophores of a species found in a plot during the whole observation period (three years) (AC3y);

- average abundance of carpophores of a species in a plot per year (aACy);

- maximum abundance of carpophores per one observation (visit) (mACv); cf. maximum density of carpophores per visit (ARNOLDs 1981), maximum abundance = maximal number of carpophores per visit (KEIZER 1993a);

- spatial frequency (SF) - percentage of subplots where carpophores of a species were found; cf. spatial frequency (ARNOLDS 1981; JANSEN 1984);

- total temporal frequency (tTF) - number of observations in a plot when carpophores of a species were found; cf. number of occurrences (LISIEWSKA 1965, 1978; BUJAKIEWICZ 1981, 1991-1992), temporal frequency (ARNOLDS 1981);

- number of years when carpophores of a species were found (TFy).

In comparisons of fungal occurrence in the subsequent succession phases two parameters were applied (in the ECM and non-ECM species, separately):

- average annual density of carpophores of a species in the plots representing the same succession phase, per $1000 \mathrm{~m}^{2}$ (aDCy) - the comparison shows the differences in carpophore production in the subsequent succession phases;

- average spatial frequency of a species in the plots representing the same succession phase (aSF) - the comparison shows the changes in spatial distribution of carpophores in the subsequent succession phases; as the number of plots as well as the number of subplots differ in the succession phases (Fig. 6), aSF were presented as the following classes: $\mathrm{I}=1-10 \%, \mathrm{II}=11-20 \%, \mathrm{III}=21-30 \%, \mathrm{IV}=31-40 \%, \mathrm{~V}=41-50 \%, \mathrm{VI}=51-$ $60 \%, \mathrm{VII}=61-70 \%, \mathrm{VIII}=71-80 \%, \mathrm{IX}=81-90 \%, \mathrm{X}=91-100 \%$.

For comparisons of species composition and diversity Sørenson's indices as well as Shannon's indices based on aDCy were calculated (KreBs 2001; ZAK \& WILLIG 2004) for the ECM and non-ECM species, separately.

Species which occurred in only one succession phase (in one or more plots) were referred to as exclusive species for that phase.

Statistical analysis of the data on the occurrence of fungal species in the chronosequence studied was based on the total number of carpophores recorded in three seasons (DC3y) after the logarithmic transformation using the formula $v=\ln (y+1)$ (KeIzer 1993a) where $\mathrm{v}$ is the transformed value and $\mathrm{y}$ is the DC3y. The transformation reduces extreme values in the dataset and creates a scale similar to the one proposed by ARNOLDs (1981).

Groups (clusters) of species revealing similar patterns of abundance in particular periods of vegetation succession were distinguished with k-mean analysis (STATISTICA 9).

Mycological similarities of the plots and succession phases examined were analyzed with cluster analysis using the Euclidean distance as a similarity measure and Ward's method of grouping (STATISTICA 9). 
Analysis of the ECM fungi productivity. The methods proposed by ARNolDs (1981) were applied. For each species a specific, average value of the dry weight of a carpophore was assessed by weighing a number of representative, normally developed, carefully cleaned carpophores from the present study herbarial collection. According to ARNOLDS (1981), the results obtained using this method are only 3 to 5\% higher than these obtained by weighing the carpophores dried at a temperature of $50^{\circ} \mathrm{C}$. To calculate the average annual production of the ECM species, the specific dry weight of each species was multiplied by its average annual abundance.

It should be kept in mind that the production figures are underestimated; the number of observations and their frequency was not sufficient for recording completely all carpophores, some of them were omitted. Permanent or more frequent monitoring was not possible given the remoteness of the study area $(450 \mathrm{~km})$.

Mycological data - ectomycorrhizal roots. Quantitative examination of the ECM roots in the surface soil was carried out in September 1997 and in October 1998. In each plot in the Jelonka reserve (except for the plot 82 - phase 2) 6 soil cores were sampled $(14.9 \mathrm{~cm}$ deep, $3.3 \mathrm{~cm}$ in diam; $127.44 \mathrm{~cm}^{3}$ ) in each season (12 samples all together). In the Czechy Orlańskie reserve, from the five $400 \mathrm{~m}^{2}$ plots, 12 samples were collected. In the plot 82, where a single compact group of four young birches was growing (ca $1 \mathrm{~m}$ high), 3 soil cores were collected in each season at a distance of $0.5 \mathrm{~m}$ from the centre of the group.

The root samples were stored at $4^{\circ} \mathrm{C}$ before processing. They were washed carefully and all living roots of ECM trees (pine, aspen, willow, birch, spruce) were picked by hand under the dissecting microscope. The total length of fine roots $(<2 \mathrm{~mm}$; VoGT et al. 1983) was estimated using the line intercept method (Tennant 1975; $2 \mathrm{~mm}$ grid). The mycorrhizal root tips were counted in two groups (KeIzer 1993a): (1) living tips with well developed mycorrhizal mantle, vividly coloured and firm, and (2) poor condition or dead tips with damaged or easily detachable mycorrhizal mantle, scruffy surface, usually dark brown colour. In the samples collected in 1998, mycorrhizal frequency was assessed (percentage of the number of living ECM tips in the total number of root tips). All the figures were calculated for $100 \mathrm{~cm}^{3}$ of soil. Qualitative analysis of ectomycorrhizae was not within the scope of this project.

\section{RESULTS}

\subsection{Fungi in permanent plots}

Phase 2

Plot 82. Post-arable rusty soil; plough humous horizon $(0-31 \mathrm{~cm})$ of loamy sand; surface soil pH 5.5 (in $\mathrm{H}_{2} \mathrm{O}$ ), C/N 14.4, median soil moisture in September-November varies between 9.67-18.15\% (Appendix 1). Vegetation cover very dense (100\% cover), consisting mainly of grass and herbs, with domination of Poa pratensis, Agrostis capillaris, Stellaria graminea, Achillea millefolium, Vicia spp., and with evenly scattered mosses (Appendix 2). Four solitary juniper specimens present (layer $c / b$ ). The plot is ectomycorrhizal (ECM) 
tree-free with the exception of four birches growing in one group ca $1 \mathrm{~m}$ high. Although the cultivation practices in this plot have been ceased for more than 30 years (Forestry Service, pers. com., 1996), vegetation succession is still in its early initial stage. Elsewhere in the area studied, phase 2 usually lasts no longer than $2-5$ years after the field abandonment (FALIŃsKi et al. 1993; Fig. 2).

In the plot representing phase 2 of the vegetation succession 15 basidiomycete species were found (Appendix 3, Tab. A3.1). All the species recorded were saprotrophic, growing on dead plant remnants or on soil. No ECM fungi were found despite the presence of a group of four young birches in the plot.

Dense field layer reaching the height of $0.5 \mathrm{~m}$ did not favour the growth of macromycete carpophores. Infrequent soil inhabiting species which immerged from among the compact turf of living and dead plant roots and shoots possessed rather firm and elastic carpophores (Marasmius oreades) or they occurred in places occupied by mosses (Cystoderma amianthinum, Clitocybe diatreta and Mycena pura). The majority of species inhabited plant remains at different stages of decay. They belong to the genera Coprinopsis, Crinipellis, Entoloma, Mycena and Parasola. Coprinopsis friesii and Parasola plicatilis are species exclusive to phase 2, attaining relatively high frequency there.

The feature characteristic of this phase is an ephemeral occurrence of fungi. Only two species - Marasmius oreades and Crinipellis scabella were producing sporocarps regularly (temporal frequency 10 and 6 in 13 observations, respectively); the other species occurred sporadically. Some of them were fruiting occasionally but then very abundantly, e.g., apart from Marasmius oreades and Crinipellis scabella - Mycena olivaceomarginata, M. flavoalba and M. leptocephala. Usually, a high abundance of carpophores was accompanied by a high frequency.

Phase 4

Plot 67. Post-arable rusty soil; plough humous horizon present; surface soil $\mathrm{pH} 4.6$ (in $\mathrm{H}_{2} \mathrm{O}$ ), C/N 16.1, median soil moisture in September-November varies between 6.88$14.04 \%$ (Appendix 1). Row litter cover of a mosaic character, on average ca 20\%. Psammophilous grassland with high cover of moss layer and patches of lichens, with scattered juniper, birch, aspen and willow, and pine mainly in $b$ layer (Appendix 2). Pines 116/1000 $\mathrm{m}^{2}$, present in 35/40 subplots (87.5\%), 0-8 per subplot, most of 6-8 years old, the oldest specimens 11-12 years old. One spruce tree (1m high) present. Deciduous trees present in $32 / 40$ subplots $(80 \%)$. The plot is situated in the vicinity of juniper-aspen brushwood.

Plot 84. Post-arable rusty soil; plough humous horizon $(0-28 \mathrm{~cm})$ of loamy sand; surface soil $\mathrm{pH} 4.8$ (in $\mathrm{H}_{2} \mathrm{O}$ ), $\mathrm{C} / \mathrm{N}$ 14.5, median soil moisture in September-November varies between 5.02-14.85\% (Appendix 1). Row litter present only at places, under the oldest tree groups. Psammophilous grassland with high cover of moss layer, with considerable presence of juniper, birch, aspen, willow and pine mainly in $b$ layer (Appendix 2). Pines 147/1000 $\mathrm{m}^{2}$, present in 38/40 subplots (95\%), 0-11 per subplot, most 6-8 years old, the oldest specimens 12(15) years old. Three young spruce trees present in one subplot. Deciduous trees present in 40/40 subplots (100\%). The plot is situated in close vicinity to juniper-aspen brushwood.

Ninety two species of macromycetes were found in the plots representing phase 4, among them 44 ECM species (47.8\%), 47 saprotrophic species (51.1\%), and 1 species of parasite (1.1\%) (Appendix 3, Tab. A3.2, A3.3). Species similarity (based on Sørenson's 
index) between the examined plots amounts to $64.6 \%$ in the ECM fungi and $67.6 \%$ in the other species. The respective similarity for the aggregated group of vascular plants, bryophytes and lichens amounts to $70.9 \%$.

The majority of the ECM fungi are symbionts of pine. Among them Inocybe lacera is a dominating species; Suillus luteus and Amanita muscaria also occur with great abundance. Participation of Laccaria proxima, as well as of species of the genus Cortinarius producing tiny sporocarps, is distinctive. Cortinarius cinnamomeoluteus occurs regularly and with high abundance. The species mentioned fruit both with high abundance and frequency (over 50\%).

Apart of species associated with pine, ECM symbionts of deciduous trees also occurred, e.g., Leccinum aurantiacum under aspen and Lactarius vietus, Russula subfoetens and Leccinum scabrum under birch. Although the spatial frequency of these trees in the plots representing phase 4 equals that of pine, and they are also present in the neighbouring juniper-aspen brushwood, the participation of the ECM fungi specific to these hosts is relatively low, both in terms of species numbers and carpophore abundance and frequency.

Among the saprotrophic fungi, species growing on soil, frequently among mosses, prevail, like Psilocybe montana, Clitocybe diatreta and species of Entoloma.

As litter accumulation in the examined plots is low, species growing on litter and wood occur with low frequency and abundance. There are some exceptions - the species growing on the remains of herbs and grasses, such as Mycena olivaceomarginata, M. flavoalba and M. leptocephala, as well as Mycetinis scorodonius, the only species attaining relatively high abundance and frequency exclusively within phase 4. Also, Gymnopus androsaceus inhabiting pine needles under some of the oldest trees (12-15 years old) was recorded as well as sparse carpophores of Gymnopus dryophilus on fallen leaves of deciduous trees and Flammulaster granulosus on fallen twigs. Among the sporadic species growing on wood were Dacrymyces stillatus, Sphaerobolus stellatus, Tubaria confragosa (on pine twigs), Crepidotus variabilis (on dead heather parts), Hypholoma fasciculare (on the wood stake marking the plot).

Relatively abundant were the carpophores of Galerina spp., inhabiting moss tufts, mainly Polytrichum juniperinum and $P$. commune. Cantharellula umbonata, the moss parasite was also found there.

\section{Phase 5}

Plot 61. Post-arable rusty soil; plough humous horizon $(0-24 \mathrm{~cm})$ of loamy sand; surface soil pH 4.8 (in $\mathrm{H}_{2} \mathrm{O}$ ), C/N 16.2, median soil moisture in September-November varies between 4.76-14.91\% (Appendix 1). Litter cover of a mosaic character but considerable, on average ca $40 \%$, consisting mainly of loose pine and juniper needles. Psammophilous grassland with abundant presence of mosses and high cover of lichens, almost devoid of aspen, with scattered birch, evenly distributed juniper and pine mainly in $b$ layer (Appendix 2). Pines $105 / 1000 \mathrm{~m}^{2}$, present in 39/40 subplots (97.5\%), 0-6 per subplot, most 8-10(12) years old, the oldest specimens 15-17 years old; numerous seedlings. Deciduous trees present only in $5 / 40$ subplots $(12.5 \%)$. The ground disturbed by wild boars at places.

Plot 85. Post-arable rusty soil; plough humous horizon present; surface soil pH 4.8 (in $\mathrm{H}_{2} \mathrm{O}$ ), C/N 14.8, median soil moisture in September-November varies between 3.78$12.37 \%$ (Appendix 1). Row litter present only at places, under the oldest tree groups. Psammophilous grassland with considerable presence of mosses and lichens, with 
dense and evenly distributed juniper shrubs, aspen, scattered birch, and pine mainly in $b$ layer (Appendix 2). Pines 72/1000 $\mathrm{m}^{2}$, present in 28/40 subplots (70\%), 0-4(10) per subplot, most 9-11 years old, the oldest specimens 12-16 years old. Deciduous trees present in $31 / 40$ subplots $(77.5 \%)$. The plot is situated in close vicinity to juniper-aspen brushwood.

A total number of 96 species of fungi were found in the plots representing phase 5 of the vegetation development, among them 39 ECM species (40.6\%), 56 saprotrophic $(58.3 \%)$ and 1 parasitic species (1.0\%) (Appendix 3, Tab. A3.4, A3.5). Species similarity (based on Sørenson's index) between the examined plots amounts to $63.2 \%$ in the ECM fungi and $56.4 \%$ in the other species. The respective similarity in the aggregated group of vascular plants, bryophytes and lichens amounts to $58.2 \%$.

Similarly to phase 4, in the ECM fungi the species typically associated with pine prevail. The most abundant is Cortinarius cinnamomeoluteus. Numerous carpophores are still produced by Inocybe lacera although its participation, both in terms of abundance and frequency, decreases. Among dominating species are also Laccaria proxima and Hygrophorus hypothejus; high abundance and the highest frequency is attained by Suillus luteus.

A considerable share of deciduous trees in plot 85 and in its close vicinity results in the presence of Leccinum aurantiacum, Lactarius uvidus, Russula clavipes, $R$. galochroa and $R$. subfoetens - species specific to aspen and birch, however, they produce only single carpophores close to the bordering juniper-aspen brushwood.

In saprotrophic fungi the same species as in phase 4 dominate - Clitocybe diatreta and Psilocybe montana. Most of the species fruit on soil. The occurrence of a number of gasteromycetoid species, mainly Lycoperdon, is specific for this phase. The species inhabiting litter and wood are rather sporadic, only Mycena leptocephala and M. flavoalba produce abundant carpophores on decaying plant remnants and Collybia cirrhata on old sporocarps of other fungi.

Lower cover of moss layer in the plots of phase 5 comparing to the plots of the phase 4 results in a decreased abundance of Galerina species and of Cystoderma amianthinum and Cantharellula umbonata.

\section{Phase 6}

Plot 7. Post-arable rusty soil; plough humous horizon present; surface soil $\mathrm{pH} 4.7$ (in $\mathrm{H}_{2} \mathrm{O}$ ), C/N 17.2, median soil moisture in September-November varies between 5.73-13.53\% (Appendix 1). Litter cover uneven, almost lacking at places but in many subplots exceeding $70 \%$, consisting mainly of loose pine and juniper needles and twigs; in the SE part of the plot considerable amounts of aspen leaves from the neighbouring aspen brushwood. Psammophilous grassland with considerable moss cover, with scattered solitary birch and aspen, even and dense juniper shrubs and pine both in $a$ and $b$ layer (Appendix 2). Pines $131 / 1000 \mathrm{~m}^{2}$, present in 40/40 subplots (100\%), 1-8 per subplot, most 8-15 years old, the oldest specimens 17-19 years old. Deciduous trees present only in 6/40 subplots (15\%). The plot is situated in close vicinity to juniper-aspen brushwood.

Plot 13. Post-arable rusty soil; plough humous horizon $(0-25 \mathrm{~cm})$ of loamy sand; surface soil pH 4.8 (in $\mathrm{H}_{2} \mathrm{O}$ ), C/N 18.4, median soil moisture in September-November varies between 6.00-10.64\% (Appendix 1). Litter cover exceeding 70\% in most of the plot, consisting mainly of loose pine and juniper needles and twigs, also with heather remnants at places. Psammophilous grassland with moderate moss and lichen cover, with a few solitary 


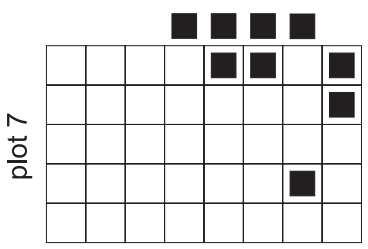

Populus tremula

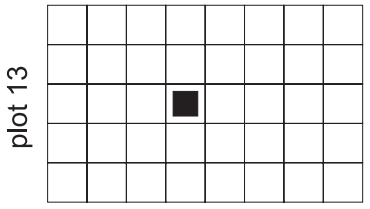

Salix caprea

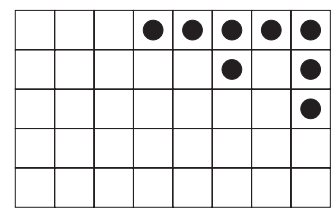

Russula fragilis

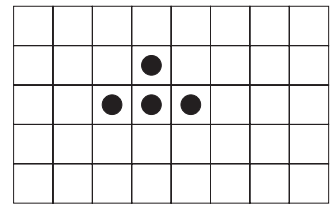

Hebeloma sp. 1

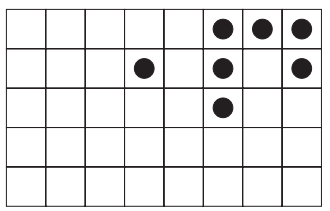

Leccinum aurantiacum

Fig. 8. Distribution of Populus tremula and Salix caprea and associated ECM fungi in the plots of phase 6.

aspens, two oak seedlings and one Salix caprea, even and dense juniper shrubs, and pine both in $a$ and $b$ layer (Appendix 2). Pines very dense, 227/1000 $\mathrm{m}^{2}$, present in 38/40 subplots $(95 \%), 0-15(21)$ per subplot, most 8-13(15) years old, the oldest specimens 17-19 years old; numerous seedlings. Deciduous trees present only in $6 / 40$ subplots $(15 \%)$. The ground disturbed by wild boars at places.

A total number of 114 species of fungi were found in the plots representing phase 6 of the vegetation development, among them 47 ECM species (41.2\%), 66 saprotrophic $(57.9 \%)$ and 1 parasitic species (0.9\%) (Appendix 3, Tab. A3.6, A3.7). Species similarity (based on Sørenson's index) between the examined plots amounts to $76.3 \%$ in the ECM fungi and $63.3 \%$ in the other species. The respective similarity in the aggregated group of vascular plants, bryophytes and lichens amounts $66.1 \%$.

The spatial frequency of deciduous trees does not exceed $15 \%$ in both of the plots. The carpophores of species like Leccinum aurantiacum, Russula fragilis, Hebeloma sp. 1 were found only in close vicinity of their probable host-trees (Fig. 8).

Mycorrhizal symbionts of pine are dominating, among them Hygrophorus hypothejus, Cortinarius cinnamomeoluteus and other species of Cortinarius producing small carpophores, Amanita muscaria, Suillus luteus, Chalciporus piperatus, Laccaria proxima, Tricholoma albobrunneum and T. portentosum. The species mentioned attain very high abundance and frequency. Abundant occurrence is also a feature of Thelephora terrestris, Inocybe lacera, Lactarius rufus, Tricholoma equestre, Cortinarius parevernius and Laccaria bicolor. It is striking that in both plots of phase 6 a number of species of Tricholoma raise their spatial frequency and start to produce conspicuously more carpophores.

The ECM species exclusive for this phase are very few and occur sporadically.

Dominant saprotrophic species are still, as in the previous phase, Clitocybe diatreta, Psilocybe montana, Cystoderma amiantinum and Rickenella fibula. Considerable bryophyte cover and a large proportion of mosses forming high tufts (Polytrichum juniperinum, $P$. commune) result in high abundance and frequency of species of Galerina. There is an increase in species richness and in carpophore abundance of species growing on litter, such as Gymnopus androsaceus and Ampulloclitocybe clavipes. The fruit bodies of species of Clitocybe and Mycena were also found more frequently on litter than on soil. For the first 
time in the chronosequence studied, there occur Strobilurus stephanocystis and Baeospora myosura, the species inhabiting pine cones.

An increasing amount of dead wood, mainly of fine woody debris, results in growing diversity of fungi on this kind of substrate - on fallen twigs, partly buried wood pieces, on dead lower branches of trees. Among them are Dacrymyces variisporus, Flammulaster granulosus, Trichaptum fuscoviolaceum, Leptosporomyces galzinii, Calocera furcata, Sphaerobolus stellatus, Pholiota gummosa, Tremella mesenterica, Phanerochaete sanguinea, $\mathrm{Hy-}$ pholoma fasciculare.

\section{Phase 6/7}

Plot 1. Post-arable rusty soil; plough humous horizon $(0-30 \mathrm{~cm})$ of loamy sand; surface soil $\mathrm{pH} 4.8$ (in $\mathrm{H}_{2} \mathrm{O}$ ), $\mathrm{C} / \mathrm{N}$ 17.7, median soil moisture in September-November varies between 4.24-10.20\% (Appendix 1). Litter cover exceeding 70\% in most of the plot, tending to accumulate in depressions, consisting almost exclusively of loose pine and juniper needles, twigs and branches, also with heather remnants at places. Patches of psammophilous grassland with moderate moss and lichen cover, with a few sparse aspens, even and dense juniper shrubs, and pine thickets both in $a$ and $b$ layer (Appendix 2). Pines 151/1000 $\mathrm{m}^{2}$, present in 39/40 subplots (97.5\%), 0-9 per subplot, most 12-15(17) years old, the oldest specimens 22-24 years old; numerous seedlings. Solitary aspens present only in 2/40 subplots $(5 \%)$. The ground disturbed by wild boars at places.

Plot 6. Post-arable rusty soil; plough humous horizon $(0-20 \mathrm{~cm})$ of loamy sand; surface soil $\mathrm{pH} 4.8$ (in $\mathrm{H}_{2} \mathrm{O}$ ), $\mathrm{C} / \mathrm{N}$ 15.7, median soil moisture in September-November varies between 4.00-15.18\% (Appendix 1). Thick litter cover exceeding $80 \%$ in most of the plot, tending to accumulate in depressions, consisting almost exclusively of loose pine and juniper needles, twigs and branches, also with heather remnants at places. Patches of psammophilous grassland with moderate moss and lichen cover, even and dense juniper shrubs, and pine thickets both in $a$ and $b$ layer (Appendix 2). Pines very dense, 257/1000 $\mathrm{m}^{2}$, present in $37 / 40$ subplots (92.5\%), 0-11(21) per subplot, most 8-15(18) years old, the oldest specimens 2325 years old; numerous seedlings. No deciduous trees present.

A total number of 105 species of fungi were found in the plots representing phase 6/7 of the vegetation development, among them 42 ECM species (40.0\%) and 63 saprotrophic species (60.0\%) (Appendix 3, Tab. A3.8, A3.9). Species similarity (based on Sørenson's index) between the examined plots amounts to $83.3 \%$ in the ECM fungi and $66.0 \%$ in the other species. The respective similarity in the aggregated group of vascular plants, bryophytes and lichens amounts to $73.6 \%$.

Nearly all the ECM fungi recorded in the examined plots are associated with pine which is a dominant tree in stand composition. The most abundant are Cortinarius cinnamomeoluteus and other species of Cortinarius producing small fruit bodies, Hygrophorus hypothejus, Laccaria proxima, Amanita muscaria, Lactarius rufus, Tricholoma portentosum, T. equestre and T. albobrunneum. The carpophores of Suillus luteus and Tricholoma saponaceum var. saponaceum are very numerous; relatively frequent are also Boletus edulis, Cortinarius anthracinus and Sarcodon squamosus. However, the abundance of many ECM fungi decreases.

A particularly high species richness as well as abundance and frequency of the genus Tricholoma is characteristic of this phase of vegetation development. 
The species composition of saprotrophic fungi does not differ very much from the previous phase; Clitocybe diatreta and Psilocybe montana are dominating, among the abundant taxa are also Gymnopus androsaceus and species of Galerina, Collybia cirrhata and Clitocybe vibecina. A great variety of microhabitats favour the occurrence of many species growing on soil, litter, wood and among bryophytes. As in the ECM fungi, many saprobic species that occurred with high frequency and produced abundant carpophores in earlier phases seem to be less productive.

Exclusive species for phase 6/7 are almost completely lacking.

\section{Phase 8}

Plot 11. Post-arable rusty soil; plough humous horizon present; surface soil pH 5.3 (in $\mathrm{H}_{2} \mathrm{O}$ ), C/N 21.0; thin humus accumulation horizon present, beginning of the podzolization process visible; median soil moisture in September-November varies between 7.12$17.89 \%$ (Appendix 1). Litter layer cover reaching almost $100 \%$, consisting mainly of aspen leaves mixed with pine and juniper needles, rich in fallen twigs and branches, in different stages of decay. Dense brushwood of aspen, pine, birch and Salix caprea in $a$ layer, with thick undergrowth of juniper and broadleaves, rather poor herb layer and scattered mosses (Appendix 2). Pines not numerous but evenly distributed, 34/1000 $\mathrm{m}^{2}$, present in 15/15 subplots (100\%), 0-5 per subplot, most 20-30 years old, the oldest specimens more than 30-35 years old. One spruce tree present. Deciduous trees present in all subplots $(100 \%)$.

Plot 16. Post-arable rusty soil; plough humous horizon $(1.5-25 \mathrm{~cm})$ of loamy sand; surface soil pH 5.0 (in $\left.\mathrm{H}_{2} \mathrm{O}\right), \mathrm{C} / \mathrm{N} 17.8$; thin humus accumulation horizon $(0-1.5 \mathrm{~cm})$ present, beginning of the podzolization process under coniferous trees visible; median soil moisture in September-November varies between 6.66-20.10\% (Appendix 1). Litter layer cover reaching almost $100 \%$, consisting mainly of aspen and birch leaves, juniper needles, rather sparse pine and spruce needles, and herbaceous plant debris, rich in fallen twigs and branches, in different stages of decay. Dense brushwood consisting mainly of aspen mixed with solitary birches, pines and spruces in $a$ layer, with thick undergrowth of juniper and broadleaves (among them 3 willow species), high cover of herb layer and scattered mosses (Appendix 2). Pines rather few, 6/1000 $\mathrm{m}^{2}$, present in 6/13 subplots (46\%), 0-1 per subplot, most 20-30 years old, the oldest specimens more than 30-35 years old. Three spruce trees present. Deciduous trees present in all subplots $(13 / 13,100 \%)$.

A total number of 183 species of fungi were found in the plots representing phase 8 of the vegetation development, among them 49 ECM species $(26.8 \%)$ and 134 saprotrophic species (73.2\%) (Appendix 3, Tab. A3.10, A3.11). Species similarity (based on Sørenson's index) between the examined plots amounts to $60.9 \%$ in the ECM fungi and $64.6 \%$ in the other species. The respective similarity in the aggregated group of vascular plants, bryophytes and lichens amounts to $66.2 \%$.

The juniper-aspen brushwood is a transitional vegetation community between psammophilous grassland complex and fresh pine forest. The tree stand in the plots representing phase 8 comprises a very high proportion of deciduous species, mainly aspen but also birch, willow and oak, and relatively scattered conifers. However, in the carpophore community of the ECM fungi both groups of symbionts are well represented - of deciduous and of coniferous trees. The former consists of, e.g., Cortinarius trivialis, C. alboviolaceus, Russula galochroa, R. versicolor, Leccinum aurantiacum, L. scabrum, 
Lactarius torminosus, L. uvidus, Inocybe flocculosa, Amanita phalloides, and many species of Cortinarius. The latter is represented by, e.g., Tricholoma portentosum, T. imbricatum, T. albobrunneum, Chalciporus piperatus, Suillus luteus, Cortinarius cinnamomeoluteus and Russula paludosa. Many of the ECM species found are host-generalists, like Amanita muscaria, A. pantherina, A. rubescens, Boletus edulis, Clitopilus prunulus, Paxillus involutus.

The ECM fungal community of phase 8 comprises a numerous group of exclusive species, among them Cortinarius trivialis and C. alboviolaceus, a majority of the species from the Cortinarius spp. II and Cortinarius spp. III complexes (producing medium-sized and big carpophores), Hebeloma sp. 3, Lactarius torminosus, Inocybe flocculosa as well as Amanita gemmata, A. phalloides, Hebeloma stenocystis, Inocybe cf. margaritispora, Lactarius necator, Russula cf. mustelina, R. versicolor. The species listed first occur with high abundance and/or frequency, in contrast to the exclusive species of the earlier phases of succession. Cortinarius trivialis, C. alboviolaceus and Lactarius torminosus were found in both plots representing phase 8 .

Twenty three ECM species which were present in the earlier phases of the succession produce their sporocarps in phase 8 but are not present in the subsequent phase - the pine forest. The optimum of occurrence of most of them in terms of abundance and frequency of carpophores coincides with the previous succession stage (the optimal stage). The optimum in phase 8 is attained only by Leccinum aurantiacum, Clitopilus prunulus, Russula clavipes, $R$. galochroa and Lactarius uvidus, these species occurring sporadically in the communities other than juniper-aspen brushwood and always in its close neighbourhood.

Three species - Amanita citrina, Cantharellus cibarius and Russula paludosa start fruiting in this phase for the first time and they continue their occurrence in the next phase - the pine forest.

Among the dominant ECM species producing large numbers of carpophores are Cortinarius trivialis and other species of small and medium-sized Cortinarius, Amanita citrina and Cantharellus cibarius.

The most abundant saprotrophic species are those which usually inhabit an accessible substrate (fallen dead branches, twigs, litter) in a plentiful way - Dacrymyces stillatus, Gymnopus androsaceus, Crepidotus lundellii and Tubaria furfuracea. Relatively abundant are also Mycena pura, M. leptocephala, M. olivaceomarginata, Galerina hypnorum, Clitocybe candicans. However, most of them occurred also in earlier phases and some even produced larger number of carpophores then.

The participation of saprobic species growing on soil is rather low $-17 \%$, of species occurring among mosses - less than 3\%; ca $80 \%$ are the litter-inhabiting and lignicolous fungi in equal proportion.

Nearly a half of the saprotrophic species found in the plots of phase 8 are exclusive taxa, some of them are relatively frequent in both of the plots, e.g., Coprinellus xanthothrix, Flammulaster rhombosporus, Mycena stipata and Psathyrella candolleana. This probably results from very specific microclimate conditions, the highest participation of deciduous trees and plentiful, highly diverse substrates.

The characteristic feature of species composition, both ECM and saprobic fungi, is also the presence of species typical of rather humid or even wet and boggy places, like Russula paludosa, Marasmius epiphyllus, Gymnopus aquosus, Mycena supina, Phaeomarasmius erinaceus and Lentinus suavissimus. 
Plots 2C-8C. Podzolic soil developing on post-arable rusty soil, plough humous horizon (20-35 cm) still present. Surface soil pH 4.6 (in $\mathrm{H}_{2} \mathrm{O}$ ), C/N 24.0, median soil moisture in September-November varies between 11.05-24.54\%. Litter layer on average $6 \mathrm{~cm}$ thick, differentiated (Ol, Of, Oh), consisting mainly of pine needles, bark, numerous fallen twigs and branches (Appendix 1). Nearly mature fresh pine forest, with scattered spruce, birch, oak and willow trees, poor undergrowth with dying junipers, rich field layer with prevailing dense shrubs of perennials and nearly $100 \%$ cover of mosses (Appendix 2). Pines mainly even-aged, over a hundred years old, on average $40 / 1000 \mathrm{~m}^{2}$, evenly distributed. Numerous pine seedlings. The ground disturbed by wild boars at places.

A total number of 98 species of fungi were found in the plots representing the phase 9/10 of the vegetation development, among them 30 ECM species (30.6\%), 67 saprotrophic species (68.4\%) and 1 species of parasite (Appendix 3, Tab. A3.12-16). Species similarity (based on Sørenson's index) between the examined plots amounts to $65.0-78.9 \%$ in the ECM fungi and 54.2-65.6\% in the other species. The respective similarity in the aggregated group of vascular plants, bryophytes and lichens amounts to 71.7-81.6\%.

The species composition of the ECM fungi is typical of fresh pine forest. Among dominating species are Paxillus involutus, Amanita citrina, Cortinarius semisanguineus and C. caperatus. Also, Russula emetica, Lactarius rufus and Thelephora terrestris occure with high abundance.

About half of the ECM species were recorded in the earlier succession phases and most of them were also more abundant there, e.g., Amanita citrina, Lactarius rufus, Thelephora terrestris, Cantharellus cibarius, Laccaria proxima, Russula fragilis and Amanita rubescens. However, the abundance of carpophores and spatial frequency of Paxillus involutus, Russula emetica, $R$. paludosa and Xerocomus badius, is markedly higher in the forest plots of phase $9 / 10$.

The other half of the ECM species are exclusive species for that phase; these are typical forest species growing under conifers, like Cortinarius caperatus and Amanita porphyria, as well as many Russula species, the genus best represented here.

The saprotrophic species grow mainly on pine litter and woody debris, and frequently occur among mosses. Among the species dominating in terms of abundance are Dacrymyces stillatus, Gymnopus androsaceus, Collybia cirrhata and Mycena zephirus - the fungi in which massive production of small carpophores is a biological feature of the species. In some species, like Leptosporomyces galzinii, Mycena metata, M. galopus, Galerina pumila, Cystoderma amiantinum and Xeromphalina cornui the abundance is relatively low but spatial frequency is high.

Many saprobic species present in the earlier succession phases attain the highest frequency and abundance in the forest plots, e.g., Collybia cirrhata, C. tuberosa, Coniophora arida, Dacrymyces stillatus, Galerina pumila, Leptosporomyces galzinii, Mycena galopus, M. metata, M. zephirus, Phlebiella sulphurea and Xeromphalina cornui. The number and frequency of carpophores in other species clearly decreases, for instance in Clitocybe candicans, C. diatreta, Lycoperdon nigrescens, Macrolepiota procera, Mycena flavoalba and M. pura. The most conspicuous "successional relict" is Psilocybe montana, a species very abundant in the optimal stage of vegetation development, typical of open psammophilous grassland with mosses and lichens. In the forest, only one carpophore was found.

Numerous saprobic species were found exclusively in phase 9/10 of the succession studied, e.g., Athelia decipiens, Botryobasidium vagum, Crepidotus applanatus, Dacrymyces 
ovisporus, D. macnabbii, Gymnopilus penetrans, Hypholoma capnoides, Mycena purpureofusca and Pseudomerulius aureus. A great majority of them are wood-inhabiting fungi.

In nearly all subplots of the forest plots Exobasidium vaccinii was present, a leaf parasite of Vaccinium vitis-idaea.

\subsection{Changes in species and sporocarp distribution along successional gradient}

\subsubsection{Species richness and diversity}

During three years of observations 300 macrobasidiomycete species were found in permanent plots, among them 98 ECM (32.7\%), 200 saprotrophic (66.7\%) and 2 parasitic species $(0.7 \%)$.

The lowest number of species (15) was found in phase 2 of the vegetation development (Fig. 9); all of them were saprobic fungi, and the majority of them were growing on herbaceous plant remnants. The number of species in the next phases gradually increases (with a slight decrease in phase 6/7) till the phase of juniper-aspen brushwood (phase 8), where 183 species were found. Although two thirds of them were saprotrophs and the proportion of the ECM species here was the lowest in the whole chronosequence, the actual number of these species was the highest. The highest proportion of the ECM fungi is characteristic of the community in the initial stage of succession (phase 4). Young, 6-8(12) year old trees, support a rich and diverse range of symbiotic species, while the group of saprotrophs is relatively poor. The highest numbers of the ECM species at plot level were recorded in phase 6 ( 38 species in each of the two plots).

The majority of the ECM species of the series studied are more or less host-specific to pine, e.g., Suillus luteus, Chalciporus piperatus, Hygrophorus hypothejus, Inocybe lacera, Cortinarius cinnamomeoluteus, Lactarius rufus, Thelephora terrestris, Tricholoma albobrunneum, T. equestre i T. portentosum. Most frequently under pine were also recorded species which could be associated with a broad range of both coniferous and deciduous trees, like Amanita muscaria, Boletus edulis and Tricholoma saponaceum var. saponaceum. Other non-specific fungi were found as frequently under pine as under birch or aspen, for instance Paxillus involutus, Amanita rubescens, Laccaria proxima, Clitopilus prunulus and Amanita citrina. The most common deciduous host-specific species were, e.g., Leccinum aurantiacum (aspen), Russula fragilis (birch, aspen), R. clavipes (birch, aspen) and R. galochroa (birch). Not surprisingly, this group is most numerous and diverse in juniper-aspen brushwood.

Saprotrophic fungi can be assigned to four main ecological groups: fungi growing on soil, litter-inhabiting fungi, fungi on dead wood and bryophilous species growing among mosses. Many of them were recorded not only on one but on different substrates.

Among the fungi most frequently found on soil were species of Entoloma, Rhodocybe, Hygrocybe, Macrolepiota, Lycoperdon, Geastrum, as well as Hygroaster asterosporus and Ripartites tricholoma. Most of them are typical of open areas like grasslands, heathlands or juniper shrubs.

The group of litter-inhabiting species were most diverse; they grew on decaying shoots of herbaceous plants (Mycena olivaceomarginata, Parasola plicatilis, Crinipellis scabella), fallen leaves of deciduous trees (Gymnopus dryophilus, Lepista nuda, Clitocybe phyllophila, Marasmius epiphyllus), juniper needles (Clitocybe diatreta, C. fragrans, C. vibecina), pine 

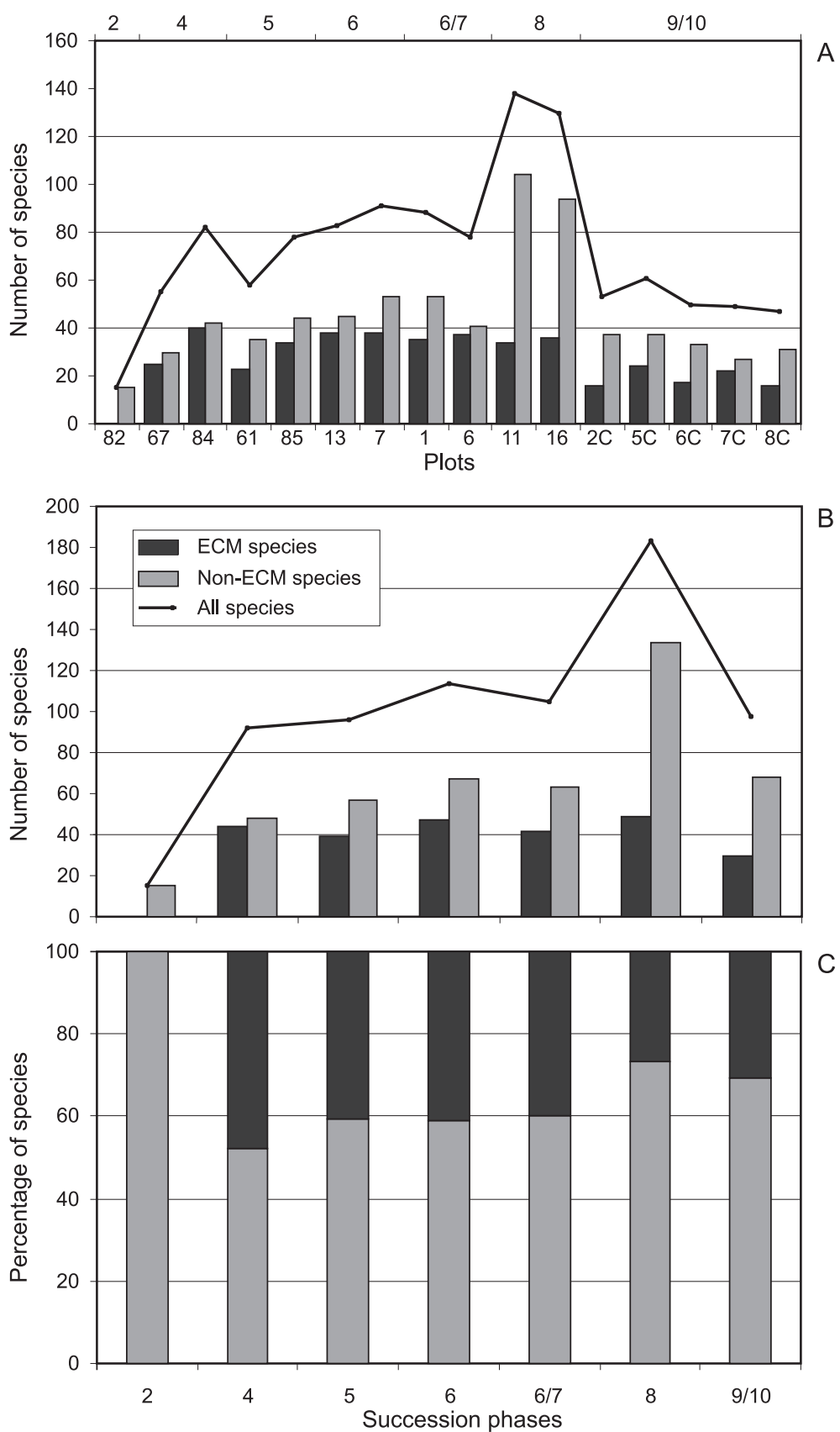

Fig. 9. Number of ECM and non-ECM species in plots (A) and succession phases (B) and percentage of these groups in the different succession phases $(\mathrm{C})$. 
needles (numerous species of Mycena and Clitocybe, Gymnopus androsaceus, Xeromphalina cornui), cones (Baeospora myosura, Auriscalpium vulgare, Strobilurus stephanocystis), twigs and pieces of bark (Tubaria furfuracea, Flammulaster granulosus, Crucibulum laeve, Sphaerobolus stellatus), as well as decaying fruit bodies of other fungi (Collybia cirrhata, C. tuberosa, C. cookei) and dung (Panaeolus papilionaceus).

Similarly, various fungi showed preferences for certain kinds of woody substrates: Amylostereum laevigatum grew on the wood of juniper, Calocera viscosa, Gymnopilus penetrans, Phanerochaete sanguinea, Phlebiella sulphurea - on the wood of pine, Inonotus rheades, Daedaleopsis confragosa, Peniophora polygonia - on the wood of aspen, Stereum hirsutum, Fomes fomentarius - on the wood of birch. Some species usually occurred on relatively freshly fallen branches, for example some species of Hyphoderma, Peniophora and Stereum, on branches and larger pieces of decorticated wood were species such as Dacrymyces stillatus, Coniophora arida and Botryobasidium vagum while on rotting logs and stumps were species like Hypholoma spp., Pseudohydnum gelatinosum, Steccherinum fimbriatum and Mycena stipata. On dead branches of trees or on dead standing trees were found species like Exidia plana, Tremella mesenterica, Dacrymyces variisporus, Inonotus rheades, Fomes fomentarius and Daedaleopsis confragosa.

Many saprotrophic species did not show any special preferences and they occurred on wood in different stage of decay, on coarse as well as on fine debris, on wood and on litter and on different types of litter.

The bryophilous fungi are also a distinct ecological group. They include species of Galerina (G. atkinsoniana, G. pumila, G. hypnorum, G. mniophila, G. calyptrata, etc.), Cystoderma (C. amiantinum, C. jasonis var. jasonis, C. jasonis var. lilacipes) and Cystodermella granulosa, Psilocybe montana, Rickenella fibula, Cantharellula umbonata. The last species is a moss parasite and occurred in Polytrichum tufts, mainly on P. juniperinum and P. commune.

Another parasitic fungus collected was Exobasidium vaccinii growing abundantly on leaves of Vaccinium vitis-idaea.

The macrofungal species diversity changes along with the succession process (Fig. 10). For the non-ECM fungi, changes in diversity index reflect the increasing number of species in subsequent phases of succession (Fig. 9; Dacrymyces stillatus, the species producing huge

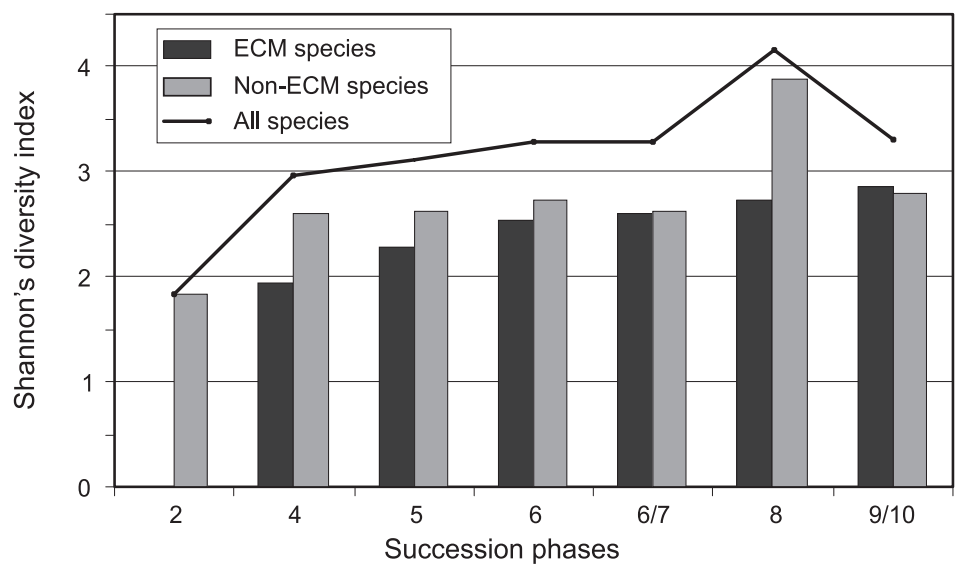

Fig. 10. Species diversity of fungi in consecutive phases of the spontaneous secondary succession on abandoned farmland. 


\begin{tabular}{|c|c|c|c|c|c|c|c|}
\hline Phases & 2 & 4 & 5 & 6 & $6 / 7$ & 8 & $9 / 10$ \\
\hline 2 & & 25.4 & 27.8 & 24.4 & 25.6 & 10.7 & 12.1 \\
\hline 4 & - & & 72.4 & 60.9 & 57.7 & 35.2 & 31.0 \\
\hline 5 & - & 69.9 & & 61.3 & 63.3 & 35.6 & 32.0 \\
\hline 6 & - & 63.7 & 67.4 & & 67.7 & 41.8 & 35.6 \\
\hline $6 / 7$ & - & 62.8 & 66.7 & 87.6 & & 45.7 & 47.3 \\
\hline 8 & - & 62.4 & 56.8 & 54.2 & 50.6 & & 41.6 \\
\hline $9 / 10$ & - & 32.4 & 26.1 & 28.6 & 27.8 & 32.9 & \\
\hline
\end{tabular}

ECM species
Fig. 11. Diagram showing Sørenson's similarity index of fungal species among consecutive phases of the spontaneous secondary succession on abandoned farmland.

numbers of very tiny carpophores, was excluded from calculations); the diversity is the highest in phase 8 , reaching 3.88 at phase level (calculation based on the data from two plots taken together, i.e. $2000 \mathrm{~m}^{2}$ ) and 3.54 and 3.66 at plot level (calculation based on the data from the two separate plots of $1000 \mathrm{~m}^{2}$; data not shown). For the ECM fungi, however, diversity increases relatively independently of species number fluctuations, which is an effect of higher species evenness (the Shannon's diversity index is increased either by having additional species, or by having a greater species evenness). It is particularly clear in the terminal phase of succession, in pine forest, where the ECM fungi attain the highest diversity at phase level 2.87 despite the relatively low number of species (Fig. 10). At plot level, ECM fungal diversity grows rapidly up to 2.55 and 2.59 in phase $6 / 7$, then slightly decreases and increases again in the pine forest (data not shown).

The species composition of fungi is very similar in the plots representing the same phase of succession (based on Sørenson's index; see chapter 5.1.), from 60.9\% to 83.3\%. High similarity, usually exceeding $60 \%$, is also a rule in the assemblages of fungi occurring in phases 4-6/7 (late initial and optimal stage of vegetation succession) (Fig. 11). The production of carpophores of the ECM species, which starts between phases 2 and 4 in the initial stage of succession, undergoes mainly quantitative changes in subsequent pre-forest phases. A distinct qualitative change can be seen between phases 8 and 9/10 when after the transitional community of juniper-aspen brushwood with pine the pine forest of Peucedano-Pinetum type is formed. Many species which occurred in earlier communities finish producing their carpophores at this point. In the pine forest, only about $50 \%$ of the ECM species, common with the earlier phases, still fruit and the similarity index decreases to about $30 \%$.

A fundamental change in species composition of saprotrophic fungi takes place twice. The first time occurs between phases 2 and 4, when dense herb-grass vegetation with fungi inhabiting abundant necromass of herbaceous plants is replaced by poor, psammophilous grassland where fungi growing on soil predominate as well as the bryophilous species and fungi growing on litter accumulating under pines and junipers. The second time is between phases $6 / 7$ and 8 , when the canopies of trees close and accumulation of litter and woody debris increases. Relatively low species similarity of saprobic fungi between juniper-aspen brushwood and the earlier vegetation types results mainly from the great number of the brushwood-exclusive species inhabiting litter and woody debris originating from deciduous trees. The species similarity between phases 4-6 and 9/10 is low because of the arrival of numerous species growing on decaying pine wood. 


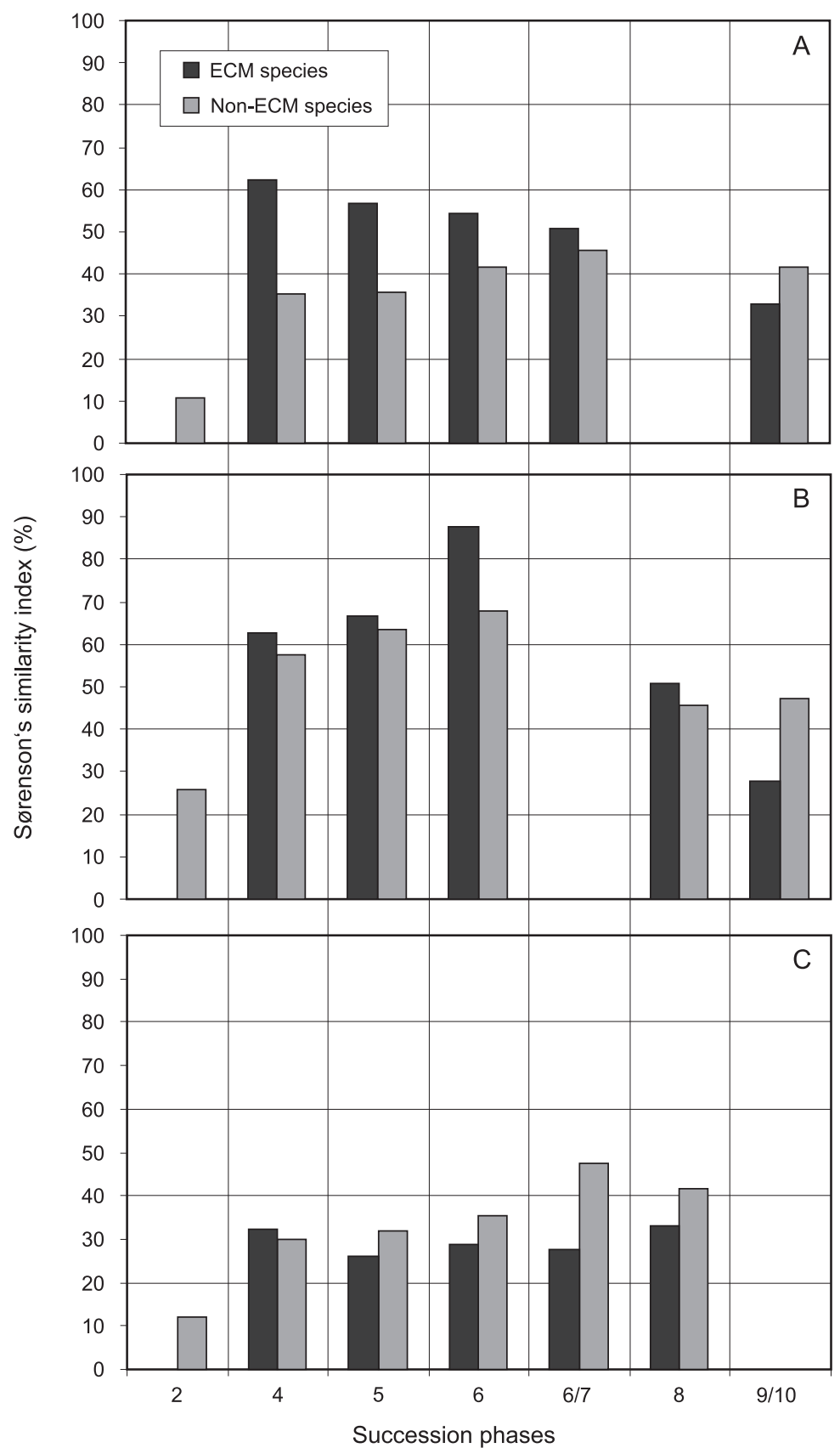

Fig. 12. Similarity in species composition among phases 6/7 (A), 8 (B) and 9/10 (C) and the other succession phases. 
Sørenson's index of fungal species similarity between the succession phases is usually higher for the communities which are closer in the chronosequence (Fig. 12, see also Fig. 11) with an exception of phase 8, where the species composition of the ECM fungi is most similar to phase 4 . This results from the higher proportion of deciduous trees in the plots representing phases 4 and 5 than in the plots of phases 6 and 6/7 (see Appendix 2, Tab. A2.1). Moreover, both plots of phase 4 and one plot of phase 5 are situated in the immediate neighbourhood of juniper-aspen brushwood (phase 8).

Most of the typical forest ECM species arrive only in the final phase of the chronosequence studied; this is reflected by the relatively low and stable similarity between the ECM species composition of pine forest (phase 9/10) and pre-forest vegetation.

\subsubsection{Species abundance patterns}

Fungal populations change with time and vegetation development, showing specific patterns of sporocarp production which can be seen in abundance changes in subsequent succession phases as well as in changes of spatial distribution. Groupings of fungal species showing similar dynamics along successional gradient were revealed with the k-mean analysis based on density of carpophores $[y=\ln (\mathrm{DC} 3 \mathrm{y}+1)]$ (Appendix 4).

\section{ECM fungi}

For the ECM fungi five species clusters were distinguished (Fig. 13; Appendix 4, Tab. A4.1):

Cluster 1. Species producing large numbers of carpophores in the initial and optimal stage of succession, and considerably fewer carpophores in the terminal stage. These are: Amanita muscaria, Chalciporus piperatus, Cortinarius cinnamomeoluteus, Hygrophorus hypothejus, Inocybe lacera, Laccaria proxima and Suillus luteus.

Cluster 2. Species producing high numbers of carpophores in the optimal stage of vegetation succession, especially in its advanced phases, and low (or lower) numbers in the other stages. Examples include: Boletus edulis, Cortinarius parevernius, Laccaria bicolor, Lactarius rufus, Rhodocollybia butyracea f. asema, Thelephora terrestris, Tricholoma albobrunneum, T. equestre, T. portentosum and T. saponaceum var. saponaceum.

Cluster 3. Species specific to or attaining the highest abundance in transitional vegetation type of juniper-aspen brushwood, e.g., Cantharellus cibarius, Clitopilus prunulus, Cortinarius alboviolaceus, C. trivialis, Inocybe flocculosa, Lactarius torminosus, Leccinum aurantiacum, Russula clavipes, $R$. galochroa and Thelephora caryophyllea.

Cluster 4. Species showing preference towards forest community, most of them arriving only in well developed pine forest; in the open vegetation they usually occur sporadically and produce few carpophores while in the forest their abundance is considerably higher. These are Amanita porphyria, Cortinarius caperatus, C. semisanquineus, C. vibratilis, Paxillus involutus, Russula badia, R. decolorans, R. emetica, R. paludosa and Xerocomus badius.

Cluster 5. Species producing relatively low numbers of carpophores, the majority of them showing less strong differences in carpophore production in particular succession phases as compared with the species grouped in the former clusters. Over half of the ECM species 


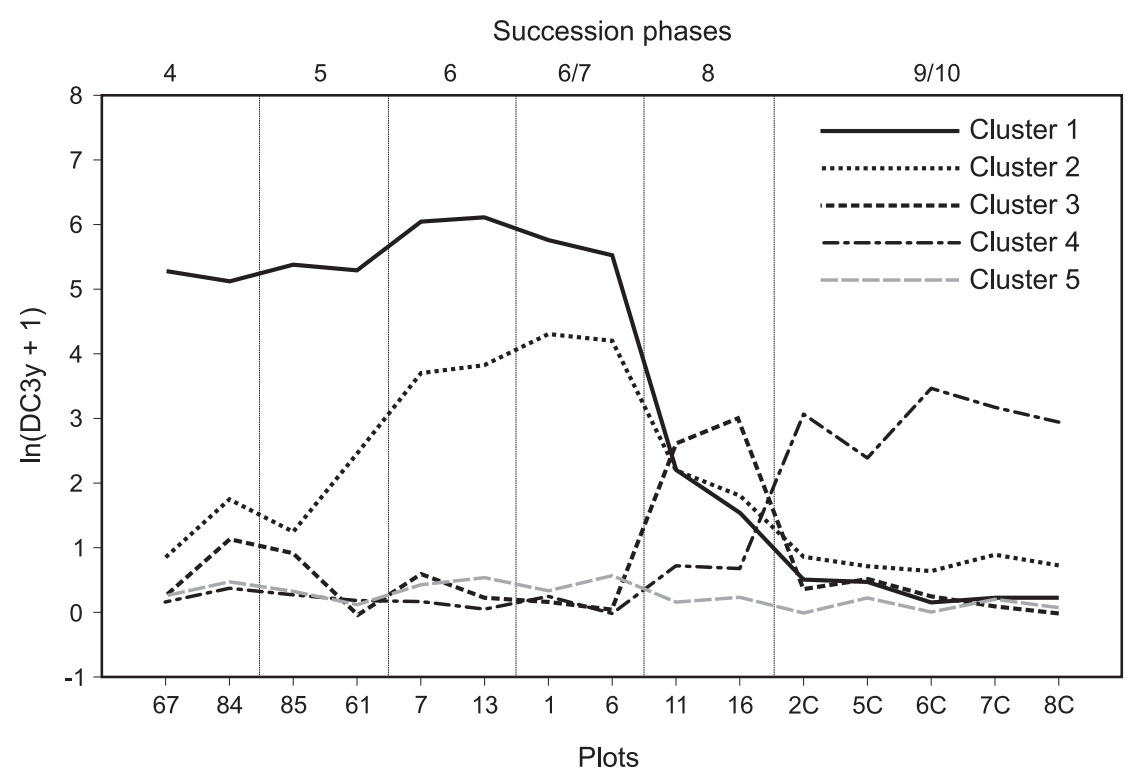

Fig. 13. ECM species grouping according to $\mathrm{k}-$ mean analysis $(\mathrm{k}=4)$. For species list in each cluster and distance from k-mean see Appendix 4.

recorded belong to this cluster (54). They include fungi occurring in a few different succession phases or just in one succession stage, as well as numerous exclusive species found in the plots representing the same succession phase or just in a single plot.

Among the ECM fungi there is a distinct but not numerous group of species producing sporocarps in all the succession phases, starting from (at least) phase 4 (Tab. 1). Amanita rubescens seems to occur relatively independently of vegetation development, while the other species show preferences towards some of the succession phases. Laccaria proxima and most of the species from the Cortinarius spp. I group (with small carpophores) occur mainly in open vegetation of initial and optimal succession stage and they tend to disappear in forest community (cluster 1). Thelephora terrestris and most of the species from the groups Cortinarius spp. II and spp. III (medium-size carpophores) as well as Rhodocollybia butyracea f. asema occur mainly in advanced phases of the optimal stage (cluster 2), the latter species continuing abundant fruiting also in transitional pre-forest community. Russula fragilis appears independently of vegetation development but always associated with deciduous trees and most abundantly in juniper-aspen brushwood (cluster 3). Paxillus involutus, rather scattered in all open communities, clearly prefers the forest phase (cluster 4).

A large group of the ECM species are associated with pre-forest vegetation type, i.e. from psammophilous grassland with single trees to transitional juniper-aspen brushwood (Tab. 1). This is especially true for the fungi grouped in clusters 1 and 2. Most of them seem to have their ecological optimum in particular succession phases or stages: Inocybe lacera in the initial stage (Fig. 14), Suillus luteus in the initial and optimal stage, Cortinarius cinnamomeoluteus in the early phase of the optimal stage, Hygrophorus hypothejus and Amanita muscaria in the optimal stage (Fig. 15), Tricholoma albobrunneum, T. equestre and T. portentosum in the last phase of optimal stage (Fig. 16). These species produce carpophores also in the juniper-aspen brushwood but, as a rule, less abundantly. 
Table 1

Distribution of the ECM species in the old-field chronosequence

\begin{tabular}{|c|c|c|c|c|c|c|c|c|c|c|c|c|c|c|}
\hline Parameter & & & & $\mathrm{aDCy}$ & & & & & & & $\mathrm{aSF}$ & & & \\
\hline Succession phase & 2 & 4 & 5 & 6 & $6 / 7$ & 8 & $9 / 10$ & 2 & 4 & 5 & 6 & $6 / 7$ & 8 & $9 / 10$ \\
\hline Laccaria proxima & $\cdot$ & 102.7 & 149.2 & 192.2 & 171.3 & 1.7 & 1.3 & $\cdot$ & VI & VI & VII & VII & II & III \\
\hline Cortinarius spp. I & . & 81.8 & 74.8 & 439.0 & 282.7 & 41.3 & 4.5 & . & VI & $\mathrm{V}$ & IX & $\mathrm{X}$ & VIII & III \\
\hline Thelephora terrestris & . & 8.0 & 13.0 & 58.7 & 21.8 & 0.2 & 12.0 & . & I & III & $\mathrm{V}$ & III & I & IV \\
\hline Cortinarius spp. II & · & 14.3 & 7.2 & 3.5 & 11.8 & 97.7 & 3.2 & . & II & II & $\mathrm{I}$ & II & $\mathrm{X}$ & III \\
\hline $\begin{array}{l}\text { Rhodocollybia butyracea } \mathrm{f} . \\
\text { asema }\end{array}$ & $\cdot$ & 0.7 & 4.3 & 17.3 & 21.7 & 33.3 & 1.0 & . & I & $\mathrm{I}$ & IV & IV & IX & I \\
\hline Russula fragilis & $\cdot$ & 11.0 & 6.5 & 9.0 & & 12.5 & 5.8 & . & II & II & I & & VII & II \\
\hline Cortinarius spp. III & . & 8.8 & 25.3 & 3.7 & 1.7 & 22.8 & 1.2 & . & I & II & II & I & $\mathrm{V}$ & II \\
\hline Paxillus involutus & . & 1.5 & 4.7 & 0.3 & 0.3 & 6.2 & 25.0 & . & I & I & I & I & II & IX \\
\hline Amanita rubescens & . & 1.8 & 3.8 & 0.8 & 1.3 & 0.3 & 0.7 & . & I & I & I & I & $\mathrm{I}$ & II \\
\hline $\begin{array}{l}\text { Tricholoma saponaceum } \\
\text { var. squamosum }\end{array}$ & . & 4.2 & $\cdot$ & $\cdot$ & $\cdot$ & $\cdot$ & 2.0 & . & I & . & . & . & . & $\mathrm{I}$ \\
\hline Inocybe lacera & . & 538.3 & 195.8 & 43.2 & 24.0 & 0.3 & . & . & IX & $\mathrm{V}$ & V & III & I & · \\
\hline Suillus luteus & . & 49.7 & 82.0 & 93.0 & 54.5 & 2.8 & · & . & VIII & IX & IX & VII & II & . \\
\hline Cortinarius cinnamomeoluteus & · & 137.8 & 281.7 & 288.3 & 321.5 & 0.5 & . & . & $\mathrm{V}$ & VIII & $\mathrm{X}$ & $\mathrm{X}$ & I & . \\
\hline Hygrophorus hypothejus & . & 23.8 & 116.0 & 363.5 & 186.3 & 0.8 & . & . & $\mathrm{V}$ & VIII & $\mathrm{X}$ & IX & I & . \\
\hline Amanita muscaria & . & 76.3 & 70.5 & 154.3 & 121.3 & 18.2 & . & . & VII & VII & IX & $\mathrm{X}$ & VIII & . \\
\hline Chalciporus piperatus & · & 19.7 & 9.2 & 63.7 & 27.3 & 1.3 & . & . & IV & IV & VIII & VII & III & . \\
\hline Tricholoma albobrunneum & . & 0.3 & 19.8 & 50.3 & 73.3 & 0.7 & . & · & I & III & VII & IX & $\mathrm{I}$ & . \\
\hline Tricholoma portentosum & . & 2.3 & 3.5 & 43.5 & 84.5 & 3.0 & . & . & I & $\mathrm{I}$ & $\mathrm{V}$ & VII & III & . \\
\hline Tricholoma equestre & . & $\cdot$ & 3.2 & 27.5 & 82.8 & 13.8 & . & . & . & $\mathrm{I}$ & IV & VIII & VIII & . \\
\hline Leccinum aurantiacum & . & 3.2 & 3.7 & 3.5 & 0.2 & 8.0 & . & . & II & II & I & I & IV & . \\
\hline Boletus edulis & . & 1.7 & 3.0 & 1.3 & 6.8 & 1.7 & . & . & I & $\mathrm{I}$ & I & III & III & . \\
\hline Clitopilus prunulus & . & 1.8 & 3.7 & 5.5 & 1.7 & 4.5 & . & . & I & I & I & I & III & . \\
\hline Amanita pantherina & · & 1.5 & 0.3 & 0.7 & 0.7 & 0.7 & · & . & I & I & I & I & $\mathrm{I}$ & $\cdot$ \\
\hline Hebeloma sp. 1 & . & 1.2 & $\cdot$ & 2.0 & $\cdot$ & 0.5 & . & . & I & . & I & . & I & . \\
\hline Russula galochroa & . & 1.8 & 0.2 & $\cdot$ & . & 3.8 & . & . & I & I & · & . & $\mathrm{V}$ & . \\
\hline Thelephora caryophyllea & . & 1.0 & $\cdot$ & . & . & 2.7 & . & . & I & . & · & . & II & . \\
\hline Hebeloma sp. 2 & . & 1.5 & . & . & . & 0.3 & . & . & I & . & . & . & $\mathrm{I}$ & . \\
\hline Coltricia perennis & . & 0.5 & . & . & . & 0.2 & . & · & I & . & · & . & I & . \\
\hline Leccinum scabrum & . & 0.3 & $\cdot$ & $\cdot$ & $\cdot$ & 1.0 & · & . & I & . & . & . & II & . \\
\hline Inocybe calida & . & 1.7 & 0.5 & 0.3 & 0.2 & $\cdot$ & . & . & I & I & I & I & . & . \\
\hline Inocybe praetervisa & . & 0.5 & 0.7 & 0.5 & 0.2 & $\cdot$ & . & $\cdot$ & I & I & $\mathrm{I}$ & $\mathrm{I}$ & . & . \\
\hline Laccaria bicolor & . & 3.8 & 0.3 & 37.8 & 16.2 & $\cdot$ & . & · & I & I & II & II & . & . \\
\hline Ramaria eumorpha & . & 0.5 & $\cdot$ & 14.5 & 0.8 & . & . & . & I & . & I & $\mathrm{I}$ & . & . \\
\hline Cortinarius purpurascens & · & 2.3 & . & 1.2 & 1.8 & $\cdot$ & . & . & I & . & I & II & · & . \\
\hline Inocybe assimilata & . & 0.3 & . & 1.2 & 4.7 & . & . & . & I & . & I & $\mathrm{I}$ & . & . \\
\hline Boletus reticulatus & . & 0.3 & . & $\cdot$ & 0.3 & . & . & . & I & . & & I & . & . \\
\hline Inocybe curvipes & · & $\cdot$ & 2.0 & 3.3 & 0.7 & $\cdot$ & · & $\cdot$ & $\cdot$ & I & I & I & · & $\cdot$ \\
\hline Cortinarius anthracinus & . & . & 0.5 & 5.0 & 7.5 & · & . & . & . & I & II & III & . & . \\
\hline $\begin{array}{l}\text { Tricholoma saponaceum } \\
\text { var. saponaceum }\end{array}$ & . & . & 5.3 & 23.5 & 44.5 & . & . & . & . & I & II & IV & . & . \\
\hline Lactarius rufus & . & . & . & 29.2 & 104.7 & 0.5 & 12.7 & $\cdot$ & $\cdot$ & . & IV & V & I & VI \\
\hline Cortinarius parevernius & . & $\cdot$ & . & 26.8 & 20.0 & 0.3 & & $\cdot$ & $\cdot$ & . & IV & IV & I & $\cdot$ \\
\hline Inocybe asterospora & . & 9.2 & . & 0.2 & $\cdot$ & $\cdot$ & . & · & II & . & I & $\cdot$ & . & . \\
\hline Hygrophorus aureus & $\cdot$ & 0.7 & $\cdot$ & $\cdot$ & · & $\cdot$ & $\cdot$ & . & I & $\cdot$ & $\cdot$ & · & · & $\cdot$ \\
\hline Lactarius vietus & $\cdot$ & 0.3 & $\cdot$ & . & · & $\cdot$ & $\cdot$ & $\cdot$ & I & . & $\cdot$ & · & · & · \\
\hline Xerocomus subtomentosus & . & 1.0 & 0.8 & . & . & · & . & · & I & $\mathrm{I}$ & . & . & . & . \\
\hline Russula subfetens & . & 0.3 & 0.2 & . & . & · & . & . & I & I & · & . & . & . \\
\hline Gyroporus castaneus & · & 0.5 & 0.5 & $\cdot$ & $\cdot$ & $\cdot$ & · & $\cdot$ & I & I & · & $\cdot$ & · & $\cdot$ \\
\hline Lactarius quieticolor & . & $\cdot$ & 2.8 & . & . & . & . & . & . & I & . & . & . & . \\
\hline
\end{tabular}




\begin{tabular}{|c|c|c|c|c|c|c|c|c|c|c|c|c|c|c|}
\hline Scleroderma fuscum & & - & 0.5 & & & - & - & - & $\cdot$ & I & . & . & - & - \\
\hline Xerocomus chrysenteron & & . & 0.3 & & & . & - & . & . & I & . & . & . & . \\
\hline Russula vinosobrunnea & & . & 0.2 & & & - & . & . & . & I & . & . & . & . \\
\hline Cortinarius cinnabarinus & - & . & 0.7 & 0.2 & & . & . & . & . & I & I & . & . & . \\
\hline Cortinarius colus & - & . & . & 9.3 & & . & - & . & . & - & II & . & . & . \\
\hline Tricholoma pessundatum & - & . & . & 0.5 & . & . & . & . & . & . & I & . & . & - \\
\hline Cortinarius acetosus & & . & . & 0.2 & & . & - & . & . & - & I & . & . & . \\
\hline Cortinarius тисовиs & & . & . & 9.0 & 4.0 & . & . & . & . & . & III & II & . & . \\
\hline $\begin{array}{l}\text { Cortinarius multiformis } \\
\text { var. coniferarum }\end{array}$ & ${ }^{\circ}$ & . & . & 3.5 & 0.7 & . & . & . & . & $\cdot$ & I & I & . & . \\
\hline Rhizopogon luteolus & t & . & . & 0.3 & 0.3 & . & . & . & . & . & I & I & . & . \\
\hline Suillus bovinus & . & . & . & 0.3 & 0.8 & . & . & . & . & . & I & I & . & \\
\hline Sarcodon squamosus & . & . & . & 2.2 & 5.0 & . & . & . & . & . & I & II & . & r \\
\hline Cortinarius spp. IV & • & . & . & 0.2 & 2.8 & . & $\cdot$ & $\cdot$ & . & . & I & I & $\cdot$ & - \\
\hline Cortinarius sanguineus & • & . & . & . & 1.0 & . & . & . & . & - & . & I & . & - \\
\hline Boletus pinophilus & . & . & . & . & 0.3 & . & - & . & . & r & . & I & . & - \\
\hline Russula clavipes & & 0.3 & 0.2 & . & & 10.3 & - & . & I & I & . & . & VIII & \\
\hline Lactarius uvidus & r & $\cdot$ & 0.2 & & & 3.0 & . & . & . & I & . & . & II & \\
\hline Tricholoma imbricatum & . & . & $\cdot$ & 0.7 & . & 3.2 & . & . & . & . & I & . & I & . \\
\hline Cortinarius trivialis & . & . & . & . & . & 117.3 & . & . & . & - & . & . & $\mathrm{X}$ & - \\
\hline Cortinarius alboviolaceus & 跮 & . & . & . & . & 17.5 & . & . & . & . & . & . & $\mathrm{V}$ & . \\
\hline Hebeloma sp. 3 & . & . & . & . & . & 16.3 & . & . & . & . & . & . & IV & . \\
\hline Lactarius torminosus & r & . & . & . & . & 4.3 & $\cdot$ & . & . & . & . & . & IV & \\
\hline Inocybe flocculosa & & . & . & . & . & 11.5 & . & . & . & . & . & . & III & \\
\hline Inocybe cf. margaritispora & & . & . & . & & 3.0 & . & . & . & . & . & . & III & \\
\hline Amanita gemmata & r & · & . & . & . & 0.8 & . & . & . & . & . & . & II & \\
\hline Lactarius necator & . & . & . & . & . & 0.5 & . & . & . & . & . & . & I & . \\
\hline Ramaria cf. abietina & . & . & . & . & . & 0.5 & $\cdot$ & $\cdot$ & . & . & . & . & I & . \\
\hline Russula mustelina & . & . & . & . & . & 0.5 & $\cdot$ & $\cdot$ & . & . & . & . & I & . \\
\hline Amanita phalloides & • & . & . & . & . & 0.2 & . & . & . & . & . & . & I & . \\
\hline Hebeloma stenocystis & & . & . & . & - & 0.2 & - & . & . & . & . & . & I & \\
\hline Russula versicolor & & & . & . & & 0.2 & . & . & . & - & . & . & I & \\
\hline Amanita citrina & . & 0.5 & . & . & . & 39.0 & 19.8 & . & I & . & . & . & $\mathrm{X}$ & IX \\
\hline Cantharellus cibarius & r & . & . & . & . & 22.8 & 2.5 & . & . & . & . & . & III & III \\
\hline Russula paludosa & r & . & . & . & . & 0.8 & 6.5 & . & . & . & . & . & I & VII \\
\hline Russula emetica & . & 0.5 & . & . & & . & 13.2 & . & I & . & . & . & . & VII \\
\hline Xerocomus badius & . & $\cdot$ & . & 0.5 & 0.8 & . & 8.7 & $\cdot$ & & . & I & I & . & VI \\
\hline Cortinarius caperatus & . & . & . & & & . & 15.3 & . & . & . & . & . & . & VIII \\
\hline Russula decolorans & & . & . & & & . & 10.2 & . & . & . & . & . & . & VIII \\
\hline Cortinarius semisanguineus & . & . & . & . & . & . & 16.3 & . & . & . & . & . & . & $\mathrm{V}$ \\
\hline Russula badia & . & . & . & . & . & . & 9.2 & . & . & . & . & . & . & $\mathrm{V}$ \\
\hline Amanita porphyria & . & . & . & . & . & . & 2.8 & . & . & - & . & . & . & IV \\
\hline Cortinarius vibratilis & r & · & $\cdot$ & $\cdot$ & . & - & 2.8 & - & $\cdot$ & - & · & $\cdot$ & · & III \\
\hline Russula xerampelina & . & · & $\cdot$ & . & · & $\cdot$ & 1.3 & - & . & . & . & . & · & III \\
\hline Russula vinosa & . & $\cdot$ & · & . & . & - & 1.7 & . & $\cdot$ & . & . & $\cdot$ & . & II \\
\hline Lactarius tabidus & . & . & . & . & & . & 2.0 & . & . & . & . & . & . & I \\
\hline Russula turci & . & . & . & . & . & . & 0.8 & . & . & . & . & . & . & I \\
\hline Chroogomphus rutilus & . & . & . & . & . & . & 0.2 & . & . & - & . & . & . & I \\
\hline Russula vesca & . & . & . & . & . & . & 0.2 & . & . & - & . & . & . & I \\
\hline Suillus variegatus & . & . & . & . & . & . & 0.2 & . & . & . & . & . & . & I \\
\hline Tylopilus felleus & - & . & . & . & & . & 0.2 & . & . & . & . & . & . & I \\
\hline
\end{tabular}

aDCy - average density of carpophores per year; aSF - average spatial frequency expressed as classes: $\mathrm{I}=1-10 \%$, $\mathrm{II}=11-20 \%, \mathrm{III}=21-30 \%, \mathrm{IV}=31-40 \%, \mathrm{~V}=41-50 \%, \mathrm{VI}=51-60 \%, \mathrm{VII}=61-70 \%, \mathrm{VIII}=71-80 \%, \mathrm{IX}=81-90 \%$, $\mathrm{X}=91-100 \%$ (the transformation makes the data comparable as the numbers of subplots in succession phases are different: phase $2-10$, phase $4-80$, phase $5-80$, phase $6-80$, phase $6 / 7-80$, phase $8-33$, phase $9 / 10-20$ ) 

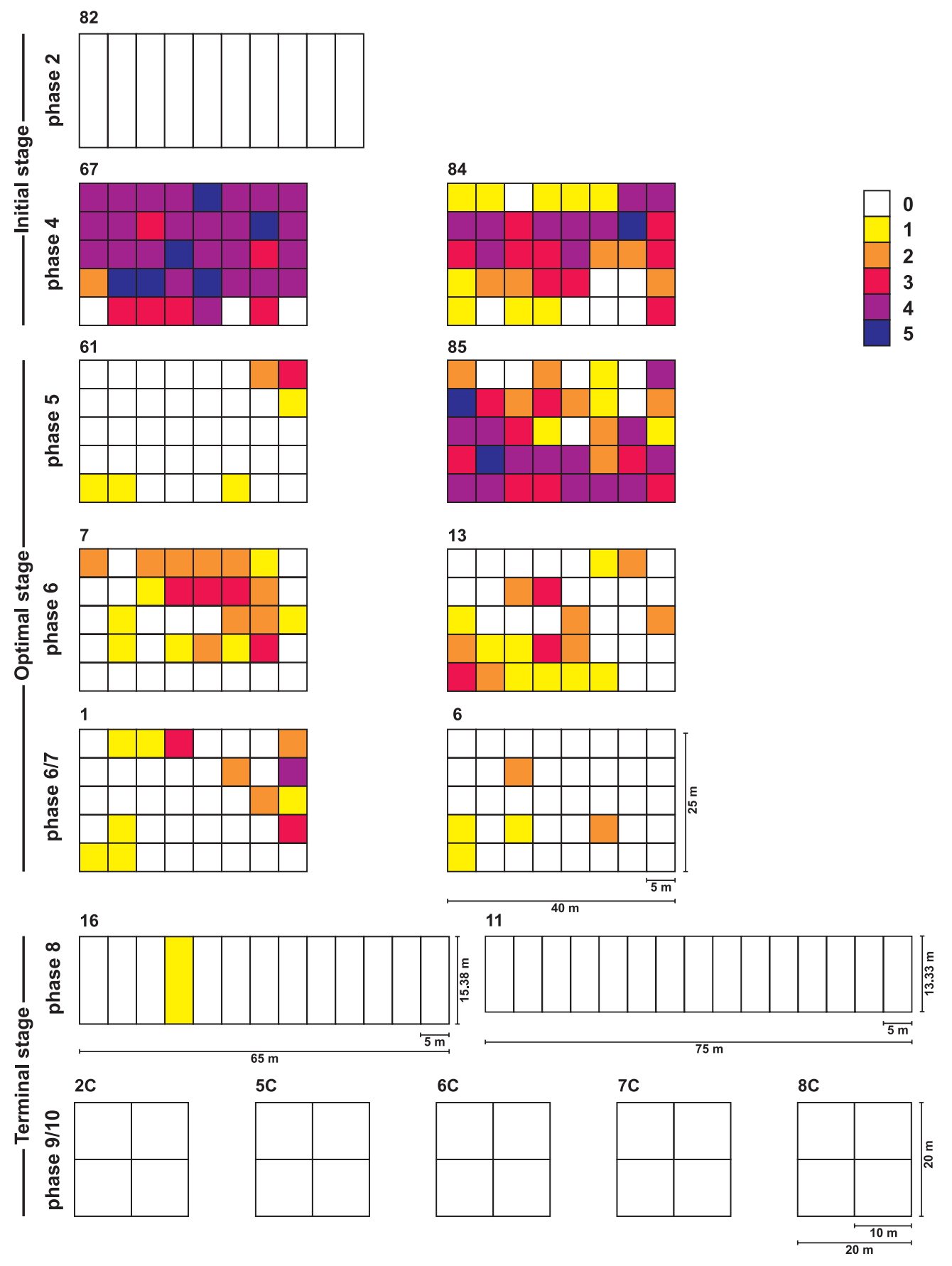

Fig. 14. Inocybe lacera - distribution in the plots based on the total abundance of carpophores (AC3y) in each subplot according to the scale by KeIzer (1993a): $1=1-3,2=4-11,3=12-32,4=33-89,5=90-243$ carpophores. 

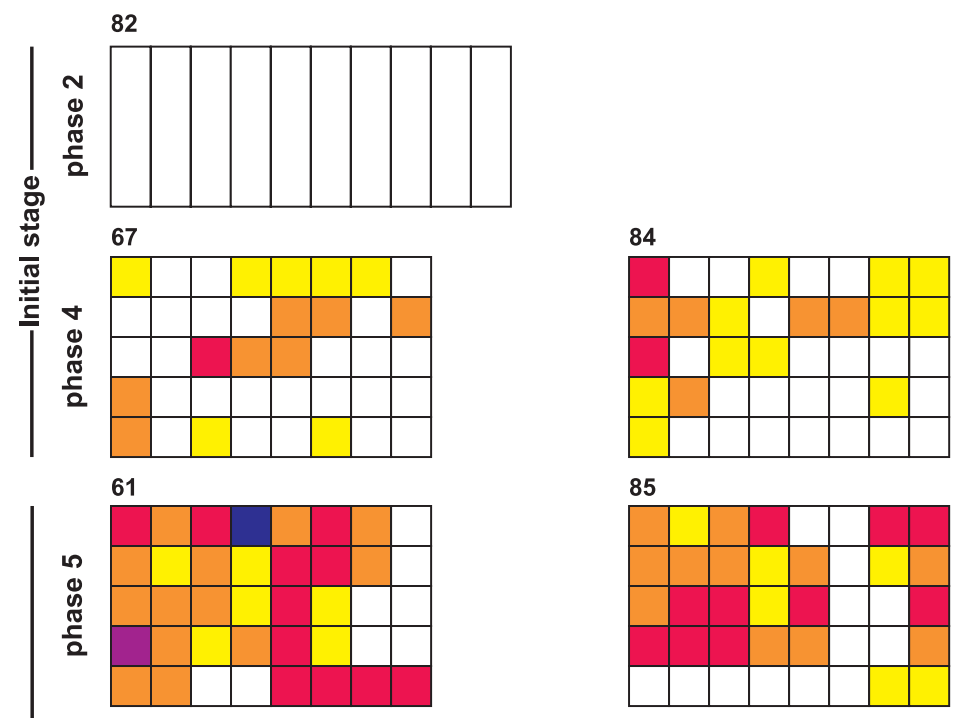

85
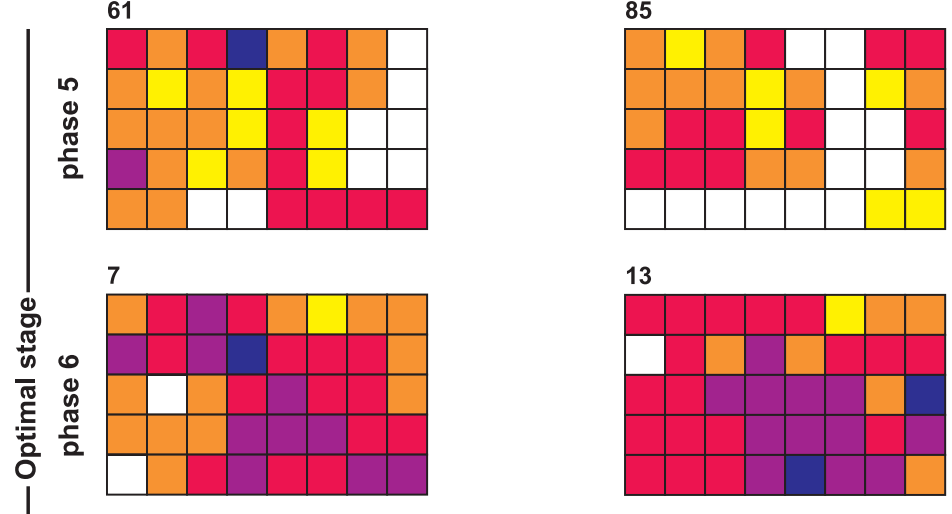

13
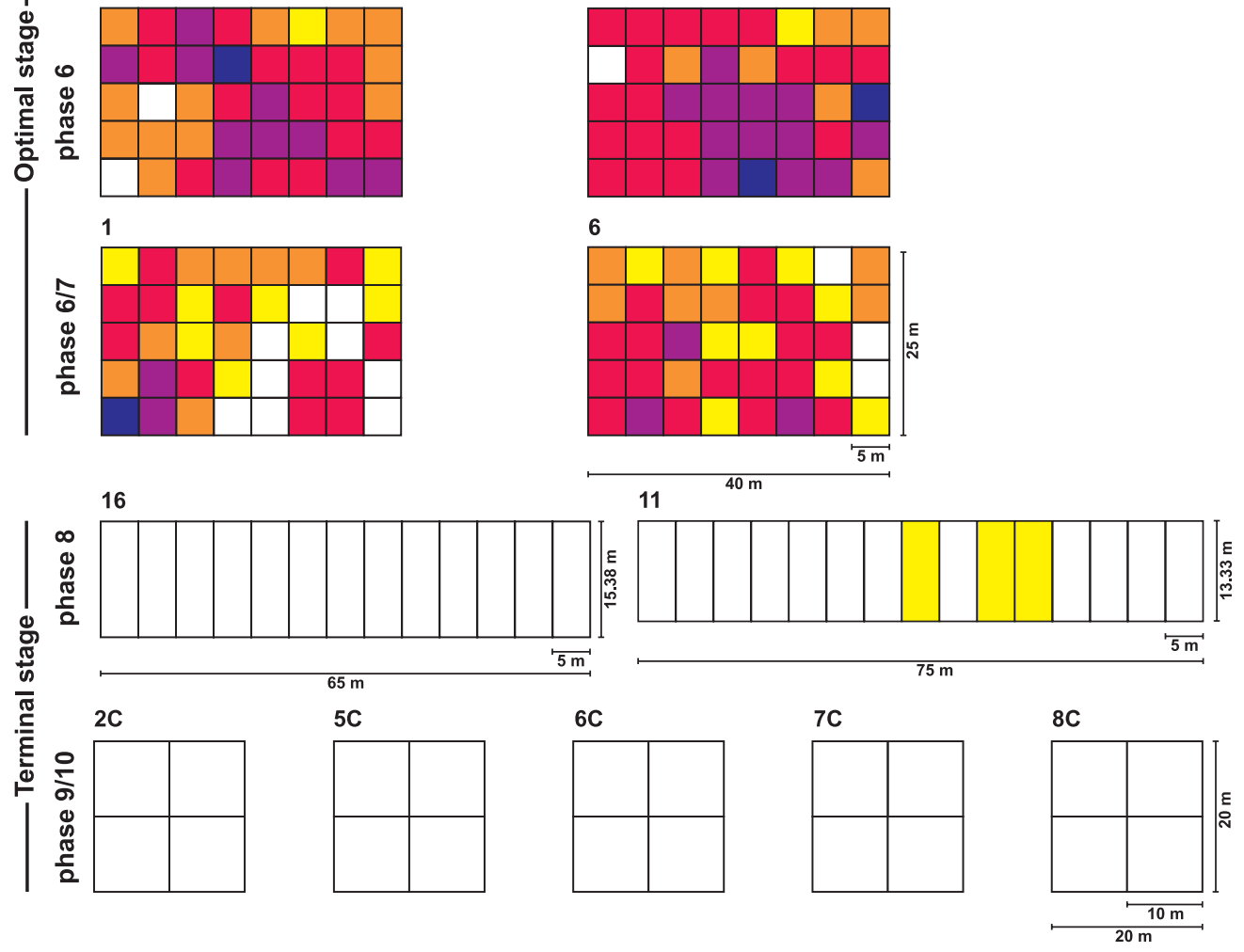

Fig. 15. Hygrophorus hypothejus - distribution in the plots based on the total abundance of carpophores (AC3y) in each subplot according to the scale by KeIzer (1993a): $1=1-3,2=4-11,3=12-32,4=33-89,5=90-243$ carpophores. 

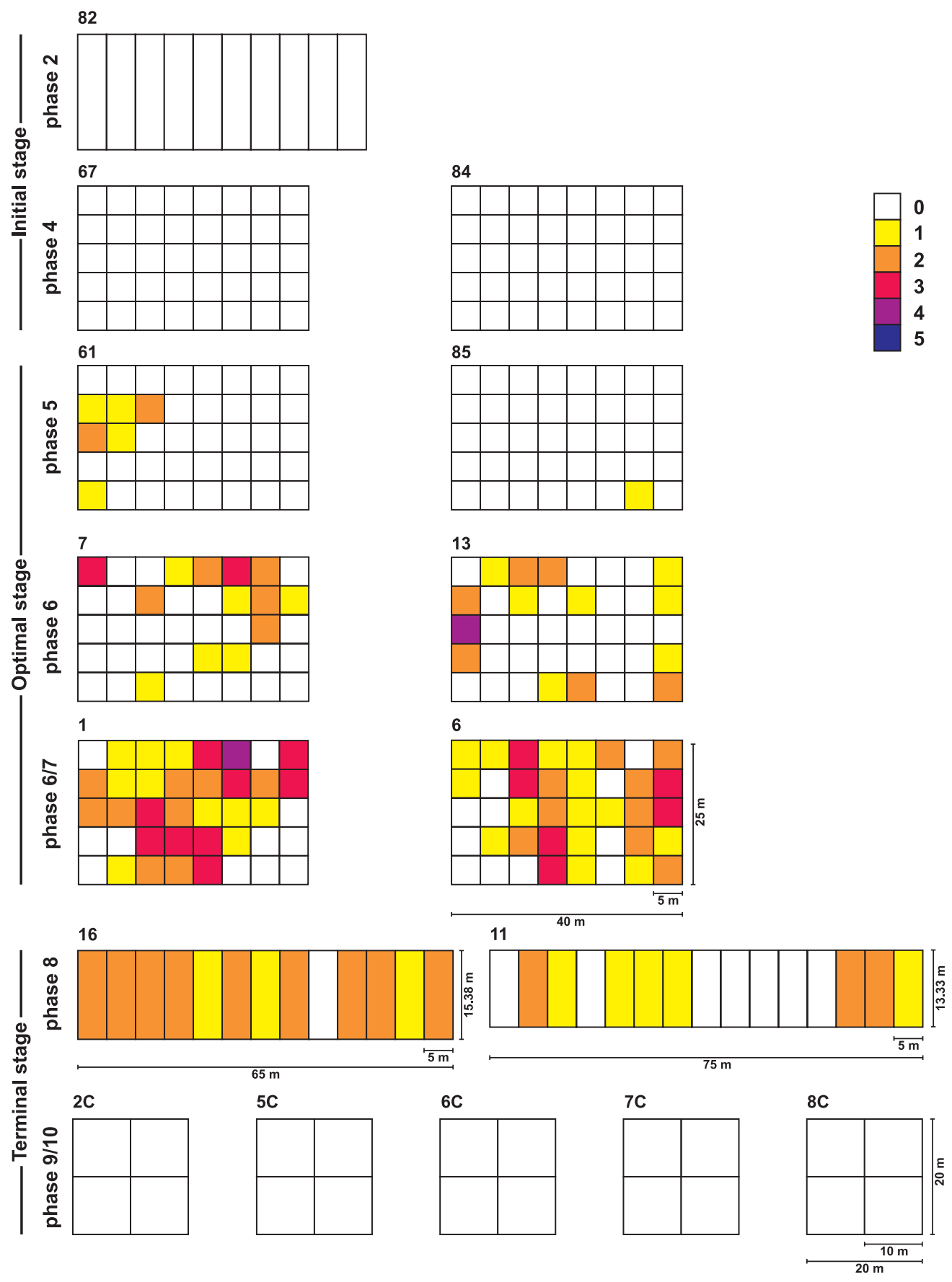

Fig. 16. Tricholoma equestre - distribution in the plots based on the total abundance of carpophores (AC3y) in each subplot according to the scale by KeIZER (1993a): $1=1-3,2=4-11,3=12-32,4=33-89,5=90-243$ carpophores. 

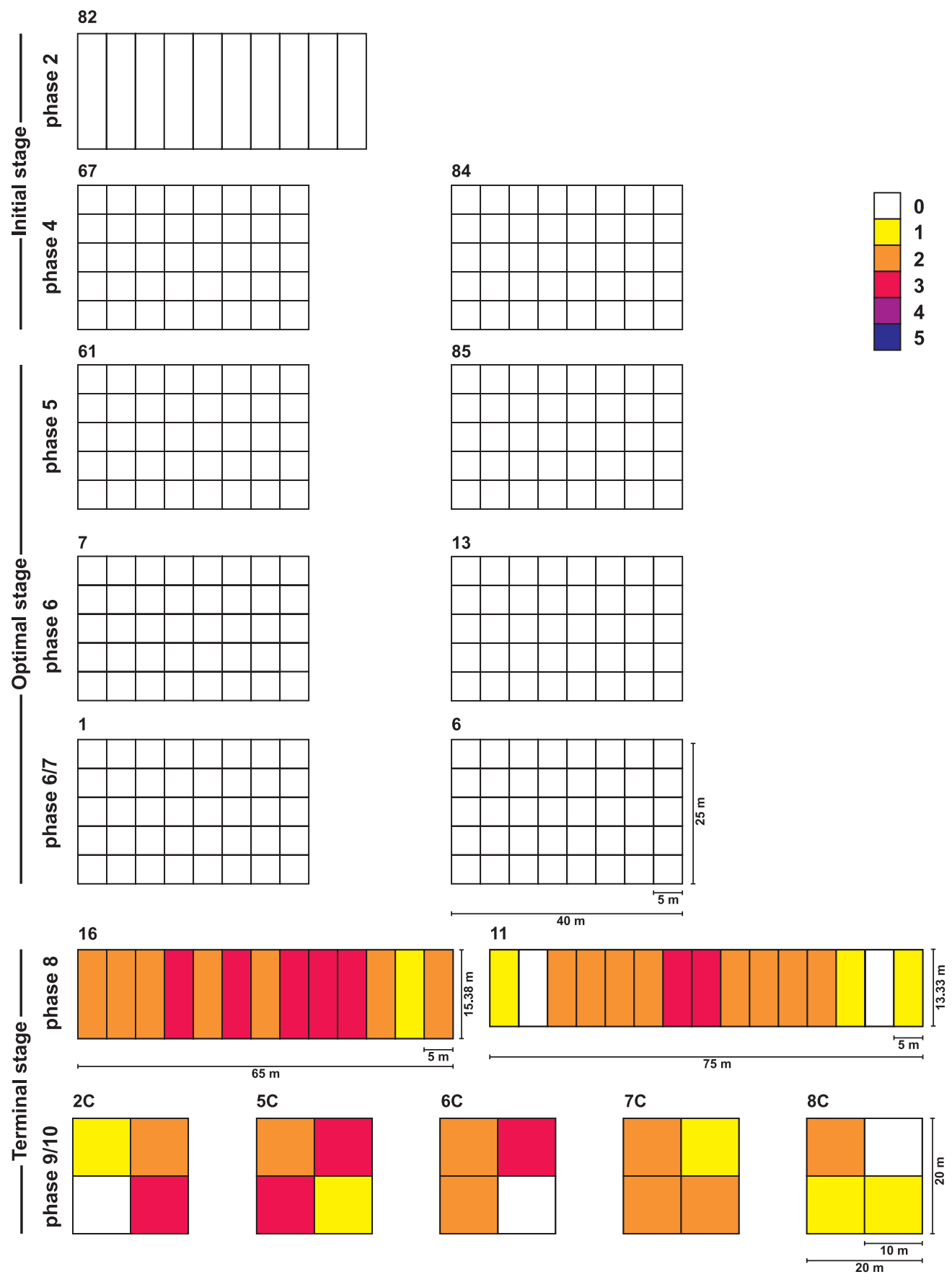

Fig. 17. Amanita citrina - distribution in the plots based on the total abundance of carpophores (AC3y) in each subplot according to the scale by KeIzer (1993a): $1=1-3,2=4-11,3=12-32,4=33-89,5=90-243$ carpophores. 
Among the species which clearly prefer open habitats and do not appear (as sporocarps) in brushwood community are most of the Inocybe species, Laccaria bicolor, Cortinarius purpurascens and $C$. anthracinus.

The majority of the ECM species attaining the highest abundance in the juniper-aspen brushwood (phase 8, cluster 3 ) are the symbionts of deciduous trees. Some of them, like Leccinum aurantiacum, L. scabrum, Russula galochroa and $R$. clavipes, accompany aspen and birch also in the plots of earlier succession phases, especially in places directly neighbouring the brushwood. Other species such as Cortinarius alboviolaceus, C. trivialis, Inocybe flocculosa and Lactarius torminosus occur exclusively in phase 8.

Most of the ECM fungi that occur in a few different succession phases arrive and start fruiting relatively early, in the initial stage or in the early phase of optimal stage, and they cease production of their carpophores in late pre-forest communities of phases $6 / 7$ or 8 (Tab.1). The species that occur both in pre-forest and in forest sites are relatively few; apart from the several species listed earlier in this chapter that occur in the chronosequence at least from phase 4; among such species are Russula emetica and Xerocomus badius - occurring sporadically out of forest (cluster 4), Amanita citrina, Cantharellus cibarius and Russula paludosa - not occurring in open vegetation (clusters 3 and 4) (Fig. 17) and Lactarius rufus - associated mainly with younger coniferous stands (cluster 2). Almost half of the species found in the forest do not occur earlier in the chronosequence. Some of them produce relatively abundant carpophores, for example Amanita porphyria, Cortinarius caperatus, C. semisanguineus, C. vibratilis, Russula badia and $R$. decolorans (cluster 4).

The number of ECM exclusive species is low in the initial and optimal stages of the vegetation succession (Tab.1) and these are sporadic species attaining low abundance and spatial frequency. In the terminal stage, the number of exclusive species distinctly increases and many of them attain high abundance and high frequency.

\section{Non-ECM fungi}

For the non-ECM fungi again five species clusters were distinguished (Fig. 18; Appendix 4, Tab. A4.2):

Cluster 1. Species producing high numbers of carpophores in all the succession stages, from the initial communities to the pine forest. These include species of Entoloma and Galerina as well as Clitocybe diatreta, Cystoderma amianthinum, Gymnopus androsaceus and Collybia cirrhata.

Cluster 2. Species producing very abundant carpophores in the complex of psammophilous grassland, juniper shrubs and pine (phases 4-6/7) and usually less abundant outside these communities. These are Ampulloclitocybe clavipes, Cantharellula umbonata, Clavaria argillacea, Galerina atkinsoniana, Hygroaster asterosporus, Lycoperdon perlatum, Psilocybe montana, Rickenella fibula; all these species grow mainly among mosses and on soil. In this group are also Mycena flavoalba, M. leptocephala and M. olivaceomarginata fruiting most abundantly in phase 2 on the remnants of herbaceous plants.

Cluster 3. A well distinguished group of 47 species with optimum of occurrence in the juniper-aspen brushwood (phase 8), characterized by abundant carpophore production in this type of vegetation. The cluster includes both species found also in the other succession phases, such as Clitocybe anisata, C. candicans, C. fragrans, Dacrymyces variisporus, Gymnopus confluens, Lycoperdon molle, Macrolepiota procera, Mycena stylobates, Sphaerobolus 


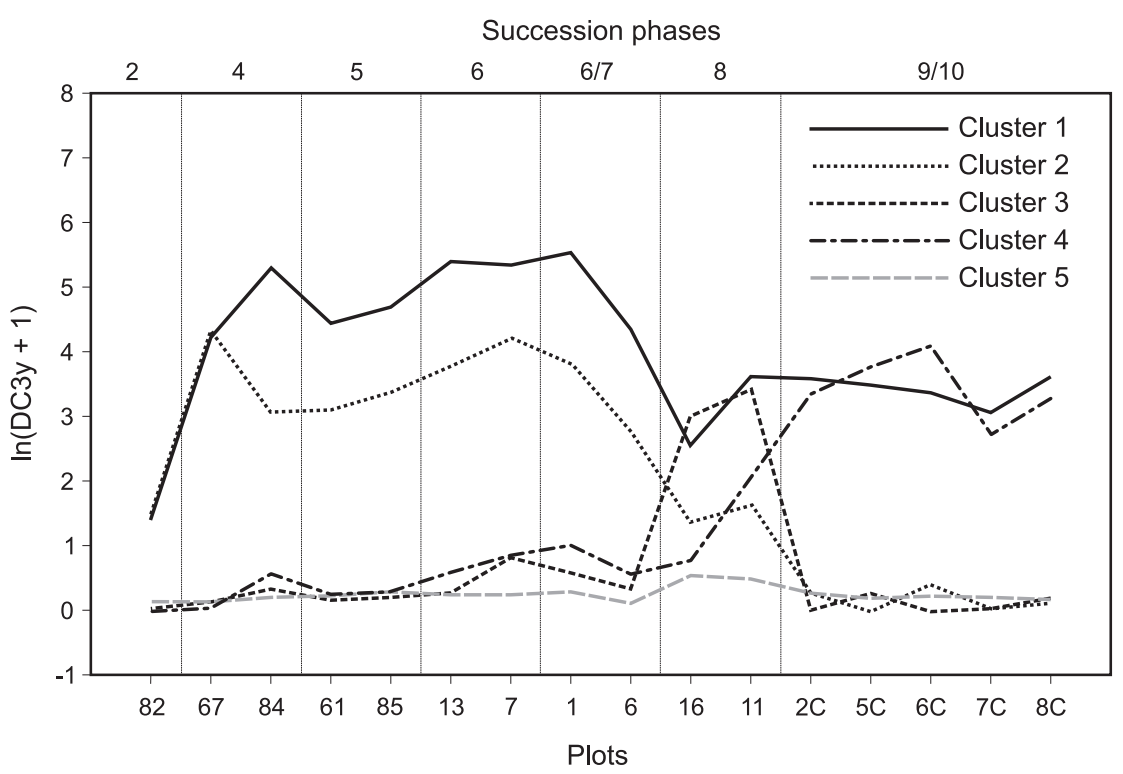

Fig. 18. Non-ECM species grouping according to k-mean analysis $(\mathrm{k}=4)$. For species list in each cluster and distance from k-mean see Appendix 4.

stellatus, and numerous exclusive species, such as Clitocybe metachroa, Coprinellus spp., Crepidotus lundelii, Exidia plana, Flammulaster rhombosporus, Hymenochaete tabacina, Peniophora polygonia, Stereum hirsutum.

Cluster 4. Species producing low numbers of carpophores in pre-forest vegetation, with optimum of occurrence and abundant carpophore production in the terminal stage of succession, particularly in the pine forest. Among them are typical litter-inhabiting species, e.g., Auriscalpium vulgare, Baeospora myosura, Collybia tuberosa,, Mycena galopus, M. metata, M. vulgaris, M. zephirus, Xeromphalina cornui; wood-inhabiting species, e.g., Dacrymyces stillatus, Hypholoma capnoides, Leptosporomyces galzinii, Phlebiella sulphurea; as well as a parasite of Vaccinium vitis-idaea: Exobasidium vaccinii.

Cluster 5. Species producing relatively sparse carpophores, occurring in a few succession phases, and a majority of exclusive species. It is the most numerous group of species - over 120 taxa.

Most of the species which already appear in the initial stage of succession (phases 2 and 4) also occur in the optimal and terminal stage (Tab. 2). A great majority of them produce their carpophores much more abundantly in a particular succession phase or stage, depending on the type and amount of substrate available. For example, Crinipellis scabella, Marasmius oreades, Mycena flavoalba, M. leptocephala, M. olivaceomarginata prefer the habitats rich in the remnants of herbaceous plants (phase 2). Clitocybe vibecina and Gymnopus androsaceus occur abundantly on the sites of accumulation of row pine and juniper needles (late optimal and terminal stage). Hypholoma fasciculare and Dacrymyces stillatus are most numerous in the pine forest, where coniferous woody debris is most abundant.

Distinct differences in carpophore numbers produced in the subsequent succession phases can be seen mainly in the species growing on soil and among mosses, grouped in 
Table 2

Distribution of the non-ECM species in the old-field chronosequence

\begin{tabular}{|c|c|c|c|c|c|c|c|c|c|c|c|c|c|c|}
\hline Parameter & & & & aDCy & & & & & & & aSF & & & \\
\hline Succession phase & 2 & 4 & 5 & 6 & $6 / 7$ & 8 & $9 / 10$ & 2 & 4 & 5 & 6 & $6 / 7$ & 8 & $9 / 10$ \\
\hline Crinipellis scabella & 227.5 & ${ }^{\circ}$ & 5.3 & 3.0 & & & & $\mathrm{X}$ & $\cdot$ & I & I & & 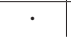 & \\
\hline Entoloma undatum & 0.5 & . & & & 0.2 & & - & I & . & & . & I & . & \\
\hline Rickenella fibula & 3.0 & 20.2 & 24.3 & 110.3 & 12.2 & & . & I & V & IV & VI & II & . & \\
\hline Marasmius oreades & 113.0 & . & 0.2 & 1.7 & 1.2 & 2.0 & . & $\mathrm{X}$ & . & I & I & I & I & \\
\hline Mycena olivaceomarginata & 56.0 & 12.7 & 3.2 & 1.3 & 1.5 & 7.5 & . & IX & V & I & I & I & VI & \\
\hline Mycena leptocephala & 82.0 & 11.5 & 17.8 & 46.5 & 27.5 & 20.5 & - & VIII & II & III & V & V & VIII & . \\
\hline Mycena flavoalba & 104.5 & 30.7 & 14.8 & 4.7 & 5.5 & 21.5 & 0.2 & $\mathrm{X}$ & II & II & I & II & $\mathrm{V}$ & I \\
\hline Galerina spp. & 25.0 & 39.8 & 20.2 & 71.3 & 59.7 & 3.8 & 5.3 & VII & IV & III & V & IV & III & IV \\
\hline Clitocybe diatreta & 4.0 & 73.7 & 150.5 & 357.2 & 269.8 & 11.0 & 2.2 & I & VIII & VII & IX & $\mathrm{X}$ & IV & I \\
\hline Cystoderma amianthinum & 4.5 & 45.5 & 17.5 & 100.5 & 26.3 & 1.3 & 9.7 & I & $\mathrm{V}$ & II & VII & IV & I & VII \\
\hline Mycena pura & 3.0 & 1.2 & 0.8 & 3.7 & 1.3 & 17.8 & 0.5 & IV & I & I & I & I & VIII & I \\
\hline Psilocybe montana & $\cdot$ & 123.0 & 117.7 & 7190.3 & 135.5 & 1.7 & 0.2 & & IX & IX & IX & IX & I & I \\
\hline Entoloma spp. & - & 68.7 & 37.5 & 10.8 & 8.3 & 7.5 & 4.7 & . & VIII & VI & IV & II & IV & V \\
\hline Ampulloclitocybe clavipes & - & 2.7 & 0.5 & 20.3 & 5.3 & 8.0 & 2.2 & . & I & I & III & II & III & III \\
\hline Clitocybe vibecina & - & 5.8 & 1.3 & 10.7 & 45.7 & 1.0 & 12.3 & - & I & I & II & III & II & IV \\
\hline Gymnopus androsaceus & - & 54.2 & 21.0 & 120.0 & 204.5 & 77.7 & 159.0 & & II & I & V & $\mathrm{V}$ & V & $\mathrm{X}$ \\
\hline Collybia cirrhata & - & 29.8 & 86.3 & 43.8 & 45.7 & 57.3 & 140.2 & . & III & III & III & III & III & IX \\
\hline Galerina pumila & - & 4.7 & 3.5 & 4.7 & 8.5 & 3.5 & 10.5 & . & I & I & I & II & II & VIII \\
\hline Lycoperdon nigrescens & . & 1.7 & 1.2 & $\cdot$ & . & 3.3 & 0.2 & . & I & I & . & . & III & I \\
\hline Macrolepiota procera & - & 0.7 & 1.0 & . & 1.2 & 2.8 & 0.2 & - & I & I & . & I & IV & I \\
\hline Hypholoma fasciculare & - & 2.0 & $\cdot$ & 0.2 & 0.5 & 17.7 & 41.0 & - & I & . & I & I & IV & I \\
\hline Dacrymyces stillatus & - & 8.3 & - & . & 5.0 & 254.2 & 861.0 & - & I & . & & I & IV & IX \\
\hline Mycena metata & - & 0.3 & . & 0.8 & 0.3 & 0.2 & 16.3 & - & I & - & I & I & I & VIII \\
\hline Mycena aetites & . & 0.2 & . & & 0.3 & 0.3 & 0.7 & & I & - & & I & I & I \\
\hline Paneolus papilionaceus & - & 5.0 & 0.3 & & & 0.3 & $\cdot$ & . & I & I & . & . & I & \\
\hline Hygrocybe virginea var. virginea & - & 2.3 & 7.7 & 0.2 & 0.5 & 1.2 & · & · & I & $\mathrm{I}$ & I & I & II & - \\
\hline Gymnopus putillus & - & 0.2 & 0.5 & 0.7 & 0.5 & 0.2 & . & · & I & I & I & I & I & · \\
\hline Rhodocybe caelata & - & 0.3 & 1.0 & 1.5 & 0.3 & 0.3 & - & . & I & I & I & I & I & · \\
\hline Lycoperdon perlatum & - & 4.2 & 3.5 & 7.3 & 5.8 & 4.2 & - & · & II & I & II & I & IV & . \\
\hline Flammulaster granulosus & - & 2.8 & 0.3 & 5.7 & 0.2 & 5.3 & - & . & I & I & I & I & II & · \\
\hline Mycena vitilis & . & 0.3 & 0.2 & 2.7 & 5.5 & 1.8 & . & - & I & I & I & II & II & . \\
\hline Mycena stylobates & - & 0.3 & 0.8 & 0.7 & 1.2 & 2.3 & - & - & I & I & I & I & II & . \\
\hline Galerina hypnorum & - & 1.5 & 8.8 & 4.8 & 12.2 & 29.2 & - & - & I & I & I & II & VIII & \\
\hline Lycoperdon molle & - & 5.8 & 0.7 & 2.3 & & 15.7 & . & - & I & I & I & . & VIII & - \\
\hline Sphaerobolus stellatus & - & 0.8 & . & 0.8 & & 25.2 & . & - & I & & I & . & II & - \\
\hline Clavaria argillacea & - & 239.2 & 193.0 & 47.3 & 92.8 & 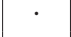 & - & - & VI & V & II & III & . & - \\
\hline Rhodocybe parilis & - & 6.8 & 8.2 & 1.5 & 0.2 & - & - & - & II & II & I & I & - & - \\
\hline Galerina atkinsoniana & - & 32.3 & 7.5 & 111.5 & 63.5 & - & - & . & III & I & VI & IV & . & . \\
\hline Hygroaster asterosporus & - & 1.3 & 1.8 & 13.8 & 11.8 & - & - & . & I & I & IV & III & . & . \\
\hline Cantharellula umbonata & - & 220.0 & 25.7 & 55.7 & $\cdot$ & - & - & - & IV & I & II & $\cdot$ & . & - \\
\hline Lycoperdon dermoxanthum & . & 4.2 & 6.7 & 0.5 & & . & . & . & II & III & I & . & . & \\
\hline Entoloma jubatum & - & 2.2 & 4.5 & 2.0 & $\cdot$ & . & - & . & I & II & I & - & - & $\cdot$ \\
\hline Rhodocybe hirneola & - & 0.2 & . & 2.0 & . & $\cdot$ & - & . & I & - & I & - & - & . \\
\hline $\begin{array}{l}\text { Cystoderma jasonis } \\
\text { var. lilacipes }\end{array}$ & - & 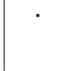 & 0.8 & 4.7 & 1.7 & . & - & - & . & I & I & I & - & $\cdot$ \\
\hline Clitocybe fragrans & . & . & 5.2 & 4.7 & 2.5 & 8.5 & - & - & . & I & I & I & VI & - \\
\hline Hygrocybe conica var. conica & . & . & 0.8 & 1.0 & 0.8 & 1.8 & - & - & . & I & I & I & II & . \\
\hline Gyтnориs impudicus & . & . & 0.7 & & 2.2 & 1.3 & . & 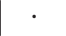 & . & I & . & I & II & \\
\hline Clitocybe odora var. odora & . & . & 1.0 & & & 3.2 & 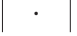 & & . & I & . & & I & \\
\hline
\end{tabular}




\begin{tabular}{|c|c|c|c|c|c|c|c|c|c|c|c|c|c|c|}
\hline Mycena adonis & . & . & 2.8 & - & & - & 0.7 & - & $\cdot$ & I & · & · & - & I \\
\hline Cystoderma jasonis var. jasonis & . & . & 0.7 & . & 3.7 & . & 0.2 & . & . & I & . & I & . & I \\
\hline Collybia cookei & . & . & 4.7 & & & 2.5 & 0.8 & . & . & I & . & . & I & I \\
\hline Collybia tuberosa & . & . & 0.3 & 8.0 & 1.2 & $\cdot$ & 14.7 & . & . & I & I & I & . & III \\
\hline Leptosporomyces galzinii & . & . & 0.2 & 1.2 & 8.0 & 1.2 & 22.0 & . & . & I & I & II & II & $\mathrm{X}$ \\
\hline Cystodermella granulosa & $\cdot$ & $\cdot$ & $\cdot$ & 4.8 & 0.8 & 0.2 & 0.5 & . & . & . & I & I & I & II \\
\hline Strobilurus stephanocystis & . & . & . & 2.5 & 20.3 & 0.7 & 0.2 & . & . & . & I & III & I & I \\
\hline Phanerochaete sanguinea & $\cdot$ & $\cdot$ & $\cdot$ & 0.5 & 0.3 & 0.7 & 0.7 & $\cdot$ & $\cdot$ & . & I & I & I & II \\
\hline Dacrymyces variisporus & . & . & . & 11.8 & 17.5 & 41.5 & 2.0 & . & . & . & I & I & V & I \\
\hline Clitocybe candicans & . & . & . & 7.2 & 0.2 & 15.2 & 0.2 & . & . & . & II & I & VII & I \\
\hline Bаеоspora mуоsura & . & . & . & 0.7 & 1.5 & 6.0 & 3.8 & . & . & . & I & I & III & III \\
\hline Mycena sanguinolenta & . & . & . & 0.3 & $\cdot$ & 11.8 & 0.3 & . & . & . & I & . & IV & I \\
\hline Mycena vulgaris & $\cdot$ & $\cdot$ & . & 12.5 & $\cdot$ & $\cdot$ & 13.5 & $\cdot$ & . & . & I & $\cdot$ & $\cdot$ & III \\
\hline Clitocybe anisata & $\cdot$ & . & . & $\cdot$ & 2.3 & 15.0 & 0.7 & . & . & . & . & I & V & I \\
\hline Auriscalpium vulgare & . & . & . & . & 0.8 & 11.0 & 2.7 & . & . & . & . & I & V & IV \\
\hline Galerina mniophila & . & . & . & . & 2.5 & $\cdot$ & 0.8 & . & . & . & . & I & . & II \\
\hline Coprinopsis friesii & 16.5 & . & . & . & $\cdot$ & . & $\cdot$ & VI & . & . & . & . & . & . \\
\hline Parasola plicatilis & 5.0 & . & . & . & . & . & . & III & . & 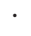 & . & . & . & . \\
\hline Clitocybe brumalis & 0.5 & . & . & . & & · & . & I & . & & . & . & . & . \\
\hline Conocybe spiculoides & 0.5 & $\cdot$ & . & · & . & $\cdot$ & . & I & $\cdot$ & . & . & $\cdot$ & $\cdot$ & . \\
\hline Mycetinis scorodonius & $\cdot$ & 45.5 & $\cdot$ & . & . & . & . & $\cdot$ & III & . & . & $\cdot$ & $\cdot$ & . \\
\hline Entoloma rhodopolium & $\cdot$ & 0.3 & . & . & . & . & $\cdot$ & $\cdot$ & I & . & . & . & $\cdot$ & . \\
\hline Conocybe rickeniana & $\cdot$ & 0.2 & $\cdot$ & · & . & $\cdot$ & · & $\cdot$ & I & . & . & $\cdot$ & $\cdot$ & . \\
\hline Crepidotus variabilis & $\cdot$ & 5.8 & 1.2 & $\cdot$ & · & $\cdot$ & . & $\cdot$ & I & I & . & $\cdot$ & $\cdot$ & . \\
\hline Psathyrella gyroflexa & . & 3.2 & 0.7 & . & . & . & . & . & II & I & . & . & . & . \\
\hline Macrolepiota mastoidea & . & 0.3 & 0.2 & . & & . & . & . & I & I & . & . & . & . \\
\hline Gymnopus dryophilus & . & 0.8 & 6.0 & . & & . & . & . & I & I & . & . & . & . \\
\hline Lycoperdon ericaeum & . & $\cdot$ & 6.8 & . & . & . & . & . & $\cdot$ & I & . & . & $\cdot$ & . \\
\hline Entoloma conferendum & . & . & 2.5 & . & - & . & - & . & . & I & . & . & . & . \\
\hline Lycoperdon marginatum & . & . & 2.3 & . & . & . & . & . & . & I & . & . & . & . \\
\hline Lycoperdon norvegicum & · & . & 0.7 & . & . & . & . & . & . & I & . & . & . & . \\
\hline Tapinella atrotomentosa & . & . & 0.3 & . & 0.2 & . & . & . & . & I & . & I & . & . \\
\hline Polyporus ciliatus & . & . & 0.2 & & 0.2 & . & - & . & . & I & . & I & . & . \\
\hline Marasmiellus vaillantii & . & . & & 9.2 & & 5.0 & - & . & . & . & I & . & II & \\
\hline Mycena parabolica & . & . & . & 0.3 & . & 0.8 & - & . & . & - & I & . & I & - \\
\hline Trichaptum fuscoviolaceum & . & . & . & 6.5 & . & $\cdot$ & . & . & . & . & I & . & . & . \\
\hline Melanoleuca graminicola & . & . & . & 2.5 & . & . & . & . & . & . & I & . & . & . \\
\hline Pholiota gumosa & . & . & . & 1.3 & . & . & - & . & . & . & I & . & . & $\cdot$ \\
\hline Calocera furcata & . & . & . & 0.8 & . & . & - & . & . & . & I & . & . & · \\
\hline Lycoperdon excipuliforme & . & . & . & 0.8 & & . & - & . & . & . & I & . & . & $\cdot$ \\
\hline Lepiota pseudolilacea & . & · & $\cdot$ & 0.3 & & . & . & . & . & . & I & . & . & \\
\hline Entoloma nitens & - & . & · & 0.2 & & . & - & . & . & . & I & . & . & \\
\hline Galerina badipes & · & . & $\cdot$ & 0.2 & & - & . & . & . & . & I & . & . & . \\
\hline Mycena arcangeliana & . & . & . & 0.2 & & . & . & . & . & . & I & . & . & . \\
\hline Psathyrella fibrillosa & . & . & . & 0.2 & 0.2 & . & . & . & . & . & I & I & . & . \\
\hline Ripartites tricholoma & $\cdot$ & · & $\cdot$ & 0.8 & 1.2 & - & · & $\cdot$ & $\cdot$ & · & I & I & $\cdot$ & · \\
\hline Mycena speirea & $\cdot$ & · & $\cdot$ & 0.5 & 15.0 & - & $\cdot$ & $\cdot$ & . & . & I & II & $\cdot$ & $\cdot$ \\
\hline Mycena septentrionalis & . & . & . & 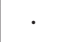 & 0.2 & . & . & . & . & . & . & $\mathrm{I}$ & . & . \\
\hline Agaricus dulcidulus & . & . & . & & 0.2 & 0.2 & - & . & . & & . & I & I & \\
\hline Clitocybe phyllophila & . & . & . & . & 8.3 & 11.8 & . & . & . & . & . & I & IV & \\
\hline Hypholoma lateritium & . & . & . & . & 0.5 & 4.0 & - & . & . & - & . & I & I & \\
\hline Amylostereum laevigatum & . & . & . & . & 0.8 & 10.0 & . & . & . & . & . & I & II & \\
\hline Cystoderma carcharias & . & $\cdot$ & . & . & 0.3 & 11.8 & $\cdot$ & . & . & . & . & I & III & \\
\hline Tubaria furfuracea & . & 0.5 & . & . & & 65.5 & . & . & I & . & . & . & VI & \\
\hline Gymnopus confluens & . & 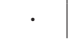 & . & 2.8 & & 145.3 & & . & & . & I & . & IV & \\
\hline
\end{tabular}




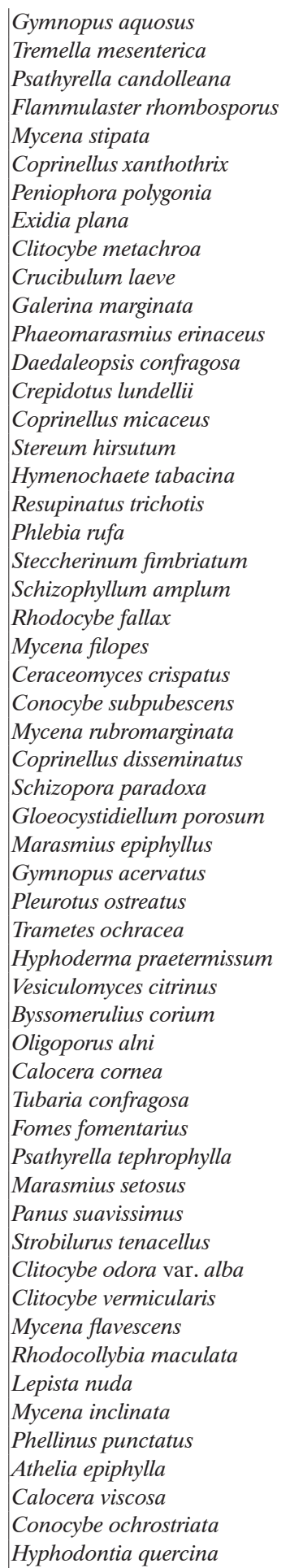

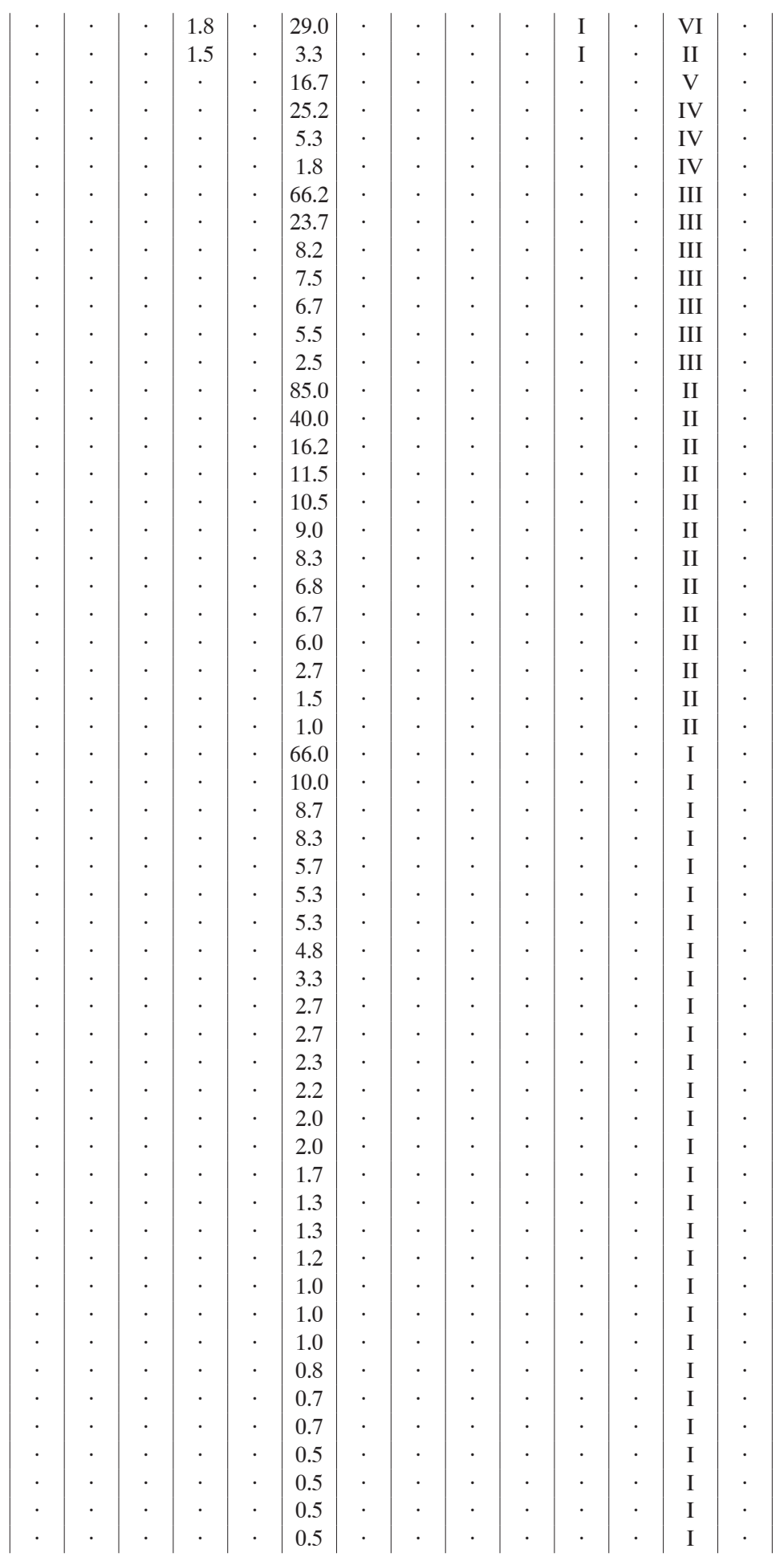




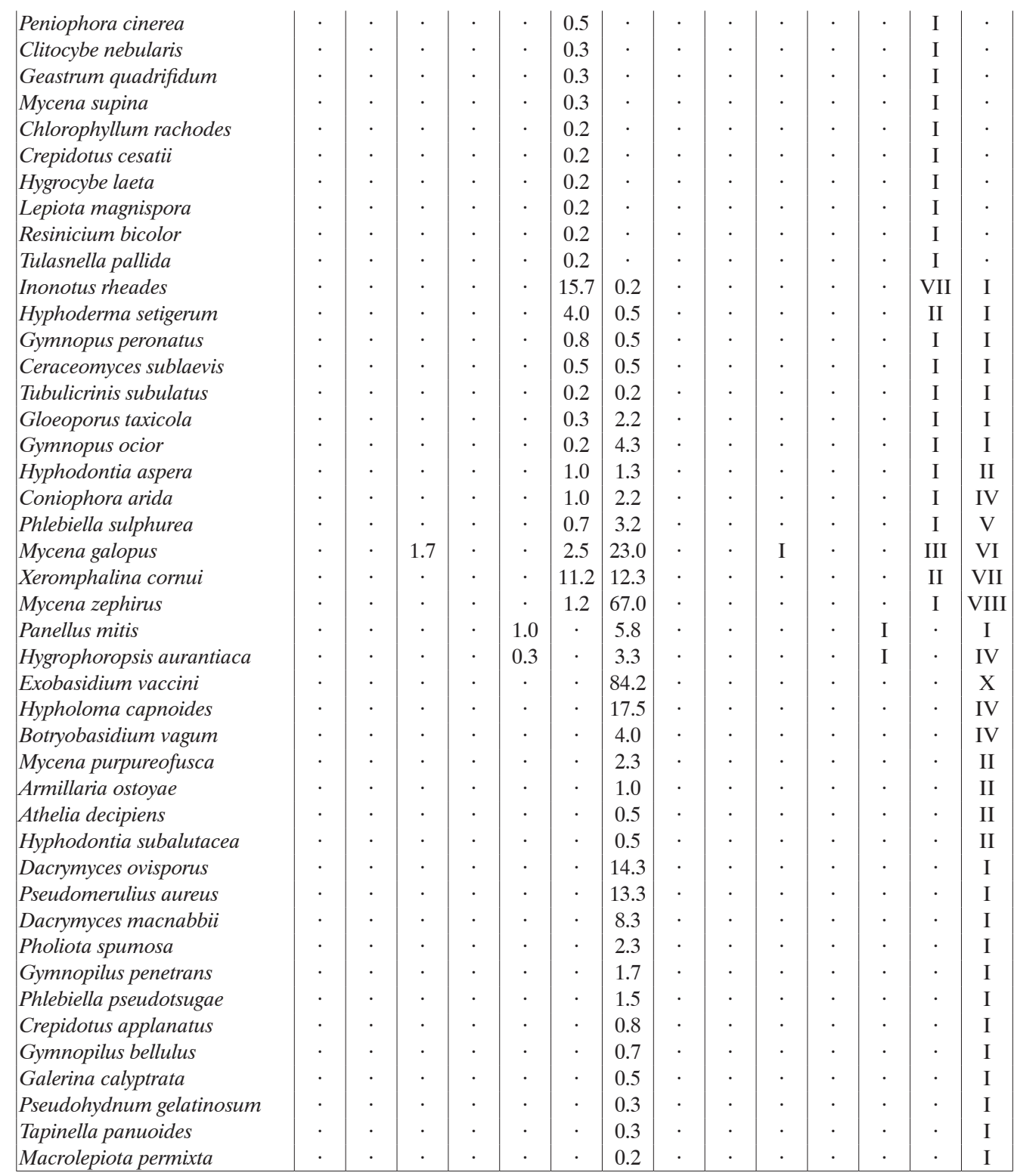

Abbreviations and comments: see Tab. 1

clusters 1 and 2, e.g., Clitocybe diatreta, Cystoderma amianthinum, Cantharellula umbonata, Galerina atkinsoniana, Hygroaster asterosporus, Psilocybe montana, Rickenella fibula. Some species, like Clavaria argillacea, Rhodocybe parilis, Galerina atkinsoniana, Hygroaster asterosporus, Lycoperdon dermoxanthum, Entoloma jubatum, Rhodocybe hirneola, Cystoderma jasonis var. lilacipes were found only in the communities of psammophilous grassland with juniper and pine (phases 4-6/7) (Tab. 2). 
The saprobic species fruiting evenly in a number of succession phases are rather few, e.g., Mycena aetites, Gymnopus putillus, and G. impudicus.

In contrast to the ECM fungi, the saprobic species occurring constantly from the advanced optimal stage, through the juniper-aspen brushwood to the pine forest (terminal stage), are numerous, e.g., Leptosporomyces galzinii, Cystodermella granulosa, Strobilurus stephanocystis, Phanerochaete sanguinea, Dacrymyces variisporus, Clitocybe candicans, Baeospora myosura and Mycena sanguinolenta (Tab. 2). Also, the group of species exclusive to the terminal stage occurring both in the brushwood and forest community, is relatively rich, e.g., Hyphoderma setigerum, Gymnopus peronatus, Hyphodontia aspera, Coniophora arida, Phlebiella sulphurea, Xeromphalina cornui and M. zephirus. These are the species inhabiting litter and dead wood.

The more developed the vegetation, the higher the number of saprotrophic exclusive species. In the early succession phases their number, abundance and spatial frequency were low (with the exception of Coprinopsis friesii and Parasola plicatilis in phase 2, and Mycetinis scorodonius in phase 4); in the juniper-aspen brushwood and in the pine forest they are frequently much higher.

\subsubsection{Spatial frequency patterns}

Apart from producing different numbers of carpophores in subsequent phases of succession, fungal species show different spatial distribution of their carpophores. For the ECM fungi, usually the increase of carpophore abundance is accompanied by an increase of spatial frequency (Tab. 1); the pattern is less clear in saprotrophs (Tab. 2). Moreover, for many ECM species, after attaining maximum abundance a decrease in carpophore production is not immediately followed by decreasing frequency and the frequency tends to stay high longer. The pattern is distinct in Amanita muscaria, Chalciporus piperatus, Tricholoma equestre and Boletus edulis (Tab. 1).

Both in the ECM and non-ECM fungi, species attaining low spatial frequency ( $\leq 30 \%$; class I-III) prevail. However, proportions of species of low, medium (31-70\%; class IVVII) or high ( $>70 \%$; class VIII-X) frequency in subsequent succession phases are different in these groups (Fig. 19A, B). For the ECM species, the relative number of species attaining low spatial frequency decreases in the course of succession process; both the relative numbers of medium and high frequency species tend to increase. For the saprobic species, the proportion of low frequency species is the highest in the optimal stage of succession (phases 5-6/7).

\subsubsection{Ectomycorrhizal carpophore production}

The average annual number of ECM carpophores per $1000 \mathrm{~m}^{2}$ slightly exceeds a thousand in phases 4 and 5. Then it grows considerably and reaches a maximum level of over 2000 carpophores in phase 6 , in a well developed optimal stage of succession with pines under 20 years old, and starts to drop again in the later phase of the optimal stage. In the terminal stage, in transitional juniper-aspen brushwood the number of carpophores decreases down to ca 500 and to 200 in the forest (Fig. 20). As far as the ECM species in the whole successional series are concerned, the most numerous fruit bodies are produced by Cortinarius 


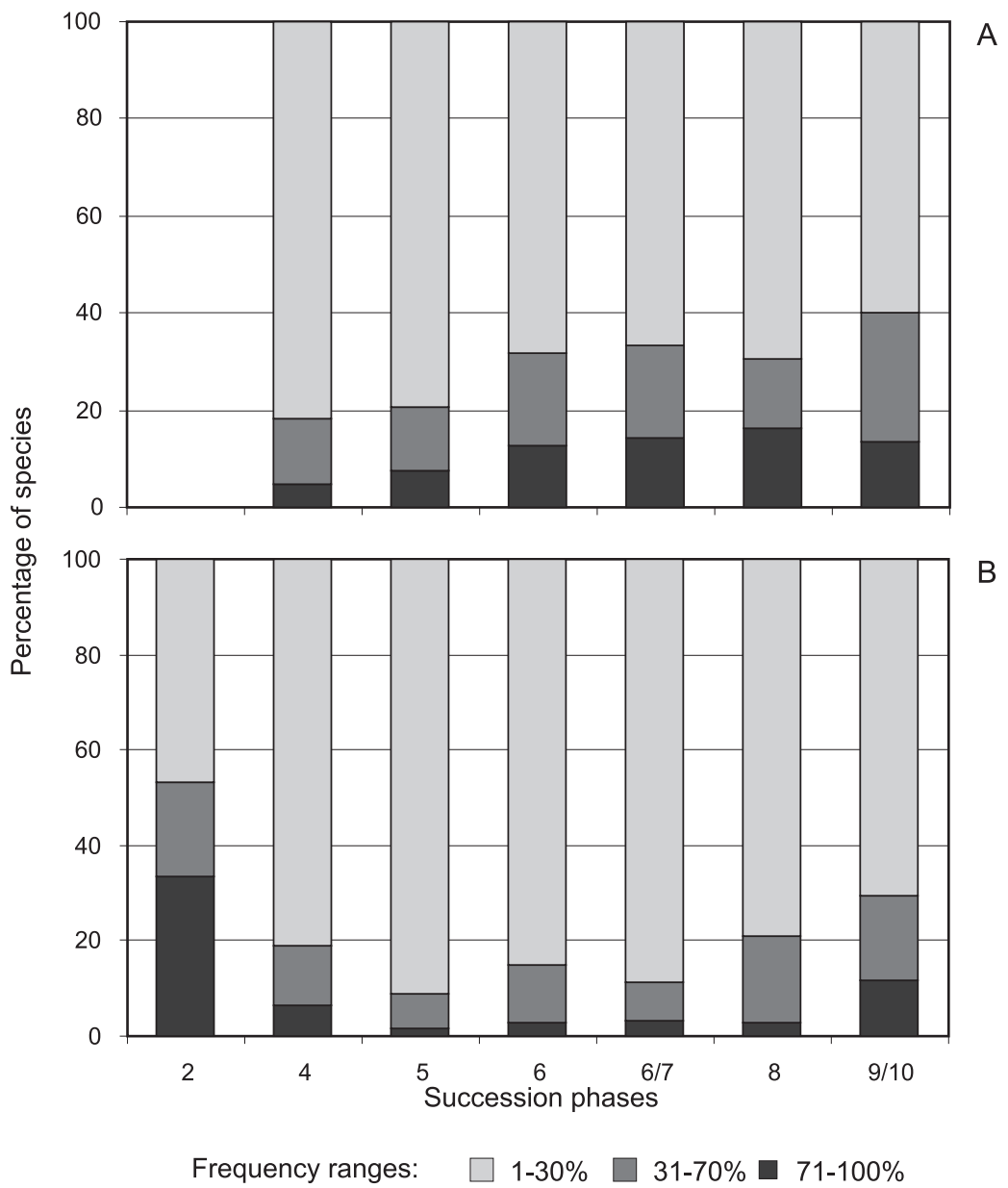

Fig. 19. Distribution of spatial frequency of ECM fungi (A) and non-ECM fungi (B) in consecutive phases of the spontaneous secondary succession on abandoned farmland.

cinamomeoluteus and other Cortinarius species from the Cortinarius I group, Inocybe lacera, Hygrophorus hypothejus and Laccaria proxima.

The average annual carpophore biomass production (as dry weight) per $1000 \mathrm{~m}^{2}$ in the ECM fungi is at its lowest in phase 9/10-273 g, and at its highest in phase 6-1491 g (Fig. 20). This means from 2.7 to $14.9 \mathrm{~kg}$ of dry weight per year per ha.

In the season richest in fungal carpophores (out of the three years of observations), in an overall study area of 1.2 ha, 19,917 fruit bodies of ECM fungi were recorded giving a total dry weight of $15.3 \mathrm{~kg}$. According to the calculations by ARNOLDs (1981) this is equivalent to about $153 \mathrm{~kg}$ of fresh carpophore biomass. The highest production - ca $21 \mathrm{~kg} \mathrm{ha}^{-1} \mathrm{~d}$.w. - was recorded in the plots representing advanced optimal stage of succession, with pines of 8-15 (19) and 12-18(25) years old (phases 6 and 6/7).

The proportion of the total ECM carpophore biomass to their number in consecutive succession phases is much lower in the initial and optimal stages; in the terminal stage (phases 8 and 9/10) it increases considerably. This means that in contrast to open plant 

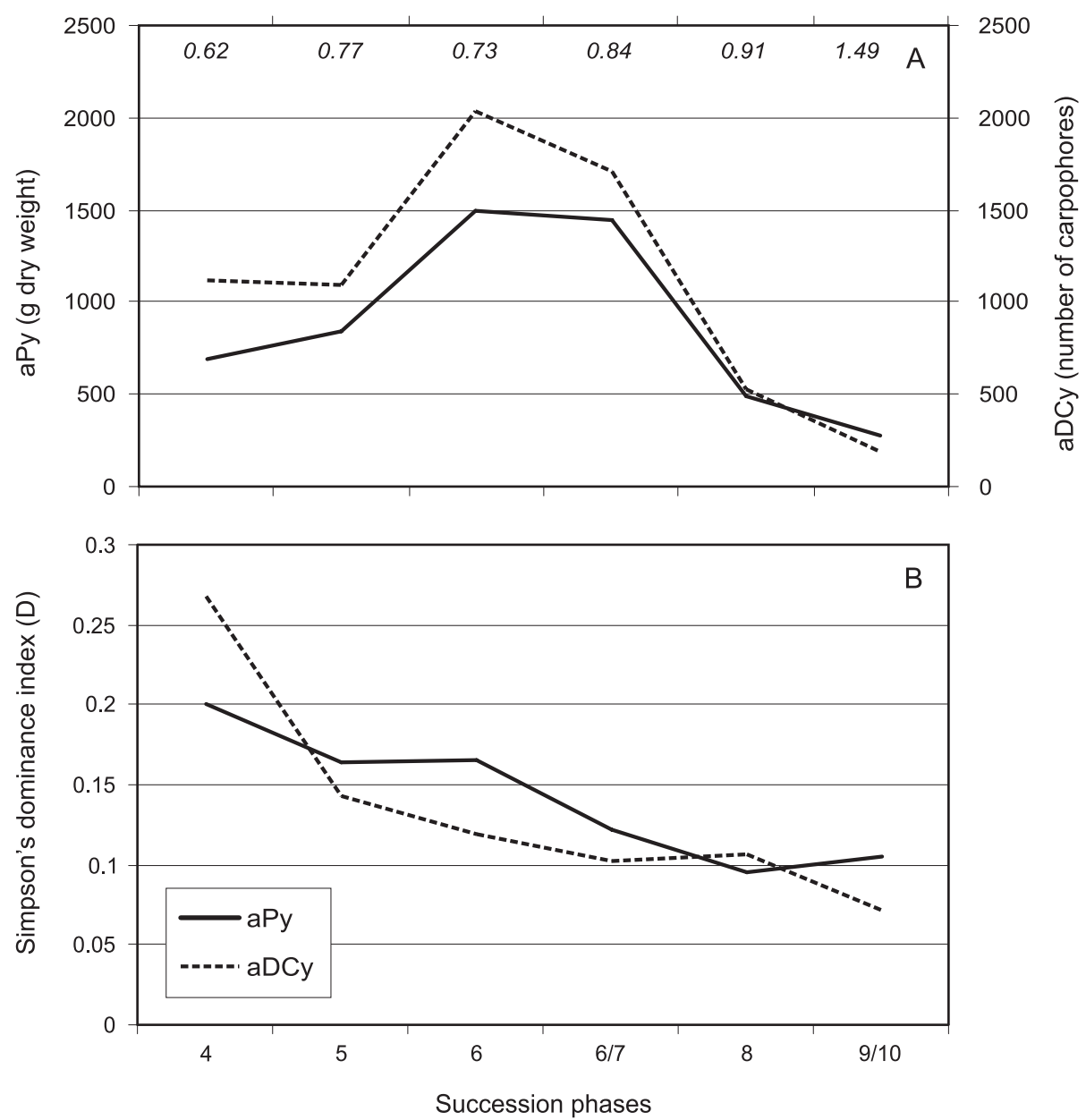

Fig. 20. Average annual carpophore production (aPy) and average annual carpophore density (aDCy) (A), and Simpson's dominance index (D) based on aPy and aDCy (B) of ECM fungi in consecutive phases of the spontaneous secondary succession on abandoned farmland. In (A) figures in italics denote the mean weight of carpophores in the subsequent succession phases.

communities where there is a high production of rather small fungal fruit bodies, in transitional and forest communities species producing bigger carpophores prevail (Fig. 20A). Mean weight of an ECM carpophore (in $\mathrm{g}$ d.w.) in the examined succession phases increased from 0.62 in phase 4 to 1.49 in phase $9 / 10$.

The highest carpophore productivity is attained by the genera Amanita, Cortinarius, Inocybe, Laccaria, Russula, Suillus and Tricholoma. The proportion of these species in the total annual carpophore production exceeds $90 \%$ in the initial communities and still reaches $75 \%$ in the pine forest (Fig. 21). The early succession phases (4 and 5) are characterized by high production of the genus Amanita (mainly A. muscaria, see Tab. 1). The genus Inocybe shows clear preference towards initial communities, while Suillus and Laccaria are typical of open vegetation. In the optimal stage, particularly in its advanced phases $(6$ and $6 / 7)$ the participation of Tricholoma becomes significant, in the juniper-aspen brushwood (8) 


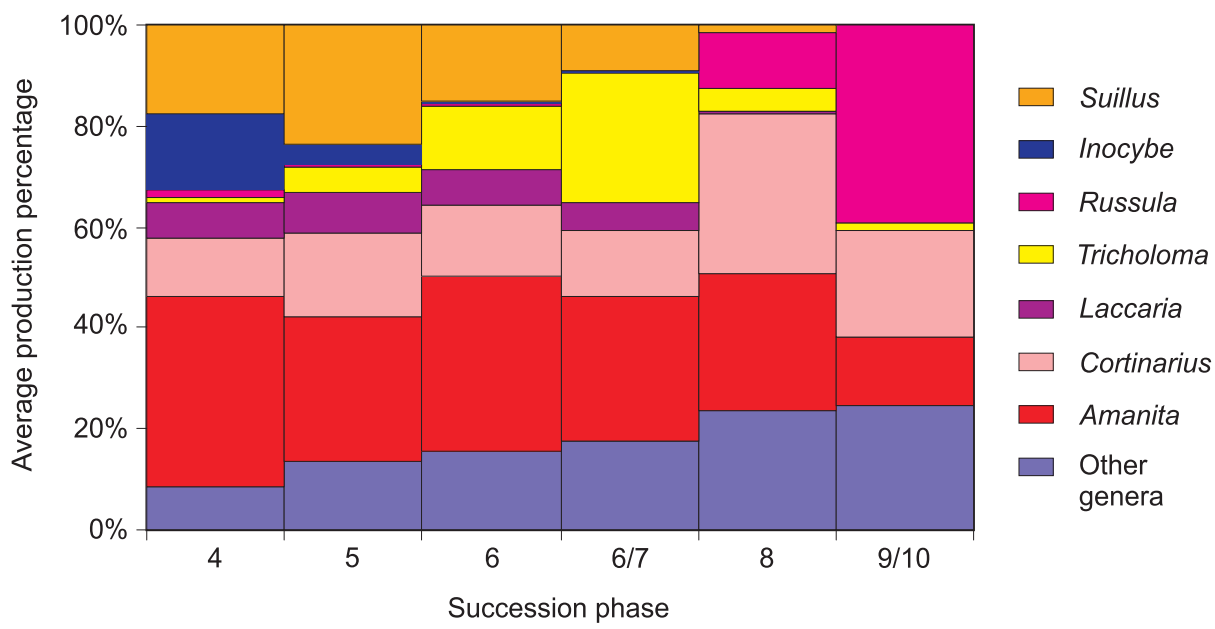

Fig. 21. Percentage of average annual production (aPy) of seven most productive ECM genera in consecutive phases of the spontaneous secondary succession on abandoned farmland.

- Cortinarius, and in the pine forest (9/10) - Russula. The vegetation development is followed by increasing participation of fungi belonging to other genera. Gradual diversification of the ECM carpophore production along the successional gradient is reflected in the decrease of Simpson's dominance index, both in biomass production and in carpophore numbers (Fig. 20B).

\subsection{Similarity structure of macrofungi}

The similarity structures of the ECM (Fig. 22) and saprobic (Fig. 23) fungal communities occurring in the subsequent succession phases revealed by cluster analysis show high coincidence with the similarity structure of vegetation (Fig. 24) as well as with the model of its succession; the species composition and the carpophore abundance patterns correspond to its subsequent phases (compare Fig. 2). A specificity of the ECM and saprobic fungal succession is also apparent.

The analysis of the species composition and carpophore density of the ECM fungi clearly separates typical forest communities (phase 9/10) from the communities of open and transitional sites (Fig. 22A). Also, it reveals high similarity among ECM communities in the plots representing phases 4 and 5, and among the communities in the plots representing phases 6 and 6/7. It is worth noticing that time (thus the age of symbiotic trees and/or soil development) is not always a decisive factor for similarity structure of fungal assemblages. Moreover, the ECM communities present in the plots occupied by juniper-aspen brushwood seem to be more similar to much earlier communities in phases 4 and 5 (see also Fig. 12). It results from a considerable proportion of species associated with deciduous trees in these plots. However, when assemblages of the ECM fungi growing in the plots of the same phase are combined and treated together, at phase level the analysis shows higher mycological similarity of brushwood and forest (phases 8 and 9/10) (Fig. 22B). 

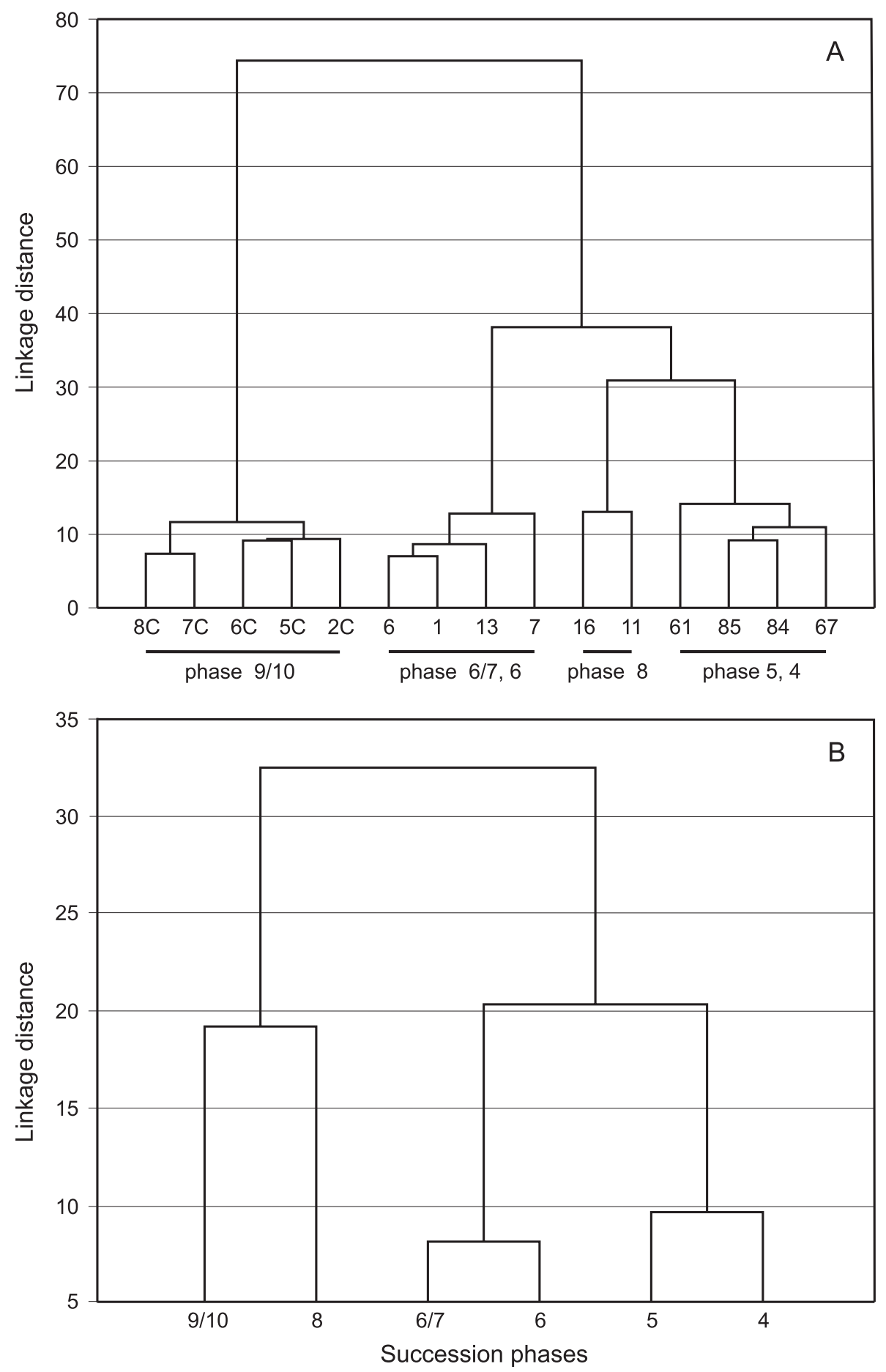

Fig. 22. Similarity structure of the examined plots (A) and succession phases (B) based on ECM species composition and annual density of carpophores. 

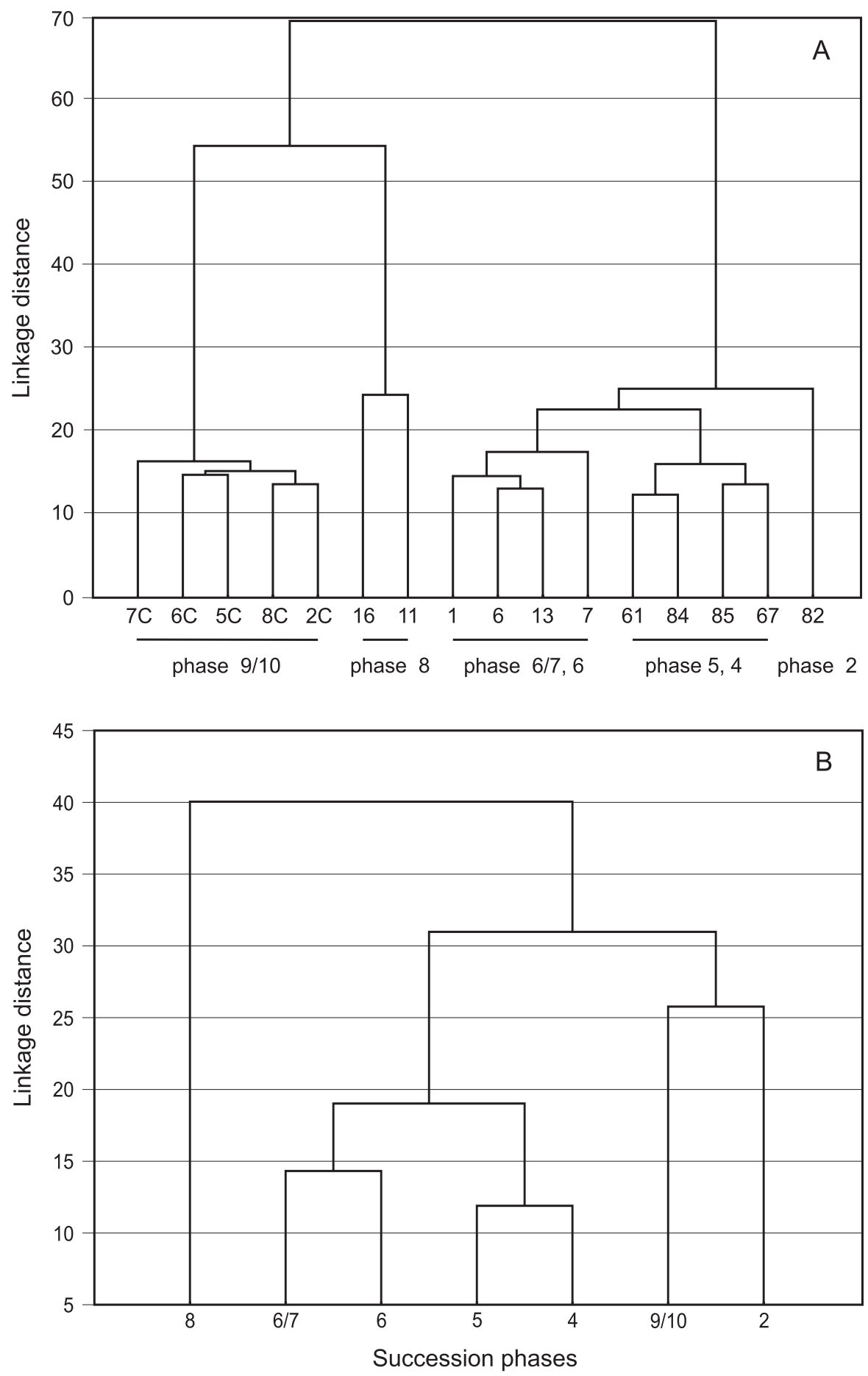

Fig. 23. Similarity structure of the examined plots (A) and succession phases (B) based on non-ECM species composition and annual density of carpophores. 

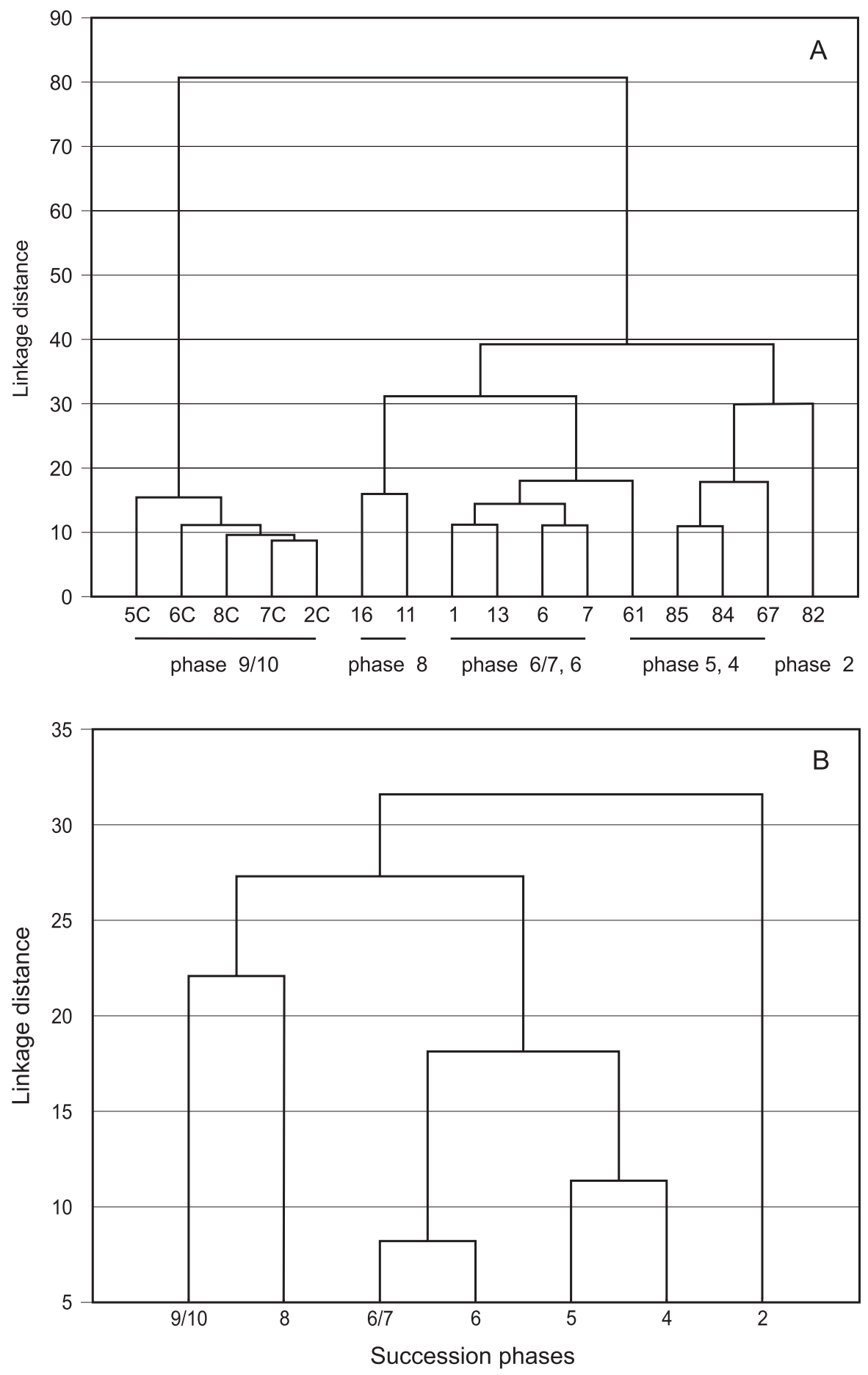

Fig. 24. Similarity structure of the examined plots (A) and succession phases (B) based on vegetation composition and cover. 
The analysis of similarity structure of the non-ECM species reveals almost the same pattern as in the ECM fungi in initial and optimal stage of succession (Fig. 23A), but in contrast, the communities of saprotrophic fungi in the plots with juniper-aspen brushwood reveal higher similarity to the communities growing in forest. The analysis clearly separates the assemblages of non-ECM fungi of phase 2, phase 8 and phase $9 / 10$; this probably reflects totally different kinds and quality of available substrates.

\subsection{Quantitative changes in ectomycorrhizal roots along successional gradient}

Examination of the ECM roots in surface soil samples revealed some differences in their vertical distribution. In early succession phases, the roots grow mainly in the upper $3-5 \mathrm{~cm}$ of mineral soil increasing considerably its stabilization. Both in initial and optimal stage, in sites of litter accumulation the ECM roots occur mainly in the interface between mineral soil and organic matter; the extramatrical mycelium frequently overgrows and binds the litter pieces together. In phase $6 / 7$, where the percentage of dead roots of pine and juniper in the surface soil is the highest, the living roots are tightly interwoven with masses of the dead ones and the hyphae emanating from the ECM mantles make it impossible to separate them. The roots and mycelium are also present in great abundance in places of humus horizon formation. In the juniper-aspen brushwood, the main body of ECM roots overgrows the humus layer and the adjacent part of litter. In the pine forest, the roots penetrate mainly the Of and Oh horizons.

Although the qualitative structure of the ectomycorrhizae is not a subject of the present study, the observations of ECM roots during the quantitative examination revealed the increasing mycorrhizal diversity along the successional gradient - the greatest number of morphotypes was found in the juniper-aspen brushwood. There is also an increase in the systems' ramification; simple or dichotomous morphotypes prevail in the earlier phases while in the latter phases also multi-ramified and coralloid systems are frequent.

The length of living fine roots and the number of ECM tips in soil samples also change in the subsequent succession phases, showing high within-phase variation (Tab. 3).

The highest length of the living ECM roots in the surface soil was found in the juniperaspen brushwood (phase 8), with an average of 54.7 and $35.7 \mathrm{~cm}$ per $100 \mathrm{~cm}^{3}$ of soil in two consecutive seasons. The number of mycorrhizal tips is also the highest - ca 305 per 100 $\mathrm{cm}^{3}$ of soil. The figures are significantly higher than in the other succession phases.

Despite considerable differences in the ECM tip number and the living root length among particular samples, plots and phases, the ratio of these two parameters, i.e. ramification index, was relatively stable in roots sampled in the same year independently of the succession phase or species composition of a tree-stand. The average index was 4.1-5.6 and 7.1-9.2 in two consecutive seasons (Tab. 3). The correlation between the root length and the number of mycorrhizal tips is high -0.90 and 0.92 , respectively (Spearman's rank correlation coefficient; $\mathrm{P}<0.0001$ ).

The number of well developed (WD) mycorrhizas varied considerably among different samples, succession phases and between sampling seasons; a relatively low proportion of WD mycorrhizas in phase 6/7 may be a result of lower soil moisture in these plots (Appendix 1, Fig. A1.1). 
Table 3

Length of living tree roots and total number of ECM root tips per $100 \mathrm{~cm}^{3}$, number of ECM tips per $\mathrm{cm}$ root length, and number of well developed (NWD) ECM tips relative to the total number of ECM tips in the soil samples ( \pm S.D.)

\begin{tabular}{|c|c|c|c|c|c|c|}
\hline ‡્兀 & $\begin{array}{l}\text { Succession } \\
\text { stage }\end{array}$ & $\begin{array}{c}\text { Succession } \\
\text { phase }\end{array}$ & $\begin{array}{c}\text { Living root } \\
\text { length } \\
\left(\mathrm{cm} / 100 \mathrm{~cm}^{3}\right)\end{array}$ & $\begin{array}{c}\text { Number of ECM } \\
\text { tips }\left(\mathrm{n} / 100 \mathrm{~cm}^{3}\right)\end{array}$ & $\begin{array}{l}\text { Number of ECM } \\
\text { tips / cm root }\end{array}$ & $\begin{array}{l}\text { NWD ECM tips } \\
(\%)\end{array}$ \\
\hline \multirow{7}{*}{$\hat{\Omega}$} & initial & 2 & $7.9 \pm 1.6$ & $34.3 \pm 29.9$ & $4.1 \pm 2.9$ & $46.49 \pm 21.34$ \\
\hline & & 4 & $21.6 \pm 14.2$ & $107.2 \pm 75.5$ & $5.0 \pm 1.6$ & $77.58 \pm 14.53$ \\
\hline & optimal & 5 & $18.5 \pm 15.4$ & $90.8 \pm 73.9$ & $5.0 \pm 1.6$ & $49.46 \pm 23.61$ \\
\hline & & 6 & $29.4 \pm 17.7$ & $138.8 \pm 75.4$ & $4.9 \pm 1.1$ & $62.13 \pm 19.20$ \\
\hline & & $6 / 7$ & $16.1 \pm 7.8$ & $81.1 \pm 53.5$ & $5.0 \pm 1.6$ & $54.38 \pm 17.18$ \\
\hline & terminal & 8 & $54.7 \pm 16.6^{*}$ & $304.5 \pm 94.6^{*}$ & $5.6 \pm 1.1$ & $77.75 \pm 15.36$ \\
\hline & & $9 / 10$ & $19.2 \pm 5.7$ & $94.6 \pm 48.6$ & $5.1 \pm 2.3$ & $73.16 \pm 11.83$ \\
\hline \multirow{7}{*}{$\stackrel{\infty}{2}$} & initial & 2 & $5.4 \pm 2.1$ & $45.8 \pm 8.3$ & $8.9 \pm 1.9$ & $87.78 \pm 2.48$ \\
\hline & & 4 & $12.0 \pm 6.8$ & $106.7 \pm 60.6$ & $9.2 \pm 3.7$ & $66.83 \pm 19.36$ \\
\hline & optimal & 5 & $8.2 \pm 5.0$ & $72.6 \pm 49.6$ & $8.6 \pm 1.3$ & $77.02 \pm 14.55$ \\
\hline & & 6 & $11.3 \pm 9.6$ & $91.5 \pm 67.5$ & $9.0 \pm 2.1$ & $60.78 \pm 20.83$ \\
\hline & & $6 / 7$ & $12.7 \pm 6.0$ & $90.0 \pm 39.9$ & $7.6 \pm 2.1$ & $39.33 \pm 18.50$ \\
\hline & terminal & 8 & $35.7 \pm 16.8^{*}$ & $304.8 \pm 147.5^{*}$ & $8.9 \pm 1.8$ & $76.27 \pm 10.09$ \\
\hline & & $9 / 10$ & $8.4 \pm 2.7$ & $58.1 \pm 18.5$ & $7.1 \pm 1.7$ & $75.79 \pm 14.88$ \\
\hline
\end{tabular}

* Figures statistically different from all the other figures of the same year within a column (Tukey HSD test, $\mathrm{p}<0.01$ )

The average frequency of ECM tips on roots exceeded $95 \%$ in all the plots, including phase 2, where no ECM sporocarps were found yet; the roots of young birches growing as one solitary group in this plot were colonized by the ECM fungi in $98.6 \%$.

\section{DISCUSSION}

Sporocarp sampling. Observations of sporocarps, their taxonomical determination, and estimation of frequency and abundance remain one of the main methods in the studies of species richness and diversity, distribution and ecology of macromycetes. The presence of sporocarps in the field is always evidence of the presence of vegetative mycelium of the species and this is the fundamental merit of this approach. However, the lack of generative structures or the lack of records of such structures does not necessarily mean that the mycelium of a certain species is not present at a site (ARNOLDS 1992b). Sporocarps are frequently ephemeral and impermanent, their production can vary considerably depending on unpredictable weather fluctuations (amount of rainfall, temperature, humidity), on seasons and a few years' cycles. For these reasons, studies based on sporocarp occurrence 
should span long-term observations, 3 to 8 years, depending on the size of monitored area and the frequency of sporocarp recording (ARNOLDS 1981, 1992a, b; BARKMAN 1987; VoGT et al. 1992; WATLING 1995; FRIEDRICH 2008).

The present study is based on a 3 year period of sporocarp observations and includes 17 recording visits for each plot (except for plot 82, phase 2, where 13 visits were performed in two seasons). Most of the visits were carried out in the periods of intensive sporocarp production (autumn) so that the maximum diversity and numbers of fruit bodies could be registered. All three seasons were relatively favourable for carpophore production. The permanent plots comprised altogether an area of $13,000 \mathrm{~m}^{2}$; to increase the exactitude of observations and to examine the sporocarp spatial distribution, the plots were divided into subplots $\left(25-100 \mathrm{~m}^{2}\right)$ searched one by one, individually. One cycle of visits to all the plots took 2-6 days. This field work resulted in a 55\% increase in the ECM species number during the second observation season but only $3 \%$ increase during the third season; for the non-ECM species these figures were $27 \%$ and $6 \%$, respectively. Continuing the sporocarp surveys in the plots for further years could blur the differences between the studied succession phases as the successional changes, especially in the vegetation of phases 4-6, were very fast.

\subsection{Macrofungi in the scheme of spontaneous secondary succession on the abandoned fields near Białowieża}

Fungi in the initial stage of vegetation succession. First macrofungi probably appear very early in the succession process, inhabiting dead plant remnants and places colonized by mosses on fresh fallow (phase 1) soon after the field abandonment. In the herb-grassland community (phase 2) 15 saprotrophic basidiomycete species were found, among which Crinipellis scabella, Marasmius oreades, Mycena flavoalba, M. olivaceomarginata and M. leptocephala prevail. These are the species characterised by broad ecological range, known from various plant communities rich in herbaceous and grass debris (ARNOLDS 1992c). High abundance and frequency of their occurrence results from considerable homogeneity of the available substrate, both in terms of its composition (abundant necromass of plant shoots and leaves decaying on compact turf of dead and living roots) and spatial distribution (high and even field layer cover). The presence of bryophilous fungi, like Galerina spp., Cystoderma amianthinum and Rickenella fibula, which accompany mosses entering the fallow, is also noticeable.

An abundant presence of agricultural weeds or even legumes can considerably slow down or even cease the succession process on post-arable fields (FALIŃSKI 1986b; VAN DER Putten et al. 2000; HedLund \& GoRmsen 2002). This phenomenon can be seen in plot 82, where compact field layer dominated with Poa pratensis, Elymus repens, Stellaria graminea, Vicia spp. and Agrostis spp., along with a thick turf of roots and herbaceous debris, has prevented juniper and tree colonization for more than 30 years after the field abandonment - the plot still represents phase 2 of the vegetation succession.

The appearance of pioneer tree seedlings, mainly of pine, which according to Falinski's model takes place in phase 2 (usually ca 5 years after field abandonment, see Fig. 2) is crucial both for the further development of plant communities towards forest and for fungal assemblages. The ECM inoculum potential of the soil in this phase, necessary for successful tree colonization (TRAPPE \& LUOMA 1992; BOERnER et al. 1996) seems high despite the short 
time after the cultivation cessation. Close vicinity to older communities with trees of various age and especially to the great species reservoir of the Białowieża old-growth forest probably contribute to the fast restoration of the ECM spore bank in the soil similar to the constant and considerable inflow of seeds from the forest plants (SYMONides 1986; FALiŃsKi et al. 1993). The position of a site in the close vicinity of a forest or the presence of single trees or groups of trees are among the most important primary and secondary factors affecting the successional trajectory of meadow-type vegetation (FALIŃSKA 2003).

Pine seedlings usually emerge in places where the plant or lichen cover has been disrupted by animals (e.g., Myrmycoleon, wild boars) or among naturally fragmented tufts of mosses (FALIŃSKI 1986b). The rate of successional processes seems to be particularly high in sites of poor psammophilous grassland character that neighbour field strips much more advanced in terms of vegetation development; i.e. juniper-aspen brushwood or nearly closed-canopy pine stand. Tree seedlings emerging close to older trees benefit via increased mycorrhizal colonization (DICKIE \& REICH 2005; DickiE et al. 2007). The facilitation is even more efficient if seedlings appear near the compact forest tree-line and are incorporated into the common mycorrhizal network of hyphae growing from the roots of mature trees (contagion model), which potentially reduces the costs of establishing mycorrhizal infection (Simard \& Durall 2004; Thiet \& Boerner 2007; Teste et al. 2009). In contrast, seedlings emerging within a dense community of tall grass and herbs are subject to strong herbaceous competition regardless of distance from trees (DickIE et al. 2007). This might also be one of the reasons why the succession process and trees colonization in plot 82 (phase 2) have been arrested.

In phase 4 , young, mostly 6-8 year old trees are accompanied by over 40 symbiotic ECM fungal species producing epigeous sporocarps. A majority of them are more or less hostspecific to pine, even in places where birch, aspen and willow are also abundant. This might confirm a 'coniferous' direction of the vegetation succession similar to the presence of pioneer lichen species - Cladonia cornuta and C. gracilis (FALIŃsKi et al. 1993). The highest carpophore abundance and very high spatial frequency is attained by Inocybe lacera, Suillus luteus and Amanita muscaria. Numerous carpophores occur of Cortinarius, especially Cortinarius cinnamomeoluteus, and also Laccaria proxima, Hygrophorus hypothejus and Chalciporus piperatus. These species form a group, which later constantly accompanies plant communities in optimal stage of succession, producing very abundant and frequent sporocarps. They are still present in the juniper-aspen brushwood but their abundance and frequency there is low. The highest production in terms of carpophore biomass in the initial stage is attained by the genera Amanita (mainly A. muscaria), Suillus and Inocybe.

The ECM species comprise nearly half of the fungi occurring in phase 4. A relatively low diversification of available substrates and a high cover of field and moss layers do not favour saprotrophic fungi, which are not as numerous as in the later phases. The species growing on soil and among mosses prevail: Psilocybe montana, Clitocybe diatreta, Clavaria argillacea, Cystoderma amianthinum, Rickenella fibula. The species inhabiting litter, which is not abundant yet, are rather few; similarly, the species inhabiting wood occur sporadically. Most species found in the initial stage also occur in the optimal stage of the vegetation succession.

Inocybe lacera and I. asterospora, the species attaining maximum abundance and frequency in phase 4, as well as Cantharellula umbonata, Mycetinis scorodonius and the species of Entoloma, which were found exclusively in both plots of phase 4, can be regarded as distinctive species for this phase. 
Fungi in the optimal stage of vegetation succession. As far as fungi are concerned, the borderline between the communities of the last phase of the initial stage and the early phase of the optimal stage is not distinct. The number of both ECM and saprotrophic fungal species increases. Besides the fungi known from phase 4, a few ECM species, such as Laccaria bicolor and species of Tricholoma, considerably increase their presence. A group of new species attaining the highest abundance and, in most cases, high frequency in the optimal stage appear, for instance Cortinarius mucosus, C. parevernius and Lactarius rufus. The proportion of species occurring with high spatial frequency increases and the dominance index decreases. For phase 6, when pines are 8-15(19) years old, considerably higher abundance, production and spatial frequency of the following combination of species is distinctive: Hygrophorus hypothejus, Amanita muscaria, Chalciporus piperatus, Laccaria proxima and L. bicolor. On the other hand, the presence of a few species exclusive for the optimal stage, such as Inocybe curvipes, Cortinarius anthracinus, C. mucosus, C. colus, Tricholoma saponaceum and Sacrodon squamosus, is also characteristic. Lactarius rufus and Xerocomus badius are the only two ECM species which start fruiting in the optimal stage of the vegetation development and still occur in the pine forest; the abundance of the first one is the highest around canopy closure, the latter one clearly prefers mature forest conditions. The number of carpophores and the productivity of the ECM fungi reach their maximum, the species richness is the highest at plot level (38 species on $1000 \mathrm{~m}^{2}$ in both plots). This coincides with reaching maturity by the open community of psammophilous grassland with rich moss-lichen layer, junipers and pines (Spergulo-Corynephoretum cladinetosum mitis) (FALIŃSKI et al. 1993). It is interesting that in phase 6 the number of lichen species and the cover of lichens is also the highest in the chronosequence studied (FALIŃsKI et al. 1993).

Later, when pines are 12-18 to 25 years old, the crowns of trees growing in large groups tend to meet and form a canopy in places. Together with big juniper shrubs they intercept considerable amount of rainfall, while additionally very dense roots drain the soil. As a result xeric conditions are created (FALIŃSKI et al. 1993). Shade increases as does the production and accumulation of litter. At the same time the number of ECM carpophores, especially small ones, decreases considerably; the productivity and species richness is also slightly lower. Very abundant occurrence of different species of Tricholoma is distinctive for this phase of vegetation development, marking a specific period of canopy closure, intensified litter accumulation but still the lack of a true humus layer and very low $\mathrm{C}$ and $\mathrm{N}$ content in the mineral superficial soil (Appendix 1).

In the group of saprotrophic fungi, the species which appeared in phase 4 still prevail in the optimal stage. Most of them attain maximum carpophore abundance. Early in this stage, numerous species of "gasteromycetes" occur, such as Lycoperdon molle, L. nigrescens, L. perlatum, L. ericaeum, L. marginatum, L. norvegicum (the last three species were found exclusively in phase 5), Lycoperdon dermoxanthum (maximum abundance and frequency in phase 5) and Scleroderma fuscum. In close vicinity of the plot representing this phase Lycoperdon utriforme was also found. High species richness of this group of fungi seems to be distinctive for phase 5 of the vegetation development.

Bryophilous species are very abundant and frequent in the optimal stage, e.g., species of Galerina and Cystoderma amianthinum in large tufts of Polytrichum commune and P. juniperinum, as well as Psilocybe montana and Rickenella fibula in the synusia of Polytrichum piliferum. Some other species typical of open areas of psammophilous grasslands, heaths and juniper thickets (BREITENBACH \& KRÄNZLIN 1986-2000; BAS et al. 1988-1995) grow 
abundantly on soil, mainly in moss-lichen patches, e.g., Hygroaster asterosporus, Entoloma jubatum, Hygrocybe virginea and a few species of Rhodocybe.

As the amount and diversity of organic debris increases, species inhabiting litter (mainly pine and juniper needles) and wood become more and more numerous. Great numbers of them also occur in the later succession phases, in the juniper-aspen brushwood and pine forest.

Fungi in the terminal stage of vegetation succession - juniper-aspen brushwood. The brushwood community is characterised by the highest species richness and the highest overall diversity of macromycetes.

Changes of the species composition of the ECM fungi in comparison with the previous stages are relatively minor, while quantitative changes are distinct. Numerous species, which occurred earlier, cease production of their carpophores and occur with low abundance and frequency. In the case of some species, for instance Amanita muscaria, Chalciporus piperatus, Tricholoma equestre and Boletus edulis, initially the number of carpophores is strongly limited and later also the spatial frequency decreases. Such a phenomenon was also observed in the brushwood communities for psammophilous mosses (FALIŃsKi et al. 1993).

Species that appear in the juniper-aspen brushwood for the first time and are still present in the pine forest are few. These are Cantharellus cibarius, Russula paludosa and Amanita citrina.

Many ECM species are exclusive for the juniper-aspen brushwood, some of which achieve high carpophore abundance. As compared with the earlier phases, the number of species host-specific to deciduous trees increases considerably. The following species are distinctive for this phase: Cortinarius trivialis, C. alboviolaceus, Russula clavipes, Lactarius uvidus and L. torminosus.

The species richness of ECM fungi at phase level is the highest. In contrast, the number of ECM carpophores, as well as their biomass production, is much lower than in the optimal stage, approaching the values observed in the forest. The genus Cortinarius prevails in terms of the number of species, carpophore abundance and production.

The species composition of saprotrophic fungi changes considerably; almost $50 \%$ of species found in the juniper-aspen brushwood are exclusive for this community. This may be a consequence of the dominance of deciduous trees and of exceptional resource heterogeneity and niche diversification resulting from high cover and density of undergrowth shrubs and trees, humid microclimate and plenty of variable substrates originating from both conifer and broadleaved trees. The majority of saprotrophic species (ca 80\%) inhabit litter and wood. The proportion of bryophilous species is relatively low (ca 3\%) although they are still present in scattered moss patches.

A shift in the dominance structure of saprotrophic species can be observed. The species attaining high abundance and low spatial frequency as well as the species attaining low abundance and high spatial frequency are much more numerous. In the earlier succession phases the species which were frequent were usually also abundant.

A few species known to occur predominantly in humid, even wet and boggy places (also in the flood plain and riparian vegetation) were found, such as Russula paludosa, Gymnopus aquosus, Lentinus suavissimus, Marasmius epiphyllus, Mycena supina, Phaeomarasmius erinaceus. They correspond to a group of higro- and hydrophilous mosses distinctive for the juniper-aspen brushwood (FALIŃsKi et al. 1993), from among which Amblystegium serpens, Brachythecium salebrosum and Brachytheciastrum velutinum were recorded in the 
plots examined. The presence of such species results from specific microclimatic conditions: high cover of shrubs and trees, deep shade and relatively high soil humidity.

Fungi in the terminal stage of vegetation succession - nearly mature fresh pine forest. In comparison with the earlier succession phases, the number of species decreases, especially of the ECM fungi - their number is lower than in phases 4 and 5. Much lower is also the abundance of carpophores and their biomass production. In contrast to the optimal stage, there are no ECM species producing hundreds of fruit bodies, their spatial distribution is scattered but relatively even.

After mainly quantitative changes in the ECM sporocarp community in the earlier phases, the change associated with the development of pine forest is much more of qualitative character. About 50\% of the ECM species found there are new for the chronosequence studied. These are species occurring mainly in pine and mixed forests (with pine as co-dominant tree), e.g., Amanita porphyria, Cortinarius caperatus, C. semisanguineus, Suillus variegatus, Lactarius tabidus, Tylopilus felleus. The most distinctive is an occurrence of numerous species of Russula, attaining the highest biomass production of any genus. The presence of Russula emetica, R. paludosa and $R$. vinosa, species occurring usually in humid or mossy forests, indicates a mesophilous character of the habitat.

In contrast, $73 \%$ of saprotrophic species present in the pine forest were growing also in open or pre-forest vegetation phases. Some of them occur less abundantly, such as Mycena flavoalba, Clitocybe diatreta, Psilocybe montana, Macrolepiota procera, which are species preferring open communities and likely to disappear in mature forest. On the other hand, the abundances of many species inhabiting litter and pine wood, e.g., Gymnopus androsaceus, Mycena galopus, M. zephirus, Xeromphalina cornui and Dacrymyces stillatus, Leptosporomyces galzinii, Coniophora arida are the highest in the pine forest. However, some of these fungi, similarly to some ECM species and a considerable group of typically forest mosses (FALIŃSKi et al. 1993), appear as early as in phases 4 and 5 of vegetation development, usually around pines. The majority of the saprotrophic species occurring exclusively in the forest are wood-inhabiting taxa.

\subsection{Patterns of fungal succession in post-agricultural land}

Among the main causes and mechanisms of succession applying both to vegetation and fungi are an availability of space and availability of species of differential performance. Thus the whole process strongly depends on arrival and establishment of species (PICKETT et al. 1987; FrANKLAND 1992). The cessation of agricultural practices and field abandonment, especially when the land is liberated from any direct human impact and permanently left aside, creates a space for undisturbed, spontaneous secondary succession. Spores present in large quantities in the air are the most common and readily available supply of different fungal species. The arrival of spores on a particular substrate is usually a random process, although it depends on, e.g., distance from a source, topography, season, fungal life cycles and dispersal mechanisms (FrANKLAND 1992). Potential fungal colonists are affected by factors associated with the resource or substrate quality, microclimate and other organisms (BoDDY 1992).

Forming symbiosis with proper ECM fungi is necessary for effective land colonization by trees in boreo-temperate bioms. To make it possible, the presence of inoculum in form of 
spores, sclerocia or mycelium is crucial (Trappe \& LuOma 1992; Molina et al. 1992). Arable soil usually lacks ECM inoculum potential and it may only appear some years after the cultivation cessation (BOERNER et al. 1996). However, millions of spores present in the air as well as spores left by numerous mycofagous animals can quickly rebuilt a dormant spore bank, especially in areas where forests are in close vicinity (AlLEN M.F. 1987; CÁZARES \& TRAPPE 1994; JumpPonen et al. 2002; AsHKANNEJHAD \& HoRTON 2006; Menkis et al. 2007).

Species richness, diversity and carpophore production

The proximity of forests, among them the Białowieża old-growth forest, the presence of more advanced vegetation communities on neighbouring field strips which were abandoned earlier as well as management history (extensive agriculture and low mineral fertilizing) resulted in relatively fast natural tree regeneration. Pines, aspens and birches were usually establishing as early as 2 to 5 years after field abandonment (FALIŃsKi 1986a, b; FALIŃSKI et al. 1993). Non-disturbed vegetation development also resulted in accumulation and increasing diversification of substrates for saprobic macrofungi. In the open communities where pines were 6-8 to 12 years old, carpophores of as much as 92 macrofungal species were recorded, among them 44 ECM species. After this initial shift in species number, the ECM species richness stabilized and showed only minor increases and fluctuations in open and pre-forest vegetation. The highest overall species richness (183 species) was observed in the juniper-aspen brushwood, mainly because of an exceptionally high number of saprotrophs (134 species). Finally, the number of species in the pine forest decreased considerably both in mycorrhizal and saprotrophic fungi to 30 and 67 taxa, respectively.

According to FALIŃSKI (1986b), natural and undisturbed development of Central European fresh pine forest Peucedano-Pinetum lasts about 140 years before achieving maturity, stable species composition and proper vertical structure. The data on the species richness of fungal community in old-growth forest of this type are inconsistent.

In a 27 ha patch of the old-growth forest of the same type but of primeval origin growing in the Białowieża National Park, a total of 288 macrobasidiomycete species were found (non-regular, 4 years examination within research plot V-100) including $100 \mathrm{ECM}$ species, 93 litter-inhabiting species and 93 species growing on wood (BUJAKIEWICZ 1997; LISIEWSKA 1997a, b, c, d; SKIRGIEŁŁo 1997a, b, c, d, e, f). The number of epigeous species (ascomycetes and basidiomycetes, including ECM, soil and litter-inhabiting fungi) found per hectare fluctuated between 10 and 43 (26 on average) (ŻARNOwIEC et al. 1996) and the average number of epixylous species was 13 (CHLEBICKI et al. 1996). This would mean that in the old-growth pine forest the number of fruiting fungal species found per hectare is even lower than in 0.2 ha in the nearly mature 100-year-old first-generation spontaneous stand growing on former arable land (69 epigeous species including 30 ECM and 39 soil- and litter-inhabiting saprotrophic fungi, and 28 species growing on wood).

On the other hand, in the same type of old-growth forest, approximately in the same part of the Białowieża National Park, but in the years 1955-1956, NESPIAK (1959) found 87 and 80 species of basidiomycete cup-fungi alone in two plots, $100 \mathrm{~m}^{2}$ each, and in their vicinity (altogether 124 species). Such species richness would be much higher than the richness found in the present study. Difference in species numbers between the two studies in the Białowieża old-growth may be attributed to the high year-to year variation of carpophore production caused by different weather conditions, to spatial heterogeneity of the oldgrowth and of fungal assemblages and, to some extent, to different accuracy in examining small $\left(100 \mathrm{~m}^{2}\right)$ and large (1 ha) plots, on regular and non-regular basis. Considering the 
negative processes affecting fungi in the European forests (ARNOLDS 1991; SCHMITT 1991; Termorshuizen \& Schaffers 1991; Fellner 1993) it cannot be excluded that this difference reflects a general trend of loss of biodiversity, especially severe in the case of ECM fungi in old stands.

The number of carpophores produced both by the ECM and saprotrophic fungi as well as the ECM carpophore biomass production increased along the old-field successional gradient till achieving its maximum in the optimal stage of vegetation development, in the complex of psammophilous grassland with juniper shrubs and pines mainly 8-15 to 20 years old. The figures decreased slightly around the canopy closure (pines 12-18 to 25 years old) and then decreased conspicuously in the terminal stage, especially in the pine forest.

Similar observations concerning changes of the species richness and carpophore production in the Pinus sylvestris stands in Finland were made by HinTikKA (1988). He compared the species numbers and abundances of the ECM and saprotrophic fungi (excluding species growing on wood) in plantations representing four age classes and found the lowest average number of species and carpophores in the youngest, partly open, sapling stands of pines 5-15 years old. Both species richness and carpophore abundance increased rapidly in the pole stands (20-30 years old), were slightly lower in thinning stands (30-50 years old) and decreased in the stands over 70 years old. TERMORSHUIZEN (1991) found much higher ECM species richness and carpophore abundance in young stands (4-13 years old) than in older stands (50-80 years old) of Pinus sylvestris in the Netherlands.

An initial increase of species number and abundance of ECM fungi up to its maximum in the middle-aged stands and a decrease of these parameters in older stands were found also for other tree species. RICEK (1981) observed a gradual increase of the number of species to 29 in the age class 15-20 years (canopy closure) and up to 48 in the age class 20-25 years in the stands of Picea abies. In older stands (40-45 years old), the species richness decreased again. For Pseudotsuga menziesii, JANSEN (1991) found the highest numbers of species and sporocarps (16 and 5500, respectively) in young stands 8-18 years old (right before canopy closure) and their gradual decrease in older stands, 20-36 and 41-54 years old, down to 8 species and 280 sporocarps in the latter case. In the Norway spruce plantation on formerly agricultural land, GÁPER \& LIZOŇ (1995) observed an increase in the number of ECM fungi and their abundance from 7 species and 341 sporocarps in the first three years after tree planting to 11 species and 3967 sporocarps in years 7-10 and a further increase to 19 species but a decrease to less than 400 carpophores in years 24-27 (older stands were not included).

Successional changes in the carpophore production mean both changes in carpophore numbers and in their standing biomass. In the present study, the average annual carpophore biomass production by the ECM fungi increased from zero in phase 2 (lack of ECM sporocarps) to $6.9 \mathrm{~kg} \mathrm{ha}^{-1}$ of dry weight (d.w.) in phase 4 and to $14.9 \mathrm{~kg} \mathrm{ha}^{-1} \mathrm{~d} . \mathrm{w}$. in phase 6 (pines 8-15 to 20 years old), then it slightly decreased around the canopy closure and dropped considerably to $4.9 \mathrm{~kg} \mathrm{ha}^{-1} \mathrm{~d}$.w. in the juniper-aspen brushwood and to $2.7 \mathrm{~kg} \mathrm{ha}^{-1}$ d.w. in the pine forest with ca 100 years old stand. The figures are underestimated as even if the observations are carried out in the peak season at weekly intervals $10-30 \%$ of the total sporocarp production could be missed (RICHARDSON 1970).

In the earlier succession phases, as much as nearly $70 \%$ of the ECM annual carpophore biomass was produced by 3 species (Amanita muscaria, Suillus luteus, Cortinarius cinnamomeoluteus). In the later phases, the dominance index decreased considerably and in the pine forest, 3 most productive species (Russula badia, Cortinarius caperatus, Paxillus 
involutus) accounted for about $44 \%$ of the ECM annual biomass. Similar results were obtained by DAHLBERG et al. (1997) in the Nowary spruce forest of the same age: the 3 most productive species (all of them were Cortinarius spp.) accounted for about $44 \%$ of the average annual carpophore biomass production by all ECM fungi.

GARDES \& BRUNS (1996) found that the ECM species producing abundant carpophores do not always produce abundant mycorrhizae and that the most abundant mycorrhizae may belong to the species producing sparse carpophores or even not producing them at all. Thus the ECM species differ in the way they allocate their biomass between these structures. According to Dahlberg et al. (1997), in the Norway spruce forest in Sweden, the proportion of carpophore biomass in the overall species biomass (carpophore and mycorrhizae) can vary considerably among species, for instance for Russula decolorans it equals 0.6-0.9\% while for Cortinarius brunneus - 10-16\%. Moreover, the annual carpophore biomass production $\left(8.8 \mathrm{~kg} \mathrm{ha}^{-1}\right.$ d.w.) comprised less than $5 \%$ of the biomass production of mycorrhizae (250-400 $\mathrm{kg} \mathrm{ha}^{-1} \mathrm{~d}$.w.). In turn, WALLANDER et al. (2001) revealed that $80 \%$ of the total biomass of the ECM fungi may belong to the extramatrical mycelium growing in soil; it can amount to $700 \mathrm{~kg} \mathrm{ha}^{-1}$ in the pine stand. The following question arises: if the sporocarp biomass production of the ECM fungi assemblage associated with 10-20 years old pines is over five times greater than that of the assemblage in the pine forest with 100 year old trees, does it mean that the below-ground biomass of mycorrhizae and extramatrical mycelium follows the same pattern or that the allocation of the biomass into sporocarps in the younger, successional stands is bigger then in mature stands. It should be kept in mind that, as in the present study, at least some of the ECM species occur in both age ranges.

The maximum number of ECM carpophores and their biomass was found in phase 6, when pines were about 10-20 years old and their cover reached 50\% (compare Appendix 2, Tab. A2.1). The culmination of the ECM production in oligotrophic pine plantations may occur a bit later, under 20-30 years old trees (HinTIKKA (1988). The period of stand development, when trees gain their size and approach the state of canopy closure, seems to have significant consequences for the development of fungal assemblages (Dighton \& MASOn 1985; Dighton et al. 1986; JANSEN 1991; VisSer 1995). It is thought also to be a period of the highest photosynthesis activity of trees, the highest growth rate and the highest needle area (compare Hintikka 1988; Trofymow et al. 2003; Simard et al. 2004). In the stands of Pseudotsuga menziesii, the biomass of epigeous ECM carpophores was ca 6 times greater in the age classes 30-35 and 45-50 years than in the class $>400$ years (Sмітн et al. 2002); the first 50 years is the time of the fastest growth of the Douglas fir. There is a high correlation between the total ECM carpophore biomass and the rate of photosynthesis and annual tree growth rate in individual host-fungus associations (HöGBERG et al. 2001; NARA et al. 2003a). On the other hand, nutrient supply (mainly N and P) of trees, which depends largely on the symbiotic ECM fungi, may significantly affect their photosynthesis level; thus this bi-directional relationship and feedback can be of great importance for both partners (NARA et al. 2003a).

However, an increase of the species richness along with increasing tree age and developing vegetation was also reported, for example in the subalpine Norway spruce forest (but with an almost doubled sporocarp production in the younger stand) (SENN-IRLET \& BIERI 1999), in road-side verges (KeIZER \& ARnolds 1994) and stands of Tsuga heterophylla-Pinus contorta (KRANABeTter et al. 2005). In the latter case, however, the difference between the species numbers in the stands 20 and 60 years old was much bigger than in the stands over 100 and over 200 years old, in which the number of species was growing 
only very slowly. The number of species can also stabilise after canopy closure as in stands of Pseudotsuga menziesii (with peak productivity in middle-aged stands; Sмгтн et al. 2002). In a chronosequence of Pinus banksiana regenerating after wildfire, VISSER (1995) found a rapid increase in the species richness of the ECM fungi (based both on sporocarp and ectomycorrhizae occurrences) between 6 and 41 year old stands which then stabilised in 65 and 122 year old stands.

Comparisons of the species numbers and abundances among different studies should be made with caution as they refer to different plot sizes, different tree species and different stand histories. However, both the age of trees and the stand structure with a kind of turning point around canopy closure seem to be the key factors for the successional changes of the ECM fungi.

Another important determinant of the fungal species richness is the species richness of trees. According to Sснміт et al. (2005), it accounts for nearly $30 \%$ of the variation in the species richness of macrofungi as a group and between $9 \%$ and $19 \%$ of the variation in the species richness for subgroups of ectomycorrhizal fungi, wood-inhabiting fungi and fungi growing on soil or litter. Communities with high tree species richness are correspondingly characterized by high macrofungal species richness. In the present study, such an effect was also observed. In plots 84 (phase 4) and 85 (phase 5), where the proportions of different deciduous trees were higher than in plots 67 and 61 (phases 4 and 5, respectively), the species richness of fungi was also higher. The richest fungal species composition was found in the juniper-aspen brushwood, where the proportion of deciduous trees and their species number was the highest. An exceptional increase in species numbers was observed for saprotrophic species but the effect was also clear in the group of mycorrhizal ones. At least ten species of ECM fungi would probably not have occurred at this stage of vegetation development if the succession had run without the presence of deciduous trees, especially aspen, in the stand (successional trajectory also present in the Jelonka reserve; the vegetation in plots 13 (phase 6), 1 and 6 (phase 6/7) is likely to develop in such a way; compare Appendix 2, Tab. A2.1). In such cases, the species richness of the ECM fungi in the early terminal stage of vegetation development is probably lower than in the juniperaspen brushwood ( 49 species) but higher than in the mature pine forest ( 30 species). It may also be slightly lower than at the time of canopy closure (42 species).

An increase or decrease in the species richness does not necessarily mean the same changes in the species diversity, as the diversity is affected by the species evenness. In the subsequent succession phases examined in the present study, gradual increase in species diversity (Shannon's diversity index) was observed with higher rates of change in the earlier communities (till phase 6) and slowing down thereafter. The ECM fungal diversity was the highest in the terminal pine forest with pines ca 100 year old (compare Fig. 10), despite the number of species being lower than in the earlier succession phases. This results from the increasing evenness in the carpophore abundances in the ECM fungi assemblages. However, at plot level $\left(1000 \mathrm{~m}^{2}\right)$, the highest diversity in the pre-forest vegetation was attained in phase 6/7 with pines 12-18 up to 25 years old, which is the time of attaining distinct canopy closure. Then it slightly decreased but in the mature pine forest it increased again. This finding supports the results of a study in the Pinus contorta plantation claiming the highest ECM diversity in successional systems occurring around canopy closure (DIGHTON \& MASON 1985; Dighton et al. 1986). It should be kept in mind that the number of species included in this study was limited to the prevailing ones (Shannon's diversity index is relatively sensitive to the number of 'occasional' species), the oldest stands were 27 years old 
and that the examined plots were relatively small. It seems that the ECM species diversity is area-dependent and may achieve its maximum in stands in the later stages of succession, after the canopy closure, if the area examined is large enough to cover the potential species richness and the large-scale habitat homogeneity. According to SÅSTAD (1995), in a homogeneous vegetation of the Vaccinio-Pinetum type pine forest the spatial patterns of fungal distribution did not deviate from a random distribution. TwIEG et al. (2007), who examined the diversity of the ECM fungi (based on ECM root tips) in four age classes of Pseudotsuga menziesii stands, found the greatest increase in the 5- to 26-yr-old age class, a period corresponding with tree canopy closure, and only a minor increase thereafter, with similar diversities in 65- and 100-yr-old stands. However, the authors claim that especially in older stands sampling was inadequate to account for all species present.

The saprotrophic fungi achieve maximum diversity in the juniper-aspen brushwood. This is in accordance with the observations in deciduous and coniferous forests in Canada (VILLENEUVE et al. 1989), where the diversity index was much higher in the former communities mainly because of the higher number of saprotrophic species, whereas the numbers of the ECM species were comparable. A significant correlation between the number of litter colonizing saprotrophs and tree species richness was also found in conifer plantations by FERRIS et al. (2000). In phase 8, about $80 \%$ of species were litter- and wood inhabiting fungi. Such a high number of saprobes probably resulted from the high cover and diversification of the litter layer containing decaying remnants of herbaceous plants, fallen leaves and needles, twigs and bark pieces from different species of trees and shrubs, cones, etc, as well as abundant dead branches lying on the ground or still attached to trees, dying junipers, and a few although still solitary logs. Large amounts of fine woody debris, typical of dense, close stands of relatively young trees, can considerably increase the number of species present at a site (NORDÉN et al. 2004). In the juniper-aspen brushwood, true litter horizon was observed for the first time in the chronosequence studied, at some places it was even differentiated into $\mathrm{Ol}$ and $\mathrm{Of}$ horizons. Moreover, for the first time thin humous horizon of initial mull type or initial moder developed (Appendix 1). Accumulating litter and its composition, depth, moisture, presence of different stages of decomposition and time-related changes in chemical composition positively affect the richness of basidiomycetes (Dix \& FrankLand 1987; Lisiewska 1992; Osono \& TaKeda 2001; Osono et al. 2006). Soil characteristics, particularly of the humus layer, are also important variables for saprotrophic fungi community structure (TYLER 1989; RÜLING \& TYLER 1990). According to ARNOLDS $(1981,1992 c)$ a remarkable relation exists between organic matter content in the soil and sporocarp productivity: in the communities outside forest, the highest productivity was observed in grasslands on soils with rather low organic matter content.

The effect of woody debris on the species richness and abundance of saprotrophic fungi was also conspicuous in the pine forest. The number of wood inhabiting species was the highest there; they produced numerous carpophores and comprised a large group of exclusive species. Large numbers of them inhabited coarse woody debris in different stage of decay: numerous pine branches and larger pieces of wood lying on the ground, logs and stumps (Appendix 5). The amounts of coarse woody debris as well as the size of logs and wood diameter are positively related to fungal species richness and basidiocarp production of wood-inhabiting fungi and can strongly affect their community structure (BADER et al. 1995; Renvall 1995; Høiland \& Bendiksen 1996; Lindblad 1998; Ferris et al. 2000; NorDÉN et al. 2004; URCELAY \& RoBledo 2009). Species richness is also reported to increase with progressive wood decay (Renvall 1995; HøILAND \& Bendiksen 1996). Relatively high 
soil moisture as well as high cover of field and moss layers (Appendix 1 and 2) seem to create favourable microclimatic conditions, which are among the most important abiotic variables affecting this group of fungi (BODDY 1992).

\section{Spatial distribution}

Differences in the carpophore spatial frequencies of individual species among the plots representing subsequent succession phases are an indication of their preferences and specificity towards the stage of vegetation development. The presence of carpophores approximately reflects the distribution of the species below-ground (JANSEN 1984; GUIDOT et al. 2001; ZHOU et al. 2001; Hirose et al. 2004), although their first appearance indicates rather the beginning of fruiting and not necessarily the species establishment.

The spatial distribution of the ECM species along the old-field chronosequence studied suggests that succession of these fungi starts simultaneously with trees colonisation and can be impressively fast. Moreover, as the observed secondary succession of vegetation was entirely natural and spontaneous, all the ECM fungi were indigenous; possible interference of nursery species is excluded. The initial species composition, resulting most probably from the establishment of numerous populations of the same and different species from spore deposits over a relatively short time (not more than 6-8 years after the arrival of first cohort of trees, but probably earlier), tends to persist for several to tens of years (Fig. 25, compare Figs 14, 15). This corresponds to the 'initial floristics' model proposed by EGLER (1954) for secondary successional community development. In this model, all species present in the entire chronosequence may be present soon after disturbance, but different groups of species prevail over time. First populations of nearly $50 \%$ of the ECM species present in this series were able to establish during the first years of succession, many of them long before attaining their maximum abundance and spatial frequency. An establishment of some species from the vegetative mycelia spreading from the neighbouring, more developed vegetation patches was highly probable, such as: Amanita citrina, Russula galochroa, $R$. clavipes, $R$. emetica.

As the youngest stands examined in this study comprised 6-8(12) year old trees and they hosted not less than $33( \pm 7)$ ECM species/1000 $\mathrm{m}^{2}$, a strict group of the earliest colonizers forming symbioses with tree seedlings cannot be distinguished based on the spatial frequency alone. A majority of these species can be regarded as early arriving multistage fungi. Among them the group of species present along the whole chronosequence (phases 4-9/10) can be distinguished as well as groups of species which withdraw after canopy closure or before the mature forest formation.

The species richness is built primarily by an accumulation of species, with a distinct although not numerous group of species specific to the optimal stage of vegetation development, followed by partial but considerable replacement best seen between brushwood and forest phase of the terminal succession stage. As a result many species typical of open vegetation as well as species continuing their fruiting in brushwood community disappeared and a group of species specific to old-growth forests gradually established. Similar observations were made, e.g., by VisSER (1995), BrAdBURY et al. (1998), KRANABETTER et al. (2005) and TwIEg et al. (2007), who also found the accumulation of species being the major way of building the ECM species composition in successional stands but only a few species being replaced. According to KRANABETTER et al. (2005), in the western hemlock - lodgepole pine old-growth forests (with trees over 200 years old) the frequency of sporocarps was evenly divided between species established in early- and mid-seral stages of development 
(40\% each), followed by species associated with late-seral stands (20\%). However, in the present study the replacement of species was much more intensive: species not occurring earlier comprised $50 \%$ of the ECM assemblage in the nearly mature pine forest.

Apart from the "core" species associated with pine, a group of "peripheral" species host-specific to deciduous trees were found throughout the studied series, mainly in the juniper-aspen brushwood. The "peripheral" species associated with small populations of paper birch or spruce independently of the main stand development were also found by KRANABETTER et al. (2005).

The species persistence and shifts in their spatial distribution over time seem to depend on their life histories (i.e. dispersal, abilities to colonize trees of different age, physiological and nutritional demands, competitive abilities, etc); at least some species show clear preferences for younger trees/earlier developmental phases, such as Inocybe lacera and Suillus luteus, for the communities around canopy closure, such as Tricholoma albobrunneum and T. portentosum, or to mature trees/stands, such as Paxillus involutus, Russula badia and other species.

For the saprotrophic species similar patterns seem to apply (Fig. 26). The majority of species that were not sporadic were multistage fungi, showing preference for the substrates that were continuously available in the whole chronosequence or its part: herbaceous plant debris, moss-lichen synusia, moss tufts, litter and woody debris. The replacement of species was clearly connected with changing resource types and quality; the main changes in species composition took place after the post-fallow herb-grass community transformation into the psammophilous grassland with juniper and pine, after the canopy closure and in the mature forest community. Similar to the "peripheral" ECM fungi, a group of species inhabiting deciduous litter and wood can be distinguished. The changes resemble to some extent those in successional roadside verges (KeIZer 1993b) with species specific to open grassland (Mycena flavoalba group), bryophilous species and a distinct group of wood inhabiting fungi.

Fungal dynamics - establishing new species, changes in sporocarp production and their spatial distribution, is a result of population processes both at inter- and intra-specific level. As summarised by AMEND et al. (2009), there are species forming large genets (i.e. continuous mycelial individuals of the same genotype) likely propagating vegetatively, such as Suillus bovinus (DAhlberg \& Stenlid 1990, 1994) and Xerocomus spp. (Fiore-Donno \& MARTIN 2001), as well as species growing as much smaller genets which rather propagate via spores, as it was found, e.g., in Hebeloma cylindrosporum (Guidot et al. 2002), Laccaria amethystina (FIORE-DonNo \& MARTIN 2001) and Lactarius xanthogalactus, Russula cremoricolor and Amanita francheti (REDECKER et al. 2001). Both small and large genets can be formed by Russula brevipes (Bergemann \& Miller 2002). In some species the size of genets positively correlates with forest development and tree age, but the number of genets decreases (DAHLBERG 1997). For Suillus bovinus, estimated numbers of 700-5700 genets ha ${ }^{-1}$ in younger (15-20 years old) stands and 30-120 ha-1 in older (70-140 years old) stands were found (DAHLBERG \& STENLID 1994). The maximum size of genets was 1.7-5.3 m in the younger forest and to $17.5 \mathrm{~m}$ in the older ones. At the same time the production of sporocarps per unit area decreased. In contrast, Laccaria amethystina formed small genets also in mature forests (FIORE-DONNO \& MARTIN 2001). Limited carpophore numbers and still large sizes of genets in older forests suggest their fragmentation into several ramets (i.e. spatially discontinuous mycelial units of the same genotype) (DAHLberg \& STENLID 1995; SAWYER et al. 2001). Such a process could be an explanation why in some species, for 


\begin{tabular}{|c|c|c|c|c|c|c|c|}
\hline \multirow{2}{*}{ Stages and phases of succession } & \multicolumn{2}{|c|}{ Initial stage } & \multicolumn{3}{|c|}{ Optimal stage } & \multicolumn{2}{|c|}{ Terminal stage } \\
\hline & 2 & 4 & 5 & 6 & $6 / 7$ & 8 & $9 / 10$ \\
\hline Range of pine age & - & $6-8(12)$ & $8-12(16)$ & $8-15(19)$ & $12-18(25)$ & $20-30(35)$ & $\sim 100$ \\
\hline \multicolumn{8}{|l|}{ Laccaria proxima } \\
\hline \multicolumn{8}{|l|}{ Cortinarius spp. I } \\
\hline \multicolumn{8}{|l|}{ Thelephora terrestris } \\
\hline \multicolumn{8}{|l|}{ Rhodocollybia butyracea f. asema } \\
\hline \multicolumn{8}{|l|}{ Cortinarius spp. II } \\
\hline \multirow{2}{*}{\multicolumn{8}{|c|}{ Russula fragilis }} \\
\hline \multirow{2}{*}{\multicolumn{8}{|c|}{ Cortinarius spp. III }} \\
\hline & & & & & & & \\
\hline \multicolumn{8}{|l|}{ Paxillus involutus } \\
\hline \multicolumn{8}{|l|}{ Amanita rubescens } \\
\hline \multicolumn{8}{|l|}{ Inocybe lacera } \\
\hline \multicolumn{8}{|l|}{ Suillus luteus } \\
\hline \multicolumn{8}{|l|}{ Cortinarius cinnamomeoluteus } \\
\hline \multicolumn{8}{|l|}{ Hygrophorus hypothejus } \\
\hline \multicolumn{8}{|l|}{ Amanita muscaria } \\
\hline \multicolumn{8}{|l|}{ Chalciporus piperatus } \\
\hline \multicolumn{8}{|l|}{ Tricholoma albobrunneum } \\
\hline \multicolumn{8}{|l|}{ Tricholoma portentosum } \\
\hline \multicolumn{8}{|l|}{ Tricholoma equestre } \\
\hline \multicolumn{8}{|l|}{ Leccinum aurantiacum } \\
\hline \multicolumn{8}{|l|}{ Boletus edulis } \\
\hline \multicolumn{8}{|l|}{ Clitopilus prunulus } \\
\hline \multicolumn{8}{|l|}{ Amanita pantherina } \\
\hline \multicolumn{8}{|l|}{ Hebeloma sp. 1} \\
\hline \multicolumn{8}{|l|}{ Inocybe calida } \\
\hline Inocybe praetervisa & & & & & & & \\
\hline Laccaria bicolor & & & & & & & \\
\hline Cortinarius purpurascens & & & & & & & \\
\hline Inocybe assimilata & & & & & & & \\
\hline Inocybe asterospora & & & & & & & \\
\hline Inocybe curvipes & & & & & & & \\
\hline
\end{tabular}




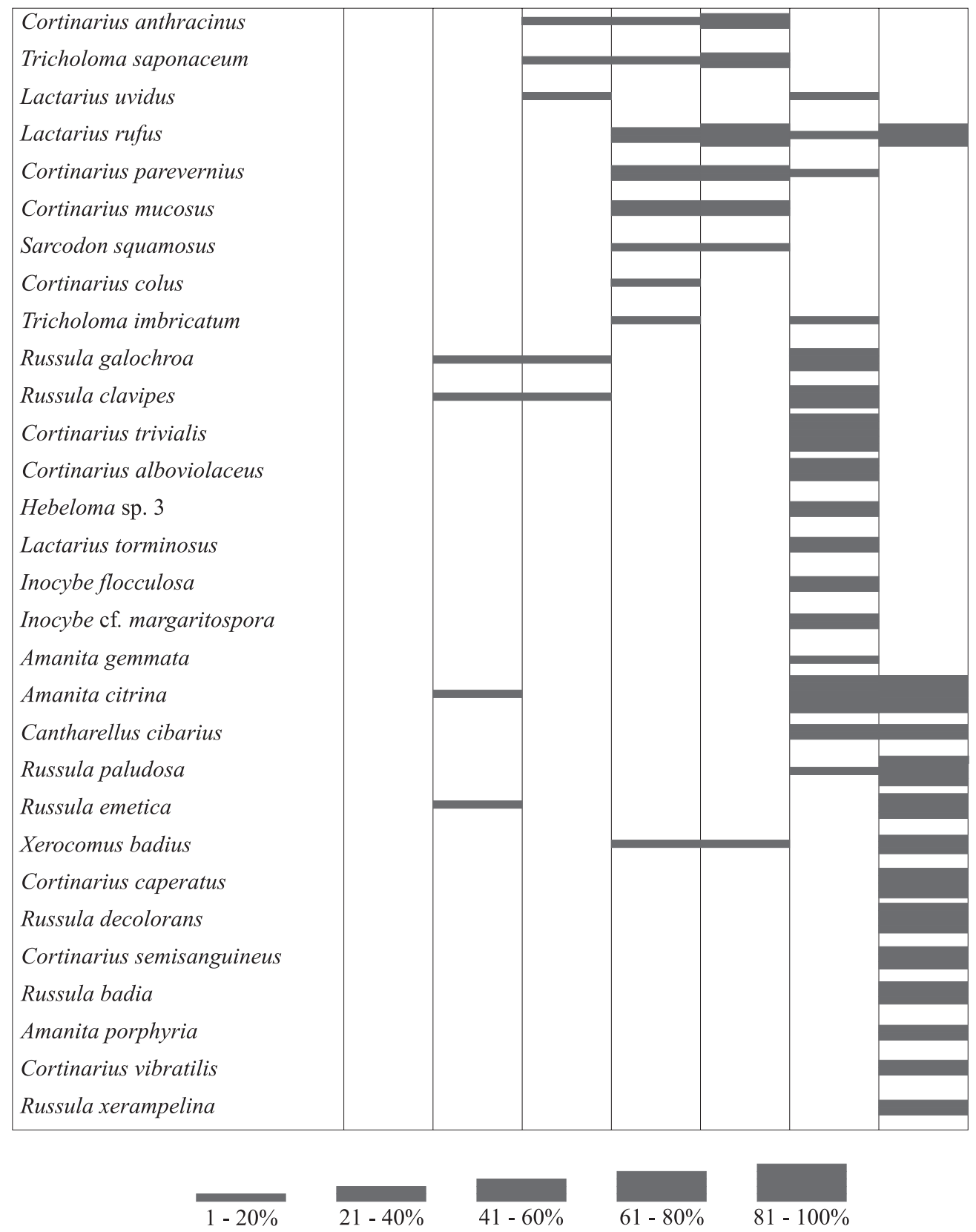

Fig. 25. Spatial frequency of ECM fungi in consecutive phases of the spontaneous secondary succession on abandoned farmland; sporadic species occurring with very low abundance or only in one plot are excluded. 


\begin{tabular}{|c|c|c|c|c|c|c|c|}
\hline \multirow{2}{*}{ Stages and phases of succession } & \multicolumn{2}{|c|}{ Initial stage } & \multicolumn{3}{|c|}{ Optimal stage } & \multicolumn{2}{|c|}{ Terminal stage } \\
\hline & 2 & 4 & 5 & 6 & $6 / 7$ & \begin{tabular}{|l|}
8 \\
\end{tabular} & $9 / 10$ \\
\hline Range of pine age & - & $6-8(12)$ & $8-12(16)$ & $8-15(19)$ & $12-18(25)$ & $20-30(35)$ & $\sim 100$ \\
\hline \multicolumn{8}{|l|}{ Coprinopsis friesii } \\
\hline \multicolumn{8}{|l|}{ Crinipellis scabella } \\
\hline \multicolumn{8}{|l|}{ Rickenella fibula } \\
\hline \multicolumn{8}{|l|}{ Marasmius oreades } \\
\hline \multicolumn{8}{|l|}{ Mycena olvaceomarginata } \\
\hline \multicolumn{8}{|l|}{ Mycena leptocephala } \\
\hline \multicolumn{8}{|l|}{ Mycena flavoalba } \\
\hline \multicolumn{8}{|l|}{ Galerina spp. } \\
\hline \multicolumn{8}{|l|}{ Clitocybe diatreta } \\
\hline \multicolumn{8}{|l|}{ Cystoderma amianthinum } \\
\hline \multicolumn{8}{|l|}{ Mycena pura } \\
\hline \multicolumn{8}{|l|}{ Psilocybe montana } \\
\hline \multicolumn{8}{|l|}{ Entoloma spp. } \\
\hline \multicolumn{8}{|l|}{ Ampulloclitocybe clavipes } \\
\hline \multicolumn{8}{|l|}{ Clitocybe vibecina } \\
\hline \multicolumn{8}{|l|}{ Gymnopus androsaceus } \\
\hline \multicolumn{8}{|l|}{ Collybia cirrhata } \\
\hline \multicolumn{8}{|l|}{ Galerina pumila } \\
\hline \multicolumn{8}{|l|}{ Dacrymyces stillatus } \\
\hline \multicolumn{8}{|l|}{ Mycena metata } \\
\hline \multicolumn{8}{|l|}{ Lycoperdon nigrescens } \\
\hline \multicolumn{8}{|l|}{ Macrolepiota procera } \\
\hline \multicolumn{8}{|l|}{ Hypholoma fasciculare } \\
\hline \multicolumn{8}{|l|}{ Galerina hypnorum } \\
\hline \multicolumn{8}{|l|}{ Lycoperdon molle } \\
\hline Lycoperdon perlatum & & & & & & & \\
\hline Clavaria argillacea & & & & & & & \\
\hline Galerina atkinsoniana & & & & & & & \\
\hline Hygroaster asterosporus & & & & & & & \\
\hline Cantharellula umbonata & & & & & & & \\
\hline
\end{tabular}




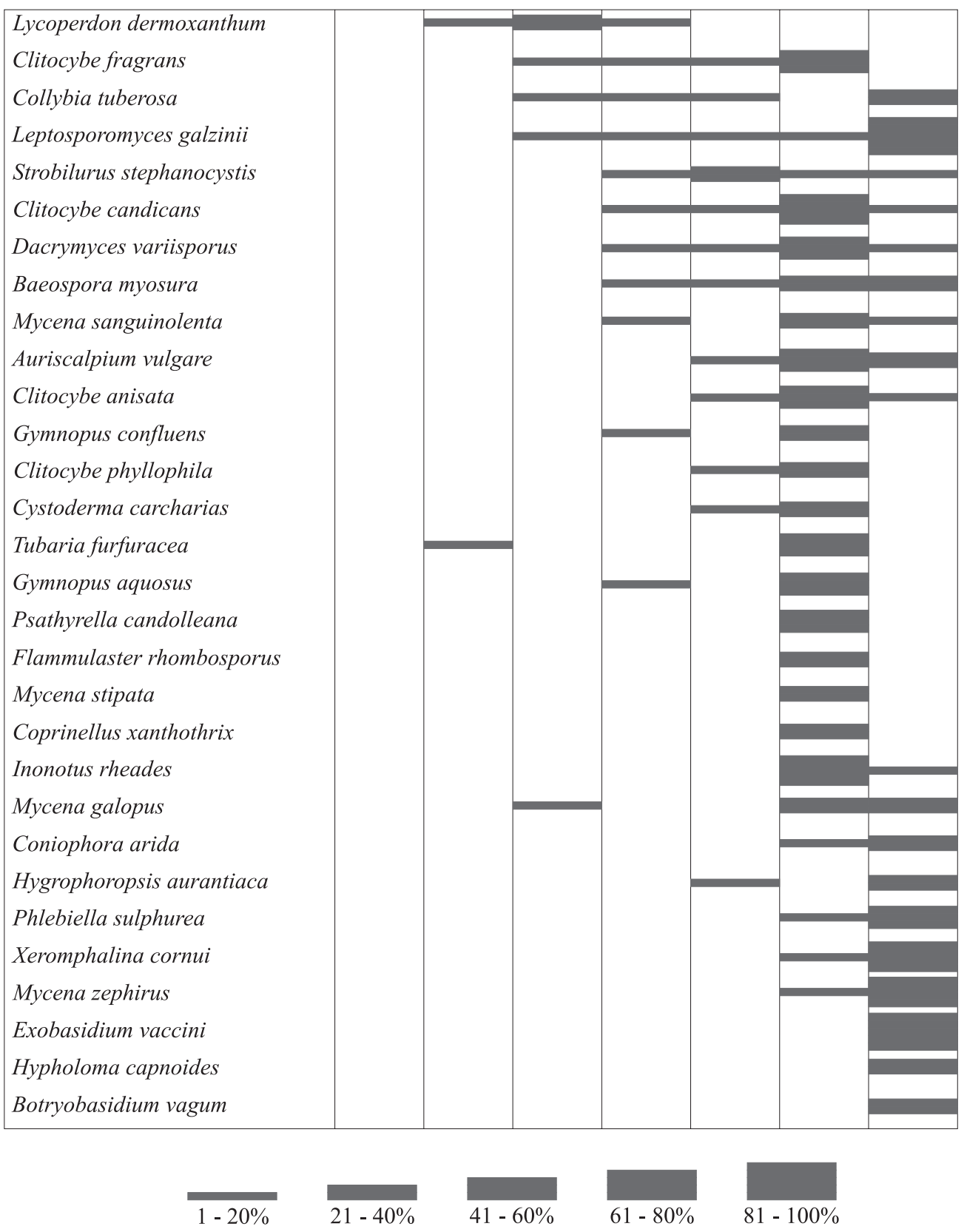

Fig. 26. Spatial frequency of most frequent non-ECM fungi in consecutive phases of the spontaneous secondary succession on abandoned farmland. 
instance Amanita muscaria, Chalciporus piperatus, Tricholoma equestre and Boletus edulis, after attaining maximum abundance a decrease in carpophore production is not immediately followed by decreasing spatial frequency - the frequency tends to stay high longer. Similarly, high carpophore abundances combined with high spatial frequencies typical of Inocybe lacera, Suillus luteus, Amanita muscaria and Laccaria proxima early after trees encroachment suggest rapid and simultaneous establishment of numerous genets of these species originating from spore dispersal.

\section{Changes in species composition of ECM fungi}

An open community of psammophilous grassland with 6-8(12) year old pines was characterized by the presence of a rich and diverse community of ECM fungi corresponding to the 'initial floristics' model (EGLER 1954). Among them a small group of species attained not only very high spatial frequency but also high sporocarp abundance, which suggests that they reveal a special affinity for the youngest trees and might have started fruiting before the other species. In this group are Inocybe lacera, Laccaria proxima, Suillus luteus, Cortinarius cinnamomeoluteus and Amanita muscaria. These species also accounted for most of the sporocarp biomass production in early succession phases. At least the first three species are regarded as 'early stage fungi' (MAson et al. 1982, 1983; Dighton \& MAson 1985). However, they were not soon replaced by other species but persisted in developing vegetation at least till the pre-forest phase - the juniper-aspen brushwood.

The majority of the ECM species present in the initial, optimal and early terminal stages of the old-field succession are rather 'multi-stage fungi', similar to the observations in jack pine stands regenerating after a wildfire (VISSER 1995) or in primary succession in a glacier forefront (JUMPPONEN et al. 2002). However, most of these 'multi-stage fungi' showed preferences for a particular period of vegetation development, which was manifested with more abundant sporocarp production and/or higher spatial frequency.

In the terminal pine forest, species regarded as 'late stage fungi', especially of the genus Russula, but also Amanita, Cortinarius, Lactarius and Xerocomus prevailed. Most of the typical forest species were recorded in the successional series late, only in the nearly mature stand. Relatively few 'late stage species' started fruiting earlier: Lactarius rufus and Xerocomus badius in the stands around canopy closure, and Amanita citrina, Cantharellus cibarius and Russula paludosa in the juniper-aspen brushwood. It seems that, in contrast to the initial rapid and somewhat chaotic species colonization, the recruitment of new species along with advancing age and maturity of the forest long after the canopy closure is much slower and gradual.

The pattern described above seems to agree well with the 'early-' and 'late-stage' model, especially if it is amended by adding 'multi-stage fungi'. The model has played a very inspiring role in mycorrhizal ecology and research on spatio-temporal changes in ECM communities. It was supported (e.g., JANSEN 1991; VISSER 1995; HeLm et al. 1996) as well as opposed (e.g., Termorshuizen 1991; Keizer \& Arnolds 1994; Jumpronen et al. 1999; Bonet et al. 2004). In the present study, an occurrence of a narrow group of species specific for the intermediate part of the chronosequence (pines 10-20 years old, the cover exceeding $50 \%$ ), namely Cortinarius anthracinus, $C$. colus, $C$. mucosus, $C$. paraevernius and numerous species of Tricholoma cannot be explained within the early-, late- or multi-stage fungi concepts unless they were regarded as intermediate-stage fungi. Some of these species were present also in the middle-aged pine stands described, e.g., by HiNTIKKA (1988; oligotrophic, mainly 20-30 and 30-50 years old stands, $45-90 \%$ canopy closure) and TermorshuIzEN 
(1991; spontaneous, 8-13 years old stand on drifting sands, $85-95 \%$ canopy closure). An abundant occurrence of carpophores of different species of Tricholoma in pine stands around canopy closure was observed also on mineral soils with no humus yet formed, in pine plantations on post-arable land and on post-mining heap (KAŁUCKA, unpubl. data).

Changes of the ECM fungi composition in the chronosequence studied can be at least partly explained as the sequence of fungi representing different life histories. Various assemblages of species found in stands of different ages are believed to exhibit characters that are adaptations to changes in habitat conditions as the trees mature (FranKLAND 1998). In the earlier succession phases, r-selected species prevailed, growing on mineral soil, producing relatively small carpophores but in mass quantities, such as Inocybe lacera, Cortinarius cinnamomeoluteus and other species of this genus with tiny fruit bodies, Hygrophorus hypothejus and Laccaria proxima. Later, on xeric mineral soil with low C and $\mathrm{N}$ content and high row litter cover, species producing abundant, but bigger carpophores became numerous, mainly Tricholoma spp. and some Cortinarius spp. (stress-tolerant species?). In the pine forest, with developing organic layers, big carpophores of different Russula species as well as Cortinarius (mainly C. caperatus) and Amanita prevailed, but their abundance is much lower; such species are usually regarded as K-selected (Dighton \& MASON 1985; LAST et al. 1987).

Strong links between the patterns of the ECM species composition, frequency and abundance, and vegetation development, age of trees, stand structure and soil development suggest that ECM fungal succession would be better explained against a background of vegetation succession and stages of stand development. It seems that the successional trajectory of ECM fungi of the spontaneous, old-field series leading to the formation of fresh pine forest is a 3 -stage process:

- colonization stage - rapid colonization by a rich ECM community dominated by Inocybe lacera, Laccaria proxima, Suillus luteus, Cortinarius cinnamomeoluteus, Amanita muscaria and Hygrophorus hypothejus; increase in species richness and diversity, sporocarp abundance and biomass production (phases 4 and 5, initial and early optimal stage of vegetation development: open psammophilous grassland with junipers and pines up to 12(16) years old);

- stabilisation stage - stabilisation of the ECM community, prevalence of Laccaria proxima, Suillus luteus, Cortinarius cinnamomeoluteus and other small-sized Cortinarius species, Amanita muscaria, Hygrophorus hypothejus and Chalciporus piperatus, arriving and abundant occurrence of Lactarius rufus, Cortinarius mucosus and C. parevernius, more and more abundant occurrence of many species of Tricholoma; further increase in the species richness and diversity, maximum overall carpophore abundance and biomass production (phases 6 and 6/7; advanced and late optimal stage of vegetation development: psammophilous grassland with rich moss and lichen layer, juniper shrubs and pines up to 18(25) years old, ca 50\% pine cover up to canopy closure); the period of canopy closure with intensified litter accumulation and xeric soil conditions marked with decreasing carpophore numbers and prevalence of Tricholoma spp. in the biomass production;

- replacement stage - gradual change in the ECM species composition, partial replacement of species typical of the pre-forest vegetation and arrival of numerous forest species, mainly of Russula, Lactarius, Cortinarius and Amanita; increase in the species diversity, decrease in the species richness, conspicuous decrease in the overall carpophore abundance and biomass, prevalence of Russula in the biomass production (phases 8 to 
10 , terminal stage of vegetation development; formation of the forest vertical structure, development of soil profile and humus layer, pines over 30 years old, up to 100 in the present study); if the vegetation successional trajectory comprises a transitional, early terminal community of the juniper-aspen brushwood, then a presence of numerous species host-specific to deciduous trees is considerable resulting in a temporal shift in species richness and prevalence of Cortinarius in the carpophore biomass production.

A similar, 3-stage scheme of the ECM fungi succession (based on the occurrence of ECM roots) was proposed by TwIEG et al. (2007) for the successional series of mixed, Douglas fir and paper birch temperate forest developing after stand-replacing fire and clearcutting; a kind of classification of ECM fungi based on their presence in different stages of forest development was also proposed by KEIZER \& ARNOLDS (1994). It seems that some common general patterns could influence the ECM fungal succession during secondary succession of the forest community.

\section{Dynamics of ectomycorrhizal roots}

As summarized by SMITH \& READ (2008), fine roots of trees $(<2 \mathrm{~mm}$ in diameter) are predominantly found in the superficial organic layers and most of them in boreal and temperate forest bioms are ectomycorrhizal. The fine roots of Norway spruce in European forests develop mainly in the upper $10 \mathrm{~cm}$ of soil (STOBER et al. 2000). Most fine root biomass (over 80\%) of Scots pine was found in the upper $(0-15 \mathrm{~cm})$ soil level (OLEKSYN et al. 1999). A similar distribution of Pinus sylvestris ECM root biomass was also found by PERsson (1983). As much as $80 \%$ of ectomycorrhizal tips can occur in the top $5 \mathrm{~cm}$ of soil profile (Mikola et al. 1966). In boreal Pinus sylvestris-Picea abies forests, ECM roots most intensively penetrate the superficial organic layers of the podzol, but numerous mycorrhizae of various species occur also in the mineral horizons (RosLing et al. 2003).

Concentration of the fine roots, of which more than $90 \%$ were always ectomycorrhizal, in the superficial soil part was observed also in the chronosequence studied. However, the main body of the roots moved from the mineral to organic horizons along with the vegetation succession and development of the soil profile. A similar trend was found by VoGT et al. (1981) in stands of Abies amabilis in the USA. Accumulating litter and humus layer formed underneath are the substrates, which can be intensively exploited at least by some of the ECM species associated with mature stands as a source of nitrogen (SMiTH \& READ 2008).

The length of the fine roots and the number of ECM tips found in the subsequent succession phases did not differ significantly apart from phase 8 (juniper-aspen brushwood), where they were much higher. However, the average length of the roots as well as the number of ectomycorrhizae in the initial and optimal stage of vegetation development (pines up to 20-25 years old) were usually higher than in the pine forest (pines ca 100 years old). Similar observations were made by TERMORSHUIZEN (1991) in Pinus sylvestris stands of different ages in the Netherlands. In the younger stands, 4-13 years old, the length of ECM roots and the number of ECM tips were usually higher than in the older stands, 50-80 years old, and standard deviations were very high. JANSEN (1991) observed a distinct decrease in the number of ECM tips from the average $128 / 100 \mathrm{~cm}^{3}$ in young stands (8-18 years old) to $30 / 100 \mathrm{~cm}^{3}$ in older stands (41 and 54 years old) in the plantations of Pseudotsuga menziesii in the Netherlands. In the Pseudotsuga menziesii stands, the culmination of the fine root biomass and ectomycorrhizae coincides with attaining maximum biomass of foliage and crowns (Vogt et al. (1983). Later the biomass decreases, earlier and faster in the rich sites than in the poor sites. 
An occurrence of numerous fine roots and ectomycorrhizae may be favoured by rather thin humus and sparse field layer. TERMORSHUizen (1991) found that in 60 years old pine stands characterized by such features the number of ECM root tips and the length of fine roots were as high as in young stands.

An exceptionally high density of tree roots in the juniper-aspen brushwood may be an effect of mixed character of the stand and the predominance of deciduous trees with high proportion of aspen (Strong \& LA Roi 1983; Villeneuve et al. 1989; Twieg et al. 2007). Strong \& La Roi (1983) compared the stands of Pinus banksiana, Populus tremuloides and Picea glauca in different age and on different soils and they found that in the 48 year old aspen stands on mineral sandy soil the densities of roots, both total and in the superficial soil, were the highest. The roots were concentrated mainly in the zone between the organic and mineral layers.

In all the succession phases studied, independently of the stand composition, age of trees and high standard deviations in the root length and the number of mycorrhizas, high positive correlation was found between the length of living fine roots and the number of ECM tips. Also, the ramification index, i.e., the number of ECM tips per $\mathrm{cm}$ of the root length, shows no statistically significant differences among phases in a given year and is characterized with much smaller standard deviations. In two seasons it attained the values of 4.7-5.7 and 7.0-8.9, respectively. In Pinus sylvestris stands in different ages and of different origin (spontaneous and planted, different rotations, different soils) in the Netherlands, TERmorshuizen (1991) found a similar correlation, but the ramification index was 1.6-2.0. According to Meyer (1987), the index is an indication of the fine root vitality. In the Pinus sylvestris stands situated in a zone of low air pollution in Poland, the ramification index equaled 2.7-3.8, and in the stands suffering from industrial emissions it was 1.3-2.2 (Józefaciukowa et al. 1995). High indices recorded in the old-field chronosequence studied may indicate good condition of trees and high mycorrhizal activity of their roots.

\section{SUMMARY OF RESULTS AND CONCLUSIONS}

1. The research on the macrofungi in the process of spontaneous secondary succession was carried out in the chronosequence of old fields abandoned at different times and inhabited by vegetation at different succession stages. The study area is situated near the southwest peripheries of the Białowieża old-growth forest (NE Poland), in two nature reserves, Jelonka and Czechy Orlańskie. Both sites are extensively studied in the framework of long-term ecological research on the process of natural fresh coniferous forest return after centuries of deforestation and agricultural management conducted by the Białowieża Geobotanical Station, University of Warsaw.

2. The sporocarps of macromycetes were subject to qualitative and quantitative analyses in three consecutive seasons (17 field observations); the study focused on basidiomycetes as the proportion of ascomycete fruit bodies was negligible. The ECM roots were also examined in two seasons for the number of ECM tips and fine root length. A series of soil analyses, as well as vegetation examination, were performed to document concurrent habitat features. 
3. The succession of macrofungi was examined against the background of the old-field succession model proposed by FALIŃSKI (1986b) and FALIŃSKI et al. (1993). Eleven permanent plots, $1000 \mathrm{~m}^{2}$ each, situated in the Jelonka reserve, represented 6 phases of secondary succession, from a fallow herb-grassland (phase 2), a complex of psammophilous grasslands, juniper shrubs and Scots pine thickets (phases 4-6/7) to a brushwood of juniper, trembling aspen and Scots pine (phase 8), corresponding to the initial, optimal and early terminal stage of vegetation development. Five plots representing nearly mature pine forest of Peucedano-Pinetum type (phase 9/10, pines ca 100 years old), situated in the Czechy Orlańskie reserve were also included, each of them of 400 $\mathrm{m}^{2}$. Each succession phase studied was represented by a total area of $2000 \mathrm{~m}^{2}$, with the exception of the earliest phase 2 , for which one $1000 \mathrm{~m}^{2}$ plot was selected.

4. The series yielded 300 species of macromycetes (including 6 collective taxa) found in permanent plots. Among them were 98 species of ECM fungi (32.7\%), 200 species of saprotrophic fungi $(66.7 \%)$ and 2 species of plant parasites (0.7\%). Additional 18 species were found outside the plots.

5. In the early successional, tree-less herb-grassland (phase 2, initial stage) 15 basidiomycete species were found. All the species recorded were saprotrophic, growing on dead plant remnants or on soil. The highest spatial frequency and abundance was achieved by Crinipellis scabella, Marasmius oreades, Mycena olivaceomarginata, M. flavoalba and M. leptocephala, Coprinopsis friesii and Galerina spp.

6. Along with the development of poor psammophilous grassland and colonization of the area by the ECM trees, rapid establishment of macrofungi occurred; in phase 4 (initial stage), with most of pines 6-8 (up to 12) years old, a total of 92 species were recorded. Among them 44 species were ectomycorrhizal, most of them host-specific to Pinus sylvestris. The group of species comprising Inocybe lacera, Suillus luteus, Amanita muscaria, Cortinarius cinnamomeoluteus, Laccaria proxima and Hygrophorus hypothejus prevailed in terms of spatial frequency and carpophore abundance. The highest proportion of the carpophore biomass production was achieved by the genera Amanita, Suillus and Inocybe. Among saprotrophic fungi, species growing on soil and among mosses prevailed.

7. In the optimal stage of vegetation development, changes in the fungal community, especially in the ECM fungi, were mainly of quantitative character. In open complex of psammophilous grassland with rich lichen-moss bottom layer, juniper shrubs and 8-15 (up to 20) years old pine thickets (phase 6), a total of 114 macromycete species were found. Among them were 47 ECM species; with an exception of Inocybe lacera, the group of species listed earlier still prevailed, joined by Chalciporus piperatus, Laccaria bicolor, Lactarius rufus and a few species of Tricholoma. The presence of Inocybe curvipes, Cortinarius parevernius, C. anthracinus, C. mucosus, C. colus, some other Cortinarius species with rather small carpophores and Sacrodon squamosus was also specific for this stage of vegetation development. The end of the optimal stage (pines 12-18 up to 25 years old), characterised by progressing canopy closure and xeric soil conditions, was marked by the presence of numerous species of Tricholoma and their exceptionally high proportion in the carpophore biomass production. A part of the ECM species present in the optimal stage of the vegetation succession did not continue fruiting after the canopy closure. Only two new species which continued fruiting in the pine forest arrived, Lactarius rufus and Xerocomus badius. Saprotrophic species growing on soil and among mosses were still numerous, but the diversity and abundance of litter- and wood-inhabiting species conspicuously increased. 
8. The fungal species richness in the juniper-aspen brushwood (phase 8 , early terminal stage) increased to 183 species, $70 \%$ of which were saprotrophic ones. Litter- and wood-inhabiting fungi prevailed, while the species typical of open vegetation decreased in number, frequency and abundance. The ECM species composition was relatively similar to earlier phases, but the carpophore abundance and productivity decreased. Very high proportion of aspen, birch and willow in the stand resulted in the increased number of ECM species host-specific to deciduous trees, making the ECM species richness very high (49 species). In terms of carpophore biomass, Amanita and Cortinarius prevailed. Relatively few ECM species typical of forest communities arrived at this stage of vegetation development. These were Amanita citrina, Cantharellus cibarius and Russula paludosa.

9. In the fresh pine forest Peucedano-Pinetum, being the final community of the successional series studied, the fungal species richness decreased to 30 ECM and 68 non-ECM fungi. The abundance and overall carpophore biomass was also the lowest. However, in comparison with the optimal stage of vegetation development, the species diversity, both in the ECM and saprotrophic species was higher. The species composition of ECM fungi changed considerably; many species present in earlier vegetation phases were replaced by species typical of forests, such as species of Russula, Cortinarius, Lactarius and Amanita. Russula was the most productive genus, together with Cortinarius they accounted for about $60 \%$ of the carpophore biomass production. Among the saprotrophic fungi, species growing on litter and wood prevailed; the majority of exclusive saprotrophic species occurring in the forest were wood-inhabiting taxa.

10. The species colonization pattern corresponds to the 'initial floristics' model, especially for the ECM fungi. A rapid initial increase in the species number was observed, followed by long persistence and changing prevalence of different groups of species over time. The majority of the ECM species can be regarded as early arriving multistage fungi. Among them a group of species occurring along the whole chronosequence where trees were present (phases 4-9/10) can be distinguished as well as groups of species which stop fruiting after canopy closure or before the mature forest formation. The species richness is built primarily by an accumulation of species, with a distinct although not numerous group of species specific for the optimal stage of vegetation development, followed by partial but considerable replacement best seen between the brushwood and forest phases of the terminal succession stage. When the forest community mature, gradual recruitment of new species can be observed.

11. The majority of the ECM species present in the initial, optimal and early terminal stage of the old-field succession can be regarded as 'multi-stage fungi'. However, in early succession phases species regarded as 'early stage fungi' prevailed in terms of spatial distribution, carpophore abundance and biomass production, such as Inocybe lacera, Laccaria proxima, Suillus luteus, and also Cortinarius cinnamomeoluteus and Amanita muscaria. They were not soon replaced by other species but persisted in developing vegetation at least till the pre-forest phase - the juniper-aspen brushwood. In the pine forest, species regarded as 'late stage fungi', especially of the genus Russula, but also Amanita, Cortinarius, Lactarius and Xerocomus prevailed. This pattern can also be explained in terms of changing proportions of fungi representing different life histories - from $\mathrm{r}$ - to K-selected species.

12. A three-stage process for the succession of ECM fungi in the poor post-arable land till the formation of mature pine forest community is proposed: 
- colonization stage - rapid colonization by a rich ECM community dominated by Inocybe lacera, Laccaria proxima, Suillus luteus, Cortinarius cinnamomeoluteus, Amanita muscaria and Hygrophorus hypothejus; fast increase in the species richness and diversity, sporocarp abundance and biomass production;

- stabilisation stage - stabilisation of the ECM community, prevalance of Laccaria proxima, Suillus luteus, Cortinarius cinnamomeoluteus and other small-sized Cortinarius species, Amanita muscaria, Hygrophorus hypothejus and Chalciporus piperatus joined with abundant occurrence of Lactarius rufus, Cortinarius mucosus, $C$. parevernius and many species of Tricholoma; further but slower increase in the species richness and diversity, maximum overall carpophore abundance and biomass production. Late in this stage Tricholoma spp. prevail in the biomass production, abundance of carpophores of other species decreases. This stage coincides with the period of reaching stand canopy closure;

- replacement stage - gradual change in the ECM species composition, partial replacement of species typical of the pre-forest vegetation and establishment of numerous forest species, mainly of Russula, Lactarius, Cortinarius and Amanita; increase in the species diversity, decrease in the species richness, conspicuous decrease in the overall carpophore abundance and biomass, prevalence of Russula in the biomass production.

13. Changes in the fungal species composition as well as patterns of the carpophore spatial frequency, abundance and biomass production are strongly linked to the vegetation development, its rate, age of trees, stand composition and structure and soil development. Succession of the ECM fungi in the studied coniferous series seems to be affected mainly by the age of trees, stand structure and development of soil profile, but the species composition (and usually not fruiting dynamics) can be modified by the presence of additional, deciduous tree species and the presence of older and successionally more advanced vegetation stages in close vicinity. Succession of the saprotrophic species seems to be primarily affected by the presence and diversification of available substrates and microclimatic conditions resulting from the plant community composition, stand composition and structure and accumulation of organic debris.

14. The ECM roots were located in the mineral superficial soil in earlier succession phases. Later, along with the soil development, they tended to concentrate in between the mineral soil and accumulating litter and finally in the organic horizons in the terminal stage of vegetation succession. The length of fine roots and the number of ECM tips were the highest in the juniper-aspen brushwood as a result of a high proportion of aspen. Independently of the stand composition, age of trees and high standard deviations in the root length and the number of mycorrhizae, high positive correlation was found between the length of living fine roots and the number of ECM tips. The ramification index showed no statistically significant differences among phases in a given year and was characterized with much smaller standard deviations. Its relatively high values may indicate good condition of trees and high mycorrhizal activity of their roots.

15. The present study confirmed strong links and relationships between the succession of fungi and vegetation; the two processes parallel each other, and the species composition and dynamics of carpophore production of fungal assemblages match well with successional changes in phytocoenoses. Without the analysis of vegetation successional trajectory, interpretation of fungal succession, including both ECM and saprotrophic species, would be incomplete. 
Acknowledgements. I would like to express my deep gratitude to the late Prof. Dr. hab. J.B. FALIŃsKI, who entrusted me the task of supplementing his model of the vegetation succession in abandoned fields with macrofungi and invited me to work in his beloved "wasteland" of Jelonka; I am indebted for numerous enlightening discussions, encouragement for hard work and for technical support of the Białowieża Geobotanical Station of Warsaw University. I would like to offer my deep gratitude to Prof. Dr. hab. M. ŁaWrYNowicz for her scientific supervision, constant support and encouragement in difficult moments. The consultations held with Prof. Dr. hab. A. BuJAKIEwicz (Poznań) and Prof. Dr. hab. K. FALIŃSKA (Kraków) were very helpful and inspiring for the interpretation of the results of my study. A special appreciation is due to Prof. Dr. hab. J. Holeksa (Kraków) for his valuable comments broadening my understanding of ecology and for important critical remarks, which helped me very much to improve the manuscript. I am indebted to Prof. Dr. hab. W. Wojewoda (Kraków), Prof. E. Parmasto (Tartu), Prof. Dr. hab. M. Lisiewska (Poznań), Dr. H. Komorowska (Kraków), Prof. M. ŁawrYnowicz and Prof. H. BeKer (Brussels) for determinations and verifications of some fungal species and genera (see Appendix 5) as well as to Prof. Dr. hab. K. CZYŻEwSKA (Łódź) for phytosociological relevés and determination of herbaceous plants and lichens, Dr. E. FILIPIAK (Łódź) for determination of mosses, Prof. Dr. hab. K. Biaty (Toruń) for descriptions of soil profiles, Prof. Dr. hab. C. WataŁa (Łódź) and Prof. Dr. hab. A. Kruk (Łódź) for help in statistical analyses. Thanks are also due to Dr. B. SumoroK for her invaluable help during the field work, Dr. M. MichalsKi and mgr P. NowACKI for help in preparing graphics for this publication. A special gratitude is due to Prof. H. BEKER for improving the language. The author is thankful to the anonymous reviewers for their thorough reviews of the work and critical remarks. The study was financially supported by the Ministry of Science and Higher Education (Poland), grant no. 6P04F 01410.

\section{REFERENCES}

AleXandrowicz, S. 1964. Powstanie i rozwój miast województwa podlaskiego (XV w. i I poł. XVII w.). Acta Baltico-Slavica 1: 137-156.

Allen, E.B., Allen, M.F. 1990. The mediation of competition by mycorrhizae in successional and patchy environ. In: J.B. Grace, G.D. Tilman (eds.), Perspectives on plant competition. Academic Press, New York, 367-389.

Allen, M.F. 1987. Re-establishment of mycorrhizas on Mount St. Helens: migration vectors. Trans. Brit. Mycol. Soc. 88: 413-417.

Allen, M.F., Allen, E.B. 1992. Mycorrhizae and plant community development: mechanisms and patterns. In: G.C. CARRoll, D.T. WickLOW (eds.), The fungal community - its organization and role in the ecosystem. Marcel Dekker, New York, Basel, Hong Kong, 455-479.

Allen, M.F., Crisafulli, C., Friese, C.F., Jeakins, S.L. 1992. Re-formation of mycorrhizal symbioses on Mount St. Helens, 1980-90: interactions of rodents and mycorrhizal fungi. Mycol. Res. 96: 447-453.

Amend, A., Keeley, S., Garbelotto, M. 2009. Forest age correlates with fine-scale spatial structure of Matsutake mycorrhizas. Mycol. Res. 113: 541-551.

Andrews, J.H. 1992. Fungal life-history strategies. In: G.C. CARroll, D.T. Wicklow (eds.), The fungal community - its organization and role in the ecosystem. Marcel Dekker, New York, Basel, Hong Kong, 119-145.

ARNoLDS, E. 1981. Ecology and coenology of macrofungi in grassland and moist heathlands in Drenthe, the Netherlands. 1. Introduction and synecology. Biblioth. Mycol. 83. J. Cramer, Vaduz, 407 pp.

ARnolds, E. 1991. Decline of ectomycorrhizal fungi in Europe. Agr. Ecosyst. Environ. 35: 209-244.

ARNoLDS, E. 1992a. The analysis and classification of fungal communities with special reference to macrofungi. In: W. Winterhoff (ed.), Fungi in Vegetation Science. Kluwer Academic Publishers, the Netherlands, 7-47.

ARNoLDS, E. 1992b. Ecological studies on ectomycorrhizal fungi: an introduction. Giorn. Bot. Ital. 126: 765775.

ARnolds, E. 1992c. Macrofungal communities outside forests. In: W. Winterhoff (ed.), Fungi in Vegetation Science. Kluwer Academic Publishers, the Netherlands, 113-149.

AshKanneJHAD, S., Horton, T.R. 2006. Ectomycorrhizal ecology under primary succession on coastal sand dunes: interactions involving Pinus contorta, suilloid fungi and deer. New Phytol. 169: 345-354.

BADER, P., JANSSON, S., Jonsson, B.-G. 1995. Wood-inhabiting fungi and substratum decline in selectively logged boreal spruce forests. Biol. Conserv. 72: 355-362.

BARKMAN, J.J. 1987. Methods and results of mycocoenological research in the Netherlands. In: G. PACIONI (ed.), Studies on fungal communities. University of L'Aquila, Italy, 7-38. 
BARKMAN, J.J., DE VRIES, B.W.L. 1993. Check-list of fungi species recorded in the juniper brushwood on the abandoned farmland in the Jelonka reserve during 1971-1977 yrs. In: J.B. FALIŃSKI., S. CieśLIŃSKI, K. CzyżewsKa, Dynamic-floristic atlas of Jelonka reserve and adjacent areas. Distribution of vascular plant species, bryophytes and lichens on the abandoned farmlands durning secondary succession. Phytocoenosis 5 (N.S), Suppl. Cartogr. Geobot. 3: 131-138.

Barni, E., Siniscalco, C. 2000. Vegetative dynamics and arbuscular mycorrhiza in old-field successions of the western Italian Alps. Mycorrhiza 10: 63-72.

Bas, C., Kuyper, Th.W., Noordeloos, M.E., Veluinga, E.C. (eds.). 1988-1995. Flora Agaricina Neerlandica. Critical monographs on families of agarics and boleti occurring in the Netherlands. 1-3. A. A. Balkema, Rotterdam, Brookfield.

Begon, M., Harper, J.L., Townsend, C.R. 1996. Ecology: individuals, populations and communities. $3^{\text {rd }}$ Edition. Blackwell Science, Oxford.

Bergemann, S.E., Miller, S.L. 2002. Size, distribution, and persistence of genets in local populations of the latestage ectomycorrhizal basidiomycete, Russula brevipes. New Phytol. 156: 313-320.

Blasius, D., Oberwinkler, F. 1989. Succession of mycorrhizae: a matter of tree age or stand age? Ann. Sci. For. 46, Suppl. In: E. Dreyer et al. (eds.), Forest tree physiology, 758-761.

BodDY, L. 1992. Developing and function of fungal communities in decomposing wood. In: G.C. CARrolL, D.T. WickLOw (eds.), The fungal community - its organization and role in the ecosystem. Marcel Dekker, New York, Basel, Hong Kong, 749-782.

BoERner, R.E.J., DeMARs, B., LeICHT, P.N. 1996. Spatial patterns of mycorrhizal infectiveness of soil along a successional chronosequence. Mycorrhiza 6: 79-90.

Bonet, J., Fischer, C., Collinas, C. 2004. The relationship between forest age and aspect on the production of sporocarps of ectomycorrhizal fungi in Pinus sylvestris forest of the central Pyrenees. For. Ecol. Manag. 203: 157-175.

Bradbury, S.M., Danielson, R.M., Visser, S. 1998. Ectomycorrhizas of regenerating stands of lodgepole pine (Pinus contorta). Can. J. Bot. 76: 218-227.

Breitenbach, J., Kränzlin, F. 1986-2000. Fungi of Switzerland. 2-5. Verlag Mycologia, Luzern.

Brundrett, M. 1991. Mycorrhizas in natural ecosystems. In: A. Macfayden, M. Begon, A.H. Fitter (eds.), Advances in ecological research. 21. Academic Press, London, 171-313.

BujAKIEwICZ, A. 1981. Grzyby Babiej Góry. II. Wartość wskaźnikowa macromycetes w zespołach leśnych. Acta Mycol. 17, 1-2: 63-125.

BuJAKIEwICZ, A. 1991-1992. Badania mikosocjologiczne w zespole Ficario-Ulmetum campestris w rezerwacie „Wielka Kępa Ostromecka” nad Wisłą. Acta Mycol. 27, 2: 227-290.

Bujakiewicz, A. 1992. Macrofungi on soil in deciduous forests. In: W. Winterhoff (ed.), Fungi in Vegetation Science. Kluwer Academic Publishers, the Netherlands, 49-78.

Bujakiewicz, A. 1997. Fungi. Agaricales. In: J.B. Faliński, W. MuŁenko (eds.), Cryptogamous plants in the forest communities of Białowieża National Park. Ecological atlas (Project CRYPTO 4). Phytocoenosis 9 (N.S.), Suppl. Cartogr. Geobot. 7: 304-407.

CÁzARES, E., Trappe, J.M. 1994. Spore dispersal of ectomycorrhizal fungi on a glacier forefront by mammal mycophagy. Mycologia 86: 507-510.

CÁZARes, E., Trappe, J.M., Jumpronen, A. 2005. Mycorrhiza-plant colonization patterns on a subalpine glacier forefront as a model system of primary succession. Mycorrhiza 15: 405-416.

Chlebicki, A., Żarnowiec, J., Cieśliński, S., Klama, H., Bujakiewicz, A., ZaŁuski, T. 1996. Epixylites, lignicolous fungi and their links with different kinds of wood. In: J.B. FALiński, W. MuŁenko (eds.), Cryptogamous plants in the forest communities of Białowieża National Park. Functional groups analysis and general synthesis (Project CRYPTO 3). Phytocoenosis 8 (N. S.), Archiv. Geobot. 6: 75-110.

Chu-Chou, M. 1979. Mycorrhizal fungi of Pinus radiata in New Zealand. Soil Biol. Biochem. 11: 557-562.

Chu-Chou, M., Grace, L.J. 1981. Mycorrhizal fungi of Pseudotsuga menziesii in the north island of New Zealand. Soil Biol. Biochem. 13: 247-249.

Chu-Chou, M., Grace, L.J. 1988. Mycorrhizal fungi of radiata pine in different forests of the North and South Islands in New Zealand. Soil Biol. Biochem. 20: 883-886.

CZYŻEwSKA, K. 1992. Syntaksonomia śródlądowych, pionierskich muraw napiaskowych. Monogr. Bot. 74: 1-174.

DAHLberg, A. 1997. Population ecology of Suillus variegatus in old Swedish Scots pine forests. Mycol. Res. 101: 47-54.

Dahlberg, A., Stenlid, J. 1990. Population structure and dynamics in Suillus bovinus as indicated by spatial distribution of fungal clones. New Phytol. 115: 487-493. 
Dahlberg, A., Stenlid, J. 1994. Size, distribution and biomass of genets in populations of Suillus bovinus (L.: Fr.) Roussel revealed by somatic incompatibility. New Phytol. 128: 225-234.

Dahlberg, A., Stenlid, J. 1995. Spatiotemporal patterns in ectomycorrhizal populations. Can. J. Bot. 73: $1222-$ 1230.

Dahlberg, A., Jonsson, L., Nylund, J.-E. 1997. Species diversity and distribution of biomass above and below ground among ectomycorrhizal fungi in an old-growth Norway spruce forest in South Sweden. Can. J. Bot. 75: $1323-1335$.

DAnielson, R.M. 1991. Temporal changes and effects of amendments on the occurrence of sheathing (ecto-) mycorrhizas of conifers growing in oil sands tailings and coal spoil. Agric. Ecosyst. Environ. 35: 261-281.

Dickie, I.A., ReIch, P.B. 2005. Ectomycorrhizal fungal communities at forest edges. J. Ecol. 93: $244-255$.

Dickie, I.A., Schnitzer, S.A., Reich, P.B., Hobbie, S.E. 2007. Is oak establishment in old-fields and savannah openings context dependent? J. Ecol. 95: 309-320.

Dickinson, C.H., Pugh, G.J.F. (eds.). 1974. Biology of plant litter decomposition. Academic Press, New York.

Dighton, J. 2003. Fungi in ecosystem processes. Marcel Dekker, New York, Basel, 432 pp.

Dighton, J., Mason, P.A. 1985. Mycorrhizal dynamics during forest tree development. In: D. Moore, L.A. CASSElton, D.A. Wood, J.C. Frankland (eds.), Development biology of higher fungi. Cambridge University Press, Cambridge, 117-139.

Dighton, J., Poskitt, J.M., Howard, D.M. 1986. Changes in occurrence of basidiomycete fruit bodies during forest stand development: with specific reference to mycorrhizal species. Trans. Brit. Mycol. Soc. 87: 163-171.

Dix, N.J., Frankland, J.C. 1987. Tolerance of litter decomposing agarics to water stress in relation to habitat. Trans. Brit. Mycol. Soc. 88: 127-129.

Dobson, A.P., Bradshaw, A.D., BaKer, A.J.M. 1997. Hopes for the future: restoration ecology and conservation biology. Science 277: 515-521.

Dominik, T. 1951. Badanie mykotrofizmu roślinności wydm nadmorskich i śródlądowych. Acta Soc. Bot. Pol. 31: 125-164.

Dominik, T. 1961. Badania nad przeszczepianiem mikrobocenoz gleb leśnych na tereny rolne. Prace Instytutu Badawczego Leśnictwa 210: 103-159.

Dominik, T., Pachlewski, R. 1955. Badanie mykotrofizmu zespołów sosnowych w Łebie nad Bałtykiem. Rocz. Sekcji Dendrol. Polskiego Towarzystwa Botanicznego 10: 53-96.

Du, F., Shao, H.B., Shan, L., Liang, Z.S., Shao, M.A. 2007. Secondary succession and its effects on soil moisture and nutrition in abandoned old-fields of hilly region of Loess plateau, China. Colloid Surface B 58: $278-285$.

Dunabeitia, M., Rodriguez, N., Salcedo, I., Sarrionandia, E. 2004. Field mycorrhization and its influence on the establishment and development of the seedlings in a broadleaf plantation in the Basque Country. For. Ecol. Manag. 195: 129-139.

EGLER, F.E. 1954. Vegetation science concepts. I. Initial floristic composition - a factor in old-field vegetation development. Vegetatio 4: 412-417.

FALińsKA, K. 2003. Alternative pathways of succession: species turnover patterns in meadows abandoned for 30 years. Phytocoenosis 15 (N.S.), Archivum Geobot.

FALIŃSKI, J.B. 1977. Research on vegetation and plant population dynamics conducted by Białowieża Geobotanical Station of the Warsaw University in the Białowieża Primeval Forest and in the environ (1952-1977). Phytocoenosis 6, 1-2: 1-132.

FALIŃSKI, J.B. 1980a. Changes in the sex- and age-ratio in population of pioneer dioecious woody species (Juniperus, Populus, Salix) in connection with the course of vegetation succession in abandoned farmlands. Ekol. Pol. 28, 3: 327-365.

FALIŃSKI, J.B. 1980b. Vegetation dynamics and sex structure of the population of pioneer dioecious woody plants. Vegetatio 43: 23-28.

FALIŃSKI, J.B. 1986a. Vegetation dynamics in temperate lowland primeval forests. Ecological studies in Białowieża forest. Geobotany 8: 1-537. Dr W. Junk Publishers, Dordrecht/Boston/Lancaster.

FALIŃsKi, J.B. 1986b. Sukcesja roślinności na nieużytkach porolnych jako przejaw dynamiki ekosystemu wyzwolonego spod długotrwałej presji antropogenicznej. Cz. 1, 2. Wiad. Bot. 30, 1: 12-50, 30, 2: 115-126.

FAliński, J.B. 1987. Projektowany Rezerwat Jelonka w gm. Kleszczele, woj. Białystok. Białowieża. 32 pp. Mscr.

FALIŃSKI, J.B. 1990 (1991). Behaviour of the juniper population during secondary succession on abandoned farmland. In: J.B. FALIŃSKI (ed.), Vegetation processes as subject of geobotanical map. Proceedings of XXXIII Symposium of IAVS, Warsaw, April 8-12, 1990. Phytocoenosis 3 (N.S.), Suppl. Cartogr. Geobot. 2.

Faliński, J.B. 1992. Projektowany rezerwat leśny Czechy Orlańskie im. nadleśniczego inż. W. Fiedoruka (Ndl. Bielsk Podlaski. gm. Dubicze Cerkiewne, woj. Białystok), 7 pp. + nlb. Mscr. 
FALIŃSKI, J.B. 1996. Przeżywalność pionierskich gatunków drzewiastych po pożarze na torfowisku. Phytocoenosis 8 (N.S.), Seminarium Geobot. 4: 111-122.

FAlińsKi, J.B. 1998. Dioecious woody pioneer species (Juniperus communis, Populus tremula, Salix sp. div.) in the secondary succession and regeneration. Phytocoenosis 10 (N.S.), Suppl. Cartogr. Geobot. 8: 1-156.

FALiŃSKI, J.B. 2002. Białowieża Geobotanical Station of Warsaw University. Long-term studies. Bibliography. Data basis on the vegetation and environment: 1952-2002. Phytocoenosis 14 (N.S.), Suppl. Bibliogr. Geobot. 5: 1-200.

FAliński, J.B., Cieśliński, S., Czyżewska, K. 1993. Dynamic floristic atlas of Jelonka reserve and adjacent areas. Distribution of vascular plant species, bryophytes and lichens on the abandoned farmlands during secondary succession. Phytocoenosis 5 (N.S.), Suppl. Cartogr. Geobot. 3: 1-139.

Fellner, R. 1993. Air pollution and mycorrhizal fungi in central Europe. In: D.N. Pegler, L. Boddy, B. InG, P.M. KiRK (eds.), Fungi of Europe: Investigation, Recording and Conservation. Royal Botanic Gardens, Kew, 239-250.

Ferris, R., Peace, A.J., Newton, A.C. 2000. Macrofungal communities of lowland Scots pine (Pinus sylvestris L.) and Norway spruce (Picea abies (L.) Karsten.) plantations in England: relationships with site factors and stand structure. For. Ecol. Manag. 131: 255-267.

Fiore-Donno, A.M., Martin, F. 2001. Populations of ectomycorrhizal Laccaria amethystina and Xerocomus spp. show contrasting colonization patterns in a mixed forest. New Phytol. 152: 533-542.

Frankland, J.C. 1992. Mechanisms in fungal succession. In: G.C. Carroll, D.T. WiCKLow (eds.), The fungal community - its organization and role in the ecosystem. Marcel Dekker, New York, Basel, Hong Kong, 383-401.

FrankLAND, J.C. 1998. Fungal succession - unravelling the unpredictable. Mycol. Res. 102: 1-15.

FrIeDRICH, S. 2001. Macromycetes diversity of pine-tree plantings on a post-fire forest site in Notecka Forest (NW Poland). Acta Mycol. 36, 1: 127-148.

FrIEDRICH, S. 2008. Metody stosowane w badaniach grzybów wielkoowocnikowych (macromycetes). In: W. MuŁenko (ed.), Mykologiczne badania terenowe. Przewodnik metodyczny. Wyd. UMCS, Lublin, 30-47.

GÁPER, J., LIZOŇ, P. 1995. Sporocarp succession of mycorrhizal fungi in the Norway spruce plantations in formerly agricultural land. In: F. BALUšKA et al. (eds.), Structure and function of roots. Kluver Academic Publishers, the Netherlands, 349-352.

Gardes, M., Bruns, T.D. 1996. Community structure of ectomycorrhizal fungi in a Pinus muricata forest: above and below-ground views. Can. J. Bot. 74: 1572-1583.

Gebhardt, S., Neubert, K., Wöllecke, J., Münzenberger, B., Hüttl, R.F. 2007. Ectomycorrhiza communities of red oak (Quercus rubra L.) of different age in the Lusatian lignite mining district, east Germany. Mycorrhiza 17: 279-290.

GŁowACKI, Z. 1988. Zbiorowiska psammofilne klasy Sedo-Scleranthetea Wysoczyzny Siedleckiej i terenów przyległych na tle ich zasięgów. Wyższa Szkoła Rolniczo-Pedagogiczna, Siedlce. Rozpr. Nauk. 20: 1-122.

Grove, T.S., Le Tacon, F. 1993. Mycorrhiza in plantation forestry. Adv. Plant Pathol. 9: 191-228.

Guidot, A., Debaud, J.C., Marmeisse, R. 2001. Correspondence between genet diversity and spatial distribution of above- and below-ground populations of the ectomycorrhizal Hebeloma cylindrosporum. Mol. Ecol. 10: 1121-1131.

Guidot, A., Gryta, H., Gourbiere, F., Debaud, J.C., Marmeisse, R. 2002. Forest habitat characteristics affect balance between sexual reproduction and clonal propagation of the ectomycorrhizal mushroom Hebeloma cylindrosporum. Oikos 99: 25-36.

Hashimoto, Y., Hyakumachi, M. 2000. Quantities and types of ectomycorrhizal and endophytic fungi associated with Betula platyphylla var. japonica seedlings during the initial stage of establishment of vegetation after disturbance. Ecol. Res. 15: 21-31.

Hedlund, K. 2002. Soil microbial community structure in relation to vegetation management on former agricultural land. Soil Biol. Biochem. 34: 1299-1307.

Hedlund, K., Gormsen, D. 2002. Mycorrhizal colonisation of plants in set-aside agricultural land. Appl. Soil. Ecol. 19: 71-78.

Heijden van der, E.W., de Vries, F.W., Kuyper, Th.W. 1999. Mycorrhizal associations of Salix repens L. communities in succession of dunes ecosystems. I. Above-ground and below-ground views of ectomycorrhizal fungi in relation to soil chemistry. Can. J. Bot. 77: 1821-1832.

HeiJden VAn Der, E.W., VosatKa, M. 1999. Mycorrhizal associations of Salix repens L. communities in succession of dunes ecosystems. II. Mycorrhizal dynamics and interactions of ectomycorrhizal and arbuscular mycorrhizal fungi. Can. J. Bot. 77: 1833-1841.

Heijden van der, M.G.A., Klironomos, J.N., Ursic, M., Moutoglis, P., Streitwolf-Engel, R., Boller, T., WiEMKEN, A., SANDERs, I.R. 1998. Mycorrhizal fungal diversity determines plant biodiversity, ecosystem variability and productivity. Nature 396: 69-72. 
Helm, D.J., Allen, E.B., Trappe, J.M. 1996. Mycorrhizal chronosequence near Exit Glacier, Alaska. Can. J. Bot. 74: 1496-1506.

Helm, D.J., Allen, E.B., Trappe, J.M. 1999. Plant growth and ectomycorrhiza formation by transplants on deglaciated land near Exit Glacier, Alaska. Mycorrhiza 8: 297-304.

HintikKA, V. 1988. On the macromycete flora in oligotrophic pine forests of different ages in South Finland. Acta Bot. Fenn. 136: 89-94.

Hirose, D., Kikuchi, J., KanzaKi, N., Futai, K. 2004. Genet distribution of sporocarps and ectomycorrhizas of Suillus pictus in a Japanese white pine plantation. New Phytol. 164: 527-541.

Horton, T.R., CÁzares, E., Bruns, T.D. 1998. Ectomycorrhizal, vesicular-arbuscular and dark septate fungal colonization of bishop pine (Pinus muricata) seedlings in the first 5 months of growth after wildfire. Mycorrhiza 8: 11-18.

Högberg, P., Nordgren, A., Buchmann, N., Taylor, A.F.S., Ekblad, A., Högberg, M.N., Nyberg, G., Ottosson, L.M., READ, D.J. 2001. Large-scale forest girdling shows that current photosynthesis drives soil respiration. Nature 411: 789-792.

Høiland, K., Bendiksen, E. 1996. Biodiversity of wood-inhabiting fungi in boreal coniferous forest in Sör-Tröndelag County, Central Norway. Nord. J. Bot. 16: 643-659.

Jansen, A.E. 1984. Vegetation and macrofungi in acid oakwoods in the Northeast of the Netherlands. Agricult. Research Reports 923. Pudoc, Wageningen, 1-162.

Jansen, A.E. 1991. The mycorrhizal status of Douglas fir in the Netherlands: its relations with stand age, regional factors, atmospheric pollutants and tree vitality. Agric. Ecosyst. Environ. 35: 191-208.

Johnson, E.A., Mryanishi, K. 2008. Testing the assumptions of chronosequences in succession. Ecol. Lett. 11: 419-431.

Johnson, N.C., ZaK, D.R., Tilman, D., Pfleger, F.L. 1991. Dynamics of vesicular-arbuscular mycorrhizae during old field succession. Oecologia 86, 3: 349-358.

Józefaciukowa, W., Dobrowolska, D., FARFAŁ, D. 1995. Ilościowa i jakościowa ocena korzeni drobnych sosny zwyczajnej w gradiencie skażenia środowiska leśnego. Prace Instytutu Badawczego Leśnictwa, Ser. B 24: 47-61.

Jumpronen, A. 2003. Soil fungal community assembly in a primary successional glacier forefront ecosystem as inferred from rDNA sequence analyses. New Phytol. 158: 569-578.

Jumpronen, A., Trappe, J.M., CÁzAres, E. 1999. Ectomycorrhizal fungi in Lyman Lake Basin: a comparison between primary and secondary successional sites. Mycologia 91: 575-582.

Jumpronen, A., Trappe, J.M., CÁZAREs, E. 2002. Occurrence of ectomycorrhizal fungi on the forefront of retreating Lyman Glacier (Washington, USA) in relation to time since deglaciation. Mycorrhiza 12: 43-49.

KAŁUCKA I. 2008. Analiza ilościowa zbiorowisk grzybów makroskopowych na podstawie obserwacji owocników. In: W. MuŁenko (ed.), Mykologiczne badania terenowe. Przewodnik metodyczny. Wyd. UMCS, Lublin, 76-98.

KaŁucka, I., Sumorok, B. 1996. Makromycetes w zbiorowiskach roślinnych podlegających sukcesji wtórnej nie zaburzonej i zaburzonej pożarem na gruntach porolnych w rezerwacie Jelonka (Polska NE). Phytocoenosis 8 (N.S.), Seminarium Geobot. 4: 123-136.

Keever, C. 1983. A retrospective view of old-field succession after 35 years. Am. Midland Nat. 110: $397-404$.

KEIZER, P.-J. 1993a. Mycocoenology of roadside verges planted with beech trees (Fagus sylvatica L.) in Drenthe, the Netherlands. In: P.-J. KeIZER, The ecology of macromycetes in roadside verges planed with trees. Wageningen, Landbouwuniversiteit Wageningen, 19-48.

KeIZER, P.-J. 1993b. A comparison of the macromycetes occurring in roadside verges planted with common oak (Quercus robur L.) and with beech (Fagus sylvatica L.). In: P.-J. KeIZER, The ecology of macromycetes in roadside verges planed with trees. Wageningen, Landbouwuniversiteit Wageningen, 81-99.

Keizer, P.J., Arnolds, E. 1994. Succession of ectomycorrhizal fungi in roadside verges planted with common oak (Quercus robur L.) in Drenthe, the Netherlands. Mycorrhiza 4: 147-159.

Kirk, P.M., Cannon, P.F., Minter, D.W., Stalpers, J.A. 2008. Dictionary of the Fungi. 10 ${ }^{\text {th }}$ Edition. CABI Europe - UK. Cromwell Press, Trowbridge.

Klamer, M., Hedlund, K. 2004. Fungal diversity in set-aside agricultural soil investigated using terminal-restriction fragment length polymorphism. Soil Biol. Biochem. 36: 983-988.

Knudsen, H., Vesterholt, J. (eds.). 2008. Funga Nordica. Agaricoid, boletoid and cyphelloid genera. Nordsvamp, Copenhagen, $965 \mathrm{pp}$.

KondratiuK, M. 1974. Nazwy miejscowe południowo-wschodniej Białostocczyzny. Monogr. Slaw. 29: 1-304.

Kranabetter, J.M., Friesen, J., Gamiet, S., Kroeger, P. 2005. Ectomycorrhizal mushroom distribution by stand age in western hemlock - lodgepole pine forests of northwestern British Columbia. Can. J. For. Res. 35: 15271539. 
KreBS, C.J. 2001. Ecology. The experimental analysis of distribution and abundance. $5^{\text {th }}$ Edition. Addison-Wesley Longman, London.

Kropp, B.R., Langlois, C.G. 1990. Ectomycorrhizae in reforestation. Can. J. For. Res. 20: 432-451.

Last, F.T., Dighton, J., Mason, P.A. 1987. Succession of sheathing mycorrhizal fungi. Trends Ecol. Evol. 2: 157-161.

Legon, N.W., Henrici, A., Roberts, P.J., Spooner, B.M., Watuing, R. 2009. Checklist of the British and Irish Basidiomycota. $4^{\text {th }}$ update of the printed version published 2005. http://www.basidiochecklist.info/ .

LePš, J., ReJMÁNEK, M. 1991. Convergence or divergence: what should we expect from vegetation succession? Oikos 62: 261-264.

LINDBLAD, I. 1998. Wood-inhabiting fungi on fallen logs in Norway spruce: relation to forest management and substrate quality. Nord. J. Bot. 18: 243-255.

LisıewSKA, M. 1965. Udział grzybów wyższych w grądach Wielkopolski. Acta Mycol. 1: 169-271.

Lisıewska, M. 1978. Macromycetes na tle zespołów leśnych Świętokrzyskiego Parku Narodowego. Acta Mycol. 14, 1-2: 163-191.

LisieWSKA, M. 1992. Macrofungi on special substrates. In: W. Winterhoff (ed.), Fungi in Vegetation Science. Kluwer Academic Publishers, the Netherlands, 151-182.

Lisiewska, M. 1997a. Fungi. Boletales. In: J.B. Faliński, W. MuŁenko (eds.), Cryptogamous plants in the forest communities of Białowieża National Park. Ecological atlas (Project CRYPTO 4). Phytocoenosis 9 (N.S.), Suppl. Cartogr. Geobot. 7: 300-303.

Lisiewska, M. 1997b. Fungi. Dacrymycetales. In: J.B. FaLiński, W. MuŁenko (eds.), Cryptogamous plants in the forest communities of Białowieża National Park. Ecological atlas (Project CRYPTO 4). Phytocoenosis 9 (N.S.), Suppl. Cartogr. Geobot. 7: 425.

LisiewsKa, M. 1997c. Fungi. Tremellales. In: J.B. Faliński, W. MuŁenko (eds.), Cryptogamous plants in the forest communities of Białowieża National Park. Ecological atlas (Project CRYPTO 4). Phytocoenosis 9 (N.S.), Suppl. Cartogr. Geobot. 7: 426.

Lisiewska, M. 1997d. Fungi. Auriculariales. In: J.B. Faliński, W. MuŁenko (eds.), Cryptogamous plants in the forest communities of Białowieża National Park. Ecological atlas (Project CRYPTO 4). Phytocoenosis 9 (N.S.), Suppl. Cartogr. Geobot. 7: 427.

LISIEWSKA, M., SiEDLACZEK, S. 1982. Wstępne badania nad występowaniem grzybów kapeluszowych na zwałowisku górniczym „Smolnica“. Archiwum Ochrony Środowiska 1-4: 93-110.

Londo, G. 1975. Dezimalskala für die Vegetationskundliche Aufnahme von Dauerguadraten. In: W. SchmidT (ed.), Sukcessionsforschung. Bericht. Intern. Vereingung Veget., Rinteln, 613-617.

MARTYN, D. 1995. Klimaty kuli ziemskiej. Wyd. II. PWN, Warszawa.

Marx, D.H., Marrs, L.F., Cordell, C.E. 2002. Practical use of mycorrhizal fungal technology in forestry, reclamation, arboriculture, agriculture and horticulture. Dendrobiology 47: 29-42.

Mason, P.A., Last, F.T., Pelham, J., Ingleby, K. 1982. Ecology of fungi associated with an ageing stand of birches (Betula pendula and B. pubescens). For. Ecol. Manag. 4: 19-39.

Mason, P.A., Wilson, J., LAST, F.T. 1983. The concept of succession in relation to the spread of sheathing mycorrhizal fungi in inoculated tree seedlings growing in unsterile soils. Plant Soil 71: 247-256.

Menkis, A., Vasiliauskas, R., Taylor, A.F.S., Stenlid, J., Finlay, R. 2007. Afforestation of abandoned farmland with conifer seedlings inoculated with three ectomycorrhizal fungi - impact on plant performance and ectomycorrhizal community. Mycorrhiza 17: 337-348.

Meyer, F.H. 1987. Der Verzweigungsindex einer Indikator für Schaden am Feinwurzelsystem. Forstw. Cbl., H 2: 84-92.

MiHÁL, I. 1999. Production of fruiting bodies of ectomycorrhizal fungi in spruce monocultures planted on former arable land. Ekológia (Bratislava) 18, 2: 125-133.

Mikola, P., Hahl, J., Torniainen, E. 1966. Vertical distribution of mycorrhizae in pine forests with spruce undergrowth. Acta Bot. Fen. 3: 406-409.

Mirek, Z., Piękoś-Mirkowa, H., Zają̧, A., Zając, M. (eds.). 2002. Flowering plants and pteridophytes of Poland. A checklist. In: Z. Mirek (ed.), Biodiversity of Poland 1. W. Szafer Institute of Botany, Polish Academy of Sciences, Kraków, 442 pp.

MoJski, J.E. 1972. Nizina Podlaska. In: R. GALon (ed.), Gemorfologia Polski. T. 2. Niż Polski, 318-362.

Molina, R., Massicotte, H., Trappe, J.M. 1992. Specificity phenomena in mycorrhizal symbioses: community ecological consequences and practical application. In: M.F. AlLEN (ed.), Mycorrhizal functioning: an integrative plant-fungal process. Chapman and Hall, New York, 357-423.

Morin, C, Samson, J., Dessureault, M. 1999. Protection of black spruce seedlings against Cylindrocladium root rot with ectomycorrhizal fungi. Can. J. Bot. 77: 169-174. 
Mühlmann, O., Peintner, U. 2008. Mycobionts of Salix herbacea on a glacier forefront in the Austrian Alps. Mycorrhiza 18: 171-180.

NARA, K. 2006. Pioneer dwarf willow may facilitate tree succession by providing late colonizers with compatible ectomycorrhizal fungi in a primary successional volcanic desert. New Phytol. 171: 187-198.

NARA, K., NAKaYa, H., Hogetsu, T. 2003a. Ectomycorrhizal sporocarp succession and production during early primary succession on Mount Fuji. New Phytol. 158: 193-206.

Nara, K., Nakaya, H., Wu, B.Y., Zhou, Z.H., Hogetsu, T. 2003b. Underground primary succession of ectomycorrhizal fungi in a volcanic desert on Mount Fuji. New Phytol. 159: 743-756.

Natarajan, K., Mohan, V., Ingleby, K. 1992. Correlation between basidiomata production and ectomycorrhizal formation in Pinus patula plantations. Soil Biol. Biochem. 24: 279-280.

Nespiak, A. 1959. Studia nad udziałem grzybów kapeluszowych w zespołach leśnych na terenie Białowieskiego Parku Narodowego. Monogr. Bot. 8: 1-141.

Nespiak, A. 1975. Flora Polska, Grzyby (Mycota) 8. Basidiomycetes, Agaricales, Cortinariaceae, Cortinarius (1). Warszawa-Kraków, 276 pp.

Nordén, B., Ryberg, M., Götmark, F., Olausson, B. 2004. Relative importance of coarse and fine woody debris for the diversity of wood-inhabiting fungi in temperate broadleaf forests. Biol. Conserv. 117: 1-10.

Obase, K., Tamai, Y., Yajima, T., Miyamoto, T. 2007. Mycorrhizal associations in woody species at the Mt. Usu volcano, Japan. Mycorrhiza 17: 209-215.

Ochyra, R., Żarnowiec, J., Bednarek-Ochyra, H. 2003. Census catalogue of Polish mosses. In: Z. Mirek (ed.), Biodiversity of Poland 3. W. Szafer Institute of Botany, Polish Academy of Sciences, Kraków, 372 pp.

Oleksyy, J., Reich, P.B., Chalupka, W., TJoelker, M.G. 1999. Differential above- and below-ground biomass accumulation of European Pinus sylvestris populations in a 12-year-old provenance experiment. Scand. J. For. Res. 14: 7-17.

Ortega, U., Dunabeitia, M., Menendez, S., Gonzalez-Murua, C., Majada, J. 2004. Effectiveness of mycorrhizal inoculation in the nursery on growth and water relations of Pinus radiata in different water regimes. Tree Physiol. 24: 65-73.

Osono, T., TAKedA, H. 2001. Organic chemical and nutrient dynamics in decomposing beech leaf litter in relation to fungal ingrowth and succession during three year decomposition processes in a cool temperate deciduous forest in Japan. Ecol. Res. 16: 649-670.

Osono, T., Hirose, D., Fujimaki, R. 2006. Fungal colonization as affected by litter depth and decomposition stage of needle litter. Soil Biol. Biochem. 38: 2743-2752.

Park, D. 1968. The ecology of terrestrial fungi. In: G.C. Ainsworth, A.S. Sussman (eds.), The Fungi. $3^{\text {rd }}$ Edition. Academic Press, London, 5-39.

Perry, A.D., Molina, R., Amaranthus, P.M. 1987. Mycorrhizae, mycorrhizospheres, and reforestation: current knowledge and research needs. Can. J. For. Res. 17: 929-940.

Persson, H. 1983. The distribution and productivity of fine roots in boreal forests. Plant Soil 71: 87-101.

Pickett, S.T.A., Collins, S.L., Armesto, J.J. 1987. A hierarchical consideration of causes and mechanisms of succession. Vegetatio 69: 109-114.

PIóRo, S.J. 1973. Klimat województwa białostockiego. Wojewódzkie Biuro Geodezji i Urządzeń Rolnych, Białystok.

Plan Urządzenia Gospodarstwa Leśnego Nadleśnictwa Bielsk, Obręb Kleszczele na okres 1.01.1989-31.12.1998. Okręgowy Zarząd Lasów Państwowych w Białymstoku, Białystok.

Plan Urządzenia Rezerwatu Przyrody „Jelonka” na okres 1.01.1991-31.12.2000. Okręgowy Zarząd Lasów Państwowych w Białymstoku, Białystok.

Putten van der, W.H., Mortimer, S.R., Hedlund, K., van Dijk, C., Brown, V.K., Lepš, J., Rodriguez-Barrueco, C., Roy, J., Diaz Len, T.A., Gormsen, D., Korthals, G.W., Lavorel, S., Santa Regina, I. Smilauer, P. 2000. Plant species diversity as a driver of early succession in abandoned fields: a multi-site approach. Oecologia 124: 91-99.

RaYner, A.D.M. 1992. Introduction. In: G.C. CARroll, D.T. Wicklow (eds.), The fungal community - its organization and role in the ecosystem. Marcel Dekker, New York, Basel, Hong Kong, xvii-xxiv.

Rayner, A.D.M., TodD, N.K. 1979. Population and community structure and dynamics of fungi in decaying wood. Adv. Bot. Res. 7: 333-420.

Redecker, D., Szaro, T.M., Bowman, R.J., Bruns, T.D. 2001. Small genets of Lactarius xanthogalactus, Russula cremoricolor and Amanita francheti in late-stage ectomycorrhizal successions. Mol. Ecol. 10: 1025-1034.

Reeves, F.B., Wagner, D., Moorman, T., Kiel, J. 1979. The role of endomycorrhizae in revegetation practices in the semi-arid west. I. A comparison of incidence of mycorrhizae in severely disturbed vs. natural environments. Amer. J. Bot. 66: 6-13. 
Renvall, P. 1995. Community structure and dynamics of wood-rotting basidiomycetes on decomposing conifer trunks in northern Finland. Karstenia 35: 1-51.

RICEK, E.W. 1981. Die Pilzgesellschaften heranwachsender Fichtenbestände auf ehemaligen Wiesenflächen. Z. Mykol. 47: 123-148.

Richardson, M.J. 1970. Studies of Russula emetica and other agarics in a Scots pine plantation. Trans. Brit. Mycol. Soc. 55: 217-229.

Richter, B.S., Tiller, R.L., Stutz, J.C. 2002. Assessment of arbuscular mycorrhizal fungal propagules and colonization from abandoned agricultural fields and semi-arid grasslands in riparian floodplains. Appl. Soil Ecol. 20: 227-238.

Richter, D.L., BRuhn, J.N. 1993. Mycorrhizal fungus colonization of Pinus resinosa Ait. transplanted on northern hardwood clearcuts. Soil Biol. Biochem. 25: 355-369.

Rincón, A., de Felipe, M.R., Fernández-Pascual, M. 2007. Inoculation of Pinus halepensis Mill. with selected ectomycorrhizal fungi improves seedlings establishment 2 years after planting in a degraded gypsum soil. Mycorrhiza 18: 23-32.

Rosling, A., LANDEweErt, R., Lindahl, B.D. 2003. Vertical distribution of ectomycorrhizal fungal taxa in a podzol soil profile. New Phytol. 159: 775-783.

RÜLING, A., Tyler, G. 1990. Soil factors influencing the distribution of macrofungi in oak forests of southern Sweden. Holarctic Ecol. 13: 11-18.

Santesson, R., Moberg, R., Nordin, A., Tønsberg, T., Vitikainen, O. 2004. Lichen-forming and lichenicolous fungi of Fennoscandia. Museum of Evolution, Uppsala University.

SÅstAD, S.M. 1995. Fungi-vegetation relationships in a Pinus sylvestris forest in central Norway. Can. J. Bot. 73: 807-816.

Sawyer, N.A., Chambers, S.M., Cairney, J.W.G. 2001. Distribution and persistence of Amanita muscaria genotypes in Australian Pinus radiata plantations. Mycol. Res. 105: 966-970.

Schmit, J.P., Mueller, G.M., Leacock, P.R., Mata, J.L., Wu, Q.(F.), Huang, Y. 2005. Assessment of tree species richness as a surrogate for macrofungal species richness. Biol. Conserv. 121: 99-110.

Schmitt, J.A. 1991. Present status and causes of decline of the fungus flora in west Germany, especially Saarland. In: A.E. Jansen, M. Ławrynowicz (eds.), Conservation of fungi and other cryptogamous plants in Europe. Łódź Society of Sciences and Arts, Łódź, 30-41.

Senn-Irlet, B., Bieri, G. 1999. Sporocarp succession of soil-inhabiting macrofungi in an autochthonous subalpine Norway spruce forest of Switzerland. For. Ecol. Manag. 124: 169-175.

Sierota, Z. 1996. Zagrożenie drzewostanów na gruntach porolnych przez patogeny grzybowe. Sylwan XCL, 12: $5-15$.

Simard, S.W., Durall, D.M. 2004. Mycorrhizal networks: a review of their extent, function, and importance. Can. J. Bot. 82: 1140-1165.

Simard, S.W., Sachs, D.L., Vyse, A., Blevins, L.L. 2004. Paper birch competitive effects vary with conifer tree species and stand age in interior British Columbia forests: implications for reforestation policy and practice. For. Ecol. Manag. 198: 55-74.

SkirgieŁŁo, A. 1997a. Fungi. Aphyllophorales. In: J.B. FAliński, W. MuŁenko (eds.), Cryptogamous plants in the forest communities of Białowieża National Park. Ecological atlas (Project CRYPTO 4). Phytocoenosis 9 (N.S.), Suppl. Cartogr. Geobot. 7: 275-300.

SkirgieŁŁo, A. 1997b. Fungi. Russulales. In: J.B. Faliński, W. MuŁenko (eds.), Cryptogamous plants in the forest communities of Białowieża National Park. Ecological atlas (Project CRYPTO 4). Phytocoenosis 9 (N.S.), Suppl. Cartogr. Geobot. 7: 408-421.

SkirgieŁŁo, A. 1997c. Fungi. Lycoperdales. In: J.B. FAliński, W. MuŁenKo (eds.), Cryptogamous plants in the forest communities of Białowieża National Park. Ecological atlas (Project CRYPTO 4). Phytocoenosis 9 (N.S.), Suppl. Cartogr. Geobot. 7: 421-423.

SkirgieŁŁo, A. 1997d. Fungi. Sclerodermatales. In: J.B. Faliński, W. MuŁenko (eds.), Cryptogamous plants in the forest communities of Białowieża National Park. Ecological atlas (Project CRYPTO 4). Phytocoenosis 9 (N.S.), Suppl. Cartogr. Geobot. 7: 423.

SkirgieŁŁo, A. 1997e. Fungi. Nidulariales. In: J.B. FAliński, W. MuŁenKo (eds.), Cryptogamous plants in the forest communities of Białowieża National Park. Ecological atlas (Project CRYPTO 4). Phytocoenosis 9 (N.S.), Suppl. Cartogr. Geobot. 7: 424.

SkirgieŁŁo, A. 1997f. Fungi. Phallales. In: J.B. Faliński, W. MuŁenko (eds.), Cryptogamous plants in the forest communities of Białowieża National Park. Ecological atlas (Project CRYPTO 4). Phytocoenosis 9 (N.S.), Suppl. Cartogr. Geobot. 7: 424. 
Smith, J.E., Molina, R., Huso, M.M.P., Luoma, D.L., McKay, D., Castellano, M.A., Lebel, T., Valachovic, Y. 2002. Species richness, abundance, and composition of hypogeous and epigeous ectomycorrhizal fungal sporocarps in young, rotation age, and old-growth stands of Douglas-fir (Pseudotsuga menziesii) in the Cascade Range of Oregon, U.S.A. Can. J. Bot. 80: 186-204.

Smith, S.E., Read, D. 2008. Mycorrhizal Symbiosis. $3^{\text {rd }}$ Edition. Academic Press, Elsevier, Amsterdam, Boston, Heidelberg, London, New York, Oxford, Paris, San Diego, San Francisco, Singapore, Sydney, Tokyo.

SmykaŁa, J. 1990. Historia, rozmiar i rozmieszczenie zalesień gruntów porolnych w Polsce w latach 1945-1987. Sylwan CXXXIV, 3-12: 1-7

SoBCZAK, R. 1990. Teoretyczne i praktyczne aspekty zakładania upraw i prowadzenia drzewostanów na gruntach porolnych. Sylwan CXXXIV, 3-12: 61-73.

Stoate, C., Báldi, A., Beja, P., Boatman, N.D., Herzon, I., van Doorn, A., De Snoo, G.R., Rakosy, L., Ramwell, C. 2009. Ecological impacts of early $21^{\text {st }}$ century agricultural change in Europe - a review. J. Environ. Manag. 91: 22-46.

Stober, C., George, E., Persson, H. 2000. Root growth and response to nitrogen. In: Carbon and nitrogen cycling in European forest ecosystems. Ecol. Stud. 142, 99-121.

Strong, W.L., La RoI, G.H. 1983. Rooting depths and successional development of selected boreal forest communities. Can. J. For. Res. 13: 577-588.

Sumorok, B. 2001. Post-fire macrofungi in the burnt area in the Jelonka reserve (Białowieża region, NE Poland). Acta Mycol. 36, 1: 149-158.

Symonides, E. 1986. Seed bank in old-field successional ecosystems. Ekol. Pol. 34, 1: 3-29.

SzUJECKI, A. 1990. Ekologiczne aspekty odtwarzania ekosystemów leśnych na gruntach porolnych. Sylwan CXXXIV, 3-12: 23-40.

Tacon Le, F., Alvarez, I.F., Bouchard, D., Henrion, B., Jackson, M.R., Luff, S., Parlade, J.I., Pera, J., StenSTRÖM, E., VillLeneuve, N., WALKER, C. 1994. Variations in field response of forest trees to nursery ectomycorrhizal inoculation in Europe. In: D.J. Read, D.H. Lewis, A.H. FitTer, I.J. AleXAnder (eds.), Mycorrhizas in ecosystems. CAB International, Wallingford, 119-134.

Tennant, D. 1975. A test of modified line intersect method of estimating root length. J. Ecol. 63: 995-1001.

Termorshuizen, A.J. 1991. Succession of mycorrhizal fungi in stands of Pinus sylvestris in the Netherlands. J. Veg. Sci. 2: 555-564.

Termorshuizen, A.J., Schaffers, A.P. 1991. The decline of carpophores of ectomycorrhizal fungi in stands of Pinus sylvestris L. in the Netherlands: possible causes. Nova Hedwigia 53: 267-289.

Teste, F.P., Simard, S.W., Durall, D.M., Guy, R.D., Jones, M.D., Schoonmaker, L. 2009. Access to mycorrhizal networks and roots of trees: importance to seedling survival and resource transfer. Ecology 90: 2808-2822.

THIET, R.K., BoERNER, R.E.J. 2007. Spatial patterns of ectomycorrhizal fungal inoculum in arbuscular mycorrhizal barrens communities: implications for controlling invasion by Pinus virginiana. Mycorrhiza 17: 507-517.

TRAPPE, J.M. 1962. Fungus associates of ectotrophic mycorrhizae. Bot. Rev. 28: 538-606.

Trappe, J.M., Luoma, D.L. 1992. The ties that bind: fungi in ecosystems. In: G.C. CARroll, D.T. WickLow (eds.), The fungal community - its organization and role in the ecosystem. Marcel Dekker, New York, Basel, Hong Kong, 17-27.

Trichelen van, K.K., Colpaert, J.V., Vangronsveld, J. 2001. Ectomycorrhizal protection of Pinus sylvestris against copper toxicity. New Phytol. 150: 203-213.

Trofymow, J.A., Addison, J.., Blackwell, B.A., He, F., Preston, C.A., Marshall, V.G. 2003. Attributes and indicators of old-growth and successional Douglas-fir forests on Vancouver Island. Environ. Rev. 11: 187-204.

Twieg, B.D., Durall, D.M., Simard, S.W. 2007. Ectomycorrhizal fungal succession in mixed temperate forests. New Phytol. 176: 437-447.

TYLER, G. 1989. Edaphical distribution and sporophore dynamics of macrofungi in hornbeam (Carpinus betulus L.) stands of south Sweden. Nova Hedwigia 49: 239-253.

UrCelay, C., Robledo, G. 2009. Positive relationship between wood size and basidiocarp production of polypore fungi in Alnus acuminata forest. Fungal Ecol. 2: 135-139.

Villeneuve, N., Grandtner, M.M., Fortin, J.A. 1989. Frequency and diversity of ectomycorrhizal and saprophytic macrofungi in the Laurentide Mountains of Quebec. Can. J. Bot. 67: 2616-2629.

VISSER, S. 1995. Ectomycorrhizal fungal succession in jack pine stands following wildfire. New Phytol. 129: 389-401.

Vogt, K.A., Edmunds, R.L., Grier, C.C. 1981. Biomass and nutrient concentrations of sporocarps produced by mycorrhizal and decomposer fungi in Abies amabilis stands. Oecologia 50: 170-175.

Vogt, K.A., Bloomfield, J., Ammirati, J.F., Ammirati, S.R. 1992. Sporocarp production by basidiomycetes, with emphasis on forest ecosystems. In: G.C. CARROLL, D.T. WiCKLOw (eds.), The fungal community - its organization and role in the ecosystem. Marcel Dekker, New York, Basel, Hong Kong, 563-581. 
Vogt, K.A., Moore, E.E., Vogt, D.J., Redlin, M.J., Edmonds, R.L. 1983. Conifer fine root and mycorrhizal root biomass within the forest floors of Douglas-fir stand of different ages and site productivities. Can. J. For. Res. 13: 429-437.

Vries de, B.W.L., Jansen, E., van Dobben, H.F., Kuyper, Th.W. 1995. Partial restoration of fungal and plant species diversity by removal of litter and humus layers in stands of Scots pine in the Netherlands. Biodivers. Conserv. 4: 156-164.

Wallander, H., Nilsson, L.O., Hagerberg, D., BaAth, E. 2001. Estimation of the biomass and seasonal growth of external mycelium of ectomycorrhizal fungi in the field. New Phytol. 151: 753-760.

WatLing, R. 1995. Assessment of fungal diversity: macromycetes, the problems. Can. J. Bot. 73: 15-24.

WIEMKEN, V., BOLLER, T. 2006. Delayed succession from alpine grassland to savannah with upright pine: limitation by ectomycorrhiza formation? For. Ecol. Manag. 237: 492-502.

WiŚNIEwSKI, J. 1964. Rozwój osadnictwa na pograniczu polsko-litewskim od końca XIV do połowy XVII w. Acta Baltico-Slavica 1: 115-135.

WoJewoda, W. 2003. Checklist of Polish larger Basidiomycetes. In: Z. Mirek (ed.), Biodiversity of Poland 7. W. Szafer Institute of Botany, Polish Academy of Sciences, Kraków, 812 pp.

WoJEwoda, W., ŁaWrYNowicz, M. 1992. Czerwona lista grzybów wielkoowocnikowych zagrożonych w Polsce. In: K. Zarzycki, W. Wojewoda, Z. Heinrich (eds.), Lista roślin zagrożonych w Polsce (wyd. 2). Instytut Botaniki im. W. Szafera, Polska Akademia Nauk, Kraków, 27-56.

Wojewoda, W., Ławrynowicz, M. 2006. Red list of the macrofungi in Poland. In: Z. MireK, K. Zarzycki, W. Wojewoda, Z. Szelą (eds.), Red list of plants and fungi in Poland. W. Szafer Institute of Botany, Polish Academy of Sciences, Kraków, 53-70.

ZAK, J.C., Willig, M.R. 2004. Fungal biodiversity patterns. In: G.M. Mueller, G.F. Bills, M.S. Foster (eds.), Biodiversity of Fungi. Inventory and Monitoring Methods. Elsevier Academic Press, Amsterdam, Boston, Heidelberg, London, New York, Oxford, Paris, San Diego, San Francisco, Singapore, Sydney, Tokyo, 59-75.

Zhou, Z., Miwa, M., Matsuda, Y., Hogetsu, T. 2001. Spatial distribution of the subterranean mycelia and ectomycorrhizae of Suillus grevillei genets. J. Plant Res. 114: 179-185.

Żarnowiec, J., Klama, H., Bujakiewicz, A., MuŁenko, W. 1996. Epigeits and their role in the differentiation of terricolous habitats. In: J.B. FALIŃSKI, W. MuŁENKo (eds.), Cryptogamous plants in the forest communities of Białowieża National Park. Functional groups analysis and general synthesis (Project CRYPTO 3). Phytocoenosis 8 (N. S.), Archiv. Geobot. 6: 119-131.

Dr. Izabela Kałucka

Department of Mycology

University of Łódź

Banacha 12/16

PL-90-237 Łódź

ikalucka@biol.uni.lodz.pl 


\section{Appendix 1}

\section{Soil analysis in the permanent plots}

\section{Descriptions of the soil profiles}

Phases 2-8 - Jelonka reserve, post-arable rusty soil. Phase 9/10 - Czechy Orlańskie reserve, podzolic soil developing on post-arable rusty soil. Soil profiles down to ca $60 \mathrm{~cm}$.

\section{Initial stage:}

Phase 2 - plot 82

Ap $\quad 0-31 \mathrm{~cm}$

Bv $\quad>31 \mathrm{~cm}$

Phase $4-$ plot 84

Ap $\quad 0-28 \mathrm{~cm}$

Bv 28-68 cm

\section{Optimal stage:}

Phase 5 - plot 61

Ap $\quad 0-24 \mathrm{~cm}$

Bv $\quad>24 \mathrm{~cm}$

Phase 5/6 - plot 13

Ap $\quad 0-25 \mathrm{~cm}$

$\mathrm{Bv} \quad>25 \mathrm{~cm}$

Phase 6 - plot 1

Ap $\quad 0-30 \mathrm{~cm}$

Bv $\quad 30-54 \mathrm{~cm}$

Phase 6-plot 6

Ap $\quad 0-20 \mathrm{~cm}$

$\mathrm{Bv} \quad>20 \mathrm{~cm}$
Plough humous horizon with abrupt boundary; loamy sand, dark brown, with stones of a few centimetres in diam. at places. Earthworms present.

Sand of rusty brown colour with considerable amount of gravel and stones.

Plough humous horizon with abrupt boundary; loamy sand of dark brown grey colour, solitary stones at places. Concentration of root biomass.

Loamy sand of light brown colour with considerable amount of gravel and stones of a few centimetres in diam.

Plough humous horizon with abrupt wavy boundary; loamy sand of dark grey colour. Concentration of root biomass.

Loamy sand of pale yellowish colour. Considerable amount of stones distributed at the depth of ca $40 \mathrm{~cm}$.

Plough humous horizon with abrupt boundary; loamy sand of dark grey colour. Concentration of root biomass.

Loamy sand of pale yellowish colour. Considerable amount of stones distributed at the depth of ca $50 \mathrm{~cm}$.

Plough humous horizon; loamy sand of brown grey colour, intensely overgrown with plant roots. The layer of stones of a few to several centimetres in diam. present in the contact zone with horizon Bv.

Loamy sand, rusty yellow. Layers of loamy sand of rusty colour at places. Solitary stones of a few centimeters in diam. in the whole horizon. Roots evenly distributed.

Plough humous horizon with abrupt boundary; weakly loamy sand of dark grey colour, overgrown with roots.

Sand of rusty grey yellow colour, with relatively few tree roots at places. Humic wedges after roots decay. 
Terminal stage:

Phase 8 - plot 16

Ol $\quad 1-0 \mathrm{~cm}$

A

$0-1.5 \mathrm{~cm}$

Ap

$1.5-25 \mathrm{~cm}$

Bv

$25-53 \mathrm{~cm}$

$\mathrm{Bv} / \mathrm{C}$

$>58 \mathrm{~cm}$

Phase 9/10 - plot 6C

Ol $\quad 6-5 \mathrm{~cm}$

Of $\quad 5-2 \mathrm{~cm}$

$\begin{array}{ll}\text { Oh } & 2-0 \mathrm{~cm} \\ \text { AEes } & 0-1.5 \mathrm{~cm}\end{array}$

Bfe $\quad 1.5-20 \mathrm{~cm}$

Ap 20-35 cm

$\mathrm{Bv} \quad>35 \mathrm{~cm}$
Litter horizon consisting of leaves of aspen and birch, juniper needles, solitary pine needles and dead grass, loose. Differentiation into the horizons of $\mathrm{Ol}$ and Of can be seen at places.

Humus horizon of initial mull type or initial moder in hollows; weakly loamy sand of black grey colour, intensely overgrown with mycelium and roots. In the places where pine or spruce grow, solitary bleached quartz grains are present (initiation of the podzolization process).

Plough humous horizon with abrupt boundary; loamy sand of grey brown colour, overgrown with roots of herbaceous plants and trees.

Loamy sand of yellow rusty colour, rusty at places, with solitary roots of trees. Irregular lower boundary.

Sand of yellow colour with clay layers of rusty colour.

Litter horizon consisting of pine needles, pieces of bark and fallen twigs.

Fermentation horizon; the material partly fragmented, the structure partly preserved. Mainly pine needles and twigs, overgrown with mycelium and roots.

Epihumus with solitary bleached quartz grains. Humus type - mor.

Eluvial horizon; sand of light pale colour, with bleached quartz grains prevailing. Sparse roots present.

Illuvial horizon (with iron); sand of rusty colour, gradually changing into Ap. Plough humous horizon with abrupt boundary; loamy sand of grey pale colour, with roots and solitary humic wedges after roots decay.

Fine, loamy sand of yellow pale colour. 


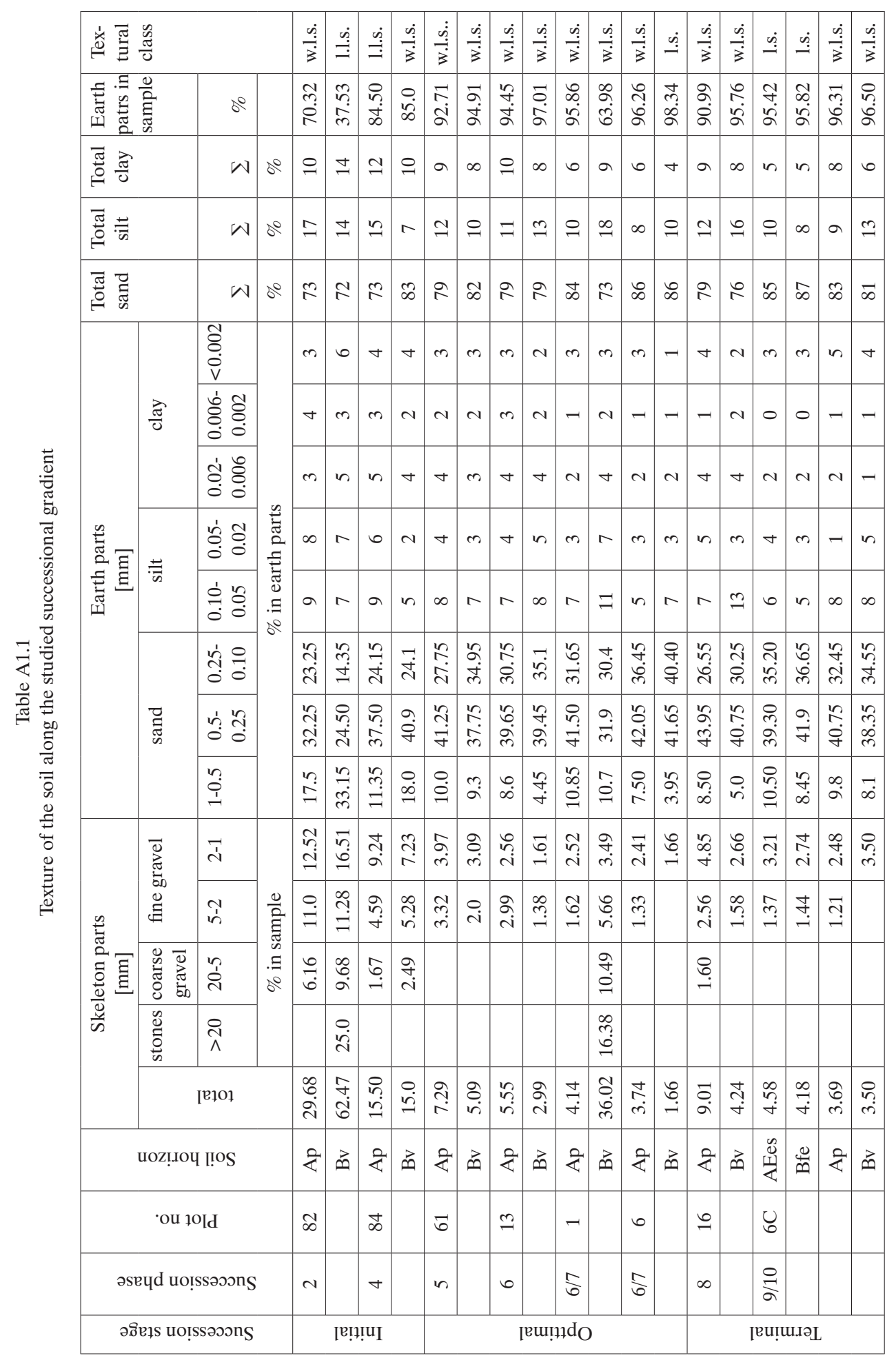

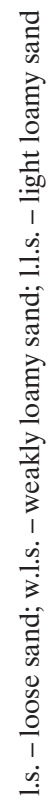


Table A1.2

Some chemical properties of the soil along the studied successional gradient - soil profiles

\begin{tabular}{|c|c|c|c|c|c|c|c|c|}
\hline \multirow{2}{*}{$\begin{array}{l}\text { Succes- } \\
\text { sion stage }\end{array}$} & \multirow{2}{*}{$\begin{array}{c}\text { Succession } \\
\text { phase }\end{array}$} & \multirow[t]{2}{*}{ Plot no. } & \multirow{2}{*}{$\begin{array}{c}\text { Soil } \\
\text { horizon }\end{array}$} & \multicolumn{2}{|c|}{$\mathrm{pH}$} & \multirow{2}{*}{$\begin{array}{l}\mathrm{C} \\
\%\end{array}$} & \multirow{2}{*}{$\begin{array}{l}\mathrm{N} \\
\%\end{array}$} & \multirow[t]{2}{*}{$\mathrm{C} / \mathrm{N}$} \\
\hline & & & & in $\mathrm{H} 2 \mathrm{O}$ & in $\mathrm{KCl}$ & & & \\
\hline \multirow[t]{5}{*}{ Initial } & 2 & 82 & Ap & 5.5 & 4.4 & 1.39 & 0.093 & 14.9 \\
\hline & & & $\mathrm{Bv}$ & 5.7 & 4.6 & 0.381 & 0.033 & 11.5 \\
\hline & 4 & 84 & $\mathrm{Ol}$ & 4.9 & 4.4 & 32.2 & 1.27 & 25.4 \\
\hline & & & Ap & 5.1 & 4.3 & 1.16 & 0.096 & 12.1 \\
\hline & & & $\mathrm{Bv}$ & 5.6 & 4.4 & 0.068 & 0.011 & 6.2 \\
\hline \multirow[t]{9}{*}{ Optimal } & 5 & 61 & $\mathrm{Ol}$ & 4.5 & 3.9 & 31.8 & 0.695 & 45.8 \\
\hline & & & Ap & 4.9 & 4.3 & 0.831 & 0.056 & 15.2 \\
\hline & & & $\mathrm{Bv}$ & 4.9 & 4.5 & 0.183 & 0.019 & 9.6 \\
\hline & 6 & 13 & $\mathrm{Ol}$ & 4.8 & 4.2 & 30.3 & 1.18 & 25.7 \\
\hline & & & Ap & 4.8 & 4.3 & 0.997 & 0.062 & 16.1 \\
\hline & & & $\mathrm{Bv}$ & 4.9 & 4.5 & 0.305 & 0.021 & 14.5 \\
\hline & $6 / 7$ & 6 & $\mathrm{Ol}$ & 4.9 & 4.4 & 32.2 & 1.04 & 31.0 \\
\hline & & & Ap & 4.9 & 4.4 & 0.550 & 0.031 & 17.7 \\
\hline & & & $\mathrm{Bv}$ & 4.8 & 4.6 & 0.232 & 0.020 & 11.6 \\
\hline \multirow[t]{12}{*}{ Terminal } & 8 & 16 & $\mathrm{Ol}$ & 6.1 & 5.8 & 34.4 & 1.70 & 20.2 \\
\hline & & & Of & 5.9 & 5.5 & 22.8 & 1.55 & 14.7 \\
\hline & & & A & 5.2 & 4.5 & 5.67 & 0.442 & 12.8 \\
\hline & & & Ap & 5.2 & 4.4 & 0.595 & 0.033 & 18.0 \\
\hline & & & $\mathrm{Bv}$ & 4.9 & 4.6 & 0.194 & 0.016 & 12.1 \\
\hline & $9 / 10$ & $6 \mathrm{C}$ & $\mathrm{Ol}$ & 4.3 & 3.8 & 35.2 & 0.607 & 58.0 \\
\hline & & & Of & 4.0 & 3.2 & 31.3 & 1.57 & 19.8 \\
\hline & & & $\mathrm{Oh}$ & 3.9 & 3.1 & 20.3 & 1.10 & 18.4 \\
\hline & & & AEes & 4.1 & 3.2 & 0.922 & 0.045 & 20.5 \\
\hline & & & Bfe & 4.8 & 4.2 & 0.700 & 0.037 & 18.9 \\
\hline & & & Ap & 5.0 & 4.4 & 0.543 & 0.029 & 18.7 \\
\hline & & & $\mathrm{Bv}$ & 5.0 & 4.5 & 0.260 & 0.017 & 15.3 \\
\hline
\end{tabular}


Table A1.3

Some chemical properties of the soil along the studied successional gradient - bulk surface soil $(0-15 \mathrm{~cm})$

\begin{tabular}{|c|c|c|c|c|c|c|c|}
\hline \multirow{2}{*}{$\begin{array}{l}\text { Succession } \\
\text { stage }\end{array}$} & \multirow{2}{*}{$\begin{array}{c}\text { Succession } \\
\text { phase }\end{array}$} & \multirow[t]{2}{*}{ Plot no. } & \multicolumn{2}{|c|}{$\mathrm{pH}$} & \multirow{2}{*}{$\begin{array}{l}\mathrm{C} \\
\%\end{array}$} & \multirow{2}{*}{$\begin{array}{l}\mathrm{N} \\
\%\end{array}$} & \multirow[t]{2}{*}{$\mathrm{C} / \mathrm{N}$} \\
\hline & & & in $\mathrm{H} 2 \mathrm{O}$ & in $\mathrm{KCl}$ & & & \\
\hline \multirow[t]{3}{*}{ Initial } & 2 & 82 & 5.5 & 4.8 & 1.63 & 0.113 & 14.4 \\
\hline & 4 & 67 & 4.6 & 4.1 & 1.43 & 0.089 & 16.1 \\
\hline & & 84 & 4.8 & 4.2 & 1.16 & 0.080 & 14.5 \\
\hline \multirow[t]{6}{*}{ Optimal } & 5 & 61 & 4.8 & 4.2 & 1.25 & 0.077 & 16.2 \\
\hline & & 85 & 4.8 & 4.2 & 1.08 & 0.073 & 14.8 \\
\hline & 6 & 7 & 4.7 & 4.2 & 1.05 & 0.061 & 17.2 \\
\hline & & 13 & 4.8 & 4.2 & 1.07 & 0.058 & 18.4 \\
\hline & $6 / 7$ & 1 & 4.8 & 4.2 & 0.957 & 0.054 & 17.7 \\
\hline & & 6 & 4.8 & 4.2 & 0.833 & 0.053 & 15.7 \\
\hline \multirow[t]{3}{*}{ Terminal } & 8 & 11 & 5.3 & 4.5 & 1.20 & 0.057 & 21.0 \\
\hline & & 16 & 5.0 & 4.2 & 1.07 & 0.060 & 17.8 \\
\hline & $9 / 10$ & $2 \mathrm{C}-8 \mathrm{C}$ & 4.6 & 4.1 & 0.983 & 0.041 & 24.0 \\
\hline
\end{tabular}

Table A1.4

Surface soil moisture $(\%)$ in observation plots compared among sampling terms $(26 / 07,09 / 09,12 / 09,20 / 10,06 / 11)$

\begin{tabular}{|c|c|c|c|c|c|}
\hline $\begin{array}{l}\text { Succession } \\
\text { stage }\end{array}$ & $\begin{array}{l}\text { Succession } \\
\text { phase }\end{array}$ & Plot no. & $\begin{array}{l}\text { Minimum median } \\
\text { (sampling term) }\end{array}$ & $\begin{array}{l}\text { Maximum median } \\
\text { (sampling term) }\end{array}$ & $\begin{array}{c}\text { Kruskal-Wallis test } \\
\qquad \mathrm{df}=4\end{array}$ \\
\hline \multirow[t]{3}{*}{ Initial } & 2 & 82 & $9.67(09 / 09 /)$ & $18.15(20 / 10)$ & $\mathrm{n}=30 ; \mathrm{H}=10.00^{*}$ \\
\hline & \multirow[t]{2}{*}{4} & 67 & $6.88(09 / 09 /)$ & $14.04(06 / 11)$ & $\mathrm{n}=30 ; \mathrm{H}=14.90^{* *}$ \\
\hline & & 84 & $5.02(09 / 09 /)$ & $14.85(06 / 11)$ & $\mathrm{n}=29 ; \mathrm{H}=15.51^{* *}$ \\
\hline \multirow[t]{6}{*}{ Optimal } & \multirow[t]{2}{*}{5} & 61 & $4.76(09 / 09 /)$ & $14.91(06 / 11)$ & $\mathrm{n}=30 ; \mathrm{H}=21.13^{* * *}$ \\
\hline & & 85 & $3.78(09 / 09 /)$ & $12.37(06 / 11)$ & $\mathrm{n}=30 ; \mathrm{H}=12.38^{*}$ \\
\hline & \multirow[t]{2}{*}{6} & 7 & $5.73(09 / 09 /)$ & $13.53(20 / 10)$ & $\mathrm{n}=29 ; \mathrm{H}=15.31^{* *}$ \\
\hline & & 13 & $6.00(09 / 09 /)$ & $10.64(06 / 11)$ & $\mathrm{n}=30 ; \mathrm{H}=17.89^{* *}$ \\
\hline & \multirow[t]{2}{*}{$6 / 7$} & 1 & $4.24(09 / 09 /)$ & $10.20(06 / 11)$ & $\mathrm{n}=30 ; \mathrm{H}=20.08^{* * *}$ \\
\hline & & 6 & $4.00(09 / 09 /)$ & $15.18(06 / 11)$ & $\mathrm{n}=30 ; \mathrm{H}=12.67^{*}$ \\
\hline \multirow[t]{3}{*}{ Terminal } & \multirow[t]{2}{*}{8} & 11 & $7.12(09 / 09 /)$ & $17.89(06 / 11)$ & $\mathrm{n}=30 ; \mathrm{H}=11.88^{*}$ \\
\hline & & 16 & $6.66(09 / 09 /)$ & $20.10(06 / 11)$ & $\mathrm{n}=30 ; \mathrm{H}=18.35^{* *}$ \\
\hline & $9 / 10$ & $2 \mathrm{C}, 5 \mathrm{C}, 6 \mathrm{C}, 7 \mathrm{C}, 8 \mathrm{C}$ & $11.05(09 / 09 /)$ & $24.54(26 / 07)$ & $\mathrm{n}=60 ; \mathrm{H}=6.69^{\mathrm{ns}}$ \\
\hline
\end{tabular}

ns - not significant differences, $\mathrm{p}>0.05$; significant difference for at least one pair of sampling terms at $* \mathrm{p}<0.05$, $* * \mathrm{p}<0.01, * * * \mathrm{p}<0.001$ 
Table A1.5

Surface soil moisture (\%) in observation plots compared among the plots ( 82 - phase $2 ; 67,84$ - phase $4 ; 61,85$ - phase $5 ; 7,13$ - phase $6 ; 1,6$ - phase $6 / 7$; 2C, 5C, 6C, 7C, 8C - phase 9/10)

\begin{tabular}{|c|c|c|c|}
\hline Sampling term & $\begin{array}{c}\text { Minimum median } \\
\text { (plot no.) }\end{array}$ & $\begin{array}{c}\text { Maximum median } \\
\text { (plot no.) }\end{array}$ & $\begin{array}{c}\text { Kruskal-Wallis test } \\
\mathrm{df}=11\end{array}$ \\
\hline $26 / 07$ & $7.82(1)$ & $24.54(2 \mathrm{C}, 5 \mathrm{C}, 6 \mathrm{C}, 7 \mathrm{C}, 8 \mathrm{C})$ & $\mathrm{n}=128 ; \mathrm{H}=74.64^{* * * *}$ \\
\hline $09 / 09$ & $3.78(85)$ & $11.05(2 \mathrm{C}, 5 \mathrm{C}, 6 \mathrm{C}, 7 \mathrm{C}, 8 \mathrm{C})$ & $\mathrm{n}=65 ; \mathrm{H}=23.94 *$ \\
\hline $12 / 09$ & $4.79(13)$ & $14.59(2 \mathrm{C}, 5 \mathrm{C}, 6 \mathrm{C}, 7 \mathrm{C}, 8 \mathrm{C})$ & $\mathrm{n}=65 ; \mathrm{H}=44.78^{* * * *}$ \\
\hline $20 / 10$ & $7.46(6)$ & $20.54(2 \mathrm{C}, 5 \mathrm{C}, 6 \mathrm{C}, 7 \mathrm{C}, 8 \mathrm{C})$ & $\mathrm{n}=65 ; \mathrm{H}=31.20^{* *}$ \\
\hline $06 / 11$ & $10.20(1)$ & $23.96(2 \mathrm{C}, 5 \mathrm{C}, 6 \mathrm{C}, 7 \mathrm{C}, 8 \mathrm{C})$ & $\mathrm{n}=65 ; \mathrm{H}=34.01^{* * *}$ \\
\hline
\end{tabular}

significant difference for at least one pair of plots at ${ }^{*} \mathrm{p}<0.05,{ }^{* *} \mathrm{p}<0.01,{ }^{* * *} \mathrm{p}<0.001,{ }^{* * * *} \mathrm{p}<0.0001$

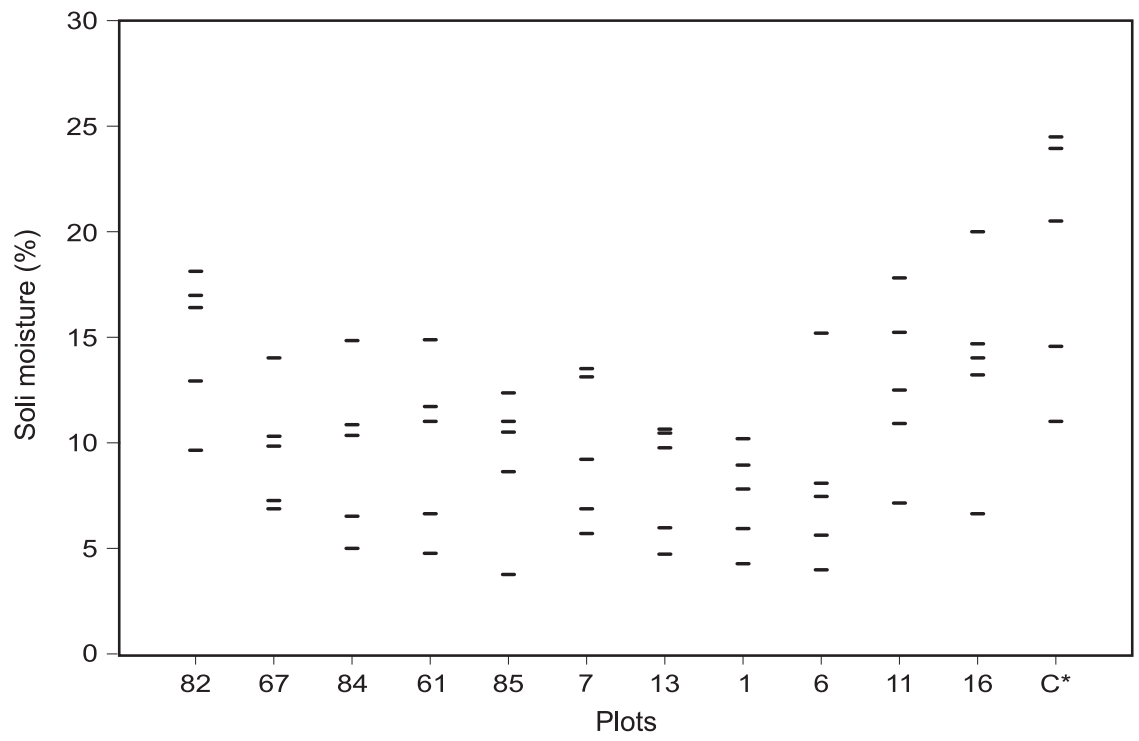

Fig. A1.1. Surface soil moisture (\%) in permanent plots - medians in five sampling terms $(26 / 07,09 / 09,12 / 09$, 20/10, 06/11); for numbers of samples see 4. Material and methods.

$\mathrm{C}^{*}$ - stands for the plots 2C, 5C, 6C, 7C, 8C (phase 9/10); soil samples from these plots have been analysed together. 
Appendix 2

Vegetation description in the permanent plots 
Table A2.1

Vegetation description in the permanent plots in the Jelonka reserve (June 1997; Londo method; [ ] - cover by the crowns of trees growing outside the examined subplot; $\mathrm{n}$ - no data)

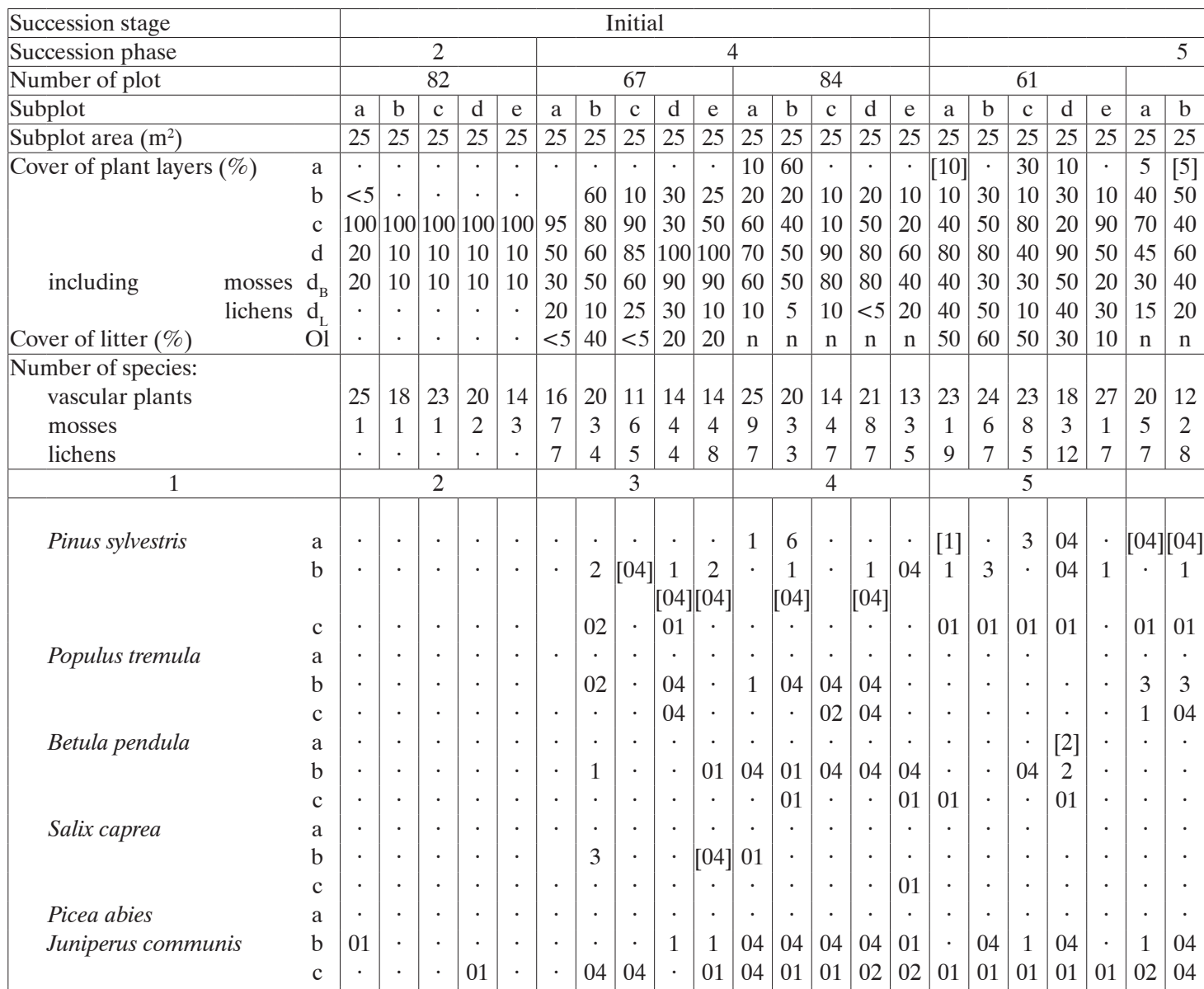

\section{Salix repens}

subsp. rosmarinifolia b

Salix cinerea

Salix aurita

Frangula alnus

Viburnum opulus

Rosa sp.

Rhamnus cathartica

Pyrus communis

Quercus robur

Padus serotina

Sorbus aucuparia

Ch Aperetalia

Vicia hirsuta

Vicia angustifolia

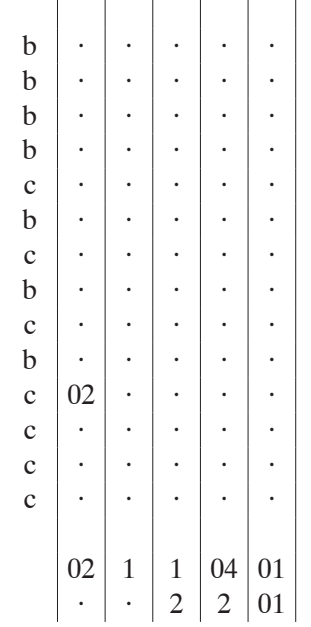




\begin{tabular}{|c|c|c|c|c|c|c|c|c|c|c|c|c|c|c|c|c|c|c|c|c|c|c|c|c|c|c|c|c|c|}
\hline \multicolumn{23}{|c|}{ Optimal } & \multicolumn{7}{|c|}{ Terminal } \\
\hline & & & \multicolumn{10}{|c|}{6} & \multicolumn{10}{|c|}{$6 / 7$} & \multicolumn{7}{|c|}{8} \\
\hline \multicolumn{3}{|l|}{85} & \multicolumn{5}{|c|}{7} & \multicolumn{5}{|c|}{13} & \multicolumn{5}{|c|}{1} & \multicolumn{5}{|c|}{6} & \multicolumn{5}{|c|}{11} & \multicolumn{2}{|l|}{16} \\
\hline $\mathrm{c}$ & d & $\mathrm{e}$ & $\mathrm{a}$ & $\mathrm{b}$ & $\mathrm{c}$ & $\mathrm{d}$ & $\mathrm{e}$ & $\mathrm{a}$ & $\mathrm{b}$ & $\mathrm{c}$ & d & e & $\mathrm{a}$ & $\mathrm{b}$ & $\mathrm{c}$ & $\mathrm{d}$ & $\mathrm{e}$ & $\mathrm{a}$ & $\mathrm{b}$ & $\mathrm{c}$ & d & $\mathrm{e}$ & $\mathrm{a}$ & $\mathrm{b}$ & $\mathrm{c}$ & d & $\mathrm{e}$ & & $\mathrm{N}$ \\
\hline 25 & 25 & 25 & 25 & 25 & 25 & 25 & 25 & 25 & 25 & 25 & 25 & 25 & 25 & 25 & 25 & 25 & 25 & 25 & 25 & 25 & 25 & 25 & 25 & 25 & 25 & 25 & 25 & 1001 & 100 \\
\hline$\cdot$ & & [5] & $\cdot$ & 30 & 60 & 40 & 50 & 20 & 50 & 50 & 50 & 40 & 20 & 10 & 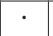 & 70 & 50 & [30] & 30 & $\cdot$ & 70 & 60 & 80 & 80 & 80 & 40 & 80 & \begin{tabular}{l|l}
80 & 8 \\
\end{tabular} & 80 \\
\hline 20 & 30 & 10 & 20 & 30 & 40 & 40 & 40 & 40 & 20 & 30 & 20 & 20 & 50 & 30 & 40 & 30 & 40 & 70 & 40 & 40 & 30 & 60 & 60 & 70 & 60 & 70 & 80 & 30 & 40 \\
\hline 70 & 60 & 60 & 20 & 40 & 30 & 60 & 40 & 40 & 30 & 30 & 20 & 30 & 20 & 50 & 70 & 20 & 20 & 40 & 20 & 80 & 30 & 50 & 40 & 30 & 20 & 20 & 5 & 70 & 60 \\
\hline 60 & 60 & 80 & 90 & 40 & 60 & 20 & 40 & 60 & 30 & 30 & 60 & 40 & 50 & 60 & 70 & 20 & 30 & 80 & 60 & 603 & 30 & $<5$ & 5 & $<5$ & 30 & 50 & 5 & 25 & 20 \\
\hline 40 & 30 & 60 & 60 & 20 & 60 & 20 & 30 & 40 & 20 & 10 & 20 & 20 & 30 & 20 & 40 & 20 & 15 & 70 & 30 & 30 & 10 & $<5$ & 5 & $<5$ & 30 & 40 & 5 & 20 & 20 \\
\hline 20 & 30 & 25 & 30 & 20 & $<5$ & $<5$ & 10 & 20 & 10 & 20 & 40 & 20 & 20 & 40 & 40 & $<5$ & 20 & 20 & 30 & 30 & 20 & $<5$ & & $\cdot$ & $<5$ & 10 & & 5 & $<5$ \\
\hline $\mathrm{n}$ & $\mathrm{n}$ & $\mathrm{n}$ & 20 & 90 & 70 & 85 & 100 & 40 & 90 & 100 & 100 & 80 & 70 & 80 & $<5$ & 90 & 90 & 90 & 80 & \begin{tabular}{l|l}
20 & 1
\end{tabular} & 100 & 90 & 100 & 1001 & 100 & $\begin{array}{lll}90 & 10 \\
\end{array}$ & $100 \mid 10$ & 1001 & 100 \\
\hline 17 & 19 & 13 & 19 & 23 & 17 & 19 & 23 & 17 & 14 & 28 & 23 & 20 & 21 & 17 & 20 & 16 & 18 & 23 & 13 & 17 & 12 & 12 & 27 & 26 & 19 & 31 & 23 & 31 & 39 \\
\hline 5 & 4 & 3 & 2 & 4 & 4 & 11 & 11 & 3 & 2 & 4 & 4 & 6 & 6 & 10 & 11 & 6 & 5 & 5 & 9 & 8 & 7 & 3 & 6 & 4 & 9 & 7 & 2 & 6 & 7 \\
\hline 6 & 7 & 10 & 15 & 8 & 1 & 3 & 5 & 3 & 3 & 4 & 5 & 4 & 8 & 10 & 7 & 3 & 4 & 7 & 8 & 7 & 5 & 1 & & · & 8 & 7 & & & 2 \\
\hline 6 & & & & & 7 & & & & & 8 & & & & & 9 & & & & & 10 & & & & & 11 & & & 12 & \\
\hline
\end{tabular}

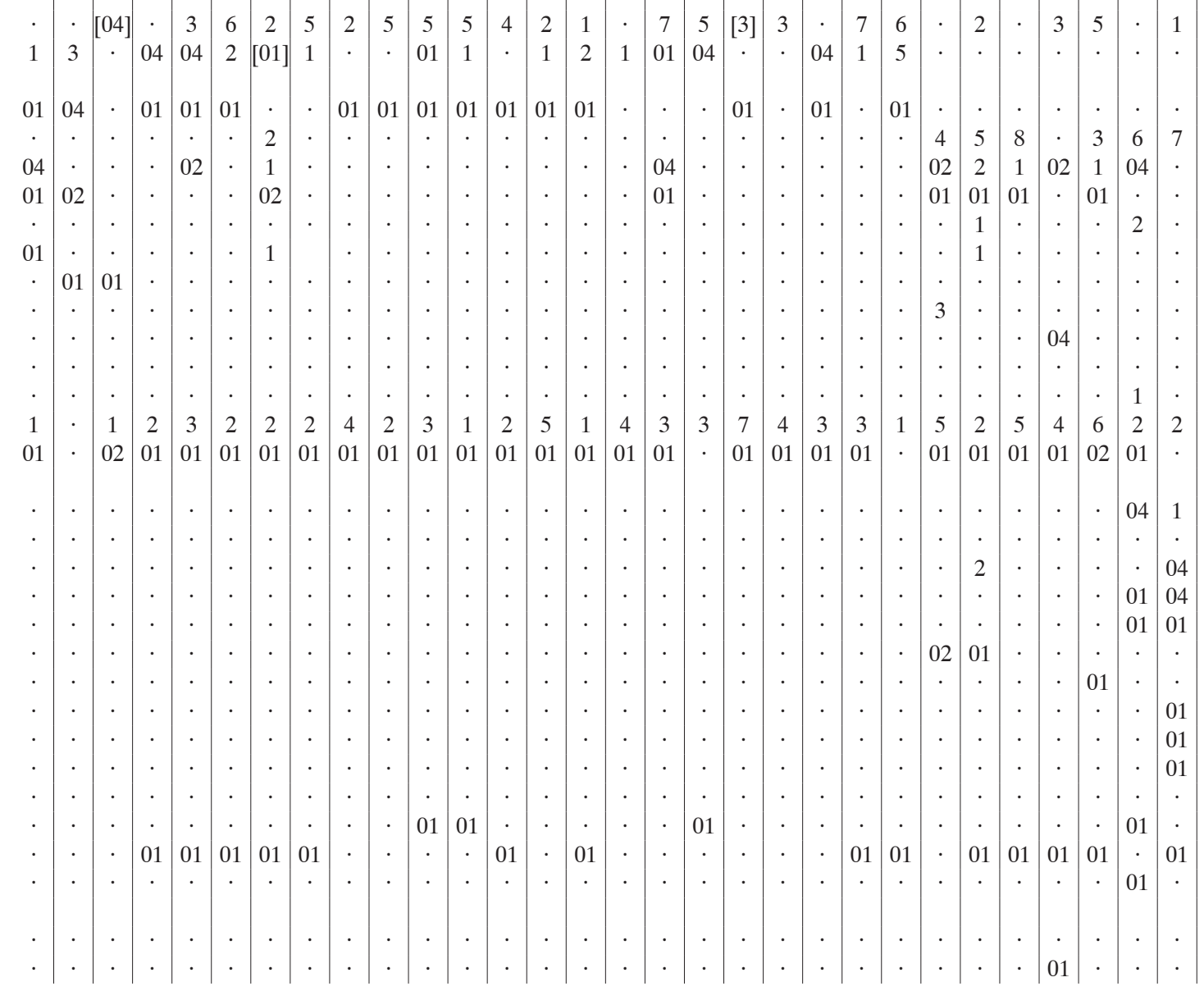

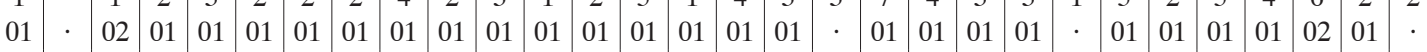




\begin{tabular}{|c|c|c|c|c|c|c|c|c|c|c|c|c|c|c|c|c|c|c|c|c|c|c|c|c|}
\hline \multirow{3}{*}{\begin{tabular}{|l} 
Succession stage \\
Succession phase \\
Number of plot \\
\end{tabular}} & \multicolumn{16}{|c|}{ Initial } & \\
\hline & \multirow{2}{*}{\multicolumn{5}{|c|}{$\begin{array}{c}2 \\
82\end{array}$}} & \multicolumn{11}{|c|}{4} & & & & & & & & \\
\hline & & & & & & & & 67 & & & & & 84 & 4 & & & & & 61 & & & & & 5 \\
\hline \multicolumn{25}{|l|}{ Ch Agropyro-Rumicion crispi } \\
\hline Rumex crispus & & & . & $\cdot$ & 04 & & & . & & & & & . & & & & & & . & & & & & \\
\hline \multicolumn{25}{|l|}{ Ch Artemisietea, Onopordion* } \\
\hline Artemisia vulgaris & & & . & 02 & $\cdot$ & . & . & . & & & & & . & & & & . & & . & & & & & . \\
\hline * Berteroa incana & & & 01 & 01 & . & . & . & . & . & & . & . & . & & & . & . & . & . & & & & . & . \\
\hline *Melandrium album & 02 & & & & & |. & $\cdot \mid$ & $\cdot$ & $\cdot$ & & • & & · & & & . & . & - & . & & & & & · \\
\hline \multicolumn{25}{|c|}{ Ch Isoëto-Nanojuncetea, Cyperetalia fusci ${ }^{*}$, Radiolion linoidis*** } \\
\hline * Gnaphalium uliginosum & & & 01 & & & |. & 1 & . & 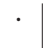 & & 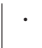 & 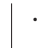 & . & & & 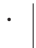 & 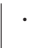 & & & & & & & \\
\hline ** Hypericum humifusum & . & . & . & . & . & . & 01 & . & . & & . & . & . & . & & . & 01 & 01 & 01 & 101 & & 1 & - & . \\
\hline \multicolumn{25}{|c|}{ Ch Molinio-Arrhenatheretea, Molinietalia*, Arrhenatheretalia**, Cynosurion ${ }^{* * *}$} \\
\hline Poa pratensis & 2 & $2 \mid$ & 2 & 3 & $\mid \cdot$ & |. & $|\cdot|$ & $\cdot$ & $\cdot$ & & & - & . & & & . & . & & . & & & & & . \\
\hline Vicia cracca & 01 & 04 & 02 & . & . & . & . & . & . & & . & & . & & & . & . & & & & & & & . \\
\hline Rumex acetosa & 02 & $\cdot$ & . & . & . & . & & . & & & & & & & & & & & & & & & & . \\
\hline Achillea millefolium & 04 & 1 & 1 & 2 & 2 & 1 & 01 & 1 & 02 & 01 & 02 & 01 & 02 & 20 & 2 & - & 01 & 01 & 01 & 101 & $1 \quad 0$ & 1 & 04 & 02 \\
\hline Holcus lanatus & & . & . & . & 01 & 02 & $\cdot$ & . & & 01 & . & . & . & & & - & . & . & . & & & & $\cdot$ & . \\
\hline *Juncus conglomeratus & 02 & . & . & . & . & . & . & . & . & $\cdot$ & - & . & - & & & . & - & . & . & & & . & . & . \\
\hline ** Taraxacum officinale s.l. & . & . & . & . & . & . & . & . & . & - & - & . & . & & & . & . & . & . & & & & . & . \\
\hline *** Trifolium repens & 01 & & 01 & 04 & . & . & . & . & & & & . & . & & & . & . & . & & & & & . & . \\
\hline \multicolumn{25}{|l|}{ Ch Koelerietea } \\
\hline Potentilla argentea & 01 & $|01|$ & 01 & 01 & & & & . & & & & & & & & & - & & & & & & & \\
\hline Brachythecium albicans & . & 1 & 1 & 1 & 01 & 04 & 04 & . & . & & 04 & . & . & 0 & & - & . & - & 01 & & & & & . \\
\hline Hieracium pilosella & 01 & 01 & 04 & 2 & . & 1 & 5 & 4 & 02 & 2 & 1 & 04 & 04 & $4 \quad 0$ & & $\cdot$ & 04 & 02 & 02 & 201 & & 2 & 1 & \\
\hline Rumex acetosella & & 01 & 02 & . & . & 1 & 01 & 04 & 01 & 01 & 01 & 02 & 01 & & & 02 & 01 & 04 & 02 & 201 & & 1 & & . \\
\hline Trifolium arvense & & 02 & . & . & . & . & 01 & $\cdot$ & . & . & . & . & . & & & . & . & . & . & & & & . & . \\
\hline Rumex tenuifolius & . & $\cdot$ & . & 01 & . & 02 & 02 & 02 & . & 02 & . & 01 & 04 & $4 \quad 0$ & & 01 & . & 02 & 01 & & & & 02 & . \\
\hline Artemisia campestris & 01 & . & . & $\cdot$ & . & . & 2 & & . & & . & 02 & & & & & 01 & 01 & . & & & 1 & 04 & \\
\hline Scleranthus perennis & & · & . & . & - & 01 & $\cdot$ & . & & 01 & 02 & 04 & 01 & $1 \quad 0$ & & 02 & 01 & 01 & 02 & 201 & & 2 & 1 & \\
\hline Jasione montana & & . & . & . & . & 02 & 01 & 01 & . & 01 & 01 & 01 & $\cdot$ & 0 & & 01 & 02 & 02 & 01 & 101 & & 2 & 01 & 01 \\
\hline Ceratodon purpureus & . & . & . & . & . & 1 & . & 1 & . & 1 & 01 & . & . & 0 & & . & . & . & 04 & \begin{tabular}{l|l}
4 & 04 \\
\end{tabular} & & . & $\cdot$ & . \\
\hline $\begin{array}{l}\text { Cladonia furcata } \\
\text { var. palamea }\end{array}$ & . & . & . & . & . & . & . & . & . & . & 02 & . & 01 & 1 & & $\cdot$ & 04 & . & . & 01 & & 1 & 01 & · \\
\hline Veronica dillenii & - & . & . & . & . & . & . & . & . & & - & . & . & 0 & 1 & - & . & - & . & & & - & . & . \\
\hline Festuca ovina & & . & . & . & . & . & . & . & & & & & . & & & . & . & . & & & & & . & \\
\hline Niphotrichum canescens & & & . & . & & . & . & . & & & & & & & & & . & & & & & & & \\
\hline \multicolumn{25}{|c|}{ Ch Corynephoretalia canescentis, Corynephorion canescentis* } \\
\hline Polytrichum piliferum & $\cdot$ & . & . & |. & $\mid \cdot$ & 04 & 4 & 5 & 4 & 7 & \begin{tabular}{|l|l}
1 &
\end{tabular} & 1 & 04 & & & 1 & 4 & 2 & 2 & 4 & & 2 & 1 & 1 \\
\hline Corynephorus canescens & . & . & . & . & . & 01 & 01 & 1 & . & 04 & 04 & 04 & 02 & 20 & & 04 & 02 & 1 & 01 & 104 & & 2 & 1 & 02 \\
\hline $\begin{array}{l}\text { Cladonia arbuscula } \\
\text { subsp. mitis }\end{array}$ & . & . & . & . & . & 01 & . & 01 & 01 & 01 & 02 & 01 & 01 & 10 & & 02 & 2 & 1 & 04 & $4 \quad 04$ & & 4 & 02 & 02 \\
\hline Cladonia cervicornis & & . & . & . & . & . & . & - & - & & & . & & & & & . & 01 & & & & 1 & & \\
\hline Cetraria aculeata & . & . & . & . & . & . & . & . & . & & . & . & & & & . & . & 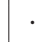 & . & & & & . & \\
\hline Cladonia uncialis & . & . & . & . & . & . & . & . & . & & . & . & . & & & . & . & . & . & & & & . & \\
\hline * Teesdalea nudicaulis & . & . & . & . & . & . & . & . & 01 & . & . & . & . & & & . & 01 & 01 & . & & & 1 & . & \\
\hline * Spergula morisonii & $\cdot$ & $|\cdot|$ & | & |. & | & |. & $|\cdot|$ & $\cdot$ & . & & - & . & . & & & . & . & & & & & & . & \\
\hline Ch Festuco-Sedetalia, Armer & nga & tae* & $\mathrm{Ko}$ & eleri & on $g$ & lauc & $c a e^{* * *}$ & & & & & & & & & & & & & & & & & \\
\hline $\begin{array}{l}\text { Thymus serpyllum } \\
\text { Helichrysum arenarium }\end{array}$ & . & . & |. & |. & $\dot{\cdot}$ & |. & $|\cdot|$ & 1 & $\cdot$ & & . & . & . & & & . & $\dot{0}$ & 01 & $\cdot \dot{0}$ & 01 & & 4 & & · \\
\hline Sedum maximum & . & . & - & - & . & . & . & . & . & & . & . & . & & & & . & & 01 & & & & & \\
\hline * Cerastium arvense & & . & 02 & 1 & . & . & . & . & . & & & & & & & & & & & & & & . & \\
\hline
\end{tabular}




\begin{tabular}{l|l|l|l|l|l|l|}
\hline \multicolumn{9}{|c|}{ Optimal } & \multicolumn{2}{c|}{ Terminal } \\
\hline & \multicolumn{3}{|c|}{6} & \multicolumn{2}{c|}{8} & \multicolumn{2}{c|}{} \\
\hline 85 & 7 & 13 & 1 & 6 & 11 & 16 \\
\hline
\end{tabular}

$\cdot|\cdot| \cdot|\cdot| \cdot|\cdot| \cdot|\cdot| \cdot|\cdot| \cdot|\cdot| \cdot|\cdot| \cdot|\cdot| \cdot|\cdot| \cdot|\cdot| \cdot|\cdot| \cdot|\cdot| \cdot|\cdot| \cdot|\cdot| \cdot|\cdot|$

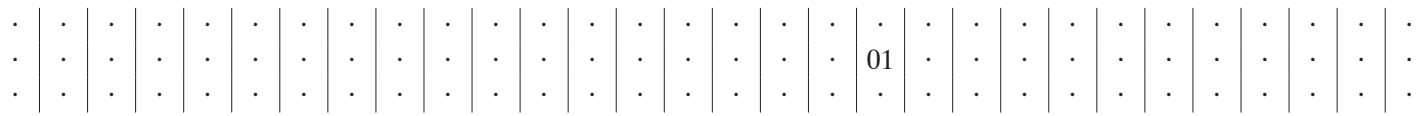

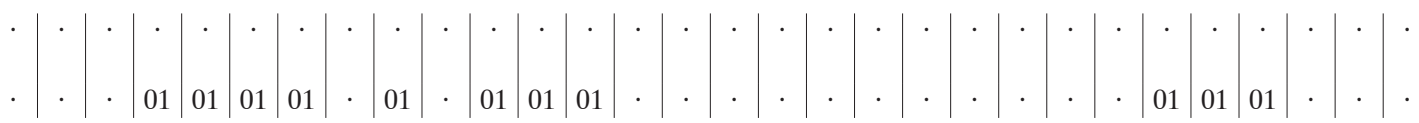

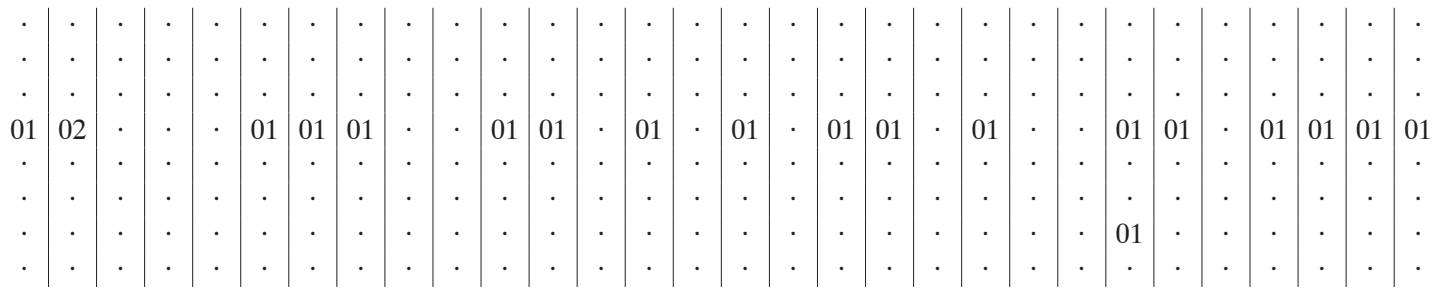

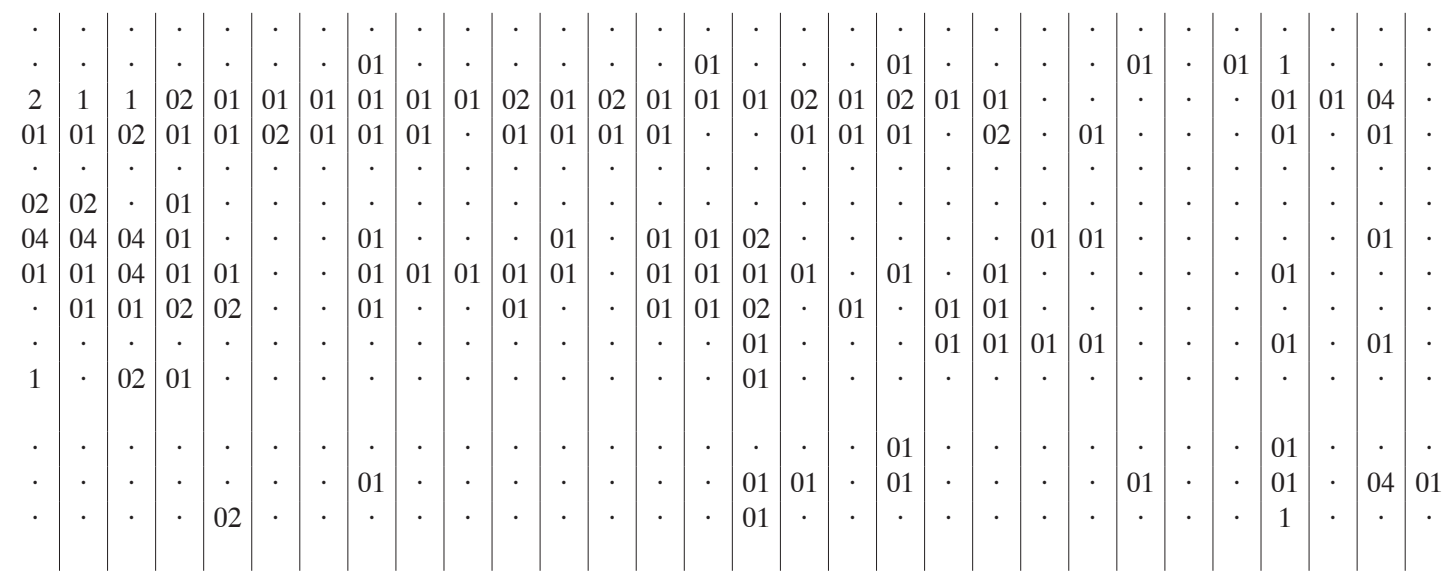

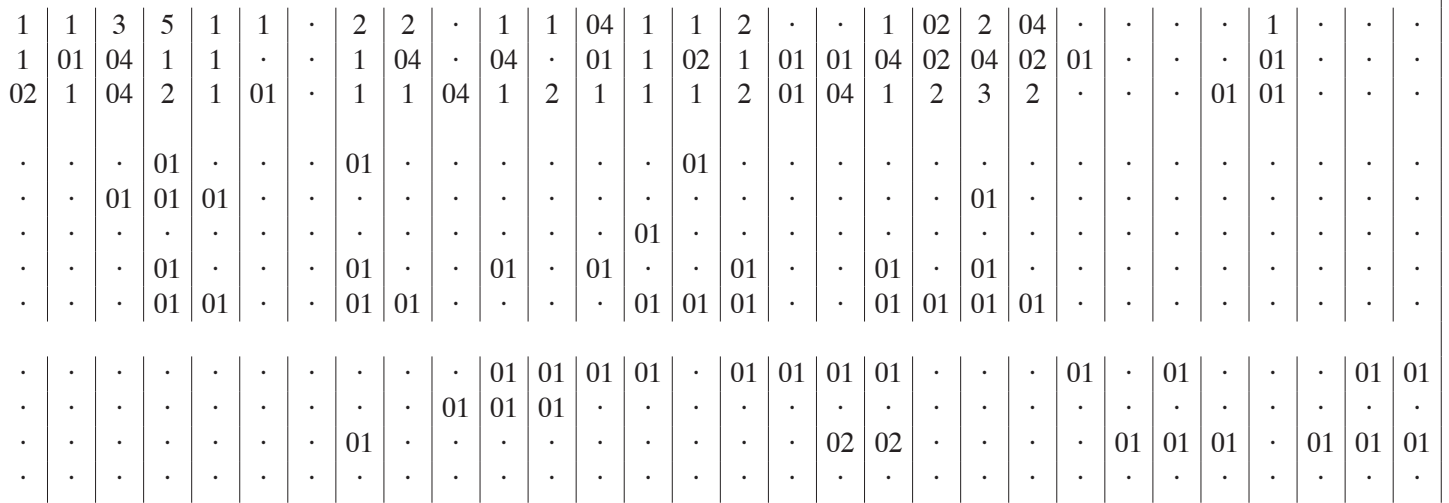




\begin{tabular}{|c|c|c|c|c|c|c|c|c|c|c|c|c|c|c|c|c|c|c|c|c|c|c|c|c|}
\hline \multirow{3}{*}{\begin{tabular}{|l|} 
Succession stage \\
Succession phase \\
Number of plot \\
\end{tabular}} & \multicolumn{16}{|c|}{ Initial } & \multirow{2}{*}{\multicolumn{8}{|c|}{5}} \\
\hline & \multirow{2}{*}{\multicolumn{5}{|c|}{$\begin{array}{c}2 \\
82\end{array}$}} & \multicolumn{11}{|c|}{4} & & & & & & & & \\
\hline & & & & & & \multicolumn{5}{|c|}{67} & \multicolumn{6}{|c|}{84} & \multicolumn{6}{|c|}{61} & \\
\hline $\begin{array}{r}* \text { Armeria maritima } \\
\text { subsp. elongata }\end{array}$ & . & . & - & - & 01 & . & . & . & . & - & . & & & . & . & - & & & - & & & & & \\
\hline ** Gypsophila fastigiata & - & . & - & . & - & . & . & . & . & . & . & & · & . & . & - & & 1 & . & . & . & - & . & . \\
\hline ** Astragalus arenarius & . & . & - & . & . & . & . & . & . & - & . & & · & - & - & . & & · & . & . & . & 01 & . & . \\
\hline ** Koeleria glauca & $\cdot$ & . & . & $\cdot$ & . & . & . & . & $\cdot$ & . & . & & · & . & $\cdot$ & $\cdot$ & & & $\cdot$ & $\cdot$ & . & & $\cdot$ & . \\
\hline Ch Trifolion medii & & & & & & & & & & & & & & & & & & & & & & & & \\
\hline Galium mollugo & 04 & 1 & . & 04 & $\cdot$ & . & $\cdot$ & . & $\cdot$ & 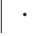 & 0 & & & . & 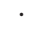 & $\cdot$ & & & . & . & . & $\cdot$ & . & . \\
\hline Ch Nardo-Callunetea & & & & & & & & & & & & & & & & & & & & & & & & \\
\hline Calluna vulgaris & . & . & . & . & . & . & 02 & . & . & - & 2 & & · & . & . & 04 & & 2 & 04 & 6 & 04 & 4 & 02 & 02 \\
\hline Luzula campestris & . & . & . & . & . & 01 & . & . & . & . & 0 & & . & . & . & 01 & & & . & . & . & . & . & 01 \\
\hline Danthonia decumbens & . & . & . & . & . & . & . & . & . & - & 0 & & · & . & . & . & & & 04 & . & . & . & - & . \\
\hline Luzula multiflora & $\cdot$ & $\cdot$ & · & · & . & · & $\cdot$ & $\cdot$ & · & . & - & & . & . & . & . & & & & . & & & & \\
\hline Ch Festuco-Brometea & & & & & & & & & & & & & & & & & & & & & & & & \\
\hline Centaurea stoebe & . & - & - & - & 01 & · & . & . & . & - & . & & · & - & - & - & & · & . & . & . & . & . & - \\
\hline Carlina vulgaris & . & . & . & . & . & . & . & $\cdot$ & $\cdot$ & . & . & & $\cdot$ & . & 02 & . & & & 01 & . & . & 01 & $\cdot$ & . \\
\hline Achillea collina & . & $\cdot$ & . & . & $\cdot$ & . & . & . & . & . & . & & $\cdot$ & . & . & . & & 1 & $\cdot$ & $\cdot$ & 01 & . & & . \\
\hline Ch Quercetea robori-petraea & & & & & & & & & & & & & & & & & & & & & & & & \\
\hline Hieracium sabaudum & - & - & . & - & - & - & 01 & - & - & - & & & - & - & . & - & & & . & . & - & - & . & - \\
\hline Holcus mollis & . & . & . & . & . & . & . & . & . & . & . & & 1 & . & 01 & . & & . & . & . & . & . & . & . \\
\hline Ch Dicrano-Pinion & & & & & & & & & & & & & & & & & & & & & & & & \\
\hline Dicranum polysetum & - & . & . & - & - & . & . & . & - & - & . & & . & - & - & - & & & . & . & . & . & . & . \\
\hline Monotropa hypopitys & . & . & . & $\cdot$ & . & $\cdot$ & . & $\cdot$ & . & . & . & & . & . & . & . & . & · & . & . & . & . & . & . \\
\hline Cladonia gracilis & . & . & . & . & . & . & . & . & . & . & . & & . & . & . & . & & 1 & 1 & . & 04 & 04 & . & 02 \\
\hline Ptilidium ciliare & . & . & . & . & . & . & . & . & . & . & . & & . & . & . & . & & & . & . & $\cdot$ & . & . & . \\
\hline $\begin{array}{l}\text { Cladonia arbuscula } \\
\text { subsp. arbuscula }\end{array}$ & . & . & . & . & . & . & . & . & . & . & . & & . & . & . & . & & & . & . & . & . & . & . \\
\hline Chimaphila umbellata & . & . & - & . & - & . & . & . & . & - & . & & - & . & . & - & & · & . & . & - & . & $\cdot$ & . \\
\hline Ch Epilobietea, Epilobion an & $l i i^{*}$ & & & & & & & & & & & & & & & & & & & & & & & \\
\hline Calamagrostis epigejos & $\cdot$ & . & . & . & . & . & - & . & - & - & . & & • & - & . & - & & & 1 & . & 02 & - & . & . \\
\hline Fragaria vesca & $\cdot$ & . & . & . & $\cdot$ & $\cdot$ & . & $\cdot$ & . & . & . & & $\cdot$ & . & . & · & . & · & $\cdot$ & . & $\cdot$ & $\cdot$ & $\cdot$ & . \\
\hline $\begin{array}{l}\text { * Chamaenerion angusti- } \\
\text { folium }\end{array}$ & . & . & . & . & . & . & . & . & . & . & & & . & . & . & . & & & . & . & . & . & . & . \\
\hline Accompanying species & & & & & & & & & & & & & & & & & & & & & & & & \\
\hline Elymus repens & 02 & 04 & . & . & 4 & . & . & . & - & - & . & & . & . & . & . & & & . & . & . & . & . & . \\
\hline Vicia sp. & 1 & 2 & . & . & . & . & . & . & . & . & . & & · & . & . & . & & · & $\cdot$ & . & . & . & . & . \\
\hline Cirsium arvense & . & . & 02 & . & 3 & $\cdot$ & . & . & . & . & . & & · & . & . & . & & · & $\cdot$ & . & . & . & . & . \\
\hline Silene sp. & 01 & . & 02 & $\cdot$ & . & . & . & . & . & . & . & & · & . & . & . & & · & $\cdot$ & . & . & . & . & . \\
\hline Viola arvensis & $\cdot$ & . & 01 & 01 & . & $\cdot$ & . & . & . & . & . & & · & . & . & . & & · & . & . & & . & . & . \\
\hline Carex hirta & 04 & - & $\cdot$ & . & . & . & . & . & . & . & . & & . & . & . & . & & . & . & . & . & . & - & . \\
\hline Conyza canadensis & 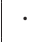 & - & · & · & 01 & . & . & · & · & . & . & & · & · & . & $\cdot$ & & · & $\cdot$ & . & $\cdot$ & - & - & · \\
\hline Lathyrus sylvestris & . & . & . & . & 01 & - & . & . & . & . & . & & · & . & - & . & & · & . & . & - & - & . & . \\
\hline Oenothera sp. & 01 & . & . & . & . & . & . & . & . & . & . & & . & . & . & . & & . & . & . & . & . & . & . \\
\hline Viola tricolor & . & . & 01 & . & . & . & . & . & . & . & . & & . & . & . & . & & . & . & . & . & . & . & . \\
\hline Stellaria graminea & 3 & 3 & 3 & 3 & 2 & . & . & . & . & . & . & & . & . & . & . & & . & . & . & . & . & . & . \\
\hline Solidago virgaurea & 04 & 01 & 1 & 1 & . & 1 & 1 & 1 & 2 & 2 & 0 & & 4 & 04 & 2 & 1 & & 2 & 2 & 04 & 04 & 1 & 2 & 1 \\
\hline Knautia arvensis & 01 & 01 & 04 & 02 & . & 02 & 04 & . & 04 & • & 0 & & 1 & & . & . & & 1 & & 01 & & 01 & & \\
\hline Convolvulus arvensis & 02 & 01 & 01 & 02 & . & 04 & & 01 & & 01 & & & & & . & . & & & & & & 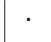 & . & \\
\hline Hypericum perforatum & 01 & 01 & $\cdot$ & 01 & 01 & 02 & - & $\cdot$ & 01 & . & 0 & & . & . & . & . & & 1 & 01 & 02 & . & 04 & 02 & . \\
\hline Agrostis capillaris & 2 & 2 & 1 & . & . & 6 & . & 5 & 01 & 01 & . & & . & 04 & . & . & & 1 & 01 & 01 & 01 & 01 & . & . \\
\hline $\begin{array}{l}\text { Sciuro-hypnum oedipo- } \\
\text { dium }\end{array}$ & 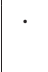 & $\cdot$ & . & 02 & 02 & 01 & . & 01 & · & $\cdot$ & 0 & & & & 01 & . & & & 01 & 01 & & . & . & . \\
\hline Polytrichum commune & 2 & . & - & . & . & . & 04 & 02 & 1 & 04 & 1 & & 2 & 5 & 6 & 2 & & · & . & - & & . & . & \\
\hline
\end{tabular}




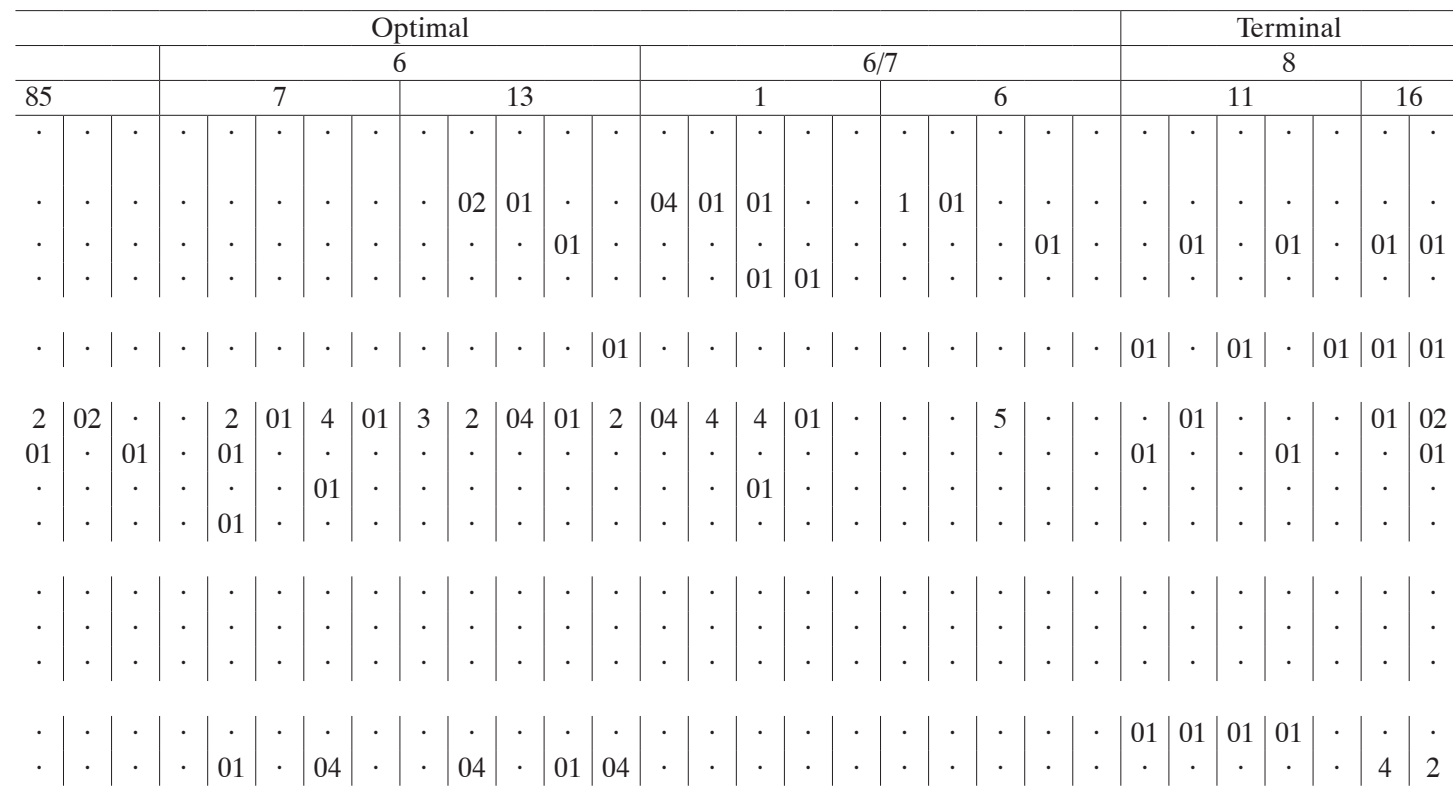
\begin{tabular}{c|c|c|c|c|c|c|c|c|c|c|c|c|c|c|c|c|c|c|c|c|c|c|c|c|c|c|c|c|c|}
01 & 01 & $\cdot$ & $\cdot$ & $\cdot$ & $\cdot$ & 01 & $\cdot$ & $\cdot$ & $\cdot$ & $\cdot$ & $\cdot$ & $\cdot$ & $\cdot$ & 01 & 01 & $\cdot$ & 01 & $\cdot$ & 01 & $\cdot$ & $\cdot$ & $\cdot$ & $\cdot$ & $\cdot$ & 01 & $\cdot$ & $\cdot$ & 02 & $\cdot$ \\
$\cdot$ & $\cdot$ & $\cdot$ & $\cdot$ & $\cdot$ & 01 & $\cdot$ & $\cdot$ & $\cdot$ & $\cdot$ & $\cdot$ & 01 & $\cdot$ & $\cdot$ & $\cdot$ & $\cdot$ & $\cdot$ & $\cdot$ & $\cdot$ & $\cdot$ & $\cdot$ & $\cdot$ & 01 & $\cdot$ & $\cdot$ & 01 & $\cdot$ & 01 & $\cdot$ &. \\
$\cdot$ & $\cdot$ & 02 & 01 & 01 & $\cdot$ & $\cdot$ & $\cdot$ & 1 & $\cdot$ & $\cdot$ & 1 & 1 & 04 & 02 & $\cdot$ & $\cdot$ & $\cdot$ & $\cdot$ & 1 & $\cdot$ & 01 & $\cdot$ & $\cdot$ & $\cdot$ & $\cdot$ & $\cdot$ & $\cdot$ & $\cdot$ & $\cdot$ \\
$\cdot$ & $\cdot$ & $\cdot$ & $\cdot$ & $\cdot$ & $\cdot$ & 01 & $\cdot$ & $\cdot$ & $\cdot$ & $\cdot$ & $\cdot$ & $\cdot$ & $\cdot$ & $\cdot$ & $\cdot$ & $\cdot$ & $\cdot$ & $\cdot$ & $\cdot$ & $\cdot$ & $\cdot$ & $\cdot$ & $\cdot$ & $\cdot$ & $\cdot$ & $\cdot$ & $\cdot$ & $\cdot$ & $\cdot$ \\
. & $\cdot$ & $\cdot$ & $\cdot$ & $\cdot$ & & & & $\cdot$ & $\cdot$ & $\cdot$ & $\cdot$ & $\cdot$ & $\cdot$ & $\cdot$ & $\cdot$ & $\cdot$ & $\cdot$ & $\cdot$ & $\cdot$ & $\cdot$ & $\cdot$ & $\cdot$ & $\cdot$ & $\cdot$ & 01 & $\cdot$ & $\cdot$ & $\cdot$ & $\cdot$ \\
.
\end{tabular}

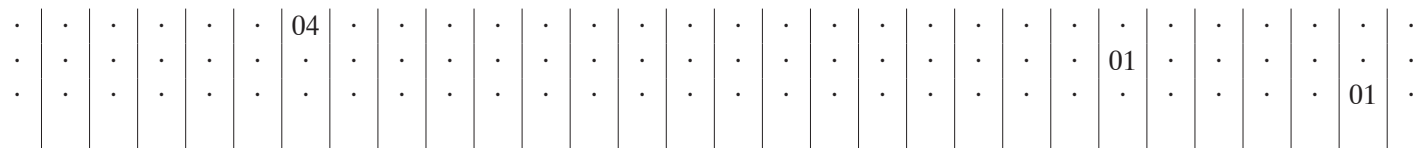

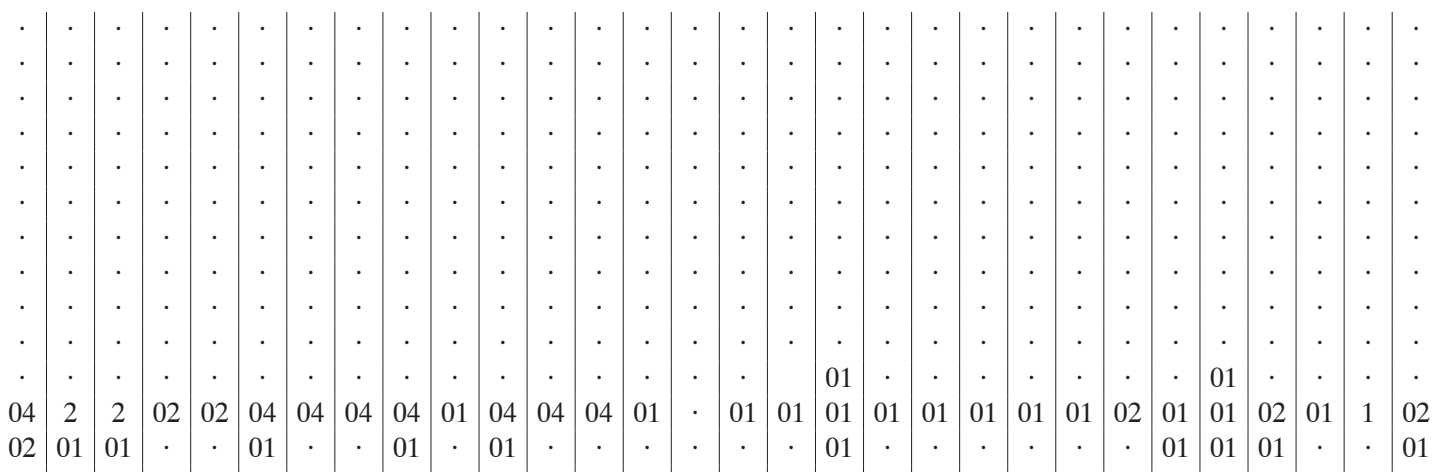
$\begin{array}{llllllllllllllllllllllllllllllllllllll}. & 01 & . & 01 & 01 & 01 & . & . & 01 & 01 & 01 & 01 & . & . & . & . & . & . & . & . & 01 & . & . & . & 01 & . & . & . & 01 & 01\end{array}$ \begin{tabular}{ccccccccccccccccccccccccccccccccccc|c}
. &. &. &. & 01 & 01 &. & 01 & 01 &. & 01 &. & 01 & 01 &. &. & 01 & 01 & 01 & 01 & 01 & 01 & 01 & 01 &. & 01 &. & 01 & 04 & 04 \\
. &. &. & 02 & 02 & 02 &. &. & 01 &. & 02 & 02 & 02 & 02 &. &. & 04 & 01 & 02 &. & 01 & 01 &. & 01 & 01 &. & 01 & 02
\end{tabular}

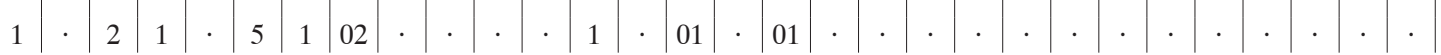




\begin{tabular}{|c|c|c|c|c|c|c|c|c|c|c|c|c|c|c|c|c|c|c|c|c|c|c|}
\hline \multirow{3}{*}{\begin{tabular}{|l} 
Succession stage \\
Succession phase \\
Number of plot \\
\end{tabular}} & \multicolumn{15}{|c|}{ Initial } & \multirow{2}{*}{\multicolumn{7}{|c|}{5}} \\
\hline & \multirow{2}{*}{\multicolumn{4}{|c|}{$\frac{2}{82}$}} & \multicolumn{11}{|c|}{4} & & & & & & & \\
\hline & & & & & & & 67 & & & & & & 84 & & & & & 61 & & & & \\
\hline Agrostis gigantea & & & . & 2 & & & $\cdot$ & . & . & & & & $\cdot$ & . & $\cdot$ & . & . & . & 01 & 02 & & \\
\hline Pleurozium schreberi & & . & . & 1 & 02 & . & . & . & . & 04 & 4 & & 04 & 01 & $\cdot$ & $\cdot$ & 02 & 02 & . & . & 01 & \\
\hline Peисеdanum oreoselinum & . & 1 & . & . & . & . & . & . & . & . & 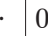 & 02 & . & . & . & . & 02 & . & . & . & 02 & \\
\hline Festuca rubra & . & 04 & . & . & . & . & . & . & . & 01 & 11 & · & 01 & . & . & 01 & 01 & 01 & 01 & 04 & 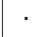 & \\
\hline Euphrasia stricta & & & 01 & . & . & 01 & . & . & . & & & . & . & . & . & . & . & . & . & . & . & \\
\hline Polytrichum juniperinum & & . & & . & 1 & & 01 & 3 & 1 & 4 & 4 & 3 & 2 & 1 & 1 & . & 1 & . & 04 & . & 2 & 3 \\
\hline Melampyrum pratense & & . & . & . & & . & . & & & 04 & 4 & 1 & 04 & 04 & 02 & & • & . & . & . & 04 & 04 \\
\hline Poa angustifolia & & . & . & . & & 1 & . & 01 & . & 04 & 4 & & 02 & 01 & . & - & . & . & . & . & & 02 \\
\hline Cladonia chlorophaea s.l. & . & . & . & . & 02 & 04 & 04 & 1 & 02 & 01 & $1 \mid 0$ & 01 & $\cdot$ & 01 & . & . & . & 02 & 02 & . & 02 & \\
\hline Cladonia cornuta & . & . & . & . & 01 & $\cdot$ & 02 & 01 & 1 & 04 & 4 & & 04 & 01 & 04 & 1 & 2 & . & 04 & 1 & . & 1 \\
\hline Cladonia cf. glauca & - & . & . & . & 2 & 1 & 2 & 2 & 01 & & & . & . & 01 & . & . & . & . & . & . & - & 02 \\
\hline Cladonia phyllophora & - & . & . & . & . & 01 & . & . & 01 & 02 & 2 & . & 02 & . & 02 & 1 & 1 & 04 & 1 & 1 & 04 & 04 \\
\hline $\begin{array}{l}\text { Cladonia furcata } \\
\text { var. furcata }\end{array}$ & & . & . & . & . & . & . & . & 01 & 04 & \begin{tabular}{l|l}
4 & 0
\end{tabular} & 04 & 02 & . & . & 02 & . & 01 & 01 & 01 & 04 & 04 \\
\hline Cladonia subulata & & - & . & . & & 02 & 01 & . & - & & & & 01 & 01 & . & & . & 01 & - & . & & \\
\hline Hypochoeris radicata & - & . & . & . & 01 & & . & . & . & 01 & $1 \mid$\begin{tabular}{l|l}
1 & 0
\end{tabular} & 01 & $\cdot$ & . & . & 01 & . & 01 & . & . & 01 & \\
\hline Cladonia furcata f. fissa & - & - & . & . & & . & . & . & . & . & & - & 01 & 01 & 01 & . & . & . & . & . & . & \\
\hline Placynthiella uliginosa & - & - & . & . & 04 & . & . & . & 02 & $\cdot$ & & - & . & . & . & 02 & 02 & . & 04 & . & 01 & \\
\hline Hурпит сирressiforme & - & - & - & - & $\cdot$ & $\cdot$ & $\cdot$ & 04 & . & 02 & 2 & - & · & $\cdot$ & $\cdot$ & $\cdot$ & 02 & 04 & $\cdot$ & . & 02 & \\
\hline Carex ericetorum & & - & · & · & $\cdot$ & $\cdot$ & · & 02 & - & & & - & - & 02 & $\cdot$ & $\cdot$ & $\cdot$ & $\cdot$ & $\cdot$ & . & $\cdot$ & \\
\hline Euphrasia sp. & & - & - & . & . & $\cdot$ & $\cdot$ & $\cdot$ & - & 02 & 2 & & - & 01 & - & $\cdot$ & $\cdot$ & $\cdot$ & . & . & 02 & 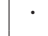 \\
\hline Cladonia fimbriata & & - & - & . & 01 & . & . & . & . & 01 & 1 & & . & . & . & . & . & . & . & . & 01 & 02 \\
\hline Carex ovalis & & . & . & . & 02 & . & . & . & . & & & - & - & . & . & . & . & . & . & . & . & \\
\hline Hieracium umbellatum & . & . & . & . & . & . & . & . & . & . & & . & . & 01 & . & . & . & . & . & 01 & 02 & - \\
\hline Cephaloziella starkei & . & - & - & . & . & · & . & . & . & 01 & 1 & . & . & . & - & . & 02 & . & . & . & 01 & . \\
\hline $\begin{array}{l}\text { Brachythecium } \\
\text { salebrosum }\end{array}$ & - & - & . & . & . & . & 01 & . & . & & & & . & . & . & . & $\cdot$ & 04 & . & . & $\cdot$ & . \\
\hline $\begin{array}{l}\text { Brachytheciastrum } \\
\text { velutinum }\end{array}$ & & . & . & - & . & . & $\cdot$ & . & . & $\cdot$ & & - & - & 01 & $\cdot$ & $\cdot$ & . & 01 & . & . & ${ }^{\circ}$ & \\
\hline Pohlia nutans & & - & - & . & 01 & . & · & - & - & & & - & - & - & . & - & . & $\cdot$ & . & - & - & \\
\hline Cladonia floerkeana & - & . & . & . & . & . & . & . & . & - & • & - & . & . & 01 & . & . & . & 01 & . & . & \\
\hline Cladonia scabriuscula & - & - & . & . & 01 & . & . & . & . & . & - & - & . & . & . & - & . & . & . & . & . & \\
\hline Cladonia pleurota & . & · & . & · & . & $\cdot$ & · & . & 01 & · & · & . & · & $\cdot$ & · & . & · & . & · & . & · & \\
\hline Cladonia crispata & . & . & . & . & . & . & . & . & . & . & · & . & . & . & . & 01 & . & . & 01 & . & . & 02 \\
\hline Euphrasia vernalis & & . & . & . & . & . & . & . & . & . & & . & . & . & . & 01 & 01 & . & . & 01 & . & \\
\hline $\begin{array}{l}\text { Chamaecytisus } \\
\text { ratisbonensis }\end{array}$ & & & . & . & & & . & . & . & & & & . & . & . & & . & 1 & . & 2 & & \\
\hline Linaria vulgaris & - & . & - & . & - & . & . & . & . & . & & - & . & . & . & . & . & 01 & . & 01 & . & \\
\hline Erigeron acris & . & . & . & · & . & . & . & . & . & . & & . & . & . & . & . & . & $\cdot$ & . & $\cdot$ & 01 & \\
\hline Viola canina & . & · & . & $\cdot$ & · & $\cdot$ & · & · & $\cdot$ & · & & - & · & $\cdot$ & - & - & · & $\cdot$ & . & $\cdot$ & 01 & \\
\hline Viola sp. 1 & . & . & . & . & . & . & . & . & . & . & & . & . & . & . & . & . & . & . & 01 & . & \\
\hline Silene vulgaris & & . & . & . & . & . & . & . & . & · & & . & . & . & . & . & 01 & . & . & . & . & \\
\hline Trapeliopsis granulosa & & . & . & . & . & . & . & . & . & & & & . & . & . & . & 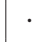 & . & 01 & & & \\
\hline Cladonia coccifera & & · & · & . & $\cdot$ & - & · & - & . & & & & $\cdot$ & $\cdot$ & $\cdot$ & . & 01 & · & . & . & & \\
\hline $\begin{array}{l}\text { Stereocaulon } \\
\text { condensatum }\end{array}$ & & . & . & . & . & . & . & . & . & & & & . & . & . & . & . & . & 01 & . & . & \\
\hline Cladonia deformis & · & · & - & . & . & . & . & · & · & - & - & - & - & $\cdot$ & - & 01 & . & . & . & . & . & \\
\hline Cladonia rangiferina & & - & · & · & $\cdot$ & $\cdot$ & · & · & $\cdot$ & · & & - & $\cdot$ & $\cdot$ & $\cdot$ & $\cdot$ & · & . & . & . & . & \\
\hline Pteridium aquilinum & & · & . & $\cdot$ & $\cdot$ & $\cdot$ & · & · & $\cdot$ & & & & . & $\cdot$ & $\cdot$ & . & . & . & . & . & . & \\
\hline $\begin{array}{l}\text { Polytrichiastrum } \\
\text { formosum }\end{array}$ & & & & . & & & . & & & & & & . & . & & & . & . & . & & & \\
\hline Cerastium holosteoides & & & . & $\theta$ & & . & . & 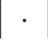 & & & & & & . & & & . & . & . & . & & \\
\hline
\end{tabular}




\begin{tabular}{|c|c|c|c|c|c|c|c|c|c|c|c|c|c|c|c|c|c|c|c|c|c|c|c|c|c|c|c|c|c|}
\hline \multicolumn{23}{|c|}{ Optimal } & \multicolumn{7}{|c|}{ Terminal } \\
\hline & & & \multicolumn{10}{|c|}{6} & \multicolumn{10}{|c|}{$6 / 7$} & \multicolumn{6}{|c|}{8} & \\
\hline \multicolumn{3}{|l|}{85} & \multicolumn{5}{|c|}{7} & \multicolumn{5}{|c|}{13} & \multicolumn{5}{|c|}{1} & \multicolumn{5}{|c|}{6} & \multicolumn{5}{|c|}{11} & \multicolumn{2}{|c|}{16} \\
\hline & & $\cdot$ & 01 & & & 01 & 01 & 01 & 01 & 01 & 01 & 01 & 01 & 01 & 02 & 2 & 01 & & & & 01 & & & 02 & & & & 04 & \\
\hline 04 & . & - & & 02 & 01 & 02 & 02 & 1 & 1 & 01 & 04 & 04 & & 02 & 1 & 1 & 04 & 5 & 04 & 04 & 02 & 01 & 02 & 01 & 04 & 1 & 02 & 1 & \\
\hline . & - & - & - & & $\cdot$ & . & 01 & - & . & & . & & 02 & 01 & 01 & . & 1 & 01 & 01 & $\cdot$ & . & . & 02 & 01 & 04 & 04 & 02 & 02 & \\
\hline . & . & - & - & 01 & 01 & 01 & 01 & 01 & 01 & 02 & 02 & 01 & 01 & 01 & $\cdot$ & 01 & 04 & 01 & 01 & 01 & 01 & 01 & 01 & 02 & 01 & 02 & 01 & 04 & \\
\hline . & . & - & . & & $\cdot$ & $\cdot$ & ${ }^{\circ}$ & . & ${ }^{\circ}$ & & . & & & $\cdot$ & • & $\cdot$ & . & . & . & . & ${ }^{\circ}$ & $\cdot$ & . & $\cdot$ & . & . & · & . & \\
\hline 3 & 2 & 1 & - & 04 & . & . & . & . & 1 & & 01 & 02 & & $\cdot$ & $\cdot$ & - & . & - & 04 & - & $\cdot$ & - & - & . & . & . & . & . & \\
\hline . & 02 & . & . & 01 & 01 & 04 & 02 & . & 01 & 01 & 04 & & . & 01 & . & 02 & 04 & - & 01 & & & - & . & . & - & . & . & 02 & \\
\hline . & 04 & . & . & 01 & . & . & . & . & . & 01 & . & 01 & & • & . & . & . & . & . & 02 & & . & 01 & - & - & 01 & 01 & 04 & \\
\hline 01 & 01 & 02 & 01 & 01 & - & $\cdot$ & 01 & - & & & - & & 01 & & & & $\cdot$ & & 01 & & & & . & . & 01 & 01 & & 01 & \\
\hline 04 & 04 & 1 & 01 & 01 & . & 01 & & . & 04 & 1 & . & & & 1 & & & 04 & 01 & 01 & 01 & 01 & . & & & 01 & & & 01 & \\
\hline . & & 04 & . & & . & . & & . & & $\cdot$ & . & & & 01 & . & . & $\cdot$ &. & $\cdot$ & . & & . & . & . & $\cdot$ & $\cdot$ & - & $\cdot$ & \\
\hline . & 04 & 04 & 01 & 01 & . & 01 & 01 & . & 04 & 1 & 1 & 04 & 04 & 1 & 1 & 01 & 04 & 01 & 01 & 01 & 01 & - & . & . & 01 & 01 & · & . & \\
\hline 04 & 1 & . & 01 & 01 & . & . & & . & . & 01 & 04 & 02 & 04 & 1 & 02 & 01 & 1 & 01 & 01 & 01 & 01 & $\cdot$ & . & . & 01 & 1 & . & 02 & \\
\hline
\end{tabular}
01
04
01
01
01
$01 \cdot 01$
$\begin{array}{llllll}01 & 01 & 01 & 01 & 01\end{array}$

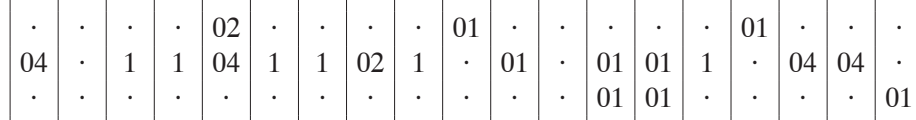

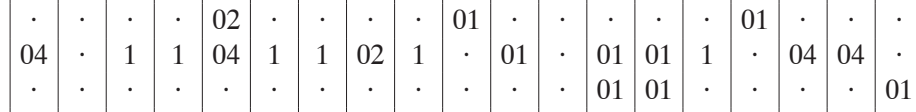

$\cdot$\begin{tabular}{c|c|c|c}
$\cdot$ & 04 & 01 \\
01 & &
\end{tabular}

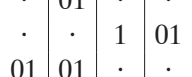

0101

$\begin{array}{llll}01 & 01 & 01\end{array}$

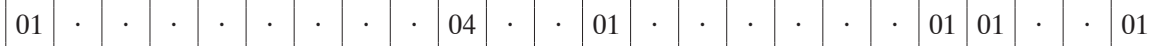

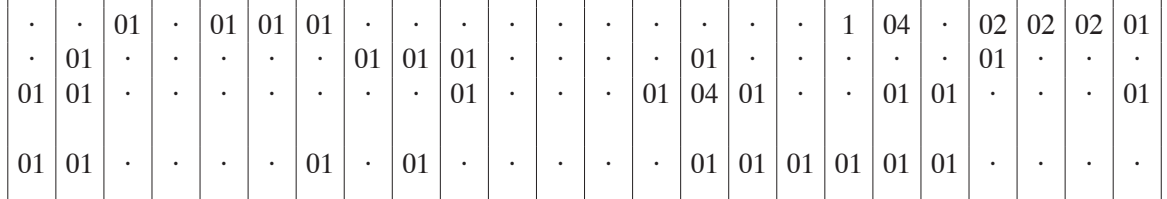

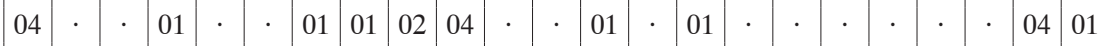

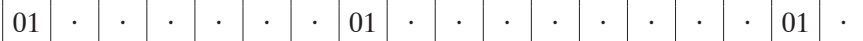

01

01
01
01
\begin{tabular}{l|l|l|l}
04 & 04 & 02 & 01
\end{tabular}
01
\begin{tabular}{l|l|l|l|l|l|l}
02 & 04 & 01 & 1 & 01 & 04 & 04
\end{tabular}

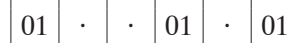

01

$\begin{array}{llll}2 & 3 & 1 & 3\end{array}$

02

$\begin{array}{lllllllllllllll}2 & 1 & 2 & 3 & 5 & 2 & 2 & 1 & 02 & 02 & \cdot & 2\end{array}$

01

04 


\begin{tabular}{|c|c|c|c|c|c|c|c|c|c|c|c|c|c|c|c|c|c|c|c|c|c|c|}
\hline \multirow{3}{*}{\begin{tabular}{|l} 
Succession stage \\
Succession phase \\
Number of plot \\
\end{tabular}} & \multicolumn{15}{|c|}{ Initial } & \multirow{2}{*}{\multicolumn{7}{|c|}{5}} \\
\hline & \multirow{2}{*}{\multicolumn{5}{|c|}{$\begin{array}{c}2 \\
82\end{array}$}} & \multicolumn{10}{|c|}{4} & & & & & & & \\
\hline & & & & & & \multicolumn{5}{|c|}{67} & \multicolumn{5}{|c|}{84} & \multicolumn{5}{|c|}{61} & \\
\hline Luzula sp. & - & . & $\cdot$ & . & . & . & . & $\cdot$ & . & . & . & . & . & . & - & . & . & . & & . & & \\
\hline Amblystegnum serpens & . & . & . & . & . & . & . & . & . & . & . & . & . & . & - & . & . & . & · & . & . & . \\
\hline Cladonia macilenta & . & . & - & . & . & . & . & . & . & $\cdot$ & $\cdot$ & . & $\cdot$ & $\cdot$ & . & . & - & . & & . & . & \\
\hline Cladonia squamosa & & - & - & . & - & . & . & - & & & • & & & & . & - & . & $\cdot$ & & & & \\
\hline Cetraria islandica & . & . & . & - & . & . & . & . & . & . & - & . & . & • & - & - & . & . & & . & - & \\
\hline $\begin{array}{l}\text { Vincetoxicum } \\
\text { hirundinaria }\end{array}$ & · & . & . & . & . & . & . & . & . & - & . & - & . & . & . & . & . & . & ${ }^{\circ}$ & . & . & \\
\hline Dicranum scoparium & . & - & - & . & . & . & . & . & . & - & . & - & . & - & - & . & . & . & - & - & - & \\
\hline Lophocolea bidentata & - & . & - & . & . & . & . & . & . & . & . & - & . & - & - & . & . & . & . & - & - & \\
\hline Lophocolea heterophylla & . & . & . & . & . & . & . & . & . & . & . & . & . & . & - & . & . & . & . & . & . & $\cdot$ \\
\hline $\begin{array}{l}\text { Pseudoscleropodium } \\
\quad \text { purum }\end{array}$ & $\cdot$ & . & . & . & . & . & . & . & . & - & . & . & . & - & . & . & - & . & - & . & . & e \\
\hline Plagiomnium affine & . & . & - & . & . & . & . & . & . & - & . & - & - & . & - & - & - & - & & - & . & \\
\hline Dicranum sp. & - & . & . & . & . & . & . & . & . & . & . & . & . & . & . & . & - & . & . & . & . & \\
\hline Placynthiella oligotropha & - & . & . & . & . & . & . & . & . & . & . & - & . & . & - & . & . & . & - & . & . & \\
\hline Cladonia coniocraea & - & . & . & . & . & . & . & . & . & . & - & . & . & . & - & . & . & . & . & . & . & \\
\hline Pimpinella saxifraga & & 04 & - & . & . & . & . & . & . & . & $\cdot$ & . & . & . & - & . & $\cdot$ & . & - & . & . & \\
\hline Genista tinctoria & & . & . & . & . & . & . & . & . & . & . & . & . & . & - & . & . & . & . & . & . & \\
\hline Viola sp. 2 & & - & - & . & . & . & . & . & & & - & - & . & - & - & . & . & & & & & \\
\hline Veronica officinalis & & - & - & . & . & · & . & . & r & & - & - & - & - & - & $\cdot$ & . & . & & & - & \\
\hline Viola sp. 3 & - & . & - & . & . & . & . & . & . & - & . & - & . & . & . & . & . & . & & - & - & \\
\hline Saxifraga sp. & - & . & - & . & . & . & . & . & . & . & . & - & . & . & - & . & . & . & - & - & . & \\
\hline Galium verum & . & . & - & . & . & . & . & . & . & . & - & - & - & . & . & . & . & - & . & - & . & \\
\hline Veronica chamaedrys & - & . & - & . & . & . & . & . & . & . & - & - & - & . & - & . & . & . & - & - & . & \\
\hline Carex spicata & . & . & . & . & . & . & . & . & . & . & . & . & . & . & . & . & . & . & . & . & . & \\
\hline Erophila verna & . & . & · & $\cdot$ & $\cdot$ & . & . & . & . & . & . & - & - & . & - & . & - & . & & . & . & \\
\hline Luzula pallescens & & . & . & . & . & . & . & . & . & & . & - & . & & . & . & & & & & & \\
\hline Thuidium tamariscinum & . & · & · & . & . & . & . & . & . & . & . & . & . & . & . & . & . & . & & . & . & \\
\hline Plagiomnium cuspidatum & & . & . & . & . & . & . & . & . & . & . & . & . & . & . & . & . & . & . & . & . & \\
\hline
\end{tabular}




\begin{tabular}{l|l|l|l|l|l|l|l|l|l|l|l|l|l|l|l|l|l|l|l|l|l|l|l|l|l|l|l|l|l|}
\hline \multicolumn{10}{|c|}{ Optimal } \\
\hline
\end{tabular}


Table A2.2

Vegetation description in the permanent plots in the Czechy Orlańskie reserve (based on FALIŃSKI 1992, changed; only the plots used for mycological examination are included;

Braun-Blanquet method)

\begin{tabular}{|c|c|c|c|c|c|c|}
\hline \multirow{2}{*}{$\begin{array}{l}\text { Succession phase } \\
\text { Number of plot }\end{array}$} & & \multicolumn{5}{|c|}{$9 / 10$} \\
\hline & & $2 \mathrm{C}$ & $5 \mathrm{C}$ & $6 \mathrm{C}$ & $7 \mathrm{C}$ & $8 \mathrm{C}$ \\
\hline Relevé area $\left(\mathrm{m}^{2}\right)$ & & 200 & 200 & 200 & 200 & 200 \\
\hline \multicolumn{7}{|l|}{ Cover of plant layers (\%) } \\
\hline & $\mathrm{a}$ & 60 & 60 & 50 & 60 & 60 \\
\hline & $a_{1}$ & 60 & 60 & 50 & 60 & 60 \\
\hline & $a_{2}$ & 10 & 10 & $\cdot$ & 10 & $\cdot$ \\
\hline & $\mathrm{b}$ & 10 & 30 & 20 & 10 & + \\
\hline & $\mathrm{c}$ & 90 & 80 & 70 & 80 & 70 \\
\hline & $\mathrm{d}$ & 100 & 90 & 100 & 100 & 100 \\
\hline \multicolumn{2}{|l|}{ Number of species } & 28 & 26 & 31 & 24 & 22 \\
\hline \multicolumn{2}{|l|}{ 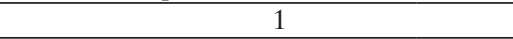 } & 2 & 3 & 4 & 5 & 6 \\
\hline \multirow[t]{2}{*}{ Pinus sylvestris $^{1}$} & $\mathrm{a}$ & 4.4 & 4.4 & 4.4 & 4.4 & 4.4 \\
\hline & $\mathrm{c}$ & $\cdot$ & $\cdot$ & + & + & $\cdot$ \\
\hline \multirow[t]{3}{*}{ Picea $_{\text {abies }}^{2}$} & $\mathrm{a}$ & 1.1 & 2.1 & . & $\cdot$ & . \\
\hline & $\mathrm{b}$ & 1.2 & 1.1 & . & 1.2 & + \\
\hline & $\mathrm{c}$ & + & + & · & + & + \\
\hline \multirow[t]{3}{*}{ Betula pendula ${ }^{2}$} & $\mathrm{a}$ & $\cdot$ & . & . & 1.1 & . \\
\hline & $\mathrm{b}$ & +.2 & 1.2 & 1.1 & $\cdot$ & + \\
\hline & $\mathrm{c}$ & + & + & $\cdot$ & $\cdot$ & + \\
\hline \multirow[t]{2}{*}{ Betula pubescens ${ }^{2}$} & $\mathrm{a}$ & $\cdot$ & 2.2 & . & . & . \\
\hline & $\mathrm{c}$ & + & $\cdot$ & . & . & . \\
\hline \multirow{2}{*}{ Quercus petraea ${ }^{2}$} & $\mathrm{a}$ & $\cdot$ & 2.1 & . & . & . \\
\hline & $\mathrm{c}$ & $\cdot$ & $\cdot$ & . & . & + \\
\hline Salix caprea & $\mathrm{b}$ & 1.1 & $\cdot$ & $\cdot$ & $\cdot$ & $\cdot$ \\
\hline \multirow[t]{2}{*}{ Frangula alnus } & $\mathrm{b}$ & 1.1 & 2.2 & 2.2 & 1.1 & 1.1 \\
\hline & $\mathrm{c}$ & + & + & + & + & $\cdot$ \\
\hline \multirow[t]{2}{*}{ Juniperus communis } & $\mathrm{b}$ & $\cdot$ & 3.3 & 2.3 & 1.2 & + \\
\hline & $\mathrm{c}$ & + & + & + & + & + \\
\hline Populus tremula & $\mathrm{c}$ & + & $\cdot$ & $\cdot$ & $\cdot$ & $\cdot$ \\
\hline \multicolumn{7}{|c|}{ Ch Peucedano-Pinetum, Dicrano-Pinion } \\
\hline Chamaecytisus ratisbonensis & & 1.2 & 1.2 & 2.2 & 2.2 & 1.2 \\
\hline Chimaphila umbellata & & + & +.2 & 1.2 & + & +.2 \\
\hline Pyrola chlorantha & & + & $\cdot$ & + & $\cdot$ & + \\
\hline Diphasiastrum complanatum & & $\cdot$ & $\cdot$ & 2.3 & $\cdot$ & $\cdot$ \\
\hline \multicolumn{7}{|c|}{ Ch Querco-Piceetum, Vaccinio-Piceion } \\
\hline Goodyera repens & & $\cdot$ & $\cdot$ & $\cdot$ & $\cdot$ & + \\
\hline \multicolumn{7}{|c|}{ Ch Vaccinio-Piceetalia, Vaccinio-Piceetea } \\
\hline Vaccinium myrtillus & & 2.3 & 4.4 & 2.2 & 4.4 & 3.4 \\
\hline Vaccinium vitis-idaea & & 4.4 & 2.2 & 3.4 & 3.3 & 3.3 \\
\hline Dicranum polysetum & & +.2 & 1.2 & 1.2 & 1.2 & 1.2 \\
\hline Ptilium crista-castrensis & & + & +.2 & +.2 & +.2 & +.2 \\
\hline Melampyrum pratense & & +.2 & + & 1.2 & 1.2 & + \\
\hline Orthilia secunda & & $\cdot$ & +.2 & +.2 & $\cdot$ & +.2 \\
\hline Trientalis europaea & & + & $\cdot$ & + & · & $\cdot$ \\
\hline $\begin{array}{l}\text { Accompanying species } \\
\text { Luzula pilosa }\end{array}$ & & 1.2 & +.2 & +.2 & + & + \\
\hline
\end{tabular}




\begin{tabular}{|l} 
Pleurozium schreberi \\
Hylocomium splendens \\
Polytrichum commune \\
Dryopteris carthusiana \\
Festuca rubra \\
Festuca ovina \\
Rubus idaeus \\
Lycopodium clavatum \\
Pteridium aquilinum \\
Hieracium lachenalii \\
Agrostis capillaris \\
Rubus saxatilis \\
Acer platanoides \\
Polytrichum juniperinum \\
Solidago virgaurea \\
Carpinus betulus \\
Hieracium pilosella \\
Rumex acetosella
\end{tabular}

\begin{tabular}{|c|c|c|c|c|c|}
\hline & 3.3 & 4.4 & 3.4 & 3.4 & 4.4 \\
\hline & 4.4 & 3.4 & 3.4 & 3.4 & 3.4 \\
\hline & +.2 & +.2 & +.2 & +.2 & +.2 \\
\hline & $\cdot$ & +.2 & + & . & . \\
\hline & +.2 & + & + & +.2 & . \\
\hline & 1.2 & 2.2 & 1.2 & 1.2 & 1.2 \\
\hline $\mathrm{b} / \mathrm{c}$ & $\cdot$ & $\cdot$ & + & $\cdot$ & $\cdot$ \\
\hline & . & 1.2 & . & . & 2.2 \\
\hline & . & 1.2 & . & . & $\cdot$ \\
\hline & . & + & + & + & . \\
\hline & $\cdot$ & + & + & + & . \\
\hline & + & $\cdot$ & . & . & . \\
\hline & + & . & + & + & $\cdot$ \\
\hline & . & . & . & +.2 & +.2 \\
\hline & . & . & + & . & $\cdot$ \\
\hline $\mathrm{c}$ & + & . & $\cdot$ & + & . \\
\hline & $\cdot$ & . & . & + & . \\
\hline & +.2 & . & . & . & . \\
\hline
\end{tabular}

Sporadic species: plot 2C-Veronica officinalis +; plot 6C-Danthonia decumbens + , Carex ericetorum 1.2 , Agrostis alba $[=$ A. gigantea or A stolonifera $]+$, Hieracium umbellatum $+;$ plot $7 \mathrm{C}-$ Carex ovalis +.2

${ }^{1}$ layer a referes to layer $\mathrm{a}_{1}$ in FALIŃSKI $(1992) ;{ }^{2}$ layer a referes to layer a ${ }_{2}$ in FALIŃSKI (1992) 
114 


\section{Appendix 3}

\section{Macrofungi in the plots representing subsequent phases of vegetation succession in the old-fields near the Białowieża old-growth forest}

Table A3.1

Macrofungi in plot 82 (phase 2, Jelonka reserve)

\begin{tabular}{|l|c|c|c|c|c|c|c|c|}
\hline Species & $\mathrm{AC}$ '95 & $\mathrm{AC}$ '96 & $\mathrm{AC} 2 \mathrm{y}$ & $\mathrm{aACy}$ & $\mathrm{mACv}$ & $\mathrm{SF} \%$ & $\mathrm{tTF}$ & $\mathrm{TFy}$ \\
\hline Crinipellis scabella & 43 & 412 & 455 & 227.5 & 366 & 100 & 6 & 2 \\
Marasmius oreades & 103 & 123 & 226 & 113.0 & 61 & 100 & 10 & 2 \\
Mycena flavoalba & 157 & 52 & 209 & 104.5 & 157 & 100 & 2 & 2 \\
Mycena olivaceomarginata & 96 & 16 & 112 & 56.0 & 76 & 90 & 4 & 2 \\
Mycena leptocephala & 164 & $\cdot$ & 164 & 82.0 & 164 & 80 & 1 & 1 \\
Galerina spp. & 40 & 10 & 50 & 25.0 & 39 & 70 & 3 & 2 \\
Coprinopsis friesii & $\cdot$ & 33 & 33 & 16.5 & 31 & 60 & 2 & 1 \\
Mycena pura & 1 & 5 & 6 & 3.0 & 2 & 40 & 4 & 2 \\
Parasola plicatilis & 4 & 6 & 10 & 5.0 & 6 & 30 & 2 & 2 \\
Cystoderma amianthinum & 5 & 4 & 9 & 4.5 & 5 & 10 & 2 & 2 \\
Clitocybe diatreta & 8 & $\cdot$ & 8 & 4.0 & 8 & 10 & 1 & 1 \\
Rickenella fibula & 6 &. & 6 & 3.0 & 6 & 10 & 1 & 1 \\
Clitocybe brumalis & 1 & $\cdot$ & 1 & 0.5 & 1 & 10 & 1 & 1 \\
Conocybe spiculoides & 1 & $\cdot$ & 1 & 0.5 & 1 & 10 & 1 & 1 \\
Entoloma undatum & 1 &. & 1 & 0.5 & 1 & 10 & 1 & 1 \\
\hline
\end{tabular}

$\mathrm{AC}$ - abundance of carpophores during the indicated year; AC2y - abundance of carpophores during 2 years of observations; $\mathrm{aDCy}$ - average density of carpophores per year; $\mathrm{mDCv}$ - maximum density of carpophores per visit; SF\% - spatial frequency of a species (percentage of subplots with a species presence; plot surface - 1000 $\mathrm{m}^{2}$, number of subplots - 10); tTF - number of visits with a species presence; TFy - number of years with a species presence

Table A3.2

Macrofungi in plot 67 (phase 4, Jelonka reserve)

\begin{tabular}{|l|c|c|c|c|c|c|c|c|c|}
\hline \multicolumn{1}{|c|}{ Species } & AC'94 & AC'95 & AC'96 & AC3y & aACy & mACv & SF\% & tTF & TFy \\
\hline ECM species & & & & & & & & & \\
Inocybe lacera & 1146 & 1107 & 216 & 2469 & 823.0 & 865 & 92.5 & 9 & 3 \\
Suillus luteus & 4 & 78 & 140 & 222 & 74.0 & 72 & 85.0 & 8 & 3 \\
Amanita muscaria & 7 & 124 & 134 & 265 & 88.3 & 127 & 65.0 & 6 & 3 \\
Chalciporus piperatus & $\cdot$ & 49 & 57 & 106 & 35.3 & 28 & 57.5 & 5 & 2 \\
Laccaria proxima & 9 & 67 & 93 & 169 & 56.3 & 67 & 42.5 & 5 & 3 \\
Hygrophorus hypothejus & 11 & 14 & 37 & 62 & 20.7 & 22 & 37.5 & 4 & 3 \\
Cortinarius spp. I & 2 & 167 & 110 & 279 & 93.0 & 156 & 35.0 & 5 & 3 \\
Cortinarius cinnamomeoluteus & 4 & 17 & 35 & 56 & 18.7 & 31 & 25.0 & 6 & 3 \\
Inocybe asterospora & $\cdot$ & 20 & $\cdot$ & 20 & 6.7 & 20 & 15.0 & 1 & 1 \\
Cortinarius spp. II & $\cdot$ & $\cdot$ & 17 & 17 & 5.7 & 10 & 15.0 & 2 & 2 \\
Cortinarius spp. III & $\cdot$ & 18 & 3 & 21 & 7.0 & 18 & 12.5 & 2 & 2 \\
Hebeloma sp. 2 & $\cdot$ & 8 & 1 & 9 & 3.0 & 8 & 12.5 & 2 & 2 \\
Cortinarius purpurascens & $\cdot$ & 3 & 11 & 14 & 4.7 & 10 & 10.0 & 3 & 2 \\
Leccinum aurantiacum & $\cdot$ & $\cdot$ & 5 & 5 & 1.7 & 4 & 10.0 & 2 & 1
\end{tabular}




\begin{tabular}{|c|c|c|c|c|c|c|c|c|c|}
\hline Species & AC'94 & $\mathrm{AC} ' 95$ & AC'96 & AC3y & aACy & $\mathrm{mACv}$ & SF\% & tTF & TFy \\
\hline Hebeloma sp. 1 & $\cdot$ & 4 & 1 & 5 & 1.7 & 2 & 7.5 & 3 & 2 \\
\hline Boletus edulis & . & . & 4 & 4 & 1.3 & 3.0 & 7.5 & 2 & 1 \\
\hline Paxillus involutus & 3 & 3 & . & 6 & 2.0 & 3 & 5.0 & 2 & 2 \\
\hline Xerocomus subtomentosus & . & 5 & . & 5 & 1.7 & 5 & 5.0 & 1 & 1 \\
\hline Clitopilus prunulus & . & 3 & . & 3 & 1.0 & 2 & 5.0 & 2 & 1 \\
\hline Inocybe calida & . & 4 & . & 4 & 1.3 & 4 & 2.5 & 1 & 1 \\
\hline Hygrophorus aureus & . & 4 & . & 4 & 1.3 & 4 & 2.5 & 1 & 1 \\
\hline Thelephora terrestris & 3 & . & . & 3 & 1.0 & 3 & 2.5 & 1 & 1 \\
\hline Rhodocollybia butyracea f. asema & . & . & 3 & 3 & 1.0 & 3 & 2.5 & 1 & 1 \\
\hline Ramaria eumorpha & . & . & 3 & 3 & 1.0 & 3 & 2.5 & 1 & 1 \\
\hline Russula fragilis & . & 1 & . & 1 & 0.3 & 1 & 2.5 & 1 & 1 \\
\hline Other species & & & & & & & & & \\
\hline Psilocybe montana & 208 & 183 & 152 & 543 & 181.0 & 192 & 82.5 & 10 & 3 \\
\hline Cantharellula umbonata & 14 & 571 & 735 & 1320 & 440.0 & 362 & 72.5 & 9 & 3 \\
\hline Entoloma spp. & 19 & 56 & 34 & 109 & 36.3 & 56 & 70.0 & 5 & 3 \\
\hline Mycena olivaceomarginata & 44 & 13 & & 57 & 19.0 & 26 & 62.5 & 3 & 2 \\
\hline Rickenella fibula & 6 & 94 & 1 & 101 & 33.7 & 52 & 55.0 & 5 & 3 \\
\hline Clitocybe diatreta & 21 & 80 & 12 & 113 & 37.7 & 71 & 52.5 & 9 & 3 \\
\hline Clavaria argillacea & 167 & 83 & 94 & 344 & 114.7 & 167 & 50.0 & 5 & 3 \\
\hline Cystoderma amianthinum & 3 & 48 & 27 & 78 & 26.0 & 26 & 42.5 & 7 & 3 \\
\hline Galerina atkinsoniana & 1 & 140 & 19 & 160 & 53.3 & 75 & 37.5 & 6 & 3 \\
\hline Mycetinis scorodonius & 42 & 67 & 141 & 250 & 83.3 & 129 & 32.5 & 8 & 3 \\
\hline Collybia cirrhata & 102 & 20 & 8 & 130 & 43.3 & 88 & 32.5 & 4 & 3 \\
\hline Mycena flavoalba & 7 & 142 & 25 & 174 & 58.0 & 130 & 30.0 & 4 & 3 \\
\hline Mycena leptocephala & 1 & 42 & . & 43 & 14.3 & 42 & 27.5 & 2 & 2 \\
\hline Psathyrella gyroflexa & . & 19 & . & 19 & 6.3 & 11 & 27.5 & 2 & 1 \\
\hline Galerina spp. & 2 & 10 & 14 & 26 & 8.7 & 12 & 22.5 & 5 & 3 \\
\hline Lycoperdon molle & . & 10 & 24 & 34 & 11.3 & 16 & 12.5 & 5 & 2 \\
\hline Panaeolus papilionaceus & . & 28 & 2 & 30 & 10.0 & 17 & 12.5 & 3 & 2 \\
\hline Gymnopus androsaceus & 15 & . & 8 & 23 & 7.7 & 15 & 10.0 & 3 & 2 \\
\hline Lycoperdon nigrescens & . & 2 & 5 & 7 & 2.3 & 4 & 10.0 & 3 & 2 \\
\hline Ampulloclitocybe clavipes & . & 9 & 1 & 10 & 3.3 & 9 & 7.5 & 2 & 2 \\
\hline Lycoperdon perlatum & . & 5 & · & 5 & 1.7 & 5 & 5.0 & 1 & 1 \\
\hline Gymnopus dryophilus & 4 & . & - & 4 & 1.3 & 4 & 5.0 & 1 & 1 \\
\hline Hygroaster asterosporus & . & 2 & 1 & 3 & 1.0 & 2 & 5.0 & 2 & 2 \\
\hline Lycoperdon dermoxanthum & . & 1 & 1 & 2 & 0.7 & 1 & 5.0 & 2 & 2 \\
\hline Rhodocybe caelata & 2 & . & - & 2 & 0.7 & 1 & 5.0 & 2 & 1 \\
\hline Galerina hypnorum & . & 5 & . & 5 & 1.7 & 5 & 2.5 & 1 & 1 \\
\hline Mycena vitilis & . & . & 2 & 2 & 0.7 & 2 & 2.5 & 1 & 1 \\
\hline Galerina pumila & . & 1 & - & 1 & 0.3 & 1 & 2.5 & 1 & 1 \\
\hline Mycena pura & . & . & 1 & 1 & 0.3 & 1 & 2.5 & 1 & 1 \\
\hline Rhodocybe hirneola & 1 & . & . & 1 & 0.3 & 1 & 2.5 & 1 & 1 \\
\hline
\end{tabular}

$\mathrm{AC}$ - abundance of carpophores during the indicated year; AC3y - abundance of carpophores during 3 years of observations; $\mathrm{aDCy}$ - average density of carpophores per year; $\mathrm{mDCv}$ - maximum density of carpophores per visit; SF\% - spatial frequency of a species (percentage of subplots with the species presence; plot surface - 1000 $\mathrm{m}^{2}$, number of subplots - 40); tTF - number of visits with a species presence; TFy - number of years with a species presence; $\mathrm{x}$ - perennial carpophores 
Table A3.3

Macrofungi in plot 84 (phase 4, Jelonka reserve)

\begin{tabular}{|c|c|c|c|c|c|c|c|c|c|}
\hline \multirow{2}{*}{\multicolumn{10}{|c|}{$\begin{array}{l}\text { Species } \\
\text { ECM species }\end{array}$}} \\
\hline & & & & & & & & & \\
\hline Inocybe lacera & 431 & 191 & 139 & 761 & 253.7 & 216 & 82.5 & 6 & 3 \\
\hline Cortinarius cinnamomeoluteus & 62 & 393 & 316 & 771 & 257.0 & 365 & 75.0 & 9 & 3 \\
\hline Amanita muscaria & 4 & 98 & 91 & 193 & 64.3 & 98 & 75.0 & 5 & 3 \\
\hline Laccaria proxima & 88 & 253 & 106 & 447 & 149.0 & 205 & 70.0 & 8 & 3 \\
\hline Cortinarius spp. I & 10 & 147 & 55 & 212 & 70.7 & 146 & 67.5 & 5 & 3 \\
\hline Suillus luteus & 5 & 20 & 51 & 76 & 25.3 & 46 & 57.5 & 6 & 3 \\
\hline Hygrophorus hypothejus & 17 & 27 & 37 & 81 & 27.0 & 34 & 45.0 & 5 & 3 \\
\hline Russula fragilis & 1 & 61 & 3 & 65 & 21.7 & 61 & 37.5 & 4 & 3 \\
\hline Leccinum aurantiacum & 1 & 4 & 9 & 14 & 4.7 & 7 & 30.0 & 4 & 3 \\
\hline Cortinarius spp. II & $\cdot$ & 58 & 11 & 69 & 23.0 & 58 & 22.5 & 2 & 2 \\
\hline Amanita pantherina & 5 & 2 & 2 & 9 & 3.0 & 5 & 17.5 & 3 & 3 \\
\hline Thelephora terrestris & 3 & 20 & 22 & 45 & 15.0 & 20 & 15.0 & 6 & 3 \\
\hline Chalciporus piperatus & . & 6 & 6 & 12 & 4.0 & 4 & 15.0 & 4 & 2 \\
\hline Inocybe asterospora & . & 35 & . & 35 & 11.7 & 35 & 12.5 & 1 & 1 \\
\hline Laccaria bicolor & 1 & 14 & 8 & 23 & 7.7 & 14 & 10.0 & 3 & 3 \\
\hline Russula galochroa & $\cdot$ & 4 & 7 & 11 & 3.7 & 7 & 10.0 & 3 & 2 \\
\hline Thelephora caryophyllea & 6 & $\cdot$ & $\cdot$ & 6 & 2.0 & 5 & 10.0 & 2 & 1 \\
\hline Cortinarius spp. III & $\cdot$ & 32 & · & 32 & 10.7 & 32 & 7.5 & 1 & 1 \\
\hline Amanita rubescens & . & 7 & 4 & 11 & 3.7 & 6 & 7.5 & 3 & 2 \\
\hline Clitopilus prunulus & . & 8 & . & 8 & 2.7 & 8 & 7.5 & 1 & 1 \\
\hline Boletus edulis & . & 3 & 3 & 6 & 2.0 & 3 & 7.5 & 2 & 2 \\
\hline Tricholoma portentosum & . & 11 & 3 & 14 & 4.7 & 11 & 5.0 & 2 & 2 \\
\hline Inocybe calida & . & 6 & . & 6 & 2.0 & 6 & 5.0 & 1 & 1 \\
\hline Paxillus involutus & $\cdot$ & 3 & · & 3 & 1.0 & 3 & 5.0 & 1 & 1 \\
\hline Amanita citrina & 1 & 2 & $\cdot$ & 3 & 1.0 & 2 & 5.0 & 2 & 2 \\
\hline Gyroporus castaneus & . & 1 & 2 & 3 & 1.0 & 2 & 5.0 & 2 & 2 \\
\hline Coltricia perennis & 1 & 1 & 1 & 3 & 1.0 & 1 & 5.0 & 3 & 3 \\
\hline Hebeloma sp. 1 & . & 2 & . & 2 & 0.7 & 2 & 5.0 & 1 & 1 \\
\hline Leccinum scabrum & 1 & 1 & . & 2 & 0.7 & 1 & 5.0 & 2 & 2 \\
\hline Russula galochroa & . & 2 & . & 2 & 0.7 & 2 & 5.0 & 1 & 1 \\
\hline Tricholoma albobrunneum & 1 & 1 & . & 2 & 0.7 & 1 & 5.0 & 2 & 2 \\
\hline $\begin{array}{l}\text { Tricholoma saponaceum } \\
\text { var. squamosum }\end{array}$ & . & 25 & . & 25 & 8.3 & 25 & 2.5 & 1 & 1 \\
\hline Inocybe praetervisa & . & 3 & . & 3 & 1.0 & 3 & 2.5 & 1 & 1 \\
\hline Russula emetica & . & 3 & . & 3 & 1.0 & 3 & 2.5 & 1 & 1 \\
\hline Boletus reticulatus & . & . & 2 & 2 & 0.7 & 2 & 2.5 & 1 & 1 \\
\hline Inocybe assimilata & . & 2 & . & 2 & 0.7 & 2 & 2.5 & 1 & 1 \\
\hline Lactarius vietus & . & 2 & . & 2 & 0.7 & 2 & 2.5 & 1 & 1 \\
\hline Russula subfoetens & . & 2 & . & 2 & 0.7 & 2 & 2.5 & 1 & 1 \\
\hline Xerocomus subtomentosus & . & 1 & . & 1 & 0.3 & 1 & 2.5 & 1 & 1 \\
\hline Rhodocollybia butyracea f. asema & · & $\cdot$ & 1 & 1 & 0.3 & 1 & 2.5 & 1 & 1 \\
\hline Other species & & & & & & & & & \\
\hline Clitocybe diatreta & 103 & 187 & 39 & 329 & 109.7 & 124 & 92.5 & 8 & 3 \\
\hline Psilocybe montana & 52 & 106 & 37 & 195 & 65.0 & 50 & 85.0 & 11 & 3 \\
\hline Entoloma spp. & 37 & 262 & 4 & 303 & 101.0 & 223 & 82.5 & 5 & 3 \\
\hline Clavaria argillacea & 428 & 180 & 483 & 1091 & 363.7 & 428 & 70.0 & 5 & 3 \\
\hline Cystoderma amianthinum & 8 & 80 & 107 & 195 & 65.0 & 63 & 57.5 & 8 & 3 \\
\hline Galerina spp. & 12 & 201 & $\cdot$ & 213 & 71.0 & 200 & 55.0 & 4 & 2 \\
\hline Rhodocybe parilis & 18 & 21 & 2 & 41 & 13.7 & 15 & 40.0 & 6 & 3 \\
\hline Lycoperdon dermoxanthum & 4 & 16 & 3 & 23 & 7.7 & 15 & 32.5 & 4 & 3 \\
\hline
\end{tabular}




\begin{tabular}{|c|c|c|c|c|c|c|c|c|c|}
\hline Species & AC'94 & $\mathrm{AC}{ }^{\prime} 95$ & AC'96 & AC3y & aACy & $\mathrm{mACv}$ & SF\% & tTF & TFy \\
\hline Rickenella fibula & 3 & 16 & 1 & 20 & 6.7 & 14 & 30.0 & 5 & 3 \\
\hline Gymnopus androsaceus & 157 & 145 & . & 302 & 100.7 & 157 & 22.5 & 4 & 2 \\
\hline Collybia cirrhata & 3 & 36 & 10 & 49 & 16.3 & 30 & 22.5 & 5 & 3 \\
\hline Mycena olivaceomarginata & 6 & 7 & . & 13 & 4.3 & 6 & 20.0 & 3 & 2 \\
\hline Lycoperdon perlatum & 5 & 13 & 2 & 20 & 6.7 & 6 & 17.5 & 6 & 3 \\
\hline Clitocybe vibecina & 32 & . & 3 & 35 & 11.7 & 32 & 15.0 & 2 & 2 \\
\hline Entoloma jubatum & . & . & 13 & 13 & 4.3 & 13 & 15.0 & 1 & 1 \\
\hline Mycena leptocephala & . & 26 & . & 26 & 8.7 & 26 & 12.5 & 1 & 1 \\
\hline Mycena pura & 4 & 2 & . & 6 & 2.0 & 4 & 12.5 & 2 & 2 \\
\hline Galerina atkinsoniana & 4 & 20 & 10 & 34 & 11.3 & 14 & 10.0 & 5 & 3 \\
\hline Mycetinis scorodonius & 9 & 14 & . & 23 & 7.7 & 14 & 10.0 & 2 & 2 \\
\hline Mycena flavoalba & . & 10 & . & 10 & 3.3 & 10 & 10.0 & 1 & 1 \\
\hline Ampulloclitocybe clavipes & . & 5 & 1 & 6 & 2.0 & 5 & 10.0 & 2 & 2 \\
\hline Flammulaster granulosus & 11 & 6 & . & 17 & 5.7 & 11 & 7.5 & 2 & 2 \\
\hline Hygroaster asterosporus & - & 5 & . & 5 & 1.7 & 5 & 7.5 & 1 & 1 \\
\hline Galerina hypnorum & 1 & 2 & 1 & 4 & 1.3 & 2 & 7.5 & 3 & 3 \\
\hline Macrolepiota procera & 1 & 2 & 1 & 4 & 1.3 & 2 & 7.5 & 3 & 3 \\
\hline Lycoperdon nigrescens & 1 & 2 & . & 3 & 1.0 & 2 & 7.5 & 2 & 2 \\
\hline Galerina pumila & . & 15 & 12 & 27 & 9.0 & 15 & 5.0 & 2 & 2 \\
\hline Hygrocybe virginea var. virginea & . & 2 & 12 & 14 & 4.7 & 12 & 5.0 & 2 & 2 \\
\hline Entoloma rhodopolium & . & 2 & . & 2 & 0.7 & 2 & 5.0 & 1 & 1 \\
\hline Mycena metata & - & 2 & - & 2 & 0.7 & 2 & 5.0 & 1 & 1 \\
\hline Mycena stylobates & - & 1 & 1 & 2 & 0.7 & 1 & 5.0 & 2 & 2 \\
\hline Dacrymyces stillatus & . & 50 & - & 50 & 16.7 & 50 & 2.5 & 1 & 1 \\
\hline Crepidotus variabilis & . & 35 & . & 35 & 11.7 & 30 & 2.5 & 2 & 1 \\
\hline Hypholoma fasciculare & . & 12 & . & 12 & 4.0 & 12 & 2.5 & 1 & 1 \\
\hline Sphaerobolus stellatus & . & 5 & - & 5 & 1.7 & 5 & 2.5 & 1 & 1 \\
\hline Tubaria furfuracea & . & 3 & . & 3 & 1.0 & 2 & 2.5 & 2 & 1 \\
\hline Macrolepiota mastoidea & 2 & . & . & 2 & 0.7 & 2 & 2.5 & 1 & 1 \\
\hline Conocybe rickeniana & 1 & . & . & 1 & 0.3 & 1 & 2.5 & 1 & 1 \\
\hline Gymnopus dryophilus & . & 1 & . & 1 & 0.3 & 1 & 2.5 & 1 & 1 \\
\hline Gymnopus putillus & . & 1 & . & 1 & 0.3 & 1 & 2.5 & 1 & 1 \\
\hline Lycoperdon molle & 1 & . & . & 1 & 0.3 & 1 & 2.5 & 1 & 1 \\
\hline Mycena aetites & $\cdot$ & 1 & . & 1 & 0.3 & 1 & 2.5 & 1 & 1 \\
\hline
\end{tabular}

Abbreviations: see Tab. A3.2

Table A3.4

Macrofungi in plot 61 (phase 5, Jelonka reserve)

\begin{tabular}{|l|c|c|c|c|c|c|c|c|c|}
\hline \multicolumn{1}{|c|}{ Species } & AC'94 & AC'95 & AC'96 & AC3y & aACy & mACv & SF\% & tTF & TFy \\
\hline ECM species & & & & & & & & & \\
Suillus luteus & 5 & 202 & 120 & 327 & 109.0 & 130 & 92.5 & 8 & 3 \\
Cortinarius cinnamomeoluteus & 200 & 885 & 303 & 1388 & 462.7 & 846 & 90.0 & 11 & 3 \\
Hygrophorus hypothejus & 201 & 154 & 96 & 451 & 150.3 & 201 & 80.0 & 5 & 3 \\
Cortinarius spp. I & 49 & 206 & 93 & 348 & 116.0 & 165 & 60.0 & 8 & 3 \\
Amanita muscaria & 2 & 77 & 112 & 191 & 63.7 & 109 & 60.0 & 4 & 3 \\
Tricholoma albobrunneum & 3 & 63 & 51 & 117 & 39.0 & 53 & 42.5 & 5 & 3 \\
Laccaria proxima & 43 & 152 & 119 & 314 & 104.7 & 131 & 40.0 & 6 & 3 \\
Chalciporus piperatus & 2 & 19 & 9 & 30 & 10.0 & 13 & 35.0 & 6 & 3 \\
Cortinarius spp. III &. & 59 & 89 & 148 & 49.3 & 89 & 25.0 & 2 & 2 \\
Cortinarius spp. II &. & 20 & 9 & 29 & 9.7 & 20 & 20.0 & 3 & 2 \\
Rhodocollybia butyracea f. asema &. &. & 25 & 25 & 8.3 & 25 & 17.5 & 1 & 1 \\
Tricholoma portentosum & 5 & 9 & 7 & 21 & 7.0 & 9 & 17.5 & 4 & 3
\end{tabular}




\begin{tabular}{|c|c|c|c|c|c|c|c|c|c|}
\hline Species & AC'94 & $\mathrm{AC}{ }^{\prime} 95$ & AC'96 & AC3y & aACy & $\mathrm{mACv}$ & SF\% & $\mathrm{tTF}$ & TFy \\
\hline $\begin{array}{l}\text { Tricholoma saponaceum } \\
\text { var. saponaceum }\end{array}$ & 3 & $\cdot$ & 29 & 32 & 10.7 & 23 & 15.0 & 3 & 2 \\
\hline Inocybe lacera & 6 & 4 & 15 & 25 & 8.3 & 10 & 15.0 & 6 & 3 \\
\hline Tricholoma equestre & . & 13 & 3 & 16 & 5.3 & 10 & 15.0 & 5 & 2 \\
\hline Lactarius quieticolor & . & 16 & 1 & 17 & 5.7 & 15 & 7.5 & 3 & 2 \\
\hline Thelephora terrestris & . & 2 & 5 & 7 & 2.3 & 3 & 7.5 & 3 & 2 \\
\hline Cortinarius cinnabarinus & . & 1 & 3 & 4 & 1.3 & 3 & 7.5 & 2 & 2 \\
\hline Cortinarius anthracinus & . & 3 & . & 3 & 1.0 & 3 & 7.5 & 1 & 1 \\
\hline Paxillus involutus & . & . & 9 & 9 & 3.0 & 7 & 5.0 & 3 & 1 \\
\hline Boletus edulis & 2 & 1 & 2 & 5 & 1.7 & 2 & 5.0 & 3 & 3 \\
\hline Inocybe praetervisa & . & 1 & . & 1 & 0.3 & 1 & 2.5 & 1 & 1 \\
\hline Xerocomus subtomentosus & . & . & 1 & 1 & 0.3 & 1 & 2.5 & 1 & 1 \\
\hline \multicolumn{10}{|l|}{ Other species } \\
\hline Psilocybe montana & 162 & 81 & 64 & 307 & 102.3 & 82 & 82.5 & 12 & 3 \\
\hline Clitocybe diatreta & 199 & 264 & 153 & 616 & 205.3 & 174 & 67.5 & 10 & 3 \\
\hline Clavaria argillacea & 52 & 364 & 231 & 647 & 215.7 & 264 & 57.5 & 5 & 3 \\
\hline Entoloma spp. & 18 & 71 & 2 & 91 & 30.3 & 41 & 55.0 & 6 & 3 \\
\hline Collybia cirrhata & 127 & 322 & 7 & 456 & 152.0 & 322 & 35.0 & 4 & 3 \\
\hline Rickenella fibula & 1 & 50 & 1 & 52 & 17.3 & 37 & 32.5 & 5 & 3 \\
\hline Lycoperdon dermoxanthum & 1 & 14 & 3 & 18 & 6.0 & 13 & 30.0 & 4 & 3 \\
\hline Mycena leptocephala & 73 & 14 & . & 87 & 29.0 & 73 & 27.5 & 2 & 2 \\
\hline Mycena flavoalba & 4 & 62 & 3 & 69 & 23.0 & 54 & 17.5 & 4 & 3 \\
\hline Mycena olivaceomarginata & 6 & 5 & $\cdot$ & 11 & 3.7 & 6 & 12.5 & 3 & 2 \\
\hline Galerina atkinsoniana & 3 & 28 & 6 & 37 & 12.3 & 17 & 10.0 & 4 & 3 \\
\hline Gymnopus dryophilus & 31 & 1 & 4 & 36 & 12.0 & 31 & 10.0 & 3 & 3 \\
\hline Lycoperdon marginatum & 2 & 7 & 5 & 14 & 4.7 & 4 & 10.0 & 6 & 3 \\
\hline Galerina spp. & 9 & 3 & . & 12 & 4.0 & 9 & 10.0 & 3 & 2 \\
\hline Mycena pura & 1 & 3 & 1 & 5 & 1.7 & 3 & 10.0 & 3 & 3 \\
\hline Gymnopus androsaceus & 59 & . & . & 59 & 19.7 & 59 & 7.5 & 1 & 1 \\
\hline Galerina pumila & . & 16 & 4 & 20 & 6.7 & 13 & 7.5 & 4 & 2 \\
\hline Entoloma jubatum & . & 5 & 5 & 10 & 3.3 & 5 & 7.5 & 2 & 2 \\
\hline Macrolepiota procera & 3 & 3 & . & 6 & 2.0 & 3 & 7.5 & 2 & 2 \\
\hline Psathyrella gyroflexa & $\cdot$ & 4 & $\cdot$ & 4 & 1.3 & 3 & 7.5 & 2 & 1 \\
\hline Clitocybe fragrans & . & . & 31 & 31 & 10.3 & 31 & 5.0 & 1 & 1 \\
\hline Collybia cookei & 2 & 20 & 5 & 27 & 9.0 & 20 & 5.0 & 3 & 3 \\
\hline Hygroaster asterosporus & 4 & 1 & - & 5 & 1.7 & 4 & 5.0 & 2 & 2 \\
\hline Mycena stylobates & 1 & 2 & - & 3 & 1.0 & 1 & 5.0 & 3 & 2 \\
\hline Rhodocybe parilis & 1 & 1 & . & 2 & 0.7 & 1 & 5.0 & 2 & 2 \\
\hline Hygrocybe virginea var. virginea & 11 & 14 & 11 & 36 & 12.0 & 14 & 2.5 & 3 & 3 \\
\hline Cystoderma amianthinum & . & 17 & $\cdot$ & 17 & 5.7 & 17 & 2.5 & 1 & 1 \\
\hline Mycena adonis & 2 & 15 & . & 17 & 5.7 & 15 & 2.5 & 2 & 2 \\
\hline Crepidotus variabilis & - & 7 & . & 7 & 2.3 & 7 & 2.5 & 1 & 1 \\
\hline Ampulloclitocybe clavipes & 3 & . & . & 3 & 1.0 & 3 & 2.5 & 1 & 1 \\
\hline Gymnopus putillus & 3 & . & . & 3 & 1.0 & 3 & 2.5 & 1 & 1 \\
\hline Leptosporomyces galzinii & . & 1 & . & 1 & 0.3 & 1 & 2.5 & 1 & 1 \\
\hline Macrolepiota mastoidea & . & 1 & . & 1 & 0.3 & 1 & 2.5 & 1 & 1 \\
\hline Marasmius oreades & 1 & . & . & 1 & 0.3 & 1 & 2.5 & 1 & 1 \\
\hline Tapinella atrotomentosa & $\cdot$ & & 1 & 1 & 0.3 & 1 & 2.5 & 1 & 1 \\
\hline
\end{tabular}

Abbreviations: see Tab. A3.2 
Table A3.5

Macrofungi in plot 85 (phase 5, Jelonka reserve)

\begin{tabular}{|c|c|c|c|c|c|c|c|c|c|}
\hline Species & $\mathrm{AC}$ '94 & AC'95 & AC'96 & AC3y & aACy & $\mathrm{mACv}$ & SF\% & tTF & TFy \\
\hline $\begin{array}{l}\text { ECM species } \\
\text { Inocybe lacera }\end{array}$ & 584 & 337 & 229 & 1150 & 383.3 & 393 & 85.0 & 9 & 3 \\
\hline Laccaria proxima & 159 & 214 & 208 & 581 & 193.7 & 161 & 75.0 & 8 & 3 \\
\hline Suillus luteus & 5 & 53 & 107 & 165 & 55.0 & 64 & 70.0 & 8 & 3 \\
\hline Hygrophorus hypothejus & 23 & 124 & 98 & 245 & 81.7 & 122 & 67.5 & 5 & 3 \\
\hline Amanita muscaria & 16 & 78 & 138 & 232 & 77.3 & 134 & 67.5 & 7 & 3 \\
\hline Cortinarius cinnamomeoluteus & 9 & 144 & 149 & 302 & 100.7 & 141 & 62.5 & 7 & 3 \\
\hline Thelephora terrestris & 13 & 44 & 14 & 71 & 23.7 & 34 & 37.5 & 6 & 3 \\
\hline Cortinarius spp. I & 1 & 68 & 32 & 101 & 33.7 & 56 & 35.0 & 5 & 3 \\
\hline Chalciporus piperatus & 4 & 12 & 9 & 25 & 8.3 & 10 & 32.5 & 6 & 3 \\
\hline Russula fragilis & . & 38 & 1 & 39 & 13.0 & 38 & 30.0 & 2 & 2 \\
\hline Leccinum aurantiacum & 1 & 6 & 15 & 22 & 7.3 & 15 & 25.0 & 4 & 3 \\
\hline Clitopilus prunulus & 13 & 8 & 1 & 22 & 7.3 & 13 & 15.0 & 4 & 3 \\
\hline Amanita rubescens & 7 & 6 & 10 & 23 & 7.7 & 7 & 12.5 & 5 & 3 \\
\hline Paxillus involutus & . & 3 & 16 & 19 & 6.3 & 16 & 10.0 & 2 & 2 \\
\hline Inocybe curvipes & $\cdot$ & $\cdot$ & 12 & 12 & 4.0 & 10 & 10.0 & 2 & 1 \\
\hline Cortinarius spp. II & · & 10 & 4 & 14 & 4.7 & 10 & 12.5 & 2 & 2 \\
\hline Boletus edulis & $\cdot$ & $\cdot$ & 13 & 13 & 4.3 & 13 & 12.5 & 1 & 1 \\
\hline Cortinarius spp. III & · & 4 & $\cdot$ & 4 & 1.3 & 4 & 7.5 & 1 & 1 \\
\hline Xerocomus subtomentosus & 1 & 2 & 1 & 4 & 1.3 & 2 & 7.5 & 3 & 3 \\
\hline Scleroderma fuscum & . & 3 & . & 3 & 1.0 & 3 & 7.5 & 1 & 1 \\
\hline Gyroporus castaneus & . & 1 & 2 & 3 & 1.0 & 2 & 5.0 & 2 & 2 \\
\hline Inocybe calida & . & 3 & . & 3 & 1.0 & 3 & 5.0 & 1 & 1 \\
\hline Inocybe praetervisa & . & 1 & 2 & 3 & 1.0 & 2 & 5.0 & 2 & 2 \\
\hline Amanita pantherina & · & 2 & $\cdot$ & 2 & 0.7 & 2 & 5.0 & 1 & 1 \\
\hline Tricholoma albobrunneum & . & . & 2 & 2 & 0.7 & 2 & 5.0 & 1 & 1 \\
\hline Tricholoma equestre & . & 3 & . & 3 & 1.0 & 3 & 2.5 & 1 & 1 \\
\hline Laccaria bicolor & . & 2 & . & 2 & 0.7 & 2 & 2.5 & 1 & 1 \\
\hline Xerocomus chrysenteron & . & 2 & . & 2 & 0.7 & 2 & 2.5 & 1 & 1 \\
\hline Lactarius uvidus & . & 1 & · & 1 & 0.3 & 1 & 2.5 & 1 & 1 \\
\hline Rhodocollybia butyracea f. asema & 1 & $\cdot$ & . & 1 & 0.3 & 1 & 2.5 & 1 & 1 \\
\hline Russula clavipes & $\cdot$ & . & 1 & 1 & 0.3 & 1 & 2.5 & 1 & 1 \\
\hline Russula galochroa & $\cdot$ & . & 1 & 1 & 0.3 & 1 & 2.5 & 1 & 1 \\
\hline Russula subfetens & $\cdot$ & 1 & $\cdot$ & 1 & 0.3 & 1 & 2.5 & 1 & 1 \\
\hline Russula vinosobrunnea & . & 1 & · & 1 & 0.3 & 1 & 2.5 & 1 & 1 \\
\hline Other species & & & & & & & & & \\
\hline Psilocybe montana & 75 & 217 & 107 & 399 & 133.0 & 97 & 97.5 & 13 & 3 \\
\hline Clitocybe diatreta & 119 & 127 & 41 & 287 & 95.7 & 72 & 65.0 & 9 & 3 \\
\hline Entoloma spp. & 47 & 84 & 3 & 134 & 44.7 & 48 & 57.5 & 6 & 3 \\
\hline Galerina spp. & 10 & 43 & 56 & 109 & 36.3 & 53 & 42.5 & 6 & 3 \\
\hline Clavaria argillacea & 64 & 141 & 306 & 511 & 170.3 & 168 & 35.0 & 5 & 3 \\
\hline Rickenella fibula & 3 & 83 & 8 & 94 & 31.3 & 73 & 35.0 & 6 & 3 \\
\hline Cystoderma amianthinum & 2 & 34 & 52 & 88 & 29.3 & 32 & 35.0 & 7 & 3 \\
\hline Rhodocybe parilis & 15 & 32 & $\cdot$ & 47 & 15.7 & 24 & 35.0 & 4 & 2 \\
\hline Lycoperdon dermoxanthum & 7 & 15 & . & 22 & 7.3 & 14 & 27.5 & 3 & 2 \\
\hline Mycena leptocephala & 2 & 18 & $\cdot$ & 20 & 6.7 & 18 & 22.5 & 2 & 2 \\
\hline Entoloma jubatum & 1 & 4 & 12 & 17 & 5.7 & 12 & 22.5 & 3 & 3 \\
\hline Cantharellula umbonata & 3 & 46 & 105 & 154 & 51.3 & 55 & 17.5 & 7 & 3 \\
\hline Collybia cirrhata & 10 & 52 & $\cdot$ & 62 & 20.7 & 52 & 17.5 & 3 & 2 \\
\hline Crinipellis scabella & 26 & 6 & . & 32 & 10.7 & 21 & 17.5 & 3 & 2 \\
\hline Lycoperdon perlatum & 1 & 11 & 9 & 21 & 7.0 & 6 & 15.0 & 5 & 3 \\
\hline
\end{tabular}




\begin{tabular}{|c|c|c|c|c|c|c|c|c|c|}
\hline Species & AC'94 & $\mathrm{AC} ' 95$ & AC'96 & AC3y & aACy & $\mathrm{mACv}$ & SF\% & tTF & TFy \\
\hline Mycena flavoalba & 1 & 18 & 1 & 20 & 6.7 & 18 & 15.0 & 3 & 3 \\
\hline Galerina hypnorum & . & 22 & 31 & 53 & 17.7 & 31 & 12.5 & 3 & 2 \\
\hline Lycoperdon ericaeum & 19 & 22 & . & 41 & 13.7 & 14 & 12.5 & 4 & 2 \\
\hline Gymnopus androsaceus & 20 & 41 & 6 & 67 & 22.3 & 21 & 10.0 & 5 & 3 \\
\hline Rhodocybe caelata & 4 & 2 & . & 6 & 2.0 & 2 & 10.0 & 3 & 2 \\
\hline Hygrocybe conica var. conica & - & 5 & . & 5 & 1.7 & 5 & 10.0 & 1 & 1 \\
\hline Hygrocybe virginea var. virginea & 2 & 7 & 1 & 10 & 3.3 & 7 & 7.5 & 3 & 3 \\
\hline Clitocybe vibecina & 2 & 6 & . & 8 & 2.7 & 4 & 7.5 & 3 & 2 \\
\hline Mycena olivaceomarginata & . & 8 & . & 8 & 2.7 & 7 & 7.5 & 2 & 1 \\
\hline Entoloma conferendum & . & . & 15 & 15 & 5.0 & 15 & 5.0 & 1 & 1 \\
\hline Galerina atkinsoniana & 2 & . & 6 & 8 & 2.7 & 6 & 5.0 & 2 & 2 \\
\hline Clitocybe odora var. odora & . & . & 6 & 6 & 2.0 & 6 & 5.0 & 1 & 1 \\
\hline Cystoderma jasonis var. lilacipes & . & 5 & . & 5 & 1.7 & 5 & 5.0 & 1 & 1 \\
\hline Flammulaster granulosus & 1 & 1 & . & 2 & 0.7 & 1 & 5.0 & 2 & 2 \\
\hline Mycena galopus & . & 10 & . & 10 & 3.3 & 10 & 2.5 & 1 & 1 \\
\hline Lycoperdon nigrescens & . & 7 & . & 7 & 2.3 & 7 & 2.5 & 1 & 1 \\
\hline Hygroaster asterosporus & . & 6 & . & 6 & 2.0 & 6 & 2.5 & 1 & 1 \\
\hline Cystoderma jasonis var. jasonis & - & . & 4 & 4 & 1.3 & 4 & 2.5 & 1 & 1 \\
\hline Gymnopus impudicus & . & 4 & . & 4 & 1.3 & 4 & 2.5 & 1 & 1 \\
\hline Lycoperdon molle & 4 & . & . & 4 & 1.3 & 4 & 2.5 & 1 & 1 \\
\hline Lycoperdon norvegicum & 3 & . & 1 & 4 & 1.3 & 3 & 2.5 & 2 & 2 \\
\hline Collybia tuberosa & . & 2 & . & 2 & 0.7 & 2 & 2.5 & 1 & 1 \\
\hline Mycena stylobates & . & 2 & . & 2 & 0.7 & 2 & 2.5 & 1 & 1 \\
\hline Paneolus papilionaceus & . & . & 2 & 2 & 0.7 & 2 & 2.5 & 1 & 1 \\
\hline Collybia cookei & 1 & . & . & 1 & 0.3 & 1 & 2.5 & 1 & 1 \\
\hline Galerina pumila & . & 1 & . & 1 & 0.3 & 1 & 2.5 & 1 & 1 \\
\hline Mycena vitilis & . & 1 & . & 1 & 0.3 & 1 & 2.5 & 1 & 1 \\
\hline Polyporus ciliatus & . & . & 1 & 1 & 0.3 & 1 & 2.5 & 1 & 1 \\
\hline Tapinella atrotomentosa & . & . & 1 & 1 & 0.3 & 1 & 2.5 & 1 & 1 \\
\hline
\end{tabular}

Abbreviations: see Tab. A3.2

Table A3.6

Macrofungi in plot 7 (phase 6, Jelonka reserve)

\begin{tabular}{|l|c|c|c|c|c|c|c|c|c|}
\hline \multicolumn{1}{|c|}{ Species } & AC'94 & AC'95 & AC'96 & AC3y & aACy & mACv & SF\% & tTF & TFy \\
\hline ECM species & & & & & & & & & \\
Cortinarius cinnamomeoluteus & 255 & 406 & 277 & 938 & 312.7 & 330 & 100.0 & 11 & 3 \\
Hygrophorus hypothejus & 460 & 357 & 219 & 1036 & 345.3 & 460 & 95.0 & 5 & 3 \\
Suillus luteus & 77 & 134 & 105 & 316 & 105.3 & 72 & 87.5 & 10 & 3 \\
Cortinarius spp. I & 61 & 230 & 99 & 390 & 130.0 & 195 & 77.5 & 9 & 3 \\
Chalciporus piperatus & 27 & 127 & 58 & 212 & 70.7 & 63 & 77.5 & 8 & 3 \\
Amanita muscaria & 72 & 236 & 193 & 501 & 167.0 & 235 & 75.0 & 6 & 3 \\
Laccaria proxima & 116 & 298 & 159 & 573 & 191.0 & 277 & 62.5 & 9 & 3 \\
Tricholoma albobrunneum & 3 & 37 & 24 & 64 & 21.3 & 37 & 55.0 & 4 & 3 \\
Inocybe lacera & 47 & 51 & 45 & 143 & 47.7 & 43 & 50.0 & 9 & 3 \\
Lactarius rufus & 1 & 110 & 51 & 162 & 54.0 & 110 & 47.5 & 6 & 3 \\
Thelephora terrestris & 35 & 38 & 3 & 76 & 25.3 & 27 & 37.5 & 6 & 3 \\
Cortinarius colus & - & 56 & $\cdot$ & 56 & 18.7 & 56 & 35.0 & 1 & 1 \\
Tricholoma equestre & 3 & 38 & 34 & 75 & 25.0 & 37 & 32.5 & 6 & 3 \\
Rhodocollybia butyracea f. asema & 2 & 6 & 31 & 39 & 13.0 & 26 & 32.5 & 6 & 3 \\
Tricholoma portentosum & 8 & 21 & 49 & 78 & 26.0 & 45 & 30.0 & 4 & 3 \\
Laccaria bicolor & 58 & 25 & 93 & 176 & 58.7 & 58 & 25.0 & 8 & 3 \\
Leccinum aurantiacum & 1 & 8 & 12 & 21 & 7.0 & 9 & 17.5 & 6 & 3 \\
Russula fragilis & 2 & 48 & 4 & 54 & 18.0 & 45 & 20.0 & 5 & 3
\end{tabular}




\begin{tabular}{|c|c|c|c|c|c|c|c|c|c|}
\hline Species & AC'94 & AC'95 & AC'96 & AC3y & aACy & $\mathrm{mACv}$ & SF\% & tTF & TFy \\
\hline Cortinarius parevernius & $\cdot$ & 10 & 11 & 21 & 7.0 & 11 & 15.0 & 2 & 2 \\
\hline Cortinarius spp. III & 2 & 9 & 6 & 17 & 5.7 & 9 & 15.0 & 3 & 3 \\
\hline Boletus edulis & - & $\cdot$ & 7 & 7 & 2.3 & 3 & 15.0 & 3 & 1 \\
\hline Inocybe curvipes & . & 19 & . & 19 & 6.3 & 19 & 10.0 & 1 & 1 \\
\hline $\begin{array}{l}\text { Tricholoma saponaceum } \\
\text { var. saponaceum }\end{array}$ & . & 2 & 15 & 17 & 5.7 & 15 & 10.0 & 2 & 2 \\
\hline Cortinarius spp. II & & 1 & 12 & 13 & 4.3 & 8 & 10.0 & 3 & 2 \\
\hline Ramaria eumorpha & 19 & 31 & 9 & 59 & 19.7 & 31 & 7.5 & 3 & 3 \\
\hline Amanita rubescens & . & 3 & 2 & 5 & 1.7 & 3 & 7.5 & 2 & 2 \\
\hline Cortinarius тисоsиs & - & 3 & - & 3 & 1.0 & 3 & 7.5 & 1 & 1 \\
\hline Tricholoma pessundatum & 3 & . & . & 3 & 1.0 & 3 & 7.5 & 1 & 1 \\
\hline Cortinarius purpurascens & . & - & 4 & 4 & 1.3 & 4 & 5.0 & 1 & 1 \\
\hline Inocybe assimilata & . & . & 3 & 3 & 1.0 & 3 & 5.0 & 1 & 1 \\
\hline Amanita pantherina & 1 & 1 & . & 2 & 0.7 & 1 & 5.0 & 2 & 2 \\
\hline Tricholoma imbricatum & . & . & 3 & 3 & 1.0 & 3 & 2.5 & 1 & 1 \\
\hline Xerocomus badius & . & . & 3 & 3 & 1.0 & 3 & 2.5 & 1 & 1 \\
\hline Inocybe calida & 2 & . & . & 2 & 0.7 & 2 & 2.5 & 1 & 1 \\
\hline Rhizopogon luteolus & 2 & . & . & 2 & 0.7 & 2 & 2.5 & 1 & 1 \\
\hline Clitopilus prunulus & . & . & 1 & 1 & 0.3 & 1 & 2.5 & 1 & 1 \\
\hline Inocybe asterospora & . & 1 & ${ }^{\circ}$ & 1 & 0.3 & 1 & 2.5 & 1 & 1 \\
\hline Paxillus involutus & . & $\cdot$ & 1 & 1 & 0.3 & 1 & 2.5 & 1 & 1 \\
\hline \multicolumn{10}{|l|}{ Other species } \\
\hline Clitocybe diatreta & 345 & 239 & 141 & 725 & 241.7 & 208 & 85.0 & 8 & 3 \\
\hline Psilocybe montana & 500 & 295 & 54 & 849 & 283.0 & 254 & 80.0 & 14 & 3 \\
\hline Rickenella fibula & 45 & 156 & 82 & 283 & 94.3 & 98 & 65.0 & 10 & 3 \\
\hline Cystoderma amianthinum & 62 & 130 & 173 & 365 & 121.7 & 131 & 62.5 & 10 & 3 \\
\hline Galerina atkinsoniana & 50 & 185 & 132 & 367 & 122.3 & 159 & 50.0 & 6 & 3 \\
\hline Gymnopus androsaceus & 252 & 14 & 87 & 353 & 117.7 & 247 & 47.5 & 7 & 3 \\
\hline Ampulloclitocybe clavipes & 29 & 54 & 25 & 108 & 36.0 & 45 & 45.0 & 6 & 3 \\
\hline Galerina spp. & 130 & 64 & 39 & 233 & 77.7 & 113 & 40.0 & 6 & 3 \\
\hline Hygroaster asterosporus & 10 & 17 & 34 & 61 & 20.3 & 23 & 40.0 & 4 & 3 \\
\hline Mycena leptocephala & 95 & 59 & 7 & 161 & 53.7 & 92 & 37.5 & 6 & 3 \\
\hline Collybia cirrhata & 64 & 20 & 23 & 107 & 35.7 & 40 & 32.5 & 4 & 3 \\
\hline Entoloma spp. & 5 & 13 & 18 & 36 & 12.0 & 13 & 30.0 & 6 & 3 \\
\hline Cantharellula umbonata & 74 & 122 & 138 & 334 & 111.3 & 65 & 22.5 & 10 & 3 \\
\hline Clitocybe vibecina & 16 & 41 & 4 & 61 & 20.3 & 31 & 22.5 & 5 & 3 \\
\hline Mycena pura & 19 & 2 & 1 & 22 & 7.3 & 19 & 20.0 & 4 & 3 \\
\hline Clitocybe candicans & 22 & 2 & . & 24 & 8.0 & 20 & 17.5 & 4 & 2 \\
\hline Lycoperdon perlatum & 6 & 4 & 5 & 15 & 5.0 & 4 & 15.0 & 5 & 3 \\
\hline Strobilurus stephanocystis & . & 10 & 4 & 14 & 4.7 & 10 & 15.0 & 2 & 2 \\
\hline Flammulaster granulosus & 9 & 25 & . & 34 & 11.3 & 25 & 12.5 & 2 & 2 \\
\hline Cystodermella granulosa & 18 & 3 & 4 & 25 & 8.3 & 17 & 12.5 & 5 & 3 \\
\hline Cystoderma jasonis var. lilacipes & 9 & . & 10 & 19 & 6.3 & 9 & 12.5 & 3 & 2 \\
\hline Dacrymyces variisporus & - & 60 & . & 60 & 20.0 & 37 & 10.0 & 3 & 1 \\
\hline Mycena vitilis & . & 4 & 5 & 9 & 3.0 & 5 & 10.0 & 2 & 2 \\
\hline Rhodocybe caelata & 4 & . & 1 & 5 & 1.7 & 3 & 10.0 & 3 & 2 \\
\hline Clavaria argillacea & 2 & 15 & . & 17 & 5.7 & 15 & 7.5 & 2 & 2 \\
\hline Mycena flavoalba & 4 & 11 & . & 15 & 5.0 & 10 & 7.5 & 3 & 2 \\
\hline Mycena stylobates & 2 & 1 & 1 & 4 & 1.3 & 2 & 7.5 & 3 & 3 \\
\hline Marasmiellus vaillantii & . & 25 & 30 & 55 & 18.3 & 30 & 5.0 & 2 & 2 \\
\hline Galerina hypnorum & 9 & 20 & . & 29 & 9.7 & 16 & 5.0 & 3 & 2 \\
\hline Crinipellis scabella & . & - & 18 & 18 & 6.0 & 18 & 5.0 & 1 & 1 \\
\hline Galerina pumila & 3 & 6 & . & 9 & 3.0 & 4 & 5.0 & 4 & 2 \\
\hline
\end{tabular}




\begin{tabular}{|c|c|c|c|c|c|c|c|c|c|}
\hline Species & AC'94 & AC'95 & AC'96 & AC3y & $\mathrm{aACy}$ & $\mathrm{mACv}$ & SF\% & tTF & TFy \\
\hline Hygrocybe conica var. conica & . & 6 & - & 6 & 2.0 & 6 & 5.0 & 1 & 1 \\
\hline Rhodocybe parilis & 2 & 4 & - & 6 & 2.0 & 4 & 5.0 & 2 & 2 \\
\hline Entoloma jubatum & - & 5 & - & 5 & 1.7 & 5 & 5.0 & 1 & 1 \\
\hline Baeospora myosura & - & 4 & - & 4 & 1.3 & 4 & 5.0 & 1 & 1 \\
\hline Ripartites tricholoma & 1 & 2 & - & 3 & 1.0 & 2 & 5.0 & 2 & 2 \\
\hline Melanoleuca graminicola & - & 2 & - & 2 & 0.7 & 2 & 5.0 & 1 & 1 \\
\hline Mycena vulgaris & 25 & . & 50 & 75 & 25.0 & 50 & 2.5 & 2 & 2 \\
\hline Trichaptum fuscoviolaceum & 39 & - & . & 39 & 13.0 & 17 & 2.5 & 3 & 1 \\
\hline Clitocybe fragrans & 28 & . & - & 28 & 9.3 & 28 & 2.5 & 1 & 1 \\
\hline Gymnopus aquosus & . & . & 11 & 11 & 3.7 & 6 & 2.5 & 2 & 1 \\
\hline Tremella mesenterica & - & - & 9 & 9 & 3.0 & 4 & 2.5 & 3 & 1 \\
\hline Pholiota gummosa & . & 4 & 4 & 8 & 2.7 & 4 & 2.5 & 2 & 2 \\
\hline Calocera furcata & 5 & - & . & 5 & 1.7 & 5 & 2.5 & 1 & 1 \\
\hline Mycena metata & 5 & . & . & 5 & 1.7 & 5 & 2.5 & 1 & 1 \\
\hline Sphaerobolus stellatus & . & 5 & . & 5 & 1.7 & 5 & 2.5 & 1 & 1 \\
\hline Collybia tuberosa & - & 3 & . & 3 & 1.0 & 3 & 2.5 & 1 & 1 \\
\hline Phanerochaete sanguinea & 3 & . & . & 3 & 1.0 & 3 & 2.5 & 1 & 1 \\
\hline Leptosporomyces galzinii & - & 2 & - & 2 & 0.7 & 2 & 2.5 & 1 & 1 \\
\hline Mycena sanguinolenta & 2 & . & - & 2 & 0.7 & 2 & 2.5 & 1 & 1 \\
\hline Galerina badipes & 1 & - & - & 1 & 0.3 & 1 & 2.5 & 1 & 1 \\
\hline Gymnopus putillus & 1 & - & - & 1 & 0.3 & 1 & 2.5 & 1 & 1 \\
\hline Hypholoma fasciculare & $\cdot$ & 1 & $\cdot$ & 1 & 0.3 & 1 & 2.5 & 1 & 1 \\
\hline
\end{tabular}

Abbreviations: see Tab. A3.2

Table A3.7

Macrofungi in plot 13 (phase 6, Jelonka reserve)

\begin{tabular}{|c|c|c|c|c|c|c|c|c|c|}
\hline Species & AC'94 & $\mathrm{AC}{ }^{\prime} 95$ & AC'96 & AC3y & aACy & $\mathrm{mACv}$ & SF\% & $\mathrm{tTF}$ & TFy \\
\hline ECM species & & & & & & & & & \\
\hline Cortinarius spp. I & 595 & 1204 & 445 & 2244 & 748.0 & 859 & 100.0 & 10 & 3 \\
\hline Hygrophorus hypothejus & 437 & 443 & 265 & 1145 & 381.7 & 437 & 97.5 & 6 & 3 \\
\hline Cortinarius cinnamomeoluteus & 185 & 427 & 180 & 792 & 264.0 & 349 & 95.0 & 11 & 3 \\
\hline Amanita muscaria & 69 & 194 & 162 & 425 & 141.7 & 186 & 90.0 & 8 & 3 \\
\hline Suillus luteus & 26 & 155 & 61 & 242 & 80.7 & 79 & 90.0 & 8 & 3 \\
\hline Tricholoma albobrunneum & 34 & 132 & 72 & 238 & 79.3 & 105 & 75.0 & 5 & 3 \\
\hline Laccaria proxima & 89 & 325 & 166 & 580 & 193.3 & 276 & 72.5 & 6 & 3 \\
\hline Chalciporus piperatus & 7 & 105 & 58 & 170 & 56.7 & 65 & 72.5 & 6 & 3 \\
\hline Tricholoma portentosum & 35 & 138 & 10 & 183 & 61.0 & 136 & 52.5 & 5 & 3 \\
\hline Cortinarius parevernius & 1 & 51 & 88 & 140 & 46.7 & 70 & 52.5 & 4 & 3 \\
\hline Thelephora terrestris & 96 & 123 & 57 & 276 & 92.0 & 109 & 50.0 & 11 & 3 \\
\hline Cortinarius mисоsus & 7 & 18 & 26 & 51 & 17.0 & 25 & 47.5 & 6 & 3 \\
\hline Inocybe lacera & 34 & 51 & 31 & 116 & 38.7 & 45 & 45.0 & 8 & 3 \\
\hline Rhodocollybia butyracea f. asema & 18 & 17 & 30 & 65 & 21.7 & 30 & 37.5 & 4 & 3 \\
\hline Tricholoma equestre & 11 & 25 & 54 & 90 & 30.0 & 47 & 35.0 & 5 & 3 \\
\hline Cortinarius anthracinus & 3 & 26 & 1 & 30 & 10.0 & 26 & 32.5 & 4 & 3 \\
\hline $\begin{array}{l}\text { Tricholoma saponaceum } \\
\text { var. saponaceum }\end{array}$ & 29 & 45 & 50 & 124 & 41.3 & 45 & 25.0 & 4 & 3 \\
\hline $\begin{array}{l}\text { Cortinarius multiformis } \\
\text { f. coniferarum }\end{array}$ & 2 & 5 & 14 & 21 & 7.0 & 10 & 17.5 & 4 & 3 \\
\hline Lactarius rufus & - & 12 & 1 & 13 & 4.3 & 12 & 15.0 & 2 & 2 \\
\hline Sarcodon squamosus & 5 & 8 & . & 13 & 4.3 & 8 & 15.0 & 3 & 2 \\
\hline Laccaria bicolor & 22 & 9 & 20 & 51 & 17.0 & 22 & 12.5 & 6 & 3 \\
\hline Hebeloma sp. 1 & 3 & 9 & . & 12 & 4.0 & 9 & 10.0 & 2 & 2 \\
\hline Ramaria eumorpha & 7 & 21 & . & 28 & 9.3 & 21 & 7.5 & 2 & 2 \\
\hline
\end{tabular}




\begin{tabular}{|c|c|c|c|c|c|c|c|c|c|}
\hline Species & AC'94 & AC'95 & AC'96 & AC3y & aACy & $\mathrm{mACv}$ & SF\% & tTF & TFy \\
\hline Cortinarius spp. III & 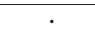 & 5 & $\cdot$ & 5 & 1.7 & 5 & 7.5 & 1 & 1 \\
\hline Clitopilus prunulus & 17 & 15 & . & 32 & 10.7 & 17 & 5.0 & 2 & 2 \\
\hline Cortinarius spp. II & 7 & 1 & . & 8 & 2.7 & 7 & 5.0 & 2 & 2 \\
\hline Inocybe assimilata & 1 & 3 & . & 4 & 1.3 & 2 & 5.0 & 3 & 2 \\
\hline Cortinarius purpurascens & . & 3 & . & 3 & 1.0 & 3 & 5.0 & 1 & 1 \\
\hline Inocybe praetervisa & . & 2 & 1 & 3 & 1.0 & 2 & 5.0 & 2 & 2 \\
\hline Amanita pantherina & . & 1 & 1 & 2 & 0.7 & 1 & 5.0 & 2 & 2 \\
\hline Suillus bovinus & . & 1 & 1 & 2 & 0.7 & 1 & 2.5 & 2 & 2 \\
\hline Boletus edulis & . & . & 1 & 1 & 0.3 & 1 & 2.5 & 1 & 1 \\
\hline Cortinarius acetosus & . & 1 & . & 1 & 0.3 & 1 & 2.5 & 1 & 1 \\
\hline Cortinarius cinnabarinus & . & 1 & . & 1 & 0.3 & 1 & 2.5 & 1 & 1 \\
\hline Cortinarius spp. IV & - & 1 & . & 1 & 0.3 & 1 & 2.5 & 1 & 1 \\
\hline Inocybe curvipes & . & . & 1 & 1 & 0.3 & 1 & 2.5 & 1 & 1 \\
\hline Paxillus involutus & - & - & 1 & 1 & 0.3 & 1 & 2.5 & 1 & 1 \\
\hline Tricholoma imbricatum & . & 1 & . & 1 & 0.3 & 1 & 2.5 & 1 & 1 \\
\hline Other species & & & & & & & & & \\
\hline Psilocybe montana & 177 & 91 & 25 & 293 & 97.7 & 92 & 95.0 & 11 & 3 \\
\hline Clitocybe diatreta & 606 & 606 & 206 & 1418 & 472.7 & 341 & 90.0 & 11 & 3 \\
\hline Cystoderma amianthinum & 78 & 129 & 31 & 238 & 79.3 & 106 & 65.0 & 9 & 3 \\
\hline Mycena leptocephala & 44 & 63 & 11 & 118 & 39.3 & 59 & 60.0 & 5 & 3 \\
\hline Rickenella fibula & 23 & 337 & 19 & 379 & 126.3 & 175 & 52.5 & 8 & 3 \\
\hline Galerina atkinsoniana & 20 & 222 & 60 & 302 & 100.7 & 162 & 52.5 & 7 & 3 \\
\hline Galerina spp. & 32 & 144 & 19 & 195 & 65.0 & 85 & 50.0 & 9 & 3 \\
\hline Gymnopus androsaceus & 328 & 34 & 5 & 367 & 122.3 & 238 & 37.5 & 5 & 3 \\
\hline Entoloma spp. & 7 & 16 & 6 & 29 & 9.7 & 12 & 35.0 & 6 & 3 \\
\hline Clavaria argillacea & 67 & 177 & 23 & 267 & 89.0 & 160 & 32.5 & 5 & 3 \\
\hline Hygroaster asterosporus & 5 & 15 & 2 & 22 & 7.3 & 15 & 30.0 & 3 & 3 \\
\hline Collybia cirrhata & 63 & 56 & 37 & 156 & 52.0 & 56 & 27.5 & 5 & 3 \\
\hline Galerina pumila & 5 & 14 & . & 19 & 6.3 & 7 & 15.0 & 3 & 2 \\
\hline Lycoperdon perlatum & 1 & 28 & . & 29 & 9.7 & 22 & 12.5 & 3 & 2 \\
\hline Ampulloclitocybe clavipes & 2 & 10 & 2 & 14 & 4.7 & 9 & 10.0 & 5 & 3 \\
\hline Melanoleuca graminicola & 4 & 9 & . & 13 & 4.3 & 5 & 10.0 & 4 & 2 \\
\hline Mycena flavoalba & 3 & 10 & . & 13 & 4.3 & 9 & 10.0 & 3 & 2 \\
\hline Clitocybe candicans & 10 & 2 & 7 & 19 & 6.3 & 10 & 7.5 & 4 & 3 \\
\hline Lycoperdon molle & 6 & 3 & 5 & 14 & 4.7 & 6 & 7.5 & 5 & 3 \\
\hline Dacrymyces variisporus & 5 & 3 & 3 & 11 & 3.7 & 5 & 7.5 & 3 & 3 \\
\hline Marasmius oreades & 6 & 3 & 1 & 10 & 3.3 & 3 & 7.5 & 4 & 3 \\
\hline Entoloma jubatum & . & 4 & 3 & 7 & 2.3 & 4 & 7.5 & 2 & 2 \\
\hline Mycena vitilis & 5 & 2 & . & 7 & 2.3 & 4 & 7.5 & 3 & 2 \\
\hline Lycoperdon excipuliforme & 4 & 1 & . & 5 & 1.7 & 2 & 7.5 & 3 & 2 \\
\hline Collybia tuberosa & 40 & . & 5 & 45 & 15.0 & 32 & 5.0 & 3 & 2 \\
\hline Cystoderma jasonis var. lilacipes & . & . & 9 & 9 & 3.0 & 9 & 5.0 & 1 & 1 \\
\hline Mycena olivaceomarginata & 8 & . & . & 8 & 2.7 & 8 & 5.0 & 1 & 1 \\
\hline Leptosporomyces galzinii & . & 5 & . & 5 & 1.7 & 5 & 5.0 & 1 & 1 \\
\hline Rhodocybe caelata & 1 & 1 & 2 & 4 & 1.3 & 2 & 5.0 & 3 & 3 \\
\hline Rhodocybe parilis & 1 & 2 & . & 3 & 1.0 & 2 & 5.0 & 2 & 2 \\
\hline Mycena parabolica & 2 & . & . & 2 & 0.7 & 2 & 5.0 & 1 & 1 \\
\hline Ripartites tricholoma & 2 & . & - & 2 & 0.7 & 2 & 5.0 & 1 & 1 \\
\hline Gymnopus confluens & - & 3 & 14 & 17 & 5.7 & 14 & 2.5 & 2 & 2 \\
\hline Rhodocybe hirneola & - & 12 & . & 12 & 4.0 & 12 & 2.5 & 1 & 1 \\
\hline Cystodermella granulosa & 4 & . & . & 4 & 1.3 & 4 & 2.5 & 1 & 1 \\
\hline Clitocybe vibecina & . & 3 & . & 3 & 1.0 & 3 & 2.5 & 1 & 1 \\
\hline Gymnopus putillus & 3 & . & . & 3 & 1.0 & 3 & 2.5 & 1 & 1 \\
\hline
\end{tabular}




\begin{tabular}{|l|c|c|c|c|c|c|c|c|c|}
\hline \multicolumn{1}{|c|}{ Species } & AC'94 & AC'95 & AC'96 & AC3y & aACy & mACv & SF\% & tTF & TFy \\
\hline Lycoperdon dermoxanthum & 1 & 2 & $\cdot$ & 3 & 1.0 & 2 & 2.5 & 2 & 2 \\
Mycena speirea & $\cdot$ & $\cdot$ & 3 & 3 & 1.0 & 3 & 2.5 & 1 & 1 \\
Lepiota pseudolilacea & $\cdot$ & 2 & $\cdot$ & 2 & 0.7 & 2 & 2.5 & 1 & 1 \\
Entoloma nitens & $\cdot$ & 1 & $\cdot$ & 1 & 0.3 & 1 & 2.5 & 1 & 1 \\
Hygrocybe virginea var. virginea & 1 & $\cdot$ & $\cdot$ & 1 & 0.3 & 1 & 2.5 & 1 & 1 \\
Mycena arcangeliana & $\cdot$ & $\cdot$ & 1 & 1 & 0.3 & 1 & 2.5 & 1 & 1 \\
Psathyrella fibrillosa & $\cdot$ & 1 & $\cdot$ & 1 & 0.3 & 1 & 2.5 & 1 & 1 \\
Strobilurus stephanocystis & $\cdot$ & $\cdot$ & 1 & 1 & 0.3 & 1 & 2.5 & 1 & 1 \\
\hline
\end{tabular}

Abbreviations: see Tab. A3.2

Table A3.8

Macrofungi in plot 1 (phase 6/7, Jelonka reserve)

\begin{tabular}{|c|c|c|c|c|c|c|c|c|c|}
\hline Species & AC'94 & AC'95 & AC'96 & AC3y & $\mathrm{aACy}$ & $\mathrm{mACv}$ & SF\% & tTF & TFy \\
\hline ECM species & & & & & & & & & \\
\hline Cortinarius spp. I & 286 & 464 & 218 & 968 & 322.7 & 304 & 95.0 & 8 & 3 \\
\hline Amanita muscaria & 70 & 150 & 101 & 321 & 107.0 & 148 & 90.0 & 5 & 3 \\
\hline Cortinarius cinnamomeoluteus & 384 & 470 & 162 & 1016 & 338.7 & 345 & 87.5 & 10 & 3 \\
\hline Hygrophorus hypothejus & 313 & 131 & 95 & 539 & 179.7 & 313 & 77.5 & 5 & 3 \\
\hline Tricholoma albobrunneum & 28 & 130 & 18 & 176 & 58.7 & 97 & 75.0 & 5 & 3 \\
\hline Tricholoma equestre & 62 & 189 & 56 & 307 & 102.3 & 168 & 72.5 & 8 & 3 \\
\hline Chalciporus piperatus & 3 & 71 & 15 & 89 & 29.7 & 51 & 72.5 & 7 & 3 \\
\hline Laccaria proxima & 101 & 194 & 91 & 386 & 128.7 & 144 & 57.5 & 9 & 3 \\
\hline Suillus luteus & 22 & 49 & 61 & 132 & 44.0 & 38 & 57.5 & 8 & 3 \\
\hline Lactarius rufus & 9 & 343 & 110 & 462 & 154.0 & 331 & 52.5 & 8 & 3 \\
\hline Tricholoma portentosum & 81 & 120 & 21 & 222 & 74.0 & 115 & 52.5 & 5 & 3 \\
\hline Rhodocollybia butyracea f. asema & 14 & 14 & 62 & 90 & 30.0 & 47 & 40.0 & 5 & 3 \\
\hline Thelephora terrestris & 27 & 68 & 5 & 100 & 33.3 & 53 & 35.0 & 9 & 3 \\
\hline Cortinarius parevernius & $\cdot$ & 18 & 38 & 56 & 18.7 & 25 & 35.0 & 3 & 2 \\
\hline $\begin{array}{l}\text { Tricholoma saponaceum } \\
\text { var. saponaceum }\end{array}$ & 30 & 51 & 58 & 139 & 46.3 & 51 & 30.0 & 4 & 3 \\
\hline Inocybe lacera & 22 & 84 & 24 & 130 & 43.3 & 63 & 30.0 & 9 & 3 \\
\hline Boletus edulis & $\cdot$ & 9 & 7 & 16 & 5.3 & 5 & 27.5 & 5 & 2 \\
\hline Cortinarius spp. II & 6 & 17 & . & 23 & 7.7 & 17 & 20.0 & 2 & 2 \\
\hline Cortinarius mисовиs & 1 & 3 & 12 & 16 & 5.3 & 12 & 15.0 & 3 & 3 \\
\hline Cortinarius spp. III & 2 & 6 & . & 8 & 2.7 & 6 & 10.0 & 2 & 2 \\
\hline Cortinarius anthracinus & . & 5 & 2 & 7 & 2.3 & 5 & 10.0 & 2 & 2 \\
\hline Cortinarius purpurascens & 1 & 1 & 2 & 4 & 1.3 & 1 & 10.0 & 4 & 3 \\
\hline Sarcodon squamosus & 5 & 7 & 2 & 14 & 4.7 & 7 & 7.5 & 3 & 3 \\
\hline Inocybe assimilata & . & 4 & 1 & 5 & 1.7 & 4 & 7.5 & 2 & 2 \\
\hline Xerocomus badius & . & 4 & 1 & 5 & 1.7 & 3 & 7.5 & 3 & 2 \\
\hline Clitopilus prunulus & 1 & 2 & 1 & 4 & 1.3 & 2 & 5.0 & 3 & 3 \\
\hline Amanita rubescens & . & 1 & 1 & 2 & 0.7 & 1 & 5.0 & 2 & 2 \\
\hline Boletus reticulatus & · & 2 & . & 2 & 0.7 & 2 & 5.0 & 1 & 1 \\
\hline Laccaria bicolor & . & . & 15 & 15 & 5.0 & 15 & 2.5 & 1 & 1 \\
\hline Cortinarius sanguineus & . & 6 & $\cdot$ & 6 & 2.0 & 6 & 2.5 & 1 & 1 \\
\hline $\begin{array}{l}\text { Cortinarius multiformis } \\
\text { f. coniferarum }\end{array}$ & . & 1 & 2 & 3 & 1.0 & 2 & 2.5 & 2 & 2 \\
\hline Paxillus involutus & . & 2 & . & 2 & 0.7 & 2 & 2.5 & 1 & 1 \\
\hline Boletus pinophilus & . & . & 1 & 1 & 0.3 & 1 & 2.5 & 1 & 1 \\
\hline Leccinum aurantiacum & . & . & 1 & 1 & 0.3 & 1 & 2.5 & 1 & 1 \\
\hline Suillus bovinus & . & 1 & . & 1 & 0.3 & 1 & 2.5 & 1 & 1 \\
\hline
\end{tabular}




\begin{tabular}{|c|c|c|c|c|c|c|c|c|c|}
\hline Species & AC'94 & AC'95 & AC'96 & AC3y & aACy & $\mathrm{mACv}$ & SF\% & tTF & TFy \\
\hline Other species & & & & & & & & & \\
\hline Clitocybe diatreta & 447 & 561 & 202 & 1210 & 403.3 & 279 & 97.5 & 9 & 3 \\
\hline Psilocybe montana & 197 & 114 & 31 & 342 & 114.0 & 111 & 72.5 & 11 & 3 \\
\hline Gymnopus androsaceus & 694 & 227 & 142 & 1063 & 354.3 & 564 & 67.5 & 9 & 3 \\
\hline Mycena leptocephala & 88 & 25 & 10 & 123 & 41.0 & 71 & 57.5 & 5 & 3 \\
\hline Cystoderma amianthinum & 71 & 54 & 10 & 135 & 45.0 & 65 & 52.5 & 7 & 3 \\
\hline Galerina spp. & 126 & 161 & 9 & 296 & 98.7 & 117 & 50.0 & 6 & 3 \\
\hline Galerina atkinsoniana & 30 & 263 & 42 & 335 & 111.7 & 186 & 42.5 & 6 & 3 \\
\hline Collybia cirrhata & 14 & 45 & 69 & 128 & 42.7 & 49 & 27.5 & 7 & 3 \\
\hline Mycena speirea & 90 & . & . & 90 & 30.0 & 90 & 27.5 & 1 & 1 \\
\hline Hygroaster asterosporus & 7 & 21 & 10 & 38 & 12.7 & 21 & 27.5 & 4 & 3 \\
\hline Entoloma spp. & 12 & 17 & 8 & 37 & 12.3 & 9 & 27.5 & 6 & 3 \\
\hline Mycena vitilis & 15 & 11 & 3 & 29 & 9.7 & 9 & 27.5 & 6 & 3 \\
\hline Galerina hypnorum & 16 & 50 & 7 & 73 & 24.3 & 47 & 25.0 & 5 & 3 \\
\hline Galerina pumila & 1 & 42 & 8 & 51 & 17.0 & 33 & 25.0 & 6 & 3 \\
\hline Clavaria argillacea & 105 & 266 & 63 & 434 & 144.7 & 259 & 22.5 & 5 & 3 \\
\hline Mycena flavoalba & 19 & 12 & 1 & 32 & 10.7 & 18 & 20.0 & 5 & 3 \\
\hline Rickenella fibula & 11 & 24 & 31 & 66 & 22.0 & 16 & 17.5 & 5 & 3 \\
\hline Dacrymyces variisporus & . & 96 & . & 96 & 32.0 & 96 & 15.0 & 1 & 1 \\
\hline Strobilurus stephanocystis & 3 & 51 & 19 & 73 & 24.3 & 51 & 15.0 & 3 & 3 \\
\hline Clitocybe vibecina & 3 & 19 & $\cdot$ & 22 & 7.3 & 19 & 15.0 & 2 & 2 \\
\hline Clitocybe phyllophila & 1 & 41 & 8 & 50 & 16.7 & 41 & 12.5 & 3 & 3 \\
\hline Ampulloclitocybe clavipes & . & 9 & 3 & 12 & 4.0 & 8 & 12.5 & 5 & 2 \\
\hline Mycena olivaceomarginata & 8 & . & 1 & 9 & 3.0 & 7 & 12.5 & 3 & 2 \\
\hline Ripartites tricholoma & · & 7 & . & 7 & 2.3 & 7 & 12.5 & 1 & 1 \\
\hline Cystoderma jasonis var. jasonis & 9 & 13 & . & 22 & 7.3 & 13 & 10.0 & 2 & 2 \\
\hline Clitocybe anisata & 6 & 8 & . & 14 & 4.7 & 8 & 10.0 & 2 & 2 \\
\hline Collybia tuberosa & 2 & 4 & 1 & 7 & 2.3 & 3 & 10.0 & 4 & 3 \\
\hline Leptosporomyces galzinii & $\cdot$ & 11 & . & 11 & 3.7 & 11 & 7.5 & 1 & 1 \\
\hline Cystoderma jasonis var. lilacipes & 5 & 5 & . & 10 & 3.3 & 5 & 7.5 & 2 & 2 \\
\hline Clitocybe fragrans & 1 & 7 & . & 8 & 2.7 & 7 & 7.5 & 2 & 2 \\
\hline Mycena stylobates & 6 & . & . & 6 & 2.0 & 6 & 7.5 & 1 & 1 \\
\hline Dacrymyces stillatus & 10 & 20 & . & 30 & 10.0 & 20 & 5.0 & 2 & 2 \\
\hline Lycoperdon perlatum & 14 & 8 & . & 22 & 7.3 & 14 & 5.0 & 4 & 2 \\
\hline Galerina mniophila & 15 & . & . & 15 & 5.0 & 15 & 5.0 & 1 & 1 \\
\hline Gymnopus impudicus & 13 & . & . & 13 & 4.3 & 13 & 5.0 & 1 & 1 \\
\hline Marasmius oreades & 7 & . & . & 7 & 2.3 & 4 & 5.0 & 2 & 1 \\
\hline Amylostereum laevigatum & . & 5 & . & 5 & 1.7 & 5 & 5.0 & 1 & 1 \\
\hline Auriscalpium vulgare & 1 & 3 & . & 4 & 1.3 & 3 & 5.0 & 2 & 2 \\
\hline Hygrocybe conica var. conica & . & 2 & . & 2 & 0.7 & 2 & 5.0 & 1 & 1 \\
\hline Panellus mitis & . & 6 & . & 6 & 2.0 & 6 & 2.5 & 1 & 1 \\
\hline Cystodermella granulosa & . & $\cdot$ & 5 & 5 & 1.7 & 5 & 2.5 & 1 & 1 \\
\hline Hygrocybe virginea var. virginea & . & 3 & . & 3 & 1.0 & 3 & 2.5 & 1 & 1 \\
\hline Gymnopus putillus & 2 & $\cdot$ & . & 2 & 0.7 & 2 & 2.5 & 1 & 1 \\
\hline Mycena pura & $\cdot$ & 2 & . & 2 & 0.7 & 2 & 2.5 & 1 & 1 \\
\hline Agaricus dulcidulus & 1 & $\cdot$ & . & 1 & 0.3 & 1 & 2.5 & 1 & 1 \\
\hline Baeospora myosura & . & . & 1 & 1 & 0.3 & 1 & 2.5 & 1 & 1 \\
\hline Cystoderma carcharias & 1 & . & . & 1 & 0.3 & 1 & 2.5 & 1 & 1 \\
\hline Entoloma undatum & . & 1 & . & 1 & 0.3 & 1 & 2.5 & 1 & 1 \\
\hline Hypholoma lateritium & . & . & 1 & 1 & 0.3 & 1 & 2.5 & 1 & 1 \\
\hline Mycena aetites & 1 & . & . & 1 & 0.3 & 1 & 2.5 & 1 & 1 \\
\hline
\end{tabular}




\begin{tabular}{|l|c|c|c|c|c|c|c|c|c|}
\hline \multicolumn{1}{|c|}{ Species } & AC'94 & AC'95 & AC'96 & AC3y & aACy & mACv & SF\% & tTF & TFy \\
\hline Mycena septentrionalis & $\cdot$ & 1 & $\cdot$ & 1 & 0.3 & 1 & 2.5 & 1 & 1 \\
Phanerochaete sanguinea & $\cdot$ & 1 & $\cdot$ & 1 & 0.3 & 1 & 2.5 & 1 & 1 \\
Psathyrella fibrillosa & $\cdot$ & 1 & $\cdot$ & 1 & 0.3 & 1 & 2.5 & 1 & 1 \\
\hline
\end{tabular}

Abbreviations: see Tab. A3.2

Table A3.9

Macrofungi in plot 6 (phase 6/7, Jelonka reserve)

\begin{tabular}{|c|c|c|c|c|c|c|c|c|c|}
\hline \multirow{2}{*}{\multicolumn{10}{|c|}{$\begin{array}{l}\text { Species } \\
\text { ECM species }\end{array}$}} \\
\hline & & & & & & & & & \\
\hline Cortinarius cinnamomeoluteus & 211 & 431 & 271 & 913 & 304.3 & 336 & 97.5 & 11 & 3 \\
\hline Cortinarius spp. I & 100 & 382 & 246 & 728 & 242.7 & 271 & 97.5 & 8 & 3 \\
\hline Amanita muscaria & 99 & 153 & 155 & 407 & 135.7 & 152 & 95.0 & 7 & 3 \\
\hline Hygrophorus hypothejus & 337 & 166 & 76 & 579 & 193.0 & 337 & 92.5 & 5 & 3 \\
\hline Tricholoma albobrunneum & 25 & 177 & 62 & 264 & 88.0 & 167 & 90.0 & 5 & 3 \\
\hline Tricholoma portentosum & 71 & 141 & 73 & 285 & 95.0 & 141 & 77.5 & 4 & 3 \\
\hline Laccaria proxima & 173 & 286 & 183 & 642 & 214.0 & 257 & 72.5 & 7 & 3 \\
\hline Suillus luteus & 17 & 109 & 69 & 195 & 65.0 & 79 & 72.5 & 8 & 3 \\
\hline Tricholoma equestre & 30 & 113 & 47 & 190 & 63.3 & 107 & 72.5 & 8 & 3 \\
\hline Chalciporus piperatus & 4 & 50 & 21 & 75 & 25.0 & 27 & 67.5 & 7 & 3 \\
\hline Lactarius rufus & 2 & 131 & 33 & 166 & 55.3 & 125 & 42.5 & 8 & 3 \\
\hline $\begin{array}{l}\text { Tricholoma saponaceum } \\
\text { var. saponaceum }\end{array}$ & 17 & 44 & 67 & 128 & 42.7 & 48 & 37.5 & 5 & 3 \\
\hline Cortinarius anthracinus & . & 38 & . & 38 & 12.7 & 38 & 37.5 & 1 & 1 \\
\hline Cortinarius parevernius & . & 46 & 18 & 64 & 21.3 & 46 & 35.0 & 3 & 2 \\
\hline Laccaria bicolor & . & 47 & 35 & 82 & 27.3 & 20 & 32.5 & 6 & 2 \\
\hline Rhodocollybia butyracea f. asema & 8 & 10 & 22 & 40 & 13.3 & 16 & 32.5 & 6 & 3 \\
\hline Boletus edulis & 7 & 4 & 14 & 25 & 8.3 & 7 & 32.5 & 7 & 3 \\
\hline Cortinarius spp. II & 2 & 16 & 30 & 48 & 16.0 & 22 & 20.0 & 4 & 3 \\
\hline Sarcodon squamosus & 3 & 9 & 4 & 16 & 5.3 & 9 & 15.0 & 3 & 3 \\
\hline Cortinarius тисовиs & . & 1 & 7 & 8 & 2.7 & 7 & 15.0 & 2 & 2 \\
\hline Thelephora terrestris & 19 & 9 & 3 & 31 & 10.3 & 19 & 12.5 & 3 & 3 \\
\hline Inocybe lacera & . & 14 & . & 14 & 4.7 & 11 & 12.5 & 2 & 1 \\
\hline Cortinarius purpurascens & . & 7 & . & 7 & 2.3 & 7 & 12.5 & 1 & 1 \\
\hline Clitopilus prunulus & . & 6 & . & 6 & 2.0 & 5 & 10.0 & 2 & 1 \\
\hline Inocybe assimilata & 3 & 20 & . & 23 & 7.7 & 20 & 7.5 & 2 & 2 \\
\hline Cortinarius spp. IV & . & . & 17 & 17 & 5.7 & 17 & 5.0 & 1 & 1 \\
\hline Amanita rubescens & . & 3 & 3 & 6 & 2.0 & 3 & 5.0 & 3 & 2 \\
\hline Amanita pantherina & . & 4 & . & 4 & 1.3 & 4 & 5.0 & 1 & 1 \\
\hline Inocybe curvipes & . & 3 & 1 & 4 & 1.3 & 3 & 5.0 & 2 & 2 \\
\hline Suillus bovinus & . & 4 & . & 4 & 1.3 & 4 & 5.0 & 1 & 1 \\
\hline Rhizopogon luteolus & . & 1 & 1 & 2 & 0.7 & 1 & 5.0 & 2 & 2 \\
\hline Ramaria eumorpha & 5 & . & . & 5 & 1.7 & 5 & 2.5 & 1 & 1 \\
\hline Cortinarius spp. III & 2 & . & . & 2 & 0.7 & 2 & 2.5 & 1 & 1 \\
\hline Boletus pinophilus & . & . & 1 & 1 & 0.3 & 1 & 2.5 & 1 & 1 \\
\hline $\begin{array}{l}\text { Cortinarius multiformis } \\
\text { f. coniferarum }\end{array}$ & . & 1 & . & 1 & 0.3 & 1 & 2.5 & 1 & 1 \\
\hline Inocybe calida & . & 1 & . & 1 & 0.3 & 1 & 2.5 & 1 & 1 \\
\hline Inocybe praetervisa & $\cdot$ & 1 & . & 1 & 0.3 & 1 & 2.5 & 1 & 1 \\
\hline Other species & & & & & & & & & \\
\hline Clitocybe diatreta & 280 & 87 & 42 & 409 & 136.3 & 193 & 97.5 & 9 & 3 \\
\hline Psilocybe montana & 207 & 229 & 35 & 471 & 157.0 & 136 & 95.0 & 12 & 3 \\
\hline
\end{tabular}




\begin{tabular}{|c|c|c|c|c|c|c|c|c|c|}
\hline Species & AC'94 & AC'95 & AC'96 & AC3y & aACy & $\mathrm{mACv}$ & SF\% & tTF & TFy \\
\hline Clitocybe vibecina & 17 & 103 & 132 & 252 & 84 & 130 & 30.0 & 4 & 3 \\
\hline Strobilurus stephanocystis & 4 & 19 & 26 & 49 & 16.3 & 23 & 30.0 & 4 & 3 \\
\hline Mycena leptocephala & 3 & 39 & . & 42 & 14.0 & 39 & 25.0 & 2 & 2 \\
\hline Gymnopus androsaceus & 119 & 19 & 26 & 164 & 54.7 & 119 & 22.5 & 4 & 3 \\
\hline Collybia cirrhata & 14 & 30 & 102 & 146 & 48.7 & 52 & 22.5 & 5 & 3 \\
\hline Galerina atkinsoniana & 6 & 40 & . & 46 & 15.3 & 38 & 22.5 & 4 & 2 \\
\hline Hygroaster asterosporus & 30 & 3 & . & 33 & 11.0 & 30 & 22.5 & 2 & 2 \\
\hline Clavaria argillacea & 102 & 21 & & 123 & 41.0 & 102 & 20.0 & 2 & 2 \\
\hline Leptosporomyces galzinii & . & 37 & . & 37 & 12.3 & 37 & 20.0 & 1 & 1 \\
\hline Cystoderma amianthinum & 3 & 17 & 3 & 23 & 7.7 & 10 & 17.5 & 6 & 3 \\
\hline Ampulloclitocybe clavipes & 6 & 14 & . & 20 & 6.7 & 13 & 17.5 & 4 & 2 \\
\hline Galerina spp. & 10 & 51 & 1 & 62 & 20.7 & 49 & 15.0 & 4 & 3 \\
\hline Macrolepiota procera & 3 & 4 & . & 7 & 2.3 & 4 & 15.0 & 3 & 2 \\
\hline Entoloma spp. & 12 & 1 & - & 13 & 4.3 & 12 & 12.5 & 2 & 2 \\
\hline Baeospora myosura & 2 & 5 & 1 & 8 & 2.7 & 3 & 12.5 & 4 & 3 \\
\hline Mycena vitilis & 3 & 1 & . & 4 & 1.3 & 3 & 7.5 & 2 & 2 \\
\hline Lycoperdon perlatum & . & 7 & 6 & 13 & 4.3 & 7 & 5.0 & 2 & 2 \\
\hline Dacrymyces variisporus & 2 & 7 & . & 9 & 3.0 & 7 & 5.0 & 2 & 2 \\
\hline Clitocybe fragrans & - & . & 7 & 7 & 2.3 & 7 & 5.0 & 1 & 1 \\
\hline Rickenella fibula & . & 7 & . & 7 & 2.3 & 7 & 5.0 & 1 & 1 \\
\hline Mycena pura & 6 & . & . & 6 & 2.0 & 3 & 5.0 & 2 & 1 \\
\hline Rhodocybe caelata & 1 & 1 & . & 2 & 0.7 & 1 & 5.0 & 2 & 2 \\
\hline Hygrocybe conica var. conica & . & 3 & . & 3 & 1.0 & 3 & 2.5 & 1 & 1 \\
\hline Hypholoma fasciculare & . & . & 3 & 3 & 1.0 & 3 & 2.5 & 1 & 1 \\
\hline Hygrophoropsis aurantiaca & . & . & 2 & 2 & 0.7 & 2 & 2.5 & 1 & 1 \\
\hline Hypholoma lateritium & - & 2 & . & 2 & 0.7 & 2 & 2.5 & 1 & 1 \\
\hline Mycena metata & 2 & . & - & 2 & 0.7 & 2 & 2.5 & 1 & 1 \\
\hline Auriscalpium vulgare & . & 1 & - & 1 & 0.3 & 1 & 2.5 & 1 & 1 \\
\hline Clitocybe candicans & . & 1 & - & 1 & 0.3 & 1 & 2.5 & 1 & 1 \\
\hline Cystoderma carcharias & . & 1 & - & 1 & 0.3 & 1 & 2.5 & 1 & 1 \\
\hline Flammulaster granulosus & . & 1 & - & 1 & 0.3 & 1 & 2.5 & 1 & 1 \\
\hline Gymnopus putillus & 1 & . & - & 1 & 0.3 & 1 & 2.5 & 1 & 1 \\
\hline Mycena aetites & . & 1 & - & 1 & 0.3 & 1 & 2.5 & 1 & 1 \\
\hline Mycena flavoalba & . & . & 1 & 1 & 0.3 & 1 & 2.5 & 1 & 1 \\
\hline Mycena stylobates & . & 1 & . & 1 & 0.3 & 1 & 2.5 & 1 & 1 \\
\hline Phanerochaete sanguinea & - & 1 & - & 1 & 0.3 & 1 & 2.5 & 1 & 1 \\
\hline Polyporus ciliatus & 1 & . & - & 1 & 0.3 & 1 & 2.5 & 1 & 1 \\
\hline Rhodocybe parilis & . & - & 1 & 1 & 0.3 & 1 & 2.5 & 1 & 1 \\
\hline Tapinella atrotomentosa & . & . & 1 & 1 & 0.3 & 1 & 2.5 & 1 & 1 \\
\hline
\end{tabular}

Abbreviations: see Tab. A3.2

Table A3.10

Macrofungi in plot 11 (phase 8, Jelonka reserve)

\begin{tabular}{|l|c|c|c|c|c|c|c|c|c|}
\hline \multicolumn{1}{|c|}{ Species } & AC'94 & AC'95 & AC'96 & AC3y & aACy & mACv & SF\% & tTF & TFy \\
\hline ECM species & & & & & & & & & \\
Rhodocollybia butyracea f. asema & 54 & 14 & 78 & 146 & 48.7 & 55 & 100.0 & 6 & 3 \\
Cortinarius spp. II & 42 & 416 & 31 & 489 & 163.0 & 416 & 93.3 & 4 & 3 \\
Cortinarius trivialis & 18 & 169 & 27 & 214 & 71.3 & 167 & 86.7 & 7 & 3 \\
Cortinarius spp. I & 5 & 97 & 86 & 188 & 62.7 & 84 & 86.7 & 8 & 3 \\
Amanita citrina & 1 & 98 & 2 & 101 & 33.7 & 95 & 86.7 & 5 & 3 \\
Hebeloma sp. 3 & 4 & 29 & 65 & 98 & 32.7 & 65 & 73.3 & 4 & 3 \\
Leccinum aurantiacum & 4 & 14 & 30 & 48 & 16.0 & 29 & 73.3 & 7 & 3 \\
Russula clavipes & 7 & 17 & 20 & 44 & 14.7 & 17 & 73.3 & 5 & 3
\end{tabular}




\begin{tabular}{|c|c|c|c|c|c|c|c|c|c|}
\hline Species & AC'94 & AC'95 & AC'96 & AC3y & aACy & $\mathrm{mACv}$ & SF\% & $\mathrm{tTF}$ & TFy \\
\hline Cortinarius spp. III & 1 & 46 & 37 & 84 & 28.0 & 46 & 66.7 & 3 & 3 \\
\hline Amanita muscaria & 25 & 19 & 29 & 73 & 24.3 & 28 & 60.0 & 5 & 3 \\
\hline Tricholoma equestre & 4 & 14 & 1 & 19 & 6.3 & 11 & 53.3 & 4 & 3 \\
\hline Cortinarius alboviolaceus & & 73 & 10 & 83 & 27.7 & 53 & 40.0 & 4 & 2 \\
\hline Russula fragilis & 2 & 8 & 2 & 12 & 4.0 & 8 & 40.0 & 4 & 3 \\
\hline Suillus luteus & $\cdot$ & 6 & 11 & 17 & 5.7 & 11 & 33.3 & 2 & 2 \\
\hline Clitopilus prunulus & . & 6 & 1 & 7 & 2.3 & 4 & 33.3 & 3 & 2 \\
\hline Amanita gemmata & 3 & 2 & . & 5 & 1.7 & 3 & 33.3 & 2 & 2 \\
\hline Paxillus involutus & 1 & 19 & 15 & 35 & 11.7 & 19 & 26.7 & 6 & 3 \\
\hline Tricholoma portentosum & 5 & 5 & 3 & 13 & 4.3 & 5 & 26.7 & 3 & 3 \\
\hline Boletus edulis & 1 & 3 & 3 & 7 & 2.3 & 2 & 26.7 & 5 & 3 \\
\hline Chalciporus piperatus & . & 2 & 3 & 5 & 1.7 & 2 & 26.7 & 3 & 2 \\
\hline Russula galochroa & . & 2 & 3 & 5 & 1.7 & 2 & 26.7 & 3 & 2 \\
\hline Thelephora caryophyllea & 3 & 3 & . & 6 & 2.0 & 3 & 20.0 & 2 & 2 \\
\hline Hygrophorus hypothejus & 4 & 1 & . & 5 & 1.7 & 4 & 20.0 & 2 & 2 \\
\hline Amanita pantherina & 1 & 3 & . & 4 & 1.3 & 3 & 20.0 & 2 & 2 \\
\hline Tricholoma imbricatum & . & 19 & . & 19 & 6.3 & 19 & 13.3 & 1 & 1 \\
\hline Lactarius uvidus & . & 10 & . & 10 & 3.3 & 10 & 13.3 & 1 & 1 \\
\hline Cortinarius cinnamomeoluteus & 3 & $\cdot$ & . & 3 & 1.0 & 3 & 13.3 & 1 & 1 \\
\hline Lactarius rufus & 2 & 1 & . & 3 & 1.0 & 2 & 13.3 & 2 & 2 \\
\hline Cortinarius parevernius & . & 2 & . & 2 & 0.7 & 2 & 13.3 & 1 & 1 \\
\hline Lactarius necator & . & . & 3 & 3 & 1.0 & 3 & 6.7 & 1 & 1 \\
\hline Lactarius torminosus & 1 & 2 & . & 3 & 1.0 & 2 & 6.7 & 2 & 2 \\
\hline Amanita rubescens & . & 1 & 1 & 2 & 0.7 & 1 & 6.7 & 2 & 2 \\
\hline Laccaria proxima & . & . & 1 & 1 & 0.3 & 1 & 6.7 & 1 & 1 \\
\hline Thelephora terrestris & . & 1 & · & 1 & 0.3 & 1 & 6.7 & 1 & 1 \\
\hline Other species & & & & & & & & & \\
\hline Auriscalpium vulgare & 41 & 12 & 13 & 66 & 22.0 & 38 & 86.7 & 7 & 3 \\
\hline Lycoperdon molle & 22 & 15 & 25 & 62 & 20.7 & 16 & 80.0 & 10 & 3 \\
\hline Clitocybe candicans & 49 & 4 & . & 53 & 17.7 & 28 & 80.0 & 3 & 2 \\
\hline Psathyrella candolleana & 59 & 24 & 2 & 85 & 28.3 & 57 & 73.3 & 6 & 3 \\
\hline Galerina hypпorum & 19 & 63 & 15 & 97 & 32.3 & 55 & 66.7 & 5 & 3 \\
\hline Mycena leptocephala & 67 & 17 & 6 & 90 & 30.0 & 66 & 66.7 & 7 & 3 \\
\hline Gymnopus androsaceus & 183 & 223 & 51 & 457 & 152.3 & 214 & 60.0 & 10 & 3 \\
\hline Tubaria furfuracea & 83 & 128 & 14 & 225 & 75.0 & 109 & 60.0 & 7 & 3 \\
\hline Mycena pura & 52 & 6 & 1 & 59 & 19.7 & 52 & 60.0 & 4 & 3 \\
\hline Lycoperdon perlatum & 7 & 14 & 3 & 24 & 8.0 & 13 & 60.0 & 5 & 3 \\
\hline Inonotus rheades & 28 & . & 9 & $\mathrm{x}$ & $\mathrm{x}$ & 28 & 60.0 & 8 & 2 \\
\hline Dacrymyces stillatus & 100 & 1090 & 135 & 1325 & 441.7 & 1080 & 53.3 & 5 & 3 \\
\hline Cystoderma carcharias & 13 & 29 & 29 & 71 & 23.7 & 29 & 53.3 & 4 & 3 \\
\hline Clitocybe phyllophila & 15 & 48 & 1 & 64 & 21.3 & 45 & 53.3 & 4 & 3 \\
\hline Entoloma spp. & 7 & 37 & . & 44 & 14.7 & 30 & 53.3 & 3 & 2 \\
\hline Baeospora myosura & 9 & 27 & . & 36 & 12.0 & 27 & 53.3 & 3 & 2 \\
\hline Dacrymyces variisporus & 10 & 142 & 40 & 192 & 64.0 & 137 & 46.7 & 5 & 3 \\
\hline Ampulloclitocybe clavipes & 11 & 21 & 4 & 36 & 12.0 & 21 & 46.7 & 4 & 3 \\
\hline Gymnopus confluens & 301 & 231 & 280 & 812 & 270.7 & 255 & 40.0 & 9 & 3 \\
\hline Mycena sanguinolenta & 2 & 44 & . & 46 & 15.3 & 44 & 40.0 & 2 & 2 \\
\hline Clitocybe diatreta & 39 & 3 & 3 & 45 & 15.0 & 22 & 40.0 & 4 & 3 \\
\hline Galerina marginata & 4 & 34 & . & 38 & 12.7 & 34 & 40.0 & 3 & 2 \\
\hline Flammulaster granulosus & 28 & 2 & 2 & 32 & 10.7 & 28 & 40.0 & 4 & 3 \\
\hline Crucibulum laeve & 1 & 10 & 17 & 28 & 9.3 & 12 & 40.0 & 4 & 3 \\
\hline Lycoperdon nigrescens & 5 & 11 & 3 & 19 & 6.3 & 11 & 40.0 & 5 & 3 \\
\hline Mycena olivaceomarginata & 8 & 4 & . & 12 & 4.0 & 8 & 40.0 & 3 & 2 \\
\hline
\end{tabular}




\begin{tabular}{|c|c|c|c|c|c|c|c|c|c|}
\hline Species & AC'94 & AC'95 & AC'96 & AC3y & aACy & $\mathrm{mACv}$ & SF\% & tTF & TFy \\
\hline Peniophora polygonia & 110 & 94 & 35 & 239 & 79.7 & 110 & 33.3 & 5 & 3 \\
\hline Flammulaster rhombisporus & 2 & 57 & 18 & 77 & 25.7 & 49 & 33.3 & 4 & 3 \\
\hline Mycena stipata & 22 & . & . & 22 & 7.3 & 20 & 33.3 & 2 & 1 \\
\hline Clitocybe fragrans & . & 7 & 3 & 10 & 3.3 & 6 & 33.3 & 4 & 2 \\
\hline Collybia cirrhata & 16 & 154 & 30 & 200 & 66.7 & 154 & 26.7 & 4 & 3 \\
\hline Stereum hirsutum & 38 & 25 & 30 & 93 & 31.0 & 28 & 26.7 & 6 & 3 \\
\hline Xeromphalina cornui & 42 & 25 & . & 67 & 22.3 & 35 & 26.7 & 3 & 2 \\
\hline Amylostereum laevigatum & . & 56 & . & 56 & 18.7 & 56 & 26.7 & 1 & 1 \\
\hline Gymnopus aquosus & 13 & 13 & 27 & 53 & 17.7 & 27 & 26.7 & 3 & 3 \\
\hline Clitocybe metachroa & 20 & 19 & 3 & 42 & 14.0 & 20 & 26.7 & 3 & 3 \\
\hline Mycena galopus & 1 & 12 & . & 13 & 4.3 & 11 & 26.7 & 3 & 2 \\
\hline Mycena stylobates & 4 & 3 & 2 & 9 & 3.0 & 4 & 26.7 & 3 & 3 \\
\hline Mycena rubromarginata & 5 & . & - & 5 & 1.7 & 5 & 26.7 & 1 & 1 \\
\hline Macrolepiota procera & 4 & . & . & 4 & 1.3 & 4 & 26.7 & 1 & 1 \\
\hline Daedaleopsis confragosa & 4 & 2 & 6 & $\mathrm{x}$ & $\mathrm{x}$ & 6 & 26.7 & 7 & 3 \\
\hline Sphaerobolus stellatus & 109 & 12 & . & 121 & 40.3 & 60 & 20.0 & 3 & 2 \\
\hline Gleocystidiellum porosum & 50 & 2 & . & 52 & 17.3 & 30 & 20.0 & 3 & 2 \\
\hline Mycena filopes & 24 & . & 3 & 27 & 9.0 & 23 & 20.0 & 3 & 2 \\
\hline Exidia plana & 3 & 10 & 10 & 23 & 7.7 & 10 & 20.0 & 3 & 3 \\
\hline Clitocybe odora var. odora & 17 & 2 & . & 19 & 6.3 & 17 & 20.0 & 2 & 2 \\
\hline Strobilurus tenacellus & 7 & 1 & . & 8 & 2.7 & 7 & 20.0 & 2 & 2 \\
\hline Mycena vitilis & 6 & . & . & 6 & 2.0 & 6 & 20.0 & 1 & 1 \\
\hline Conocybe ochrostriata & 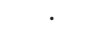 & 3 & . & 3 & 1.0 & 3 & 20.0 & 1 & 1 \\
\hline Crepidotus lundellii & 285 & 7 & 20 & 312 & 104.0 & 255 & 13.3 & 4 & 3 \\
\hline Marasmius epiphyllus & - & 15 & 35 & 50 & 16.7 & 35 & 13.3 & 2 & 2 \\
\hline Peniophorella praetermissa & 25 & 4 & . & 29 & 9.7 & 25 & 13.3 & 2 & 2 \\
\hline Phlebia rufa & 18 & 11 & $\cdot$ & 29 & 9.7 & 14 & 13.3 & 4 & 2 \\
\hline Marasmiellus vaillantii & 2 & . & 20 & 22 & 7.3 & 20 & 13.3 & 2 & 2 \\
\hline Phaeomarasmius erinaceus & - & 18 & 2 & 20 & 6.7 & 18 & 13.3 & 2 & 2 \\
\hline Vesiculomyces citrinus & 7 & 13 & . & 20 & 6.7 & 13 & 13.3 & 2 & 2 \\
\hline Tremella mesenterica & $\cdot$ & 17 & . & 17 & 5.7 & 17 & 13.3 & 1 & 1 \\
\hline Marasmius oreades & 12 & . & . & 12 & 4.0 & 9 & 13.3 & 2 & 1 \\
\hline Psilocybe montana & - & 10 & . & 10 & 3.3 & 10 & 13.3 & 1 & 1 \\
\hline Galerina pumila & 4 & 5 & . & 9 & 3.0 & 4 & 13.3 & 3 & 2 \\
\hline Clitocybe odora var. alba & . & 6 & 1 & 7 & 2.3 & 6 & 13.3 & 2 & 2 \\
\hline Clitocybe vermicularis & 6 & . & . & 6 & 2.0 & 6 & 13.3 & 1 & 1 \\
\hline Hyphodontia aspera & . & 6 & . & 6 & 2.0 & 5 & 13.3 & 2 & 1 \\
\hline Lepista nuda & . & 2 & 3 & 5 & 1.7 & 3 & 13.3 & 2 & 2 \\
\hline Mycena flavoalba & . & $\cdot$ & 5 & 5 & 1.7 & 5 & 13.3 & 1 & 1 \\
\hline Hygrocybe conica var. conica & . & 4 & . & 4 & 1.3 & 4 & 13.3 & 1 & 1 \\
\hline Hygrocybe virginea var. virginea & . & 2 & 2 & 4 & 1.3 & 2 & 13.3 & 3 & 2 \\
\hline Phlebiella sulphurea & . & 4 & . & 4 & 1.3 & 3 & 13.3 & 2 & 1 \\
\hline Strobilurus stephanocystis & . & 2 & 2 & 4 & 1.3 & 2 & 13.3 & 2 & 2 \\
\hline Ceraceomyces sublaevis & 2 & 1 & . & 3 & 1.0 & 2 & 13.3 & 2 & 2 \\
\hline Resupinatus trichotis & . & 3 & . & 3 & 1.0 & 2 & 13.3 & 2 & 1 \\
\hline Leptosporomyces galzinii & . & . & 2 & 2 & 0.7 & 2 & 13.3 & 1 & 1 \\
\hline Mycena supina & . & 2 & . & 2 & 0.7 & 1 & 13.3 & 2 & 1 \\
\hline Hymenochaete tabacina & 36 & . & . & 36 & 12.0 & 36 & 6.7 & 1 & 1 \\
\hline Clitocybe anisata & 17 & - & - & 17 & 5.7 & 17 & 6.7 & 1 & 1 \\
\hline Oligoporus alni & 11 & 4 & 1 & 16 & 5.3 & 7 & 6.7 & 4 & 3 \\
\hline Collybia cookei & 15 & . & . & 15 & 5.0 & 15 & 6.7 & 1 & 1 \\
\hline Byssomerulius corium & 12 & . & . & 12 & 4.0 & 12 & 6.7 & 1 & 1 \\
\hline Schizophyllum amplum & & 12 & . & 12 & 4.0 & 12 & 6.7 & 1 & 1 \\
\hline Marasmius setosus & - & & 10 & 10 & 3.3 & 10 & 6.7 & 1 & 1 \\
\hline
\end{tabular}




\begin{tabular}{|c|c|c|c|c|c|c|c|c|c|}
\hline Species & $\mathrm{AC} ' 94$ & $\mathrm{AC}{ }^{\prime} 95$ & AC'96 & AC3y & aACy & $\mathrm{mACv}$ & SF\% & tTF & TFy \\
\hline Hyphoderma setigerum & 8 & $\cdot$ & $\cdot$ & 8 & 2.7 & 8 & 6.7 & 1 & 1 \\
\hline Mycena zephirus & 6 & 1 & . & 7 & 2.3 & 6 & 6.7 & 2 & 2 \\
\hline Coniophora arida & 6 & . & . & 6 & 2.0 & 6 & 6.7 & 1 & 1 \\
\hline Cystoderma amianthinum & . & 6 & . & 6 & 2.0 & 6 & 6.7 & 1 & 1 \\
\hline Mycena parabolica & . & 5 & . & 5 & 1.7 & 5 & 6.7 & 1 & 1 \\
\hline Phanerochaete sanguinea & . & 4 & . & 4 & 1.3 & 3 & 6.7 & 2 & 1 \\
\hline Athelia epiphylla & 3 & . & . & 3 & 1.0 & 3 & 6.7 & 1 & 1 \\
\hline Hypholoma fasciculare & . & 3 & . & 3 & 1.0 & 3 & 6.7 & 1 & 1 \\
\hline Peniophora cinerea & . & 3 & . & 3 & 1.0 & 3 & 6.7 & 1 & 1 \\
\hline Gleoporus taxicola & . & 2 & . & 2 & 0.7 & 2 & 6.7 & 1 & 1 \\
\hline Psathyrella tephrophylla & 1 & 1 & . & 2 & 0.7 & 1 & 6.7 & 2 & 2 \\
\hline Rhodocybe caelata & 2 & . & . & 2 & 0.7 & 2 & 6.7 & 1 & 1 \\
\hline Agaricus dulcidulus & . & 1 & . & 1 & 0.3 & 1 & 6.7 & 1 & 1 \\
\hline Calocera viscosa & . & 1 & . & 1 & 0.3 & 1 & 6.7 & 1 & 1 \\
\hline Coprinellus xanthothrix & . & . & 1 & 1 & 0.3 & 1 & 6.7 & 1 & 1 \\
\hline Crepidotus cesatii & . & . & 1 & 1 & 0.3 & 1 & 6.7 & 1 & 1 \\
\hline Cystodermella granulosa & 1 & . & . & 1 & 0.3 & 1 & 6.7 & 1 & 1 \\
\hline Galerina spp. & . & 1 & . & 1 & 0.3 & 1 & 6.7 & 1 & 1 \\
\hline Geastrum quadrifidum & 1 & . & . & 1 & 0.3 & 1 & 6.7 & 1 & 1 \\
\hline Gymnopus putillus & 1 & . & . & 1 & 0.3 & 1 & 6.7 & 1 & 1 \\
\hline Hygrocybe laeta & . & . & 1 & 1 & 0.3 & 1 & 6.7 & 1 & 1 \\
\hline Tubulicrinis subulatus & . & 1 & . & 1 & 0.3 & 1 & 6.7 & 1 & 1 \\
\hline Tulasnella pallida & . & 1 & . & 1 & 0.3 & 1 & 6.7 & 1 & 1 \\
\hline Phellinus punctatus & 2 & . & 1 & $\mathrm{x}$ & $\mathrm{x}$ & 2 & 6.7 & 2 & 2 \\
\hline
\end{tabular}

Abbreviations: see Tab. A3.2; number of subplots -15

Table A3.11

Macrofungi in plot 16 (phase 8, Jelonka reserve)

\begin{tabular}{|l|c|c|c|c|c|c|c|c|c|}
\hline Species & AC'94 & AC'95 & AC'96 & AC3y & aACy & mACv & SF\% & tTF & TFy \\
\hline ECM species & & & & & & & & & \\
Cortinarius trivialis & 110 & 45 & 335 & 490 & 163.3 & 330 & 100.0 & 7 & 3 \\
Amanita citrina & 25 & 3 & 105 & 133 & 44.3 & 96 & 100.0 & 7 & 3 \\
Amanita muscaria & 9 & 11 & 16 & 36 & 12.0 & 15 & 100.0 & 4 & 3 \\
Cortinarius spp. II & 6 & 3 & 88 & 97 & 32.3 & 88 & 92.3 & 3 & 3 \\
Tricholoma equestre & 15 & 17 & 32 & 64 & 21.3 & 32 & 92.3 & 5 & 3 \\
Russula fragilis & 5 & 1 & 57 & 63 & 21.0 & 55 & 84.6 & 5 & 3 \\
Rhodocollybia butyracea f. asema & 23 & 25 & 6 & 54 & 18.0 & 24 & 76.9 & 6 & 3 \\
Cortinarius spp. I & 3 & 9 & 48 & 60 & 20.0 & 48 & 69.2 & 4 & 3 \\
Russula clavipes & $\cdot$ & 5 & 13 & 18 & 6.0 & 11 & 69.2 & 3 & 2 \\
Russula galochroa & 5 & 6 & 7 & 18 & 6.0 & 7 & 61.5 & 4 & 3 \\
Cantharellus cibarius & 20 & 81 & 36 & 137 & 45.7 & 63 & 53.8 & 11 & 3 \\
Inocybe flocculosa & $\cdot$ & $\cdot$ & 69 & 69 & 23.0 & 61 & 53.8 & 2 & 1 \\
Lactarius torminosus & 8 & $\cdot$ & 15 & 23 & 7.7 & 15 & 53.8 & 3 & 2 \\
Cortinarius alboviolaceus & 3 & 1 & 18 & 22 & 7.3 & 18 & 46.2 & 3 & 3 \\
Inocybe cf. margaritispora & 1 &. & 17 & 18 & 6.0 & 17 & 46.2 & 2 & 2 \\
Cortinarius spp. III & $\cdot$ & 1 & 52 & 53 & 17.7 & 52 & 30.8 & 2 & 2 \\
Leccinum scabrum & $\cdot$ & 4 & 2 & 6 & 2.0 & 4 & 30.8 & 2 & 2 \\
Clitopilus prunulus & 5 & $\cdot$ & 15 & 20 & 6.7 & 12 & 23.1 & 3 & 2 \\
Laccaria proxima & 2 & $\cdot$ & 7 & 9 & 3.0 & 6 & 23.1 & 3 & 2 \\
Lactarius uvidus & $\cdot$ & $\cdot$ & 8 & 8 & 2.7 & 8 & 23.1 & 1 & 1 \\
Thelephora caryophyllea &. & $\cdot$ & 10 & 10 & 3.3 & 7 & 15.4 & 2 & 1 \\
Russula paludosa & 3 &. & 2 & 5 & 1.7 & 2 & 15.4 & 3 & 2 \\
Tricholoma portentosum & 3 & 2 & $\cdot$ & 5 & 1.7 & 3 & 15.4 & 2 & 2
\end{tabular}




\begin{tabular}{|c|c|c|c|c|c|c|c|c|c|}
\hline Species & $\mathrm{AC} \mathrm{C}^{\prime} 94$ & AC'95 & AC'96 & AC3y & $\mathrm{aACy}$ & $\mathrm{mACv}$ & $\mathrm{SF} \%$ & tTF & TFy \\
\hline Tricholoma albobrunneum & $\cdot$ & $\cdot$ & 4 & 4 & 1.3 & 4 & 15.4 & 1 & 1 \\
\hline Boletus edulis & 1 & . & 2 & 3 & 1.0 & 1 & 15.4 & 3 & 2 \\
\hline Chalciporus piperatus & $\cdot$ & 1 & 2 & 3 & 1.0 & 1 & 15.4 & 3 & 2 \\
\hline Ramaria cf. abietina & 2 & . & 1 & 3 & 1.0 & 2 & 15.4 & 2 & 2 \\
\hline Hebeloma sp. 1 & . & 3 & . & 3 & 1.0 & 3 & 7.7 & 1 & 1 \\
\hline Russula mustelina & 2 & 1 & . & 3 & 1.0 & 1 & 7.7 & 3 & 2 \\
\hline Hebeloma sp. 2 & . & 2 & . & 2 & 0.7 & 2 & 7.7 & 1 & 1 \\
\hline Inocybe lacera & · & . & 2 & 2 & 0.7 & 2 & 7.7 & 1 & 1 \\
\hline Paxillus involutus & . & 2 & . & 2 & 0.7 & 2 & 7.7 & 1 & 1 \\
\hline Amanita phalloides & . & 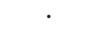 & 1 & 1 & 0.3 & 1 & 7.7 & 1 & 1 \\
\hline Coltricia perennis & . & 1 & . & 1 & 0.3 & 1 & 7.7 & 1 & 1 \\
\hline Hebeloma stenocystis & . & . & 1 & 1 & 0.3 & 1 & 7.7 & 1 & 1 \\
\hline Russula versicolor & 1 & - & . & 1 & 0.3 & 1 & 7.7 & 1 & 1 \\
\hline \multicolumn{10}{|l|}{ Other species } \\
\hline Clitocybe anisata & 61 & - & 12 & 73 & 24.3 & 59 & 92.3 & 3 & 2 \\
\hline Galerina hypnorum & 36 & 4 & 38 & 78 & 26.0 & 31 & 84.6 & 7 & 3 \\
\hline Mycena pura & 44 & 2 & 2 & 48 & 16.0 & 44 & 84.6 & 4 & 3 \\
\hline Gyтnориs аquоsиs & 105 & 15 & 1 & 121 & 40.3 & 105 & 76.9 & 3 & 3 \\
\hline Clitocybe fragrans & 16 & & 25 & 41 & 13.7 & 16 & 76.9 & 3 & 2 \\
\hline Mycena leptocephala & 19 & . & 14 & 33 & 11.0 & 19 & 76.9 & 2 & 2 \\
\hline Inonotus rheades & 19 & 8 & 6 & $\mathrm{x}$ & $\mathrm{x}$ & 19 & 76.9 & 7 & 3 \\
\hline Mycena flavoalba & 60 & 6 & 58 & 124 & 41.3 & 54 & 69.2 & 6 & 3 \\
\hline Lycoperdon molle & 26 & 3 & 3 & 32 & 10.7 & 20 & 69.2 & 7 & 3 \\
\hline Hypholoma fasciculare & 6 & 14 & 83 & 103 & 34.3 & 70 & 61.5 & 5 & 3 \\
\hline Mycena olivaceomarginata & 2 & $\cdot$ & 31 & 33 & 11.0 & 31 & 61.5 & 2 & 2 \\
\hline Clitocybe candicans & 32 & . & 6 & 38 & 12.7 & 27 & 53.8 & 4 & 2 \\
\hline Coprinellus xanthothrix & 1 & 1 & 8 & 10 & 3.3 & 8 & 53.8 & 3 & 3 \\
\hline Tubaria furfuracea & 21 & 27 & 120 & 168 & 56.0 & 91 & 46.2 & 5 & 3 \\
\hline Flammulaster rhombisporus & 12 & . & 62 & 74 & 24.7 & 62 & 46.2 & 3 & 2 \\
\hline Macrolepiota procera & 6 & 3 & 4 & 13 & 4.3 & 6 & 46.2 & 4 & 3 \\
\hline Mycena stipata & 7 & . & 3 & 10 & 3.3 & 7 & 46.2 & 3 & 2 \\
\hline Gymnopus confluens & 57 & . & 3 & 60 & 20.0 & 41 & 38.5 & 3 & 2 \\
\hline Dacrymyces variisporus & $\cdot$ & 10 & 47 & 57 & 19.0 & 47 & 38.5 & 2 & 2 \\
\hline Mycena sanguinolenta & 2 & . & 23 & 25 & 8.3 & 23 & 38.5 & 2 & 2 \\
\hline Galerina spp. & 2 & - & 20 & 22 & 7.3 & 19 & 38.5 & 3 & 2 \\
\hline Conocybe subpubescens & - & 6 & 3 & 9 & 3.0 & 4 & 38.5 & 3 & 2 \\
\hline Coprinellus micaceus & 2 & 15 & 223 & 240 & 80.0 & 223 & 30.8 & 3 & 3 \\
\hline Collybia cirrhata & . & $\cdot$ & 144 & 144 & 48.0 & 144 & 30.8 & 1 & 1 \\
\hline Steccherinum fimbriatum & 8 & 6 & 36 & 50 & 16.7 & 22 & 30.8 & 4 & 3 \\
\hline Rhodocybe fallax & 13 & . & 27 & 40 & 13.3 & 27 & 30.8 & 2 & 2 \\
\hline Phaeomarasmius erinaceus & 2 & . & 11 & 13 & 4.3 & 11 & 30.8 & 2 & 2 \\
\hline Clitocybe vibecina & . & 6 & $\cdot$ & 6 & 2.0 & 6 & 30.8 & 1 & 1 \\
\hline Crepidotus lundellii & 186 & - & 12 & 198 & 66.0 & 126 & 23.1 & 3 & 2 \\
\hline Exidia plana & 45 & 60 & 14 & 119 & 39.7 & 60 & 23.1 & 3 & 3 \\
\hline Hymenochaete tabacina & . & 5 & 28 & 33 & 11.0 & 18 & 23.1 & 4 & 2 \\
\hline Clitocybe diatreta & 13 & . & 8 & 21 & 7.0 & 13 & 23.1 & 2 & 2 \\
\hline Ceraceomyces crispatus & 14 & 2 & . & 16 & 5.3 & 10 & 23.1 & 3 & 2 \\
\hline Psathyrella candolleana & 1 & 12 & 2 & 15 & 5.0 & 12 & 23.1 & 3 & 3 \\
\hline Gyтnориs androsaceus & 8 & . & 1 & 9 & 3.0 & 8 & 23.1 & 2 & 2 \\
\hline Gyтnориs iтридicus & 1 & 2 & 5 & 8 & 2.7 & 5 & 23.1 & 3 & 3 \\
\hline Clitocybe metachroa & 7 & . & . & 7 & 2.3 & 7 & 23.1 & 1 & 1 \\
\hline Leptosporomyces galzinii & . & . & 5 & 5 & 1.7 & 5 & 23.1 & 1 & 1 \\
\hline Coprinellus disseminatus & 140 & . & 256 & 396 & 132.0 & 200 & 15.4 & 3 & 2 \\
\hline Dacrymyces stillatus & & 200 & $\cdot$ & 200 & 66.7 & 200 & 15.4 & 1 & 1 \\
\hline
\end{tabular}




\begin{tabular}{|c|c|c|c|c|c|c|c|c|c|}
\hline Species & AC'94 & AC'95 & AC'96 & AC3y & aACy & $\mathrm{mACv}$ & SF\% & tTF & TFy \\
\hline Peniophora polygonia & 157 & 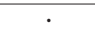 & 1 & 158 & 52.7 & 100 & 15.4 & 4 & 2 \\
\hline Resupinatus trichotis & 20 & 40 & & 60 & 20.0 & 40 & 15.4 & 2 & 2 \\
\hline Gymnopus acervatus & . & 11 & 23 & 34 & 11.3 & 23 & 15.4 & 2 & 2 \\
\hline Pleurotus ostreatus & . & 32 & . & 32 & 10.7 & 20 & 15.4 & 2 & 1 \\
\hline Schizophyllum amplum & 4 & . & 25 & 29 & 9.7 & 25 & 15.4 & 2 & 2 \\
\hline Hypholoma lateritium & 9 & 2 & 13 & 24 & 8.0 & 13 & 15.4 & 3 & 3 \\
\hline Crucibulum laeve & 9 & . & 8 & 17 & 5.7 & 9 & 15.4 & 2 & 2 \\
\hline Hyphoderma setigerum & 7 & . & 9 & 16 & 5.3 & 9 & 15.4 & 2 & 2 \\
\hline Calocera cornea & 14 & . & . & 14 & 4.7 & 14 & 15.4 & 1 & 1 \\
\hline Galerina pumila & 12 & . & . & 12 & 4.0 & 12 & 15.4 & 1 & 1 \\
\hline Marasmiellus vaillantii & $\cdot$ & . & 8 & 8 & 2.7 & 8 & 15.4 & 1 & 1 \\
\hline Clitocybe phyllophila & 7 & . & . & 7 & 2.3 & 7 & 15.4 & 1 & 1 \\
\hline Hygrocybe conica var. conica & . & . & 7 & 7 & 2.3 & 7 & 15.4 & 1 & 1 \\
\hline Mycena inclinata & 2 & 2 & . & 4 & 1.3 & 2 & 15.4 & 2 & 2 \\
\hline Hygrocybe virginea var. virginea & 1 & . & 2 & 3 & 1.0 & 2 & 15.4 & 2 & 2 \\
\hline Tremella mesenterica & 2 & 1 & . & 3 & 1.0 & 2 & 15.4 & 2 & 2 \\
\hline Galerina marginata & 1 & . & 1 & 2 & 0.7 & 1 & 15.4 & 2 & 2 \\
\hline Mycena aetites & 2 & . & . & 2 & 0.7 & 1 & 15.4 & 2 & 1 \\
\hline Mycena galopus & 1 & . & 1 & 2 & 0.7 & 1 & 15.4 & 2 & 2 \\
\hline Daedaleopsis confragosa & 4 & . & 1 & $\mathrm{x}$ & $\mathrm{x}$ & 4 & 15.4 & 2 & 2 \\
\hline Fomes fomentarius & 4 & 3 & 2 & $\mathrm{x}$ & $\mathrm{x}$ & 4 & 15.4 & 7 & 3 \\
\hline Schizopora paradoxa & 60 & $\cdot$ & . & 60 & 20.0 & 60 & 7.7 & 1 & 1 \\
\hline Trametes ochracea & 32 & . & . & 32 & 10.7 & 17 & 7.7 & 2 & 1 \\
\hline Sphaerobolus stellatus & $\cdot$ & . & 30 & 30 & 10.0 & 30 & 7.7 & 1 & 1 \\
\hline Phlebia rufa & . & . & 25 & 25 & 8.3 & 25 & 7.7 & 1 & 1 \\
\hline Tubaria confragosa & . & . & 13 & 13 & 4.3 & 13 & 7.7 & 1 & 1 \\
\hline Ampulloclitocybe clavipes & . & 12 & . & 12 & 4.0 & 12 & 7.7 & 1 & 1 \\
\hline Psathyrella tephrophylla & · & $\cdot$ & 10 & 10 & 3.3 & 10 & 7.7 & 1 & 1 \\
\hline Mycena filopes & 9 & . & . & 9 & 3.0 & 9 & 7.7 & 1 & 1 \\
\hline Panus suavissimus & 3 & . & 5 & 8 & 2.7 & 5 & 7.7 & 3 & 2 \\
\hline Mycena flavescens & . & . & 6 & 6 & 2.0 & 6 & 7.7 & 1 & 1 \\
\hline Rhodocollybia maculata & . & 6 & . & 6 & 2.0 & 6 & 7.7 & 1 & 1 \\
\hline Gyтnориs peronatus & . & . & 5 & 5 & 1.7 & 5 & 7.7 & 1 & 1 \\
\hline Mycena stylobates & . & . & 5 & 5 & 1.7 & 5 & 7.7 & 1 & 1 \\
\hline Mycena vitilis & . & . & 5 & 5 & 1.7 & 5 & 7.7 & 1 & 1 \\
\hline Amylostereum laevigatum & 4 & · & $\cdot$ & 4 & 1.3 & 4 & 7.7 & 1 & 1 \\
\hline Byssomerulius corium & 4 & . & . & 4 & 1.3 & 4 & 7.7 & 1 & 1 \\
\hline Stereum hirsutum & . & - & 4 & 4 & 1.3 & 4 & 7.7 & 1 & 1 \\
\hline Hyphodontia quercina & $\cdot$ & · & 3 & 3 & 1.0 & 3 & 7.7 & 1 & 1 \\
\hline Calocera viscosa & . & 2 & . & 2 & 0.7 & 2 & 7.7 & 1 & 1 \\
\hline Clitocybe nebularis & . & . & 2 & 2 & 0.7 & 2 & 7.7 & 1 & 1 \\
\hline Cystoderma amianthinum & $\cdot$ & 2 & . & 2 & 0.7 & 2 & 7.7 & 1 & 1 \\
\hline Paneolus papilionaceus & . & 2 & . & 2 & 0.7 & 2 & 7.7 & 1 & 1 \\
\hline Chlorophyllum rachodes & . & . & 1 & 1 & 0.3 & 1 & 7.7 & 1 & 1 \\
\hline Entoloma spp. & . & . & 1 & 1 & 0.3 & 1 & 7.7 & 1 & 1 \\
\hline Geastrum quadrifidum & 1 & . & . & 1 & 0.3 & 1 & 7.7 & 1 & 1 \\
\hline Gyтnориs ocior & . & 1 & . & 1 & 0.3 & 1 & 7.7 & 1 & 1 \\
\hline Hypochnicium detriticum & . & . & 1 & 1 & 0.3 & 1 & 7.7 & 1 & 1 \\
\hline Lepiota magnispora & . & 1 & . & 1 & 0.3 & 1 & 7.7 & 1 & 1 \\
\hline Lycoperdon nigrescens & . & . & 1 & 1 & 0.3 & 1 & 7.7 & 1 & 1 \\
\hline Lycoperdon perlatum & 1 & . & . & 1 & 0.3 & 1 & 7.7 & 1 & 1 \\
\hline Mycena metata & $\cdot$ & 1 & . & 1 & 0.3 & 1 & 7.7 & 1 & 1 \\
\hline Mycena rubromarginata & 1 & . & . & 1 & 0.3 & 1 & 7.7 & 1 & 1 \\
\hline Phellinus punctatus & 1 & . & . & $\mathrm{x}$ & $\mathrm{x}$ & 1 & 7.7 & 1 & 1 \\
\hline
\end{tabular}

Abbreviations: see Tab. A3.2; number of subplots -13 
Table A3.12

Macrofungi in plot 2C (phase 9/10, Czechy Orlańskie reserve)

\begin{tabular}{|c|c|c|c|c|c|c|c|c|c|}
\hline \multirow{2}{*}{\multicolumn{10}{|c|}{$\begin{array}{r}\text { Species } \\
\text { ECM species }\end{array}$}} \\
\hline & & & & & & & & & \\
\hline Russula emetica & . & 45 & 2 & 47 & 15.7 & 44 & 100 & 3 & 2 \\
\hline Lactarius rufus & . & 28 & 1 & 29 & 9.7 & 28 & 100 & 2 & 2 \\
\hline Paxillus involutus & 3 & 4 & 18 & 25 & 8.3 & 18 & 100 & 3 & 3 \\
\hline Xerocomus badius & 3 & 11 & 6 & 20 & 6.7 & 11 & 100 & 4 & 3 \\
\hline Amanita citrina & . & 24 & . & 24 & 8.0 & 24 & 75 & 1 & 1 \\
\hline Cortinarius spp. I & 4 & 20 & . & 24 & 8.0 & 20 & 75 & 2 & 2 \\
\hline Cortinarius spp. II & . & 8 & 9 & 17 & 5.7 & 9 & 75 & 2 & 2 \\
\hline Russula decolorans & . & 8 & 5 & 13 & 4.3 & 8 & 75 & 3 & 2 \\
\hline Russula paludosa & . & 6 & 4 & 10 & 3.3 & 4 & 75 & 4 & 2 \\
\hline Russula fragilis & $\cdot$ & 14 & $\cdot$ & 14 & 4.7 & 14 & 50 & 1 & 1 \\
\hline Cortinarius caperatus & $\cdot$ & 13 & · & 13 & 4.3 & 13 & 50 & 1 & 1 \\
\hline Thelephora terrestris & . & 1 & 2 & 3 & 1.0 & 2 & 50 & 2 & 2 \\
\hline Russula badia & $\cdot$ & 4 & $\cdot$ & 4 & 1.3 & 4 & 25 & 1 & 1 \\
\hline Amanita porphyria & $\cdot$ & 3 & · & 3 & 1.0 & 3 & 25 & 1 & 1 \\
\hline Cortinarius semisanguineus & . & 3 & . & 3 & 1.0 & 3 & 25 & 1 & 1 \\
\hline Cantharellus cibarius & $\cdot$ & 1 & $\cdot$ & 1 & 0.3 & 1 & 25 & 1 & 1 \\
\hline \multicolumn{10}{|l|}{ Other species } \\
\hline Exobasidium vaccinii & 2 & 89 & 47 & 138 & 46.0 & 80 & 100 & 7 & 3 \\
\hline Gymnopus androsaceus & 16 & 31 & 42 & 89 & 29.7 & 21 & 100 & 8 & 3 \\
\hline Leptosporomyces galzinii & . & 35 & $\cdot$ & 35 & 11.7 & 35 & 100 & 1 & 1 \\
\hline Galerina pumila & 5 & 12 & 4 & 21 & 7.0 & 9 & 100 & 6 & 3 \\
\hline Mycena zephirus & 8 & 6 & . & 14 & 4.7 & 8 & 100 & 3 & 2 \\
\hline Dacrymyces stillatus & 140 & 210 & 500 & 850 & 283.3 & 320 & 75 & 7 & 3 \\
\hline Collybia cirrhata & 45 & . & 180 & 225 & 75.0 & 180 & 75 & 2 & 2 \\
\hline Galerina spp. & 2 & 17 & $\cdot$ & 19 & 6.3 & 17 & 75 & 2 & 2 \\
\hline Mycena metata & 6 & 8 & . & 14 & 4.7 & 7 & 75 & 4 & 2 \\
\hline Botryobasidium vagum & . & 5 & 2 & 7 & 2.3 & 4 & 75 & 3 & 2 \\
\hline Entoloma spp. & . & 2 & 3 & 5 & 1.7 & 3 & 75 & 2 & 2 \\
\hline Phlebiella sulphurea & 1 & 2 & 1 & 4 & 1.3 & 1 & 75 & 4 & 3 \\
\hline Hypholoma capnoides & 4 & 40 & . & 44 & 14.7 & 22 & 50 & 4 & 2 \\
\hline Clitocybe vibecina & . & 20 & 1 & 21 & 7.0 & 18 & 50 & 3 & 2 \\
\hline Mycena galopus & 4 & 2 & 10 & 16 & 5.3 & 10 & 50 & 4 & 3 \\
\hline Cystoderma amianthinum & 5 & . & 5 & 10 & 3.3 & 5 & 50 & 3 & 2 \\
\hline Mycena purpureofusca & 4 & 1 & . & 5 & 1.7 & 4 & 50 & 2 & 2 \\
\hline Auriscalpium vulgare & . & 4 & & 4 & 1.3 & 3 & 50 & 2 & 1 \\
\hline Gymnopilus bellulus & - & 4 & . & 4 & 1.3 & 2 & 50 & 2 & 1 \\
\hline Coniophora arida & . & 2 & . & 2 & 0.7 & 2 & 50 & 1 & 1 \\
\hline Gleoporus taxicola & 10 & . & . & 10 & 3.3 & 10 & 25 & 1 & 1 \\
\hline Phlebiella pseudotsugae & . & 9 & - & 9 & 3.0 & 9 & 25 & 1 & 1 \\
\hline Crepidotus applanatus & . & 5 & . & 5 & 1.7 & 5 & 25 & 1 & 1 \\
\hline Gymnopilus penetrans & 2 & . & 3 & 5 & 1.7 & 3 & 25 & 2 & 2 \\
\hline Baeospora myosura & 1 & 1 & 1 & 3 & 1.0 & 1 & 25 & 3 & 3 \\
\hline Ceraceomyces sublaevis & . & 3 & . & 3 & 1.0 & 3 & 25 & 1 & 1 \\
\hline Ampulloclitocybe clavipes & 2 & . & . & 2 & 0.7 & 2 & 25 & 1 & 1 \\
\hline Collybia tuberosa & 2 & . & . & 2 & 0.7 & 2 & 25 & 1 & 1 \\
\hline Galerina calyptrata & . & 2 & . & 2 & 0.7 & 2 & 25 & 1 & 1 \\
\hline Pseudohydnum gelatinosum & 2 & . & . & 2 & 0.7 & 2 & 25 & 1 & 1 \\
\hline Tapinella panuoides & 2 & . & . & 2 & 0.7 & 2 & 25 & 1 & 1 \\
\hline Clitocybe anisata & . & 1 & . & 1 & 0.3 & 1 & 25 & 1 & 1 \\
\hline Hyphodontia aspera & . & 1 & . & 1 & 0.3 & 1 & 25 & 1 & 1 \\
\hline
\end{tabular}




\begin{tabular}{|l|c|c|c|c|c|c|c|c|c|}
\hline \multicolumn{1}{|c|}{ Species } & AC'94 & AC'95 & AC'96 & AC3y & aACy & mACv & SF\% & tTF & TFy \\
\hline Phanerochaete sanguinea & $\cdot$ & 1 & $\cdot$ & 1 & 0.3 & 1 & 25 & 1 & 1 \\
Psilocybe montana & 1 & $\cdot$ & $\cdot$ & 1 & 0.3 & 1 & 25 & 1 & 1 \\
Tubulicrinis subulatus & $\cdot$ & $\cdot$ & 1 & 1 & 0.3 & 1 & 25 & 1 & 1 \\
Xeromphalina cornui & 1 & $\cdot$ & $\cdot$ & 1 & 0.3 & 1 & 25 & 1 & 1 \\
\hline
\end{tabular}

$\mathrm{AC}$ - abundance of carpophores during the indicated year; AC3y - abundance of carpophores during 3 years of observations; aACy - average abundance of carpophores per year; $\mathrm{mDCv}$ - maximum abundance of carpophores per visit; SF\% - spatial frequency of a species (percentage of subplots with the species presence; plot surface $400 \mathrm{~m}^{2}$, number of subplots - 4); tTF - number of visits with a species presence; TFy - number of years with a species presence; $\mathrm{x}$ - perennial carpophores

Table A3.13

Macrofungi in plot 5C (phase 9/10, Czechy Orlańskie reserve)

\begin{tabular}{|c|c|c|c|c|c|c|c|c|c|}
\hline Species & AC'94 & AC'95 & AC'96 & AC3y & $\mathrm{aACy}$ & $\mathrm{mACv}$ & SF\% & tTF & TFy \\
\hline ECM species & & & & & & & & & \\
\hline Paxillus involutus & 8 & 12 & 23 & 43 & 14.3 & 19 & 100 & 5 & 3 \\
\hline Amanita citrina & . & 34 & 1 & 35 & 11.7 & 29 & 100 & 3 & 2 \\
\hline Russula fragilis & . & 20 & 1 & 21 & 7.0 & 20 & 75 & 2 & 2 \\
\hline Russula vinosa & . & 9 & 1 & 10 & 3.3 & 5 & 75 & 3 & 2 \\
\hline Cantharellus cibarius & 1 & 1 & 3 & 5 & 1.7 & 1 & 75 & 5 & 3 \\
\hline Cortinarius caperatus & . & 5 & . & 5 & 1.7 & 5 & 75 & 1 & 1 \\
\hline Russula emetica & . & 5 & . & 5 & 1.7 & 5 & 75 & 1 & 1 \\
\hline Lactarius tabidus & 5 & 7 & . & 12 & 4.0 & 7 & 50 & 2 & 2 \\
\hline Cortinarius vibratilis & . & 2 & 2 & 4 & 1.3 & 2 & 50 & 2 & 2 \\
\hline Laccaria proxima & 1 & 3 & . & 4 & 1.3 & 3 & 50 & 2 & 2 \\
\hline Russula xerampelina & $\cdot$ & 4 & . & 4 & 1.3 & 4 & 50 & 1 & 1 \\
\hline Lactarius rufus & 1 & 2 & . & 3 & 1.0 & 2 & 50 & 2 & 2 \\
\hline Russula paludosa & 1 & 1 & 1 & 3 & 1.0 & 1 & 50 & 3 & 3 \\
\hline Xerocomus badius & 1 & 2 & . & 3 & 1.0 & 2 & 50 & 2 & 2 \\
\hline Russula decolorans & . & 1 & 1 & 2 & 0.7 & 1 & 50 & 2 & 2 \\
\hline Thelephora terrestris & 1 & 6 & . & 7 & 2.3 & 6 & 25 & 2 & 2 \\
\hline Russula badia & 1 & 5 & . & 6 & 2.0 & 4 & 25 & 3 & 2 \\
\hline Cortinarius spp. I & · & 2 & $\cdot$ & 2 & 0.7 & 2 & 25 & 1 & 1 \\
\hline $\begin{array}{l}\text { Tricholoma saponaceum } \\
\text { var. squamosum }\end{array}$ & . & & 2 & 2 & 0.7 & 2 & 25 & 1 & 1 \\
\hline Amanita porphyria & . & 1 & & 1 & 0.3 & 1 & 25 & 1 & 1 \\
\hline Chroogomphus rutilus & . & 1 & . & 1 & 0.3 & 1 & 25 & 1 & 1 \\
\hline Cortinarius spp. II & . & 1 & . & 1 & 0.3 & 1 & 25 & 1 & 1 \\
\hline Cortinarius spp. III & . & 1 & . & 1 & 0.3 & 1 & 25 & 1 & 1 \\
\hline Rhodocollybia butyracea f. asema & $\cdot$ & $\cdot$ & 1 & 1 & 0.3 & 1 & 25 & 1 & 1 \\
\hline Other species & & & & & & & & & \\
\hline Dacrymyces stillatus & . & 100 & 301 & 401 & 133.7 & 200 & 100 & 5 & 2 \\
\hline Collybia cirrhata & 70 & 75 & 70 & 215 & 71.7 & 75 & 100 & 3 & 3 \\
\hline Gymnopus androsaceus & 68 & 35 & 80 & 183 & 61.0 & 65 & 100 & 7 & 3 \\
\hline Mycena zephirus & 108 & 59 & 3 & 170 & 56.7 & 94 & 100 & 7 & 3 \\
\hline Hypholoma capnoides & 5 & 29 & 5 & 39 & 13.0 & 29 & 100 & 3 & 3 \\
\hline Leptosporomyces galzinii & $\cdot$ & 24 & . & 24 & 8.0 & 24 & 100 & 1 & 1 \\
\hline Mycena metata & 5 & 2 & 2 & 9 & 3.0 & 3 & 100 & 4 & 3 \\
\hline Galerina pumila & 1 & 5 & 1 & 7 & 2.3 & 3 & 100 & 5 & 3 \\
\hline Mycena galopus & 4 & 23 & 7 & 34 & 11.3 & 21 & 75 & 5 & 3 \\
\hline Exobasidium vaccinii & 1 & 3 & 14 & 18 & 6.0 & 10 & 75 & 6 & 3 \\
\hline Armillaria ostoyae & . & 6 & $\cdot$ & 6 & 2.0 & 6 & 75 & 1 & 1 \\
\hline Hygrophoropsis aurantiaca & 2 & 1 & . & 3 & 1.0 & 2 & 75 & 2 & 2 \\
\hline
\end{tabular}




\begin{tabular}{|l|c|c|c|c|c|c|c|c|c|}
\hline \multicolumn{1}{|c|}{ Species } & AC'94 & AC'95 & AC'96 & AC3y & aACy & mACv & SF\% & tTF & TFy \\
\hline Clitocybe vibecina & 1 & 47 & $\cdot$ & 48 & 16 & 47 & 50 & 2 & 2 \\
Mycena vulgaris & 16 & $\cdot$ & 29 & 45 & 15.0 & 29 & 50 & 2 & 2 \\
Collybia tuberosa & 9 & 30 & $\cdot$ & 39 & 13.0 & 30 & 50 & 2 & 2 \\
Xeromphalina cornui & 3 & $\cdot$ & 1 & 4 & 1.3 & 3 & 50 & 2 & 2 \\
Cystoderma amianthinum & 1 & 1 & 1 & 3 & 1.0 & 1 & 50 & 3 & 3 \\
Phanerochaete sanguinea & $\cdot$ & 2 & $\cdot$ & 2 & 0.7 & 1 & 50 & 2 & 1 \\
Panellus mitis & $\cdot$ & $\cdot$ & 35 & 35 & 11.7 & 35 & 25 & 1 & 1 \\
Clitocybe diatreta & $\cdot$ & 12 & $\cdot$ & 12 & 4.0 & 12 & 25 & 1 & 1 \\
Dacrymyces variisporus & $\cdot$ & $\cdot$ & 12 & 12 & 4.0 & 12 & 25 & 1 & 1 \\
Galerina spp. & 3 & 4 & $\cdot$ & 7 & 2.3 & 4 & 25 & 2 & 2 \\
Collybia cookei & 5 & $\cdot$ & $\cdot$ & 5 & 1.7 & 5 & 25 & 1 & 1 \\
Botryobasidium vagum & $\cdot$ & 3 & $\cdot$ & 3 & 1.0 & 2 & 25 & 2 & 1 \\
Clitocybe anisata & $\cdot$ & 3 & $\cdot$ & 3 & 1.0 & 3 & 25 & 1 & 1 \\
Mycena pura & 2 & $\cdot$ & 1 & 3 & 1.0 & 1 & 25 & 3 & 2 \\
Auriscalpium vulgare & 2 & $\cdot$ & $\cdot$ & 2 & 0.7 & 2 & 25 & 1 & 1 \\
Galerina mniophila & $\cdot$ & 2 & $\cdot$ & 2 & 0.7 & 2 & 25 & 1 & 1 \\
Phlebiella sulphurea & $\cdot$ & 2 & $\cdot$ & 2 & 0.7 & 1 & 25 & 2 & 1 \\
Athelia decipiens & 1 & $\cdot$ & $\cdot$ & 1 & 0.3 & 1 & 25 & 1 & 1 \\
Baeospora myosura & $\cdot$ & 1 & $\cdot$ & 1 & 0.3 & 1 & 25 & 1 & 1 \\
Clitocybe candicans & 1 & $\cdot$ & $\cdot$ & 1 & 0.3 & 1 & 25 & 1 & 1 \\
Coniophora arida & $\cdot$ & 1 & $\cdot$ & 1 & 0.3 & 1 & 25 & 1 & 1 \\
Cystodermella granulosa & $\cdot$ & 1 & & 1 & 0.3 & 1 & 25 & 1 & 1 \\
Macrolepiota procera & $\cdot$ & $\cdot$ & 1 & 1 & 0.3 & 1 & 25 & 1 & 1 \\
Mycena purpureofusca & $\cdot$ & $\cdot$ & 1 & 1 & 0.3 & 1 & 25 & 1 & 1 \\
Mycena sanguinolenta & 1 & $\cdot$ & $\cdot$ & 1 & 0.3 & 1 & 25 & 1 & 1 \\
Inonotus rheades & $\cdot$ & $\cdot$ & 1 & $\mathrm{x}$ & $\mathrm{x}$ & 1 & 25 & 1 & 1 \\
\hline
\end{tabular}

Abbreviations: see Tab. A3.12

Table A3.14

Macrofungi in plot 6C (phase 9/10, Czechy Orlańskie reserve)

\begin{tabular}{|l|c|c|c|c|c|c|c|c|c|}
\hline \multicolumn{1}{|c|}{ Species } & AC'94 & AC'95 & AC'96 & AC3y & aACy & mACv & SF\% & tTF & TFy \\
\hline ECM species & & & & & & & & & \\
Paxillus involutus & 6 & 11 & 28 & 45 & 15.0 & 24 & 100 & 4 & 3 \\
Cortinarius caperatus & 1 & 22 & $\cdot$ & 23 & 7.7 & 22 & 100 & 2 & 2 \\
Amanita citrina & $\cdot$ & 35 & $\cdot$ & 35 & 11.7 & 34 & 75 & 2 & 1 \\
Russula emetica & $\cdot$ & 22 & $\cdot$ & 22 & 7.3 & 22 & 75 & 1 & 1 \\
Amanita porphyria & $\cdot$ & 5 & 3 & 8 & 2.7 & 5 & 75 & 2 & 2 \\
Russula badia & 7 & 18 & $\cdot$ & 25 & 8.3 & 14 & 50 & 3 & 2 \\
Russula paludosa & $\cdot$ & 2 & 3 & 5 & 1.7 & 3 & 50 & 2 & 2 \\
Russula decolorans & $\cdot$ & 1 & 2 & 3 & 1.0 & 1 & 50 & 3 & 2 \\
Thelephora terrestris & 13 & $\cdot$ & $\cdot$ & 13 & 4.3 & 13 & 25 & 1 & 1 \\
Xerocomus badius & 2 & 1 & 6 & 9 & 3.0 & 4 & 25 & 4 & 3 \\
Cantharellus cibarius & $\cdot$ & 8 & $\cdot$ & 8 & 2.7 & 8 & 25 & 1 & 1 \\
Cortinarius vibratilis & 6 & 2 & $\cdot$ & 8 & 2.7 & 6 & 25 & 2 & 2 \\
Cortinarius semisanguineus & 1 & 4 & 1 & 6 & 2.0 & 4 & 25 & 3 & 3 \\
Rhodocollybia butyracea f. asema & $\cdot$ & $\cdot$ & 5 & 5 & 1.7 & 5 & 25 & 1 & 1 \\
Cortinarius spp. III & 2 & $\cdot$ & $\cdot$ & 2 & 0.7 & 2 & 25 & 1 & 1 \\
Cortinarius spp. I & $\cdot$ & 1 & $\cdot$ & 1 & 0.3 & 1 & 25 & 1 & 1 \\
Tylopilus felleus & $\cdot$ & 1 & $\cdot$ & 1 & 0.3 & 1 & 25 & 1 & 1 \\
& & & & & & & & & \\
Other species & & & & & & & & & \\
Dacrymyces stillatus & 100 & 350 & 695 & 1145 & 381.7 & 645 & 100 & 5 & 3 \\
Gymnopus androsaceus & 216 & 14 & 102 & 332 & 110.7 & 202 & 100 & 11 & 3
\end{tabular}




\begin{tabular}{|c|c|c|c|c|c|c|c|c|c|}
\hline Species & AC'94 & AC'95 & AC'96 & AC3y & $\mathrm{aACy}$ & $\mathrm{mACv}$ & SF\% & tTF & TFy \\
\hline Exobasidium vaccinii & $\cdot$ & 66 & 31 & 97 & 32.3 & 47 & 100 & 5 & 2 \\
\hline Mycena galopus & 31 & 34 & 3 & 68 & 22.7 & 32 & 100 & 6 & 3 \\
\hline Mycena metata & 18 & 32 & 1 & 51 & 17.0 & 22 & 100 & 6 & 3 \\
\hline Cystoderma amianthinum & 7 & 9 & 14 & 30 & 10.0 & 13 & 100 & 5 & 3 \\
\hline Galerina pumila & 4 & 3 & 13 & 20 & 6.7 & 11 & 100 & 5 & 3 \\
\hline Mycena zephirus & 151 & 41 & 1 & 193 & 64.3 & 148 & 75 & 5 & 3 \\
\hline Collybia cirrhata & 15 & 30 & 4 & 49 & 16.3 & 30 & 75 & 3 & 3 \\
\hline Leptosporomyces galzinii & . & 18 & - & 18 & 6.0 & 18 & 75 & 1 & 1 \\
\hline Xeromphalina cornui & 14 & . & . & 14 & 4.7 & 14 & 75 & 1 & 1 \\
\hline Ampulloclitocybe clavipes & 2 & 8 & . & 10 & 3.3 & 4 & 75 & 3 & 2 \\
\hline Entoloma spp. & . & 1 & 8 & 9 & 3.0 & 5 & 75 & 3 & 2 \\
\hline Auriscalpium vulgare & 1 & 5 & . & 6 & 2.0 & 5 & 75 & 2 & 2 \\
\hline Collybia tuberosa & 2 & 11 & 34 & 47 & 15.7 & 24 & 50 & 5 & 3 \\
\hline Mycena vulgaris & 10 & 2 & 20 & 32 & 10.7 & 20 & 50 & 3 & 3 \\
\hline Pholiota spumosa & 13 & . & 1 & 14 & 4.7 & 13 & 50 & 2 & 2 \\
\hline Hygrophoropsis aurantiaca & 5 & 4 & 1 & 10 & 3.3 & 4 & 50 & 5 & 3 \\
\hline Baeospora myosura & 3 & 1 & 3 & 7 & 2.3 & 3 & 50 & 4 & 3 \\
\hline Clitocybe vibecina & . & . & 4 & 4 & 1.3 & 2 & 50 & 2 & 1 \\
\hline Hyphodontia subalutacea & . & 1 & 1 & 2 & 0.7 & 1 & 50 & 2 & 2 \\
\hline Dacrymyces ovisporus & 80 & . & . & 80 & 26.7 & 80 & 25 & 1 & 1 \\
\hline Mycena purpureofusca & 2 & 6 & . & 8 & 2.7 & 6 & 25 & 2 & 2 \\
\hline Mycena adonis & . & 4 & . & 4 & 1.3 & 4 & 25 & 1 & 1 \\
\hline Mycena aetites & - & . & 4 & 4 & 1.3 & 4 & 25 & 1 & 1 \\
\hline Phlebiella sulphurea & . & 2 & . & 2 & 0.7 & 2 & 25 & 1 & 1 \\
\hline Cystoderma jasonis var. jasonis & . & . & 1 & 1 & 0.3 & 1 & 25 & 1 & 1 \\
\hline Galerina calyptrata & 1 & . & . & 1 & 0.3 & 1 & 25 & 1 & 1 \\
\hline Galerina mniophila & . & 1 & . & 1 & 0.3 & 1 & 25 & 1 & 1 \\
\hline Galerina spp. & . & 1 & . & 1 & 0.3 & 1 & 25 & 1 & 1 \\
\hline Lycoperdon nigrescens & . & 1 & . & 1 & 0.3 & 1 & 25 & 1 & 1 \\
\hline Mycena flavoalba & 1 & . & . & 1 & 0.3 & 1 & 25 & 1 & 1 \\
\hline Strobilurus stephanocystis & . & . & 1 & 1 & 0.3 & 1 & 25 & 1 & 1 \\
\hline
\end{tabular}

Abbreviations: see Tab. A3.12

Table A3.15

Macrofungi in plot 7C (phase 9/10, Czechy Orlańskie reserve)

\begin{tabular}{|l|c|c|c|c|c|c|c|c|c|}
\hline \multicolumn{1}{|c|}{ Species } & AC'94 & AC'95 & AC'96 & AC3y & aACy & mACv & SF\% & tTF & TFy \\
\hline ECM species & & & & & & & & & \\
Cortinarius caperatus & 4 & 44 &. & 48 & 16.0 & 44 & 100 & 2 & 2 \\
Russula decolorans & $\cdot$ & 10 & 13 & 23 & 7.7 & 9 & 100 & 6 & 2 \\
Amanita citrina & $\cdot$ & 15 & 1 & 16 & 5.3 & 13 & 100 & 3 & 2 \\
Cortinarius semisanguineus & 9 & 26 & 26 & 61 & 20.3 & 26 & 75 & 5 & 3 \\
Russula paludosa & 1 & 4 & 9 & 14 & 4.7 & 8 & 75 & 6 & 3 \\
Xerocomus badius & 2 & 4 & 2 & 8 & 2.7 & 3 & 75 & 4 & 3 \\
Russula emetica & $\cdot$ & 5 &. & 5 & 1.7 & 5 & 75 & 1 & 1 \\
Thelephora terrestris & $\cdot$ & 15 &. & 15 & 5.0 & 15 & 50 & 1 & 1 \\
Lactarius rufus & 1 & 13 & $\cdot$ & 14 & 4.7 & 13 & 50 & 2 & 2 \\
Russula badia & 2 & $\cdot$ & 4 & 6 & 2.0 & 4 & 50 & 2 & 2 \\
Russula turci & $\cdot$ & 5 & $\cdot$ & 5 & 1.7 & 5 & 50 & 1 & 1 \\
Amanita porphyria & $\cdot$ & 3 & $\cdot$ & 3 & 1.0 & 3 & 50 & 1 & 1 \\
Amanita rubescens & 1 & 1 & 1 & 3 & 1.0 & 1 & 50 & 3 & 3 \\
Paxillus involutus & & 3 & $\cdot$ & 3 & 1.0 & 3 & 50 & 1 & 1 \\
Tricholoma saponaceum & 1 & 5 & 4 & 10 & 3.3 & 5 & 25 & 3 & 3 \\
var. squamosum & & & & & & & & &
\end{tabular}




\begin{tabular}{|c|c|c|c|c|c|c|c|c|c|}
\hline Species & AC'94 & $\mathrm{AC}{ }^{\prime} 95$ & AC'96 & AC3y & aACy & $\mathrm{mACv}$ & SF\% & $\mathrm{tTF}$ & TFy \\
\hline Cortinarius spp. III & $\cdot$ & 4 & $\cdot$ & 4 & 1.3 & 4 & 25 & 1 & 1 \\
\hline Laccaria proxima & . & 2 & . & 2 & 0.7 & 2 & 25 & 1 & 1 \\
\hline Russula xerampelina & . & 2 & . & 2 & 0.7 & 2 & 25 & 1 & 1 \\
\hline Cantharellus cibarius & . & . & 1 & 1 & 0.3 & 1 & 25 & 1 & 1 \\
\hline Cortinarius spp. II & . & 1 & . & 1 & 0.3 & 1 & 25 & 1 & 1 \\
\hline Cortinarius vibratilis & . & 1 & . & 1 & 0.3 & 1 & 25 & 1 & 1 \\
\hline Suillus variegatus & . & . & 1 & 1 & 0.3 & 1 & 25 & 1 & 1 \\
\hline Other species & & & & & & & & & \\
\hline Exobasidium vaccinii & 5 & 156 & 49 & 210 & 70.0 & 150 & 100 & 6 & 3 \\
\hline Gymnopus androsaceus & 38 & 45 & 89 & 172 & 57.3 & 29 & 100 & 12 & 3 \\
\hline Collybia cirrhata & 21 & 19 & 40 & 80 & 26.7 & 40 & 100 & 4 & 3 \\
\hline Leptosporomyces galzinii & . & 28 & . & 28 & 9.3 & 28 & 100 & 1 & 1 \\
\hline Dacrymyces stillatus & 165 & 290 & 45 & 500 & 166.7 & 240 & 75 & 6 & 3 \\
\hline Xeromphalina cornui & 5 & 12 & - & 17 & 5.7 & 12 & 75 & 2 & 2 \\
\hline Botryobasidium vagum & 3 & 11 & . & 14 & 4.7 & 6 & 75 & 3 & 2 \\
\hline Baеospora myosura & 3 & 6 & 2 & 11 & 3.7 & 4 & 75 & 6 & 3 \\
\hline Pseudomerulius aureus & 15 & 65 & . & 80 & 26.7 & 50 & 50 & 3 & 2 \\
\hline Hypholoma capnoides & 5 & 4 & 13 & 22 & 7.3 & 7 & 50 & 5 & 3 \\
\hline Hygrophoropsis aurantiaca & 2 & 5 & . & 7 & 2.3 & 5 & 50 & 2 & 2 \\
\hline Coniophora arida & 3 & 1 & 2 & 6 & 2.0 & 3 & 50 & 4 & 3 \\
\hline Cystoderma amianthinum & 1 & 2 & - & 3 & 1.0 & 1 & 50 & 3 & 2 \\
\hline Mycena zephirus & 1 & 1 & 1 & 3 & 1.0 & 1 & 50 & 3 & 3 \\
\hline Galerina spp. & 1 & 1 & . & 2 & 0.7 & 1 & 50 & 2 & 2 \\
\hline Dacrymyces macnabbii & 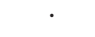 & 50 & . & 50 & 16.7 & 50 & 25 & 1 & 1 \\
\hline Gymnopus ocior & • & 26 & . & 26 & 8.7 & 26 & 25 & 1 & 1 \\
\hline Gleoporus taxicola & . & 3 & - & 3 & 1.0 & 3 & 25 & 1 & 1 \\
\hline Entoloma spp. & . & . & 2 & 2 & 0.7 & 1 & 25 & 2 & 1 \\
\hline Galerina pumila & 1 & - & 1 & 2 & 0.7 & 1 & 25 & 2 & 2 \\
\hline Mycena metata & 1 & - & 1 & 2 & 0.7 & 1 & 25 & 2 & 2 \\
\hline Mycena vulgaris & . & 2 & . & 2 & 0.7 & 2 & 25 & 1 & 1 \\
\hline Phlebiella sulphurea & . & 2 & . & 2 & 0.7 & 2 & 25 & 1 & 1 \\
\hline Athelia decipiens & 1 & . & . & 1 & 0.3 & 1 & 25 & 1 & 1 \\
\hline Clitocybe diatreta & $\cdot$ & 1 & . & 1 & 0.3 & 1 & 25 & 1 & 1 \\
\hline Clitocybe vibecina & - & 1 & - & 1 & 0.3 & 1 & 25 & 1 & 1 \\
\hline Mycena sanguinolenta & . & 1 & . & 1 & 0.3 & 1 & 25 & 1 & 1 \\
\hline
\end{tabular}

Abbreviations: see Tab. A3.12

Table A3.16

Macrofungi in plot 8C (phase 9/10, Czechy Orlańskie reserve)

\begin{tabular}{|l|c|c|c|c|c|c|c|c|c|}
\hline \multicolumn{1}{|c|}{ Species } & AC'94 & AC'95 & AC'96 & AC3y & aACy & mACv & SF\% & tTF & TFy \\
\hline ECM species & & & & & & & & & \\
Cortinarius semisanguineus & 8 & 12 & 8 & 28 & 9.3 & 12 & 100 & 5 & 3 \\
Russula decolorans &. & 7 & 13 & 20 & 6.7 & 9 & 100 & 4 & 2 \\
Russula paludosa & 1 & 3 & 3 & 7 & 2.3 & 3 & 100 & 4 & 3 \\
Paxillus involutus & 7 & 6 & 21 & 34 & 11.3 & 21 & 75 & 4 & 3 \\
Lactarius rufus &. & 30 & $\cdot$ & 30 & 10.0 & 30 & 75 & 1 & 1 \\
Russula badia & 3 & 11 & $\cdot$ & 14 & 4.7 & 10 & 75 & 3 & 2 \\
Amanita citrina & $\cdot$ & 8 & 1 & 9 & 3.0 & 7 & 75 & 3 & 2 \\
Thelephora terrestris & 30 & 4 & $\cdot$ & 34 & 11.3 & 30 & 50 & 2 & 2 \\
Xerocomus badius & 2 & 6 & 4 & 12 & 4.0 & 6 & 50 & 3 & 3 \\
Cortinarius vibratilis & 2 & 2 & $\cdot$ & 4 & 1.3 & 2 & 50 & 2 & 2 \\
Cortinarius caperatus & 2 & 1 & $\cdot$ & 3 & 1.0 & 2 & 50 & 2 & 2
\end{tabular}




\begin{tabular}{|c|c|c|c|c|c|c|c|c|c|}
\hline Species & AC'94 & AC'95 & AC'96 & AC3y & $\mathrm{aACy}$ & $\mathrm{mACv}$ & SF\% & tTF & TFy \\
\hline Laccaria proxima & 1 & 1 & $\cdot$ & 2 & 0.7 & 1 & 50 & 2 & 2 \\
\hline Russula xerampelina & . & 2 & . & 2 & 0.7 & 2 & 50 & 1 & 1 \\
\hline Amanita porphyria & . & 2 & . & 2 & 0.7 & 2 & 25 & 1 & 1 \\
\hline Amanita rubescens & 1 & . & . & 1 & 0.3 & 1 & 25 & 1 & 1 \\
\hline Russula vesca & . & 1 & . & 1 & 0.3 & 1 & 25 & 1 & 1 \\
\hline Other species & & & & & & & & & \\
\hline Collybia cirrhata & 35 & 38 & 199 & 272 & 90.7 & 186 & 100 & 5 & 3 \\
\hline Gymnopus androsaceus & 49 & 69 & 60 & 178 & 59.3 & 69 & 100 & 8 & 3 \\
\hline Exobasidium vaccinii & 3 & 13 & 26 & 42 & 14.0 & 16 & 100 & 8 & 3 \\
\hline Xeromphalina cornui & 13 & 25 & - & 38 & 12.7 & 25 & 100 & 2 & 2 \\
\hline Leptosporomyces galzinii & . & 27 & . & 27 & 9.0 & 27 & 100 & 1 & 1 \\
\hline Mycena metata & 6 & 5 & 11 & 22 & 7.3 & 11 & 100 & 5 & 3 \\
\hline Cystoderma amianthinum & 3 & 1 & 8 & 12 & 4.0 & 7 & 100 & 5 & 3 \\
\hline Dacrymyces stillatus & . & 1570 & 700 & 2270 & 756.7 & 1570 & 75 & 3 & 2 \\
\hline Mycena zephirus & 15 & 7 & . & 22 & 7.3 & 15 & 75 & 2 & 2 \\
\hline Mycena galopus & 6 & 8 & 6 & 20 & 6.7 & 6 & 75 & 6 & 3 \\
\hline Galerina pumila & 2 & 5 & 6 & 13 & 4.3 & 5 & 75 & 4 & 3 \\
\hline Entoloma spp. & - & . & 12 & 12 & 4.0 & 12 & 75 & 1 & 1 \\
\hline Phlebiella sulphurea & 4 & 5 & . & 9 & 3.0 & 4 & 75 & 4 & 2 \\
\hline Hyphodontia aspera & 1 & 6 & . & 7 & 2.3 & 6 & 75 & 2 & 2 \\
\hline Hypholoma fasciculare & 183 & 24 & 39 & 246 & 82.0 & 177 & 50 & 8 & 3 \\
\hline Auriscalpium vulgare & - & 4 & . & 4 & 1.3 & 4 & 50 & 1 & 1 \\
\hline Coniophora arida & 3 & 1 & . & 4 & 1.3 & 3 & 50 & 2 & 2 \\
\hline Cystodermella granulosa & 2 & . & . & 2 & 0.7 & 2 & 50 & 1 & 1 \\
\hline Dacrymyces ovisporus & . & 6 & . & 6 & 2.0 & 6 & 25 & 1 & 1 \\
\hline Gymnopilus penetrans & . & . & 5 & 5 & 1.7 & 5 & 25 & 1 & 1 \\
\hline Galerina spp. & . & 3 & . & 3 & 1.0 & 3 & 25 & 1 & 1 \\
\hline Gymnopus peronatus & . & . & 3 & 3 & 1.0 & 3 & 25 & 1 & 1 \\
\hline Hyphoderma setigerum & 3 & - & - & 3 & 1.0 & 3 & 25 & 1 & 1 \\
\hline Galerina mniophila & - & - & 2 & 2 & 0.7 & 2 & 25 & 1 & 1 \\
\hline Mycena vulgaris & . & 2 & . & 2 & 0.7 & 2 & 25 & 1 & 1 \\
\hline Ampulloclitocybe clavipes & 1 & - & . & 1 & 0.3 & 1 & 25 & 1 & 1 \\
\hline Athelia decipiens & . & - & 1 & 1 & 0.3 & 1 & 25 & 1 & 1 \\
\hline Baeospora myosura & - & - & 1 & 1 & 0.3 & 1 & 25 & 1 & 1 \\
\hline Hyphodontia subalutacea & 1 & . & . & 1 & 0.3 & 1 & 25 & 1 & 1 \\
\hline Macrolepiota permixta & . & . & 1 & 1 & 0.3 & 1 & 25 & 1 & 1 \\
\hline Phanerochaete sanguinea & 1 & - & . & 1 & 0.3 & 1 & 25 & 1 & 1 \\
\hline
\end{tabular}

Abbreviations: see Tab. A3.12 


\section{Appendix 4}

\section{Results of k-mean analysis of fungi}

Table A4.1

Members of clusters and distances from respective cluster centres - ECM species

\begin{tabular}{|c|c|c|c|}
\hline Species & Distance & Species & Distance \\
\hline \multicolumn{4}{|c|}{ Cluster 1 ( 8 cases $)$} \\
\hline Amanita muscaria & 0.789689 & Hygrophorus hypothejus & 0.746702 \\
\hline Chalciporus piperatus & 1.179500 & Inocybe lacera & 1.497421 \\
\hline Cotinarius cinnamomeoluteus & 1.006049 & Laccaria proxima & 0.991403 \\
\hline Cortinarius spp. I & 1.569105 & Suillus luteus & 0.624135 \\
\hline \multicolumn{4}{|c|}{ Cluster 2 (12 cases) } \\
\hline Boletus edulis & 1.204770 & Rhodocollybia butyracea f. asema & 1.198975 \\
\hline Cortinarius parevernius & 1.180209 & Thelephora terrestris & 1.987908 \\
\hline Cortinarius spp. II & 1.860347 & Tricholoma albobrunneum & 1.154798 \\
\hline Cortinarius spp. III & 1.793187 & Tricholoma equestre & 1.073890 \\
\hline Laccaria bicolor & 1.279095 & Tricholoma portentosum & 0.914971 \\
\hline Lactarius rufus & 1.957838 & Tricholoma saponaceum & 1.162415 \\
\hline \multicolumn{4}{|c|}{ Cluster 3 (13 cases) } \\
\hline Cantharellus cibarius & 1.357769 & Lactarius uvidus & 0.454643 \\
\hline Clitopilus prunulus & 1.256667 & Leccinum aurantiacum & 1.351530 \\
\hline Cortinarius alboviolaceus & 0.652723 & Russula clavipes & 0.405515 \\
\hline Cortinarius trivialis & 1.173932 & Russula galochroa & 0.493669 \\
\hline Hebeloma sp. 3 & 1.038246 & Russula fragilis & 1.873435 \\
\hline Inocybe flocculosa & 0.879006 & Thelephora caryophyllea & 0.478748 \\
\hline Lactarius torminosus & 0.562072 & & \\
\hline \multicolumn{4}{|c|}{ Cluster 4 (11 cases) } \\
\hline Amanita citrina & 1.641824 & Russula badia & 0.456178 \\
\hline Amanita porphyria & 0.649528 & Russula decolorans & 0.613345 \\
\hline Cortinarius caperatus & 0.587840 & Russula emetica & 0.978808 \\
\hline Cortinarius semisanguineus & 0.966275 & Russula paludosa & 0.459364 \\
\hline Cortinarius vibratilis & 1.006671 & Xerocomus badius & 0.649507 \\
\hline Paxillus involutus & 1.564870 & & \\
\hline \multicolumn{4}{|c|}{ Cluster 5 (54 cases) } \\
\hline Amanita gemmata & 0.523716 & Inocybe praetervisa & 0.493738 \\
\hline Amanita pantherina & 0.746301 & Lactarius necator & 0.444144 \\
\hline Amanita phalloides & 0.330851 & Lactarius quieticolor & 0.777556 \\
\hline Amanita rubescens & 1.243976 & Lactarius tabidus & 0.884765 \\
\hline Boletus pinophilus & 0.287742 & Lactarius vietus & 0.334876 \\
\hline Boletus reticulatus & 0.379404 & Leccinum scabrum & 0.550001 \\
\hline Chroogomphus rutilus & 0.408213 & Ramaria cf. abietina & 0.428299 \\
\hline Coltricia perennis & 0.389802 & Ramaria eumorpha & 1.282514 \\
\hline Cortinarius acetosus & 0.285980 & Rhizopogon luteolus & 0.340235 \\
\hline Cortinarius anthracinus & 1.252337 & Russula cf. mustelina & 0.428299 \\
\hline Cortinarius cinnabarinus & 0.474943 & Russula subfetens & 0.340537 \\
\hline Cortinarius colus & 0.974179 & Russula turci & 0.692938 \\
\hline Cortinarius тисоsиs & 1.214468 & Russula versicolor & 0.330851 \\
\hline
\end{tabular}




\begin{tabular}{|l|l|l|l|}
\hline \multicolumn{1}{|c|}{ Species } & Distance & \multicolumn{1}{|c|}{ Species } & Distance \\
\hline Cortinarius multiformis var. coniferarum & 0.750410 & Russula vesca & 0.436899 \\
Cortinarius purpurascens & 0.908160 & Russula vinosa & 0.842382 \\
Cortinarius sanguineus & 0.515556 & Russula vinosobrunnea & 0.321510 \\
Cortinarius spp. IV & 0.655574 & Russula xerampelina & 0.878182 \\
Gyroporus castaneus & 0.462315 & Sarcodon squamosus & 1.036126 \\
Hebeloma stenocystis & 0.330851 & Scleroderma fuscum & 0.413826 \\
Hebeloma sp. 1 & 0.769771 & Suillus bovinus & 0.398441 \\
Hebeloma sp. 2 & 0.637234 & Suillus variegatus & 0.412319 \\
Hygrophorus hypothejus var. aureus & 0.455719 & Tricholoma imbricatum & 0.812475 \\
Inocybe assimilata & 0.890619 & Tricholoma pessundatum & 0.381157 \\
Inocybe asterospora & 1.104966 & Tricholoma saponaceum var. squamosum & 1.176912 \\
Inocybe calida & 0.639305 & Tylopilus felleus & 0.447547 \\
Inocybe curvipes & 0.944775 & Xerocomus chrysenteron & 0.367833 \\
Inocybe cf. margaritispora & 0.763932 & Xerocomus subtomentosus & 0.598075 \\
\hline
\end{tabular}

Table A4.2

Members of clusters and distances from respective cluster centres - non-ECM species

\begin{tabular}{|c|c|c|c|}
\hline Species & Distance & Species & Distance \\
\hline \multicolumn{4}{|c|}{ Cluster 1 (6 cases) } \\
\hline Clitocybe diatreta & 1.890329 & Entoloma spp. & 1.462573 \\
\hline Collybia cirrhata & 1.745173 & Galerina spp. & 1.331584 \\
\hline Cystoderma amianthinum & 0.932323 & Gymnopus androsaceus & 1.764856 \\
\hline \multicolumn{4}{|c|}{ Cluster 2 (11 cases) } \\
\hline Ampulloclitocybe clavipes & 1.619621 & Mycena flavoalba & 1.533014 \\
\hline Cantharellula umbonata & 2.187800 & Mycena leptocephala & 1.407885 \\
\hline Clavaria argillacea & 1.912443 & Mycena olivaceomarginata & 1.737105 \\
\hline Galerina atkinsoniana & 1.158011 & Psilocybe montana & 1.832456 \\
\hline Hygroaster asterosporus & 1.185667 & Rickenella fibula & 0.950151 \\
\hline Lycoperdon perlatum & 1.239052 & & \\
\hline \multicolumn{4}{|c|}{ Cluster 3 (47 cases) } \\
\hline Amylostereum laevigatum & 0.557839 & Hyphoderma setigerum & 0.655903 \\
\hline Byssomerulius corium & 0.514562 & Hypholoma fasciculare & 1.811642 \\
\hline Clitocybe anisata & 0.886725 & Inonotus rheades & 0.415238 \\
\hline Clitocybe candicans & 0.985087 & Lycoperdon molle & 1.161743 \\
\hline Clitocybe fragrans & 1.245170 & Macrolepiota procera & 0.915513 \\
\hline Clitocybe metachroa & 0.397062 & Marasmiellus vaillantii & 0.858866 \\
\hline Clitocybe phyllophila & 0.928363 & Marasmius epiphyllus & 0.823209 \\
\hline Coprinellus disseminatus & 1.176315 & Mycena filopes & 0.358211 \\
\hline Coprinellus micaceus & 1.101572 & Mycena pura & 1.177489 \\
\hline Crepidotus lundellii & 0.872516 & Mycena sanguinolenta & 0.472491 \\
\hline Crucibulum laeve & 0.312945 & Mycena stipata & 0.353784 \\
\hline Cystoderma carcharias & 0.829006 & Mycena stylobates & 0.721379 \\
\hline Dacrymyces variisporus & 1.770178 & Mycena vitilis & 1.117191 \\
\hline Daedaleopsis confragosa & 0.484802 & Peniophora polygonia & 0.792184 \\
\hline Exidia plana & 0.546914 & Phaeomarasmius erinaceus & 0.338036 \\
\hline Flammulaster granulosus & 1.237628 & Phlebia rufa & 0.317687 \\
\hline Flammulaster rhombosporus & 0.508864 & Psathyrella candolleana & 0.408357 \\
\hline Galerina hypnorum & 1.629354 & Resupinatus trichotis & 0.657706 \\
\hline Galerina marginata & 0.572542 & Schizophyllum amplum & 0.390806 \\
\hline Gleocystidiellum porosum & 0.824749 & Sphaerobolus stellatus & 0.607043 \\
\hline Gymnopus aquosus & 0.668549 & Stereum hirsutum & 0.545113 \\
\hline
\end{tabular}




\begin{tabular}{|c|c|c|c|}
\hline Species & Distance & Species & Distance \\
\hline Gymnopus confluens & 1.125006 & Tremella mesenterica & 0.608938 \\
\hline Hygrocybe conica & 0.774268 & Tubaria furfuracea & 0.831217 \\
\hline Hymenochaete tabacina & 0.340679 & & \\
\hline \multicolumn{4}{|c|}{ Cluster 4 (14 cases) } \\
\hline Auriscalpium vulgare & 1.177597 & Leptosporomyces galzinii & 1.125963 \\
\hline Baeospora myosura & 1.149912 & Mycena galopus & 1.036916 \\
\hline Collybia tuberosa & 1.581279 & Mycena metata & 0.773333 \\
\hline Dacrymyces stillatus & 3.121296 & Mycena vulgaris & 1.472430 \\
\hline Exobasidium vaccini & 1.376177 & Mycena zephirus & 0.940386 \\
\hline Galerina pumila & 1.529068 & Phlebiella sulphurea & 0.970005 \\
\hline Hypholoma capnoides & 1.579716 & Xeromphalina cornui & 1.053344 \\
\hline \multicolumn{4}{|c|}{ Cluster 5 (124 cases) } \\
\hline Agaricus dulcidulus & 0.265466 & Lepiota pseudolilacea & 0.347784 \\
\hline Armillaria ostoyae & 0.702082 & Lepista nuda & 0.411007 \\
\hline Athelia decipiens & 0.531347 & Lycoperdon dermoxanthum & 1.307389 \\
\hline Athelia epiphylla & 0.336987 & Lycoperdon ericaeum & 0.899553 \\
\hline Botryobasidium vagum & 1.206346 & Lycoperdon excipuliforme & 0.474054 \\
\hline Calocera cornea & 0.590135 & Lycoperdon marginatum & 0.675753 \\
\hline Calocera furcata & 0.473336 & Lycoperdon nigrescens & 1.001204 \\
\hline Calocera viscosa & 0.254998 & Lycoperdon norvegicum & 0.423829 \\
\hline Ceraceomyces crispatus & 0.618744 & Macrolepiota mastoidea & 0.368881 \\
\hline Ceraceomyces sublaevis & 0.573990 & Macrolepiota permixta & 0.387989 \\
\hline Chlorophyllum rhacodes & 0.246993 & Marasmius oreades & 1.597007 \\
\hline Clitocybe brumalis & 0.309632 & Marasmius setosus & 0.538533 \\
\hline Clitocybe nebularis & 0.279329 & Melanoleuca graminicola & 0.688612 \\
\hline Clitocybe odora & 0.785122 & Mycena adonis & 0.895200 \\
\hline Clitocybe odora var. alba & 0.469758 & Mycena aetites & 0.633033 \\
\hline Clitocybe vermicularis & 0.442004 & Mycena arcangeliana & 0.296801 \\
\hline Clitocybe vibecina & 1.139557 & Mycena flavescens & 0.424183 \\
\hline Collybia cookei & 1.160069 & Mycena inclinata & 0.358777 \\
\hline Coniophora arida & 1.057121 & Mycena parabolica & 0.458667 \\
\hline Conocybe ochrostriata & 0.336987 & Mycena purpureofusca & 0.985813 \\
\hline Conocybe rickeniana & 0.302984 & Mycena rubromarginata & 0.387850 \\
\hline Conocybe spiculoides & 0.309632 & Mycena septentrionalis & 0.288917 \\
\hline Conocybe subpubescens & 0.499668 & Mycena speirea & 1.121998 \\
\hline Coprinellus xanthothrix & 0.507932 & Mycena supina & 0.294516 \\
\hline Coprinus friesii & 0.887246 & Mycetinis scorodonius & 1.560248 \\
\hline Crepidotus applanatus & 0.646016 & Oligoporus alni & 0.636647 \\
\hline Crepidotus cesatii & 0.257884 & Panellus mitis & 1.179276 \\
\hline Crepidotus variabilis & 0.999158 & Paneolus papilonaceus & 0.885524 \\
\hline Crinipellis scabella & 1.838806 & Panus suavissimus & 0.476879 \\
\hline Cystoderma jasonis & 0.858008 & Parasola plicatilis & 0.625791 \\
\hline Cystoderma jasonis var. lilacipes & 1.099015 & Peniophora cinerea & 0.336987 \\
\hline Cystodermella granulosa & 1.050270 & Phanerochaete sanguinea & 0.726263 \\
\hline Dacrymyces macnabbii & 1.187326 & Phellinus punctatus & 0.308319 \\
\hline Dacrymyces ovisporus & 1.447944 & Phlebiella pseudotsugae & 0.773731 \\
\hline Entoloma conferendum & 0.673462 & Pholiota gumosa & 0.558960 \\
\hline Entoloma jubatum & 1.223281 & Pholiota spumosa & 0.879249 \\
\hline Entoloma nitens & 0.296801 & Pleurotus ostreatus & 0.773829 \\
\hline Entoloma rhodopolium & 0.356133 & Polyporus ciliatus & 0.320874 \\
\hline Entoloma undatum & 0.315975 & Psathyrella fibrillosa & 0.303412 \\
\hline Fomes fomentarius & 0.499668 & Psathyrella gyroflexa & 0.835502 \\
\hline Galerina badipes & 0.296357 & Psathyrella tephrophylla & 0.527476 \\
\hline Galerina calyptrata & 0.530320 & Pseudohydnum gelatinosum & 0.470388 \\
\hline
\end{tabular}




\begin{tabular}{|l|l|l|l|}
\hline \multicolumn{1}{|c|}{ Species } & Distance & \multicolumn{1}{|c|}{ Species } & Distance \\
\hline Galerina mniophila & 0.913767 & Pseudomerulius aureus & 1.301152 \\
Geastrum quadrifidum & 0.219100 & Resinicium bicolor & 0.246993 \\
Gleoporus taxicola & 0.933332 & Rhodocollybia maculata & 0.424183 \\
Gymnopilus bellulus & 0.600051 & Rhodocybe caelata & 0.787312 \\
Gymnopilus penetrans & 0.885718 & Rhodocybe fallax & 0.825488 \\
Gymnopus acervatus & 0.787797 & Rhodocybe hirneola & 0.654539 \\
Gymnopus dryophilus & 0.964499 & Rhodocybe parilis & 1.400197 \\
Gymnopus impudicus & 0.814622 & Ripartites tricholoma & 0.624283 \\
Gymnopus ocior & 1.021795 & Schizopora paradoxa & 0.920818 \\
Gymnopus peronatus & 0.628279 & Steccherinum fimbriatum & 0.877747 \\
Gymnopus putillus & 0.545022 & Strobilurus stephanocystis & 1.574688 \\
Hygrocybe laeta & 0.257884 & Strobilurus tenacellus & 0.494816 \\
Hygrocybe virginea var. virginea & 1.266556 & Tapinella atrotomentosa & 0.334966 \\
Hygrophoropsis aurantiaca & 1.179235 & Tapinella panuoides & 0.470388 \\
Hyphoderma praetermissum & 0.769009 & Trametes ochracea & 0.773829 \\
Hyphodontia aspera & 0.849322 & Trichaptum fuscoviolaceum & 0.902484 \\
Hyphodontia quercina & 0.320255 & Tubaria confragosa & 0.574484 \\
Hyphodontia subalutacea & 0.544677 & Tubulicrinis subulatus & 0.351309 \\
Hypholoma lateritium & 0.751848 & Tulasnella pallida & 0.257884 \\
Lepiota magnispora & 0.246993 & Vesiculomyces citrinus & 0.685440 \\
\hline
\end{tabular}




\section{Appendix 5}

\section{List of Basidiomycota in the old-field successional series near the Białowieża old-growth forest (Jelonka reserve and Czechy Orlańskie reserve) with notes on distribution and substrates}

J - Jelonka reserve; CzO - Czechy Orlańskie reserve; I-XII - months; 1, 11, 67, 85 - plot numbers; E, V, R, I - The Red Data Book categories according to WoJEWODA \& ŁAWRYNOWICZ (2006).

\section{BASIDIOMYCOTA \\ EXOBASIDIOMYCETES \\ Exobasidiales}

Exobasidium vaccinii (Fuckel) Woronin - on leaves of Vaccinium vitis-idaea; CzO: 2, 5, 6, 7, 8, phase 9/10; X 1994, VI-X 1995, VI-XI 1996, VII 1997.

\section{DACRYMYCETES \\ Dacrymycetales}

Calocera cornea (Batsch) Fr. - on log of birch; J: 16, phase 8, X 1994.

Calocera furcata (Fr.) Fr. - on log of pine; J: 7, phase 6, X 1994; R.

Calocera viscosa (Pers.) Fr. - at a rotting stump; J: 11, 16, phase 8, IX 1995, VIII 1996.

Dacrymyces macnabbii D.A. Reid - on fallen branch of pine; CzO: 7, phase 9/10, VI 1995; rev. W. Wojewoda.

Dacrymyces ovisporus Bref. - on fallen branches of pine; CzO: 6, 8, phase 9/10, IX 1994, IX 1995; E; rev. W. Wojewoda.

Dacrymyces stillatus Nees - on fallen branches and logs of pine; J: 84, 1, 11, 16, phases 4, 6/7, 8, IX-X 1994, VI, X-XI 1995, VI, IX, XI 1996; CzO: 2, 5, 6, 7, 8, phase 9/10, VIII-X 1994, VI, VIII-X 1995, V-VI, X 1996.

Dacrymyces variisporus McNabb - on dead and living branches of pine; J: 7, 13, 1, 6, 11, 16, phases 6-8, IX-X 1994, VI, IX, XI 1995, VI, IX, XI 1996; CzO: 5, phase 9/10, IX 1996; E.

\section{TREMELLOMYCETES \\ Tremellales}

Exidia plana Donk - on branches of aspen; J: 11, 16, phase 8; IX-X 1994, VI 1995, VI, XI 1996.

Pseudohydnum gelatinosum (Scop.) P. Karst. - on rotten stump; CzO: 2, 5, phase 9/10; IX 1994, IX 1997.

Tremella mesenterica Retz. - on twigs of aspen; J: 7, 11, 16, phases 6, 8; X 1994, VI 1995, VI-VIII 1996.

\section{AGARICOMYCETES}

Agaricales

Agaricus dulcidulus Schulzer [= Agaricus semotus Fr.] - on soil; J: 1,11, phases 6/7, 8; IX 1994, X 1995.

Amanita citrina Pers. - on soil; J: 84, 11, 16, phases 4, 8; CzO: 2 , 5, 6, 7, 8, phase 9/10; IX-X 1994, VIII-X 1995, VIII-X 1996.

Amanita gemmata (Fr.) Bertill. - on soil; J: 11, phase 8; IX 1994, VI 1995.

Amanita muscaria (L.) Lam. - on soil; J: 67, 84, 61, 85, 7, 13, 1, 6, 11, 16, phases 4-8; IX 1994, IX-XI 1995,VII-XI 1996, VII 1998.

Amanita pantherina (DC.) Krombh. - on soil; J: 84, 85, 7, 13, 6, 11, phases 4-8; IX 1994, VI-VIII 1995, X 1995, VII 1996.

Amanita phalloides (Vaill. ex Fr.) Link - on soil; J: 16, phase 8; VIII 1995, IX 1998.

Amanita porphyria Alb. \& Schwein. - on soil, under pine; CzO: 2, 5, 6, 7, 8, phase 9/10; X 1995, VIII 1996, VII 1997, VII 1998.

Amanita rubescens (Pers.) Gray - on soil; J: 84, 85, 7, 1, 6, 11, phases 4-8; VI 1994, VIII, X 1995, VII-IX 1996; CzO: 5, 7, 8, phase 9/10; IX 1994, X 1995, VIII 1996, VII 1997. 
Ampulloclitocybe clavipes (Pers.) Redhead, Lutzoni, Moncalvo \& Vilgalys [= Clitocybe clavipes (Pers.) P. Kumm.] - on soil and on litter; J: 67, 84, 61, 7, 13, 1, 6, 11, 16, phases 4-8, IX-X 1994, IX-XI 1995, VIII-XI 1996; CzO: 2, 6, 8, phase 9/10, IX 1994, IX-X 1995, IX 1998.

Armillaria ostoyae (Romagn.) Herink - on stump; CzO: 5, phase 9/10; X 1995.

Baeospora myosura (Fr.) Singer - on buried cones of pine; J: 7, 1, 6, 11, phases 6-8; IX-X 1994, IX-XI 1995, XI 1996, XI 1997, CzO: 6, 7, 8, phase 9/10, IX-X 1994, IX-XI 1995, X-XI 1996.

Cantharellula umbonata (J.F. Gmel.) Singer - on mosses - Polytrichum juniperinum and P. commune; J: 67, 85, 7, phases 4-6; IX-X 1994, IX-XI 1995, VII-XI 1996, VII 1998.

Ceraceomyces crispatus (O.F. Müll.) Rauschert [= Ceraceomyces serpens (Tode) Ginns] - on fallen twigs of aspen; J: 16, phase 8, VI, X 1994, XI 1996; E; det. E. Parmasto.

Ceraceomyces sublaevis (Bres.) Jülich - on fallen branches of aspen, pine; J: 11, phase 8, X 1994, X 1995; CzO: 2, phase 9/10, X 1995; det. W. Wojewoda.

Chlorophyllum rachodes (Vittad.) Vellinga [= Macrolepiota rhacodes ('rachodes') (Vittad.) Singer - on soil; J: 16, phase 8, X 1995.

Clavaria argillacea Pers. - on soil, under Calluna vulgaris; J: 67, 84, 61, 85, 7, 13, 1, 6, phases 4-6/7, X 1994, X-XI 1995, X-XI 1996; R.

Clitocybe anisata Velen. - on soil and on litter; J: 1, 11, 16, phases 6/7, 8; IX-X 1994, IX 1995; CzO: 2, 5, phase 9/10, X 1995; det. H. Komorowska.

Clitocybe brumalis (Fr.) Gillet - among grass and herbs; J: 82, phase 2, X 1995; det. H. Komorowska.

Clitocybe candicans (Pers.) P. Kumm. - on soil and on litter, J: 7, 13, 6, 11, 16, phases 6-8, IX-X 1994, IX-X 1995, X 1996; CzO: 5, phase 9/10, IX 1994; det. H. Komorowska.

Clitocybe diatreta (Fr.) P. Kumm. - on soil and on litter, most frequently under Juniperus; J: 67, 84, 61, 85, 7, 13, 1, 6, 11, 16, phases 4-8, VI, IX-X 1994, VIII-XI 1995, VII-XI 1996, VII, IX-X 1997, VII 1998; CzO: 5, 7, phase 9/10, X 1995; det. H. Komorowska.

Clitocybe fragrans (With.) P. Kumm. - on soil and on litter; J: 61, 7, 1, 6, 11, 16, phases 5-8, X 1994, IX-X 1995, X-XI 1996, X 1997; det. H. Komorowska.

Clitocybe metachroa (Fr.) P. Kumm. - on litter; J: 11, 16, phase 8, X 1994, X 1995, X 1996; det. H. Komorowska. Clitocybe nebularis (Batsch) P. Kumm. - on soil; J: 16, phase 8, X 1995.

Clitocybe odora (Bull.) P. Kumm. var. odora - on soil and on litter; J: 85, 11, phases 5, 8, IX 1994, X-XI 1995; det. H. Komorowska.

Clitocybe odora var. alba J.E. Lange - on soil and on litter; J: 11, phase 8, X 1995, VII 1996; det. H. Komorowska. Clitocybe phyllophila (Pers.) P. Kumm. - on litter; J: 1, 11, 16, phases 6/7-8, IX 1994, IX-X 1995, X 1996; det. H. Komorowska.

Clitocybe vermicularis (Fr.) Quél. - on litter; J: 11, phase 8, VI 1994; det. H. Komorowska.

Clitocybe vibecina (Fr.) Quél. [= Clitocybe langei Singer ex Hora] - on soil and on litter; J: 84, 85, 7, 13, 1, 6, 16, phases 4-8, X 1994, IX-XI 1995, X-XI 1996, X-XI 1997; CzO: 2, 5, 6, 7, phase 9/10, IX 1994, X-XI 1995, X-XI 1996, X 1997; det. H. Komorowska.

Clitopilus prunulus (Scop.) P. Kumm. - on soil; J: 67, 84, 85, 7, 13, 1, 6, 11, 16, phases 4-8, IX 1994, IX-X 1995, VII-VIII, X 1996.

Collybia cirrhata (Pers.) Quél. - on decaying sporocarps of fungi; J: 67, 84, 61, 85, 7, 13, 1, 6, 11, 16, phases 4-8, IX-X 1994, IX-XI 1995, IX-XI 1996; CzO: 2, 5, 6, 7, 8, phase 9/10, IX 1994, IX 1995, IX-XI 1996.

Collybia cookei (Bres.) J.D. Arnold - on decaying sporocarps of fungi; J: 61, 85, 11, phases 5, 8, IX-X 1994, IX 1995, VIII 1996; CzO: 5, phase 9/10, IX 1994.

Collybia tuberosa (Bull.) P. Kumm. - on decaying sporocarps of fungi; J: 85, 7, 13, 1, phases 5-6/7, IX-X 1994, IX-X 1995, IX-X 1996; CzO: 2, 5, 6, phase 9/10, IX-X 1994, IX-X 1995, X-XI 1996.

Conocybe ochrostriata Hauskn. [= Conocybe siennophylla (Berk. \& Broome) Singer s. auct.] - on humus; J: 11, phase 8, X 1995.

Conocybe pulchella (Velen.) Hauskn. \& Svrček [ = Conocybe pseudopilosella Kühner \& Watling] - on litter; CzO, phase 9/10, XI 1997.

Conocybe rickeniana P.D. Orton - on soil, among mosses; J: 84, phase 4, VI 1994.

Conocybe spiculoides Kühner \& Watling. - among grass and herbs; J: 82, phase 2, X 1995.

Conocybe subpubescens P.D. Orton [= Conocybe cryptocystis (G.F. Akt.) Singer s. auct.] - on humus; J: 16, phase 8, IX 1995, IX, XI 1996.

Coprinellus disseminatus (Pers.) J.E. Lange [ = Coprinus disseminatus (Pers.) Gray] - on rotting wood; J: 16, phase 8, IX 1994, IX-X 1995, VII 1997. 
Coprinellus micaceus (Bull.) Vilgalys, Hopple \& Jacq. Johnson [= Coprinus micaceus (Bul.) Fr.] - on rotting wood, on humus; J: 16, phase 8, X 1994, X 1995, VIII 1996.

Coprinellus xanthothrix (Romagn.) Vilgalys, Hopple \& Jacq. Johnson [= Coprinus xanthothrix Romagn.] - on rotting wood, on humus; J: 11, 16, phase 8, IX 1994, IX 1995, IX 1996, VII, IX 1997.

Coprinopsis friesii (Quél.) P. Karst. [= Coprinus friesii Quél.] - on dead grass; J: 82, phase 2, VII-VIII 1996.

Cortinarius acetosus (Velen.) Melot [= Cortinarius rigens (Pers.) Fr.] - on soil, under pine; J: 13, phase 6, X 1995; E.

Cortinarius alboviolaceus (Pers.) Fr. - on soil, under birch, aspen; J: 11, 16, phase 8, IX 1994, IX-X 1995, VIII, X 1996.

Cortinarius anthracinus Fr. - on soil, under pine, among mosses and lichens; J: 61, 13, 1, 6, phases 5-6/7, IX-X 1994, X 1995, VIII, X 1996, IX-X 1998; V.

Cortinarius caperatus (Pers.) Fr. [= Rozites caperatus (Pers.) P. Karst.] - on soil, under pine; CzO: 2, 5, 6, 7, 8, phase 9/10, IX 1994, X 1995, VII 1998.

Cortinarius cinnabarinus Fr. - on soil, under pine; J: 61, 13, phases 5, 6, X 1995, XI 1996.

Cortinarius cinnamomeoluteus P.D. Orton - on soil, under pine; J: 67, 84, 61, 85, 7, 13, 1, 6, 11, phases 4-8, VI, IX-X 1994, IX-X 1995, VII-XI 1996, VII, XI 1997, IX 1998.

Cortinarius colus Fr. [= Cortinarius miniatopus J.E. Lange] - on soil, under pine; J: 7, phase 6, X 1995.

Cortinarius fulvescens Fr. - on soil, under pine, among mosses; J: 85, phase 5, X 1998; E.

Cortinarius mucosus (Bull.) J.J. Kickx - on soil, under pine; J: 7, 13, 1, 6, phases 6-6/7, IX-X 1994, IX-X 1995, VIII, X 1996.

Cortinarius multiformis f. coniferarum (M.M. Moser) Nespiak - on soil, under pine; J: 13, 1, 6, phases 6-6/7, X 1994, X 1995, IX-X 1996; R.

Note. The specimens match the description of the form proposed by NesPIAK (1975).

Cortinarius obtusus (Fr.) Fr. s.1. - on soil, under pine, among mosses and lichens; J: 84, 1, phases 4, 6/7, IX 1998.

Cortinarius orellanus Fr. - on soil, under pine; CzO: phase 9/10, VII 1997; R.

Cortinarius parevernius Rob. Henry - on soil, under pine; J: 7, 13, 1, 6, 11, phases 6-8, X 1994, X 1995, X-XI 1996, X 1998.

Cortinarius phoeniceus (Vent.) Maire [= Cortinarius purpureus (Pers.) Fuckel s. auct.] - on soil, under pine, among mosses; J: 1, phase 6/7, VII 1997.

Cortinarius purpurascens (Fr.) Fr. - on soil, under pine; J: 67, 7, 13, 1, 6, phases 4, 6, 6/7, X 1994, X 1995, X-XI 1996.

Cortinarius sanguineus (Wulfen) Gray - on soil, under pine, among mosses and lichens; J: 1, phase 6/7, X 1995.

Cortinarius semisanguineus (Fr.) Fr. - on soil, under pine; J: 1, phase 7, VII 1997; CzO: 2, 6, 6/7, 8, phase 9/10, IX-X 1994, X 1995, X-XI 1996, VII, X 1997, VII 1998.

Cortinarius trivialis J.E. Lange s.1. - on soil, under aspen and pine; J: 11, 16, phase 8, IX-X 1994, IX-X 1995, VIIVIII, X 1996, XI 1997, VII 1998.

Cortinarius vibratilis (Fr.) Fr. - on soil, under pine; CzO: 5, 6, 7, 8, phase 9/10, IX 1994, X 1995, X 1996.

Crepidotus applanatus (Pers.) P. Kumm. - on fallen twigs; CzO: 2, phase 9/10, IX 1995; R.

Crepidotus cesatii (Rabenh.) Sacc. [= Crepidotus sphaerosporus (Pat.) J.E. Lange] - on fallen twigs; J: 11, phase 8, VI 1996.

Crepidotus lundellii Pilát [= Crepidotus amygdalosporus Kühner] - on fallen twigs; J: 11, 16, phase 8, IX-X 1994, VI, VIII 1995, VI 1996.

Crepidotus variabilis (Pers.) P. Kumm. - on dead stems of Calluna vulgaris; J: 84, 61, phases 4-5, IX-X 1995.

Crinipellis scabella (Alb. \& Schwein.) Murrill [= Crinipellis stipitaria (Fr.) Pat.] - among grass and herbs; J: 82, 85, 7, phases 2, 5, 6, IX-X 1994, IX-XI 1995, VII-IX 1996.

Crucibulum laeve (Huds.) Kambly - on fallen twigs, on pieces of bark; J: 11, 16, phase 8, IX 1994, IX 1995, VIIVIII 1996.

Cystoderma amianthinum (Scop.) Fayod - on soil, among mosses; J: 82, 67, 84, 61, 85, 7, 13, 1, 6, 11, 16, phases 2-8, IX-X 1994, VIII-XI 1995, VIII-XI 1996, X-XI 1997; CzO: 2, 5, 6, 7, 8, phase 9/10, IX-X 1994, X-XI 1995, X-XI 1996, X-XI 1997.

Cystoderma carcharias (Pers.) Fayod - on litter; J: 1, 6, 11, phases 6/7-8, X 1994, X 1995, X-XI 1996.

Cystoderma jasonis (Cooke \& Massee) Harmaja var. jasonis [= C. longisporum (Kühner) Arnolds] - on soil, among mosses; J: 85 ,7, 1, phases 5-6/7, X 1994, X 1995, IX-X 1996, XI 1997.

Cystoderma jasonis (Cooke \& Massee) Harmaja var. lilacipes (Harmaja) I. Saar [= Cystoderma lilacipes Harmaja; C. longisporum (Kühner) Arnolds var. purpurascens Arnolds] - on soil, among mosses; J: 84, 85, 7, 13, 1, phases 4-6/7, X 1994, X 1995, X-XI 1996, XI 1997; CzO, phase 9/10, XI 1997, X 1998. 
Cystodermella granulosa (Batsch) Harmaja [ = Cystoderma granulosum (Batsch) Fayod] - on soil, among mosses; J: 85, 7, 13, 1, 11, phases 5-8, IX-X 1994, X 1995, IX-X 1996, XI 1997; CzO: 5, 8 phase 9/10, IX 1994, X 1995; I.

Entoloma conferendum (Britzelm.) Noordel. var. conferendum - on soil; J: 85, phase 5, X 1996.

Entoloma jubatum (Fr.) P. Karst. - on soil; J: 84, 61, 85, 7, 13, phases 4-6, VI 1994, X 1995, XI 1996 , IX 1998.

Entoloma nitens (Velen.) Noordel. - on soil; J: 13, phase 6, X 1995.

Entoloma rhodopolium (Fr.) P. Kumm. var. rhodopolium - on soil, among mosses; J: 84, phase 4, X 1995.

Entoloma undatum (Fr.) M.M. Moser - on soil; J: 82, 1, phases 2, 6/7, X 1995.

Flammulaster granulosus (J.E. Lange) Watling - on fallen twigs, on pieces of bark; J: 84, 85, 7, 6, 11, phases 4-8, IX 1994, IX-X 1995, VII, IX 1996, VII 1997.

Flammulaster rhombosporus (G.F. Atk.) Watling - on fallen twigs, on pieces of bark; J: 11, 16, phase 8 IX-X 1994 , IX-X 1995, XI 1996; R.

Galerina atkinsoniana A.H. Sm. - among mosses; J: 67, 84, 61, 85, 7, 13, 1, 6, phases 4-6/7, IX-X 1994, IX-XI 1995, VII-VIII, X-XI 1996, VII 1997, VII, IX 1998.

Galerina badipes (Pers.) Kühner - among mosses; J: 7, phase 6, X 1994; E.

Galerina calyptrata P.D. Orton - among mosses; J: 13, phase 6, VII 1997; CzO: 2, 6, phase 9/10, IX 1994 , X 1995.

Galerina hypnorum (Schrank) Kühner - among mosses; J: 67, 84, 85, 7, 1, 6, 11, 16, phases 4-8, IX-X 1994, IX-XI 1995, VII, X-XI 1996, VII, X-XI 1997; CzO, phase 9/10, XI 1997.

Galerina marginata (Batsch) Kühner s.l. [= Galerina unicolor (Vahl) Singer] - on fallen twigs; J: 11, 16, phase 8, IX-X 1994, X 1995, XI 1997.

Galerina mniophila (Lasch) Kühner - among mosses; J: 1, phase 6/7, VI 1994; CzO: 5, 6, 8, phase 9/10, X 1995, X 1996, XI 1997.

Galerina pumila (Pers.) M. Lange- among mosses; J: 67, 84, 61, 85, 7, 13, 1, 11, 16, phases 4-8, IX-X 1994, IX-XI 1995, IX-X 1996, X-XI 1997; CzO: 2, 5, 6, 7, 8, phase 9/10, X 1994, IX-XI 1995, X-XI 1996, X-XI 1997.

Gymnopilus bellulus (Peck) Murrill - on fallen branch; CzO: 2, phase 9/10, IX-X 1995.

Gymnopilus penetrans (Fr.) Murrill - on fallen branches, on rotting stump; CzO: 2, 8, phase 9/10, X 1994, X 1996.

Gymnopus acervatus (Fr.) Murrill [= Collybia acervata (Fr.) P. Kumm.] - on decayed wood ; J: 16, phase 8, VI 1995, VI 1996.

Gymnopus androsaceus (L.) Antonín \& Noordel. [= Marasmius androsaceus (L.) Fr.; Setulipes androsaceus (L.) Antonín] - on fallen litter of pine, rarely on fallen leaves of aspen; J: 67, 84, 61, 85, 7, 13, 1, 6, 11, 16, phases 4-8, IX-X 1994, VI, IX-XI 1995, VI-VII, IX-XI 1996; CzO: 2, 5, 6, 7, 8, phase 9/10, VIII-X 1994, VI, IX-XI 1995, VI-XI 1996, VII 1997.

Gymnopus aquosus (Bull.) Antonín \& Noordel. [= Collybia aquosa (Bull.) P. Kumm.] - on soil and on litter; J: 67, 84, 61, 7, 11, 16, phases 4-6, 8, VI 1994, VI 1995, VI-VII 1996, VII 1997.

Gymnopus confluens (Pers.) Antonín, Halling \& Noordel. [= Collybia confluens (Pers.) P. Kumm.] - on litter; J: 13, 11, 16, phases 6, 8, IX-X 1994, VIII-XI 1995, VII-IX 1996.

Gymnopus dryophilus (Bull.) Murrill [= Collybia dryophila (Bull.) P. Kumm.] - on soil and on litter; J: 7, 13, 11, 16, phases 6, 8 IX 1994, X 1995, X 1996, IX 1997.

Gymnopus impudicus (Fr.) Antonín, Halling \& Noordel. [= Micromphale impudicum (Fr.) P.D. Orton] - on soil; J: 85, 1, 16, phases 5, 6/7, 8, IX-X 1994, IX 1995, IX 1996, VII 1998.

Gymnopus ocior (Pers.) Antonín \& Noordel. [= Collybia ocior (Pers.) Vilgalys \& O.K. Mill.] - on rotting wood, on litter; J: 16, phase 8, VII 1996; CzO: 7, phase 9/10, VI 1995; E.

Gymnopus peronatus (Bolton) Antonín, Halling \& Noordel. [= Collybia peronata (Bolton) P. Kumm.] - on litter; J: 16, phase 8, IX 1995, VII, X 1997; CzO: 8, phase 9/10, IX 1996.

Gymnopus putillus (Fr.) Antonín, Halling \& Noordel. [= Collybia putilla (Fr.) Singer] - on soil and on litter; J: 84, 61, 7, 13, 1, 6, 11, phases 4-8, X 1994, IX 1995; E.

Hebeloma stenocystis J. Favre ex Quadr. - on soil; J: 16, phase 8, X 1995; det. H.J. Beker.

Hebeloma sp. 1 - on soil, under willow, aspen, pine; J: 67, 84, 13, 16, phases 4, 6, 8, X 1994, X-XI 1995 , X 1996.

Hebeloma sp. 2 - on soil; J: 67, 16, phases 4, 8, X 1995, X 1996.

Hebeloma sp. 3 - on soil; J: 11, phase 8, IX-X 1994, X 1995, X 1996.

Hygroaster asterosporus (J.E. Lange) Singer [= Omphaliaster asterosporus (J.E. Lange) Lamoure]-on soil, among mosses and lichens; J: 67, 84, 61, 85, 7, 13, 1, 6, phases 4-6/7, X 1994, X-XI 1995, X-XI 1996, X 1997; E.

Hygrocybe acutoconica (Clem.) Singer [= Hygrocybe persistens (Britzelm.) Singer] - on soil; J: 82, phase 2, VII 1997; R.

Hygrocybe conica (Schaeff.) P. Kumm. var. conica - on soil; J: 85, 7, 1, 6, 11, 16, phases 5-8, X 1995.

Hygrocybe laeta (Pers.) P. Kumm. - on humus; J: 11, phase 8, XI 1996; V. 
Hygrocybe virginea var. virginea (Wulfen) P.D. Orton \& Watling [= Camarophyllus virgineus (Wulfen) P. Kumm.] - on soil; J: 82, 84, 61, 85, 13, 1, 11, 16, phases 2-8, X 1994, X 1995, X-XI 1996, XI 1997.

Hygrophorus aureus Arrh. [= Hygrophorus hypothejus (Fr.) Fr. var. aureus (Arrh.) Imler] - on soil, among mosses; J: 67, phase 4, XI 1995; E.

Note. According to WoJEWODA \& EAWRYNOWICZ (1992) the species is threatened and has been assigned to category E. As WoJewoda (2003) does not treat it as a separate species any more but as a variety of Hygrophorus hypothejus, it has not been listed in the lattest red list (WOJEWODA \& LAWRYNOWICZ 2006).

Hygrophorus hypothejus (Fr.) Fr. - on soil, most frequently among mosses; J: 67, 84, 61, 85, 7, 13, 1, 6, 11, phases 4-8, X 1994, IX-XI 1995, X-XI 1996, XI 1997; I.

Hypholoma capnoides (Fr.) P. Kumm. - on stump; CzO: 2, 5, 7, phase 9/10, X 1994, V, X-XI 1995, X-XI 1996, X 1997.

Hypholoma fasciculare (Huds.) P. Kumm. - on decayed wood stake, on stump; J: 84, 7, 6, 11, 16, phases 4, 6-8, IX 1994, VIII, X 1995, X-XI 1996; CzO: 6, 8, phase 9/10, IX-X 1994, VIII-X 1995, VIII, X-XI 1996, IX 1997.

Hypholoma lateritium (Schaeff.) P. Kumm. - on rotting wood; J: 1, 6, 16, phases 6/7-8, X 1994, X 1995, X-XI 1996.

Inocybe assimilata Britzelm. [= Inocybe umbrina Bres.] - on soil; J: 84, 7, 13, 1, 6, phases 4, 6-6/7, X 1994, X-XI 1995, VII-VIII 1996.

Inocybe asterospora Quél. - on soil; J: 67, 84, 7, 1, phases 4, 6-6/7, X 1995, VII 1997.

Inocybe calida Velen. [= Inocybe brunneorufa Stangl \& Veselský] - on soil; J: 67, 84, 85, 7, 6, phases 4-6/7, X 1994, X 1995, VII 1997.

Inocybe curvipes P. Karst. [= Inocybe lanuginella (J. Schröt.) Konrad \& Maubl.] - on soil; J: 67, 85, 7, 13, 1, 6, phases 4-6/7, X 1995, VII, XI 1996, VII 1997.

Inocybe flocculosa (Berk.) Sacc. [= Inocybe gausapata Kühner] - on soil, under birch, aspen; J: 16, phase 8, IX-X 1995, VII 1997.

Inocybe lacera (Fr.) P. Kumm. var. lacera - on soil, under pine; J: 67, 84, 61, 85, 7, 13, 1, 6, 16, phases 4-8, VI, IX-X 1994, VI, IX-XI 1995, V, VII-XI 1996, XI 1997, IX 1998.

Inocybe cf. margaritispora (Berk.) Sacc. [= Inocybe cf. phaeosticta Furrer-Ziogas] - on soil; J: 16, phase 8, IX 1994, X 1995.

Inocybe praetervisa Quél. - on soil; J: 84, 61, 85, 13, 6, phases 4-6/7, X 1995, VII, X 1996, VII 1997, IX 1998.

Laccaria bicolor (Maire) P.D. Orton - on soil, frequently among mosses; J: 84, 61, 85, 7, 13, 1, 6, phases 4-6/7, IX 1994, VIII-XI 1995, VII-VIII, X-XI 1996, IX 1997.

Laccaria proxima (Boud.) Pat. - on soil, frequently among mosses; J: 67, 84, 61, 85, 7, 13, 1, 6, 11, 16, phases 4-8, VI, IX-X 1994, IX-XI 1995, V,VII-XI 1996, XI 1997; CzO: 5, 7, 8, phase 9/10, IX 1994, X-XI 1995, XI 1997.

Lepiota magnispora Murrill [= Lepiota ventriosospora D.A. Reid] - on soil; J: 16, phase 8, X 1996.

Lepiota pseudolilacea Huijsman [= Lepiota pseudohelveola Kühner ex Hora] - on soil; J: 13, phase 6, X 1995.

Lepista nuda (Bull.) Cooke - on soil and on litter; J: 11, phase 8, X 1995, X 1996, XI 1997.

Lycoperdon dermoxanthum Vittad. [= Bovista dermoxantha (Vittad.) De Toni; Bovista pusilla (Batsch) Pers.] - on soil; J: 67, 84, 61, 85, 7, 13, phases 4-6, IX 1994, IX-X 1995, VIII-IX 1996, VII, X 1997, IX 1998.

Lycoperdon ericaeum Bonord. - on soil; J: 85, phase 5, IX-X 1994, IX-X 1995; E.

Lycoperdon excipuliforme (Scop.) Pers. [= Calvatia excipuliformis (Scop.) Perdeck] - on soil; J: 13, phase 6, IX-X 1994, X 1995.

Lycoperdon marginatum Vittad. - on soil; J: 61, 13, phases 5-6, IX 1994, VIII-X 1995, IX, XI 1996, VII 1997; E.

Lycoperdon molle Pers. - on soil; J: 67, 84, 85, 13, 11, 16, phases 4-6, 8, VI, IX-X 1994, VIII-XI 1995, VII-XI 1996, VII, IX 1997.

Lycoperdon nigrescens Pers. - on soil; J: 67, 84, 85, 11, 16, phases 4, 5, 8, IX-X 1994, IX-X 1995, VIII-IX, XI 1996; CzO: 6, phase 9/10, IX 1995, IX 1997.

Lycoperdon norvegicum Demoulin - on soil; J: 84, 85, phases 4-5, X 1994, VIII 1996, VII 1997; I.

Lycoperdon perlatum Pers. - on soil; J: 67, 84, 85, 7, 13, 1, 6, 11, 16, phases 4-8, IX-X 1994, IX-XI 1995, X-XI 1996, IX, X 1997, VII 1998.

Lycoperdon utriforme Bull. [= Calvatia utriformis (Bull.) Jaap] - on soil; J: near the plot no. 61, phase 5, VII 1997.

Macrolepiota mastoidea (Fr.) Singer [= Macrolepiota konradii (P.D. Orton) M.M. Moser] - on soil; J: 84, 61, phase 4-5, IX 1994, X 1995, IX 1998.

Macrolepiota permixta (Barla) Pacioni - on soil; CzO: 8, phase 9/10, XI 1996.

Macrolepiota procera (Scop.) Singer - on soil; J: 84, 61, 6, 11, 16, phases 4, 5, 6/7, 8, IX-X 1994, IX-X 1995,VIII, X 1996, IX 1998; CzO: 5, phase 9/10, XI 1996. 
Marasmiellus vaillantii (Pers.) Singer - on fallen leaves of aspen; J: 85, 7, 11, 16, phases 5-6, 8, IX 1994, VIII-IX 1995, VII, IX 1996, VII 1998; rev. M. Lisiewska.

Marasmius epiphyllus (Pers.) Fr. - on fallen leaves of aspen; J: 11, phase 8, X 1995, IX 1996; rev. M. Lisiewska. Marasmius oreades (Bolton) Fr. - on soil and on litter; J: 82, 61, 13, 1, 11, phases 2, 5-8, IX-X 1994, VI, IX-XI 1995, VI-XI 1996, VII 1997.

Marasmius setosus (Sowerby) Noordel. - on fallen leaves of aspen; J: 11, phase 8, IX 1996; V; rev. M. Lisiewska. Melanoleuca graminicola (Velen.) Kühner \& Maire - on soil; J: 7, 13, phase 6, IX-X 1994, IX-X 1995.

Note: acc. to KnUdsen \& Vesterholt (2008) the species belongs to the complex of M. melaleuca (Pers.: Fr.) Murril s.l.

Mycena adonis (Bull.) Gray var. adonis - on fallen needles of pine; J: 61, phase 5, IX 1994, IX 1995; CzO: 6, phase 9/10, IX 1995; R; rev. M. Lisiewska.

Mycena aetites (Fr.) Quél. - on litter; J: 84, 1, 6, 16, phases 4, 6/7, 8, IX-X 1994, IX-X 1995; CzO; 6, phase 9/10, X 1996.

Mycena arcangeliana Bres. [= Mycena lineata (Fr.) Quél. ss. Lange] - on litter; J: 13, phase 6, XI 1996.

Mycena epipterygia (Scop.) Gray var. epipterygia - on litter; CzO, phase 9/10, XI 1997.

Mycena filopes (Bull.) P. Kumm. - on litter; J: 11, 16, phase 8, IX-X 1994, X 1996.

Mycena flavescens Velen. - on litter; J: 16, phase 8, IX 1995; R.

Mycena flavoalba (Fr.) Quél. - on decayed herbaceous plant debris, on litter; J: 82, 67, 84, 61, 85, 7, 13, 1, 6, 11, 16, phases 2-8, IX-X 1994, IX-X 1995, IX-XI 1996, XI 1997; CzO: 6, phase 9/10, IX 1994.

Mycena galopus (Pers.) P. Kumm. - on litter; J: 85, 13, 11, 16, phases 5, 6, 8, IX 1994, IX-X 1995, VII 1997; CzO: 2, 5, 6, 8, phase 9/10, IX-X 1994, IX-XI 1995, X-XI 1996, X 1997.

Mycena inclinata (Fr.) Quél. - on rotting stump; J: 16, phase 8, IX 1994, X 1996.

Mycena leptocephala (Pers.) Millet - on decayed herbaceous plant debris, on litter; J: 82, 67, 84, 61, 85, 7, 13, 1, 6, 11, 16, phases 2-8, IX-X 1994, VI, IX-X 1995, VI, IX-X 1996, XI 1997; rev. M. Lisiewska.

Mycena metata (Fr.) P. Kumm. [= M. tenella (Fr.) Quél.] - on litter, on fallen needles of pine; J: 84, 7, 6, 16, phases 4, 6, 6/7, 8, X 1994, XI 1995, XI 1996, CzO: 2, 5, 6, 7, 8, phase 9/10, IX-X 1994, IX-XI 1995, X-XI 1996, XI 1997.

Mycena olivaceomarginata (Masse) Masse [= M. avenacea (Fr.) Quél.; M. plicosa (Fr.) P. Kumm.] - on decayed herbaceous plant debris, on litter; J: 82, 67, 84, 61, 85, 13, 1, 11, 16, phases 2-8, IX-X 1994, VI, IX-XI 1995, IX 1996; rev. M. Lisiewska.

Mycena parabolica (Fr.) Quél. - on rotting wood; J: 13, 11, phases 6, 8, X 1994, X 1995; rev. M. Lisiewska. Mycena pura (Pers.) P. Kumm. - on humus, on litter; J: 82, 67, 84, 61, 7,13, 1, 6, 11, 16, phases 2-8, 6, VI, IX 1994 , IX-X 1995, VII-XI 1996,VII 1997; CzO: 5, phase 9/10, IX-X 1994, XI 1996.

Mycena purpureofusca (Peck) Sacc. - on rotting wood; CzO: 2, 5, 6, phase 9/10, IX 1994, IX 1995, X 1996; V.

Mycena rubromarginata (Fr.) P. Kumm. - on fallen twigs and decayed wood; J: 11, 16, phase 8, IX-X 1994, XI 1997.

Mycena sanguinolenta (Alb. \& Schwein.) P. Kumm. - on litter; J: 7, 11, 16, phases 6, 8, IX 1994, IX 1995; CzO: 5, 7, phase 9/10, IX 1994, IX 1995.

Mycena septentrionalis Maas Geest. [= Mycena vitrea (Fr.) Quél.] - on litter, among mosses; J: 1, phase 6/7, X 1995.

Mycena smithiana Kühner [= M. debilis (Fr.) Quél.] - on fallen needles of Juniperus; J: 16, phase 8, X 1997; det. M. Lisiewska.

Mycena speirea (Fr.) Gillet - on fallen twigs; J: 13, 1, 6, phases 6, 6/7, X 1994, IX 1996, XI 1997.

Mycena stipata Maas Geest. \& Schwöbel [= M. alcalina (Fr.) P. Kumm. s. auct. p.p.] - on rotting wood; J: 11, 16, phase 8, VI, IX 1994, IX-X 1995.

Mycena stylobates (Pers.) P. Kumm. - on fallen twigs; J: 84, 61, 85, 7, 1, 6, 11, 16, phases 4-8, IX 1994, IX-X 1995, VI, IX 1996.

Mycena supina (Fr.) P. Kumm. - on stump; J: 11, phase 8, IX-X 1995; E; det. M. Lisiewska.

Mycena vitilis (Fr.) Quél. - on litter, on fallen twigs; J: 67, 85, 7, 13, 1, 6, 11, 16, phases 4-8, IX-X 1994, IX-XI 1995, VII, X 1996.

Mycena vulgaris (Pers.) P. Kumm. - on fallen needles of pine; J:7, phase 6, X 1994, X 1996; CzO: 5, 6, 7, 8, phase 9/10, X 1994, XI 1995, X 1996.

Mycena zephirus (Fr.) P. Kumm. - on litter; J: 11, phase 8, IX 1994, X 1995. CzO: 2, 5, 6, 7, 8, phase 9/10, IX-X 1994, IX-XI 1995, X-XI 1996, X 1997.

Mycetinis scorodonius (Fr.) Wilson \& Desjardin [= Marasmius scorodonius (Fr.) Fr.] - among grass and herbs; J: 67, 84, phase 4, IX-X 1994, IX-XI 1995, VII-IX 1996. 
Panaeolus papilionaceus (Bull.) Quél. - on hare dung; J: 67, 85, 6, 16, phases 4, 5, 6/7, 8, IX-X 1995, X-XI 1996, VII 1997; R.

Panellus mitis (Pers.) Singer - on fallen branches of pine; J: 1, phase 6/7, XI 1995; CzO: 5, phase 9/10, X 1996. Parasola plicatilis (Curtis) Redhead, Vilgalys \& Hopple [= Coprinus plicatilis (Curtis) Fr.] - among grass and herbs; J: 82, phase 2, VI 1995, VI 1996.

Phaeomarasmius erinaceus (Fr.) Kühner - on fallen twigs; J: 13, 11, 16, phases 6, 8, X 1994, VI 1995, VI 1996, VII 1997; R.

Pholiota gummosa (Lasch) Singer - on rotting wood; J: 7, phase 6, X 1995, XI 1996.

Pholiota spumosa (Fr.) Singer - on rotting stump; CzO: 6, phase 9/10, IX 1994, X 1996, XI 1997.

Pleurotus ostreatus (Jacq.) P. Kumm. - on dead trunk of aspen; J: 16, phase 8, X-XI 1996.

Psathyrella candolleana (Fr.) Maire - on humus and litter; J: 11, 16, phase 8, VI, IX 1994, V, IX-X 1995, VII-VIII 1996.

Psathyrella fibrillosa (Pers.) Maire - on soil; J: 13, 1, phases 6-6/7, X 1995.

Psathyrella gyroflexa (Fr.) ss. M.M. Moser - on soil; J: 67, 61, phases 4-5, IX-X 1995.

Psathyrella tephrophylla (Romagn.) M.M. Moser ex Bon - on humus; J: 11, 16, phase 8, IX 1994, IX-X 1995.

Pseudomerulius aureus (Fr.) Jülich - on fallen branch of pine; CzO: 7, phase 9/10, IX 1994, VI, X 1995; R; det.

E. Parmasto.

Psilocybe montana (Pers.) P. Kumm. - on soil, among mosses and lichens; J: 67, 84, 61, 85, 7, 13, 1, 6, 11, phases

4-8, VI, IX-X 1994, VI,VIII-XI 1995, V-XI 1996; CzO: 2, phase 9/10, IX 1994; R.

Psilocybe phyllogena (Sacc.) Peck [= Psilocybe rhombispora (Britzelm.) Sacc.] - on soil, among mosses and lichens; J: 67, 7, 13, 1, 6, phases 4, 6-6/7, VII, IX 1997; R.

Resupinatus trichotis (Pers.) Singer - on fallen branches; J: 11, 16, phase 8, X 1994, VI, X 1995, VI 1996.

Rhodocollybia butyracea (Bull.) Lennox f. asema (Fr.) Antonín, Halling \& Noordel. [= Collybia butyracea (Bull.) P. Kumm. var. asema (Fr.) Quél.] - on soil and litter; J: 67, 84, 61, 85, 7, 13, 1, 6, 11, 16, phases 4-8, IX-X 1994, X-XI 1995, VII, X-XI 1996, XI 1997, IX 1998; CzO: 5, 6, phase 9/10, X 1996.

Rhodocollybia maculata (Alb. \& Schwein.) Singer [= Collybia maculata (Alb. \& Schwein.) P. Kumm.] - on litter; J: 16, phase 8, VI 1996.

Rhodocybe caelata (Fr.) Maire - on soil, among mosses and lichens; J: 67, 85, 7, 13, 6, 11, phases 4-8, IX-X 1994, IX 1995, IX 1996; E.

Rhodocybe fallax (Quél.) Singer - on humus; J: 16, phase 8, IX 1994, IX 1995; E.

Rhodocybe hirneola (Fr.) P.D. Orton - on soil, among mosses and lichens; J: 67, 85, 13, phases 4-6, X 1994, X 1995, VII 1998.

Rhodocybe parilis (Fr.) Singer - on soil, among mosses and lichens; J: 84, 61, 85, 7, 13, 6, phases 4-6/7, IX-X 1994, IX-X 1995, VII, IX, XI 1996, VII 1998.

Ripartites tricholoma (Alb. \& Schwein.) P. Karst. s.1. - on soil; J: 7, 13, 1, phases 6-6/7, phases 4-6/7 IX-X 1994, X 1995.

Schizophyllum amplum (Lév.) Nakasone 191996 [= Auriculariopsis ampla (Lév.) Maire] - on dead branches of aspen; J: 11, 16, phase 8, X 1994, VI 1995.

Strobilurus stephanocystis (Hora) Singer - on buried pine cones; J: 7, 13, 1, 6, 11, phases 6-8, VI 1994, V 1995, V-VI 1996; CzO: 6, phase 9/10, VI 1996.

Strobilurus tenacellus (Pers.) Singer - on buried pine cones; J: 11, phase 8, VI 1994, V 1995.

Stropharia semiglobata (Batsch) Quél. - on litter; J: 61, phase 5, X 1997.

Tapinella atrotomentosa (Batsch) Šutara [= Paxillus atrotomentosus (Batsch) Fr.] - on decayed wood stakes; J: 85, 61, 7, 6, phases 5-6/7, VII-VIII 1996, VII 1997.

Tapinella panuoides (Fr.) E.-J. Gilbert [= Paxillus panuoides (Fr.) Fr.] - on fallen branch of pine; CzO: 2, phase 9/10, IX 1994.

Tricholoma albobrunneum (Pers.) P. Kumm. - on soil, under pine; J: 84, 61, 85, 7, 13, 1, 6, 16, phases 4-8, X 1994, X-XI 1995, X-XI 1996, X 1997, IX 1998; det. H. Komorowska.

Tricholoma equestre (L.) P. Kumm. - on soil, under pine; J: 61, 85, 7, 13, 1, 6, 11, 16, phases 5-8, IX-X 1994, X-XI 1995, VIII-XI 1996; I.

Tricholoma imbricatum (Fr.) P. Kumm. - on soil, under pine; J: 7, 13, 11, phases 6, 8, X 1995, X 1996, X 1998; det. H. Komorowska.

Tricholoma pessundatum (Fr.) Quél. - on soil, under pine; J: 7, phase 6, X 1994 ; R; det. H. Komorowska.

Tricholoma portentosum (Fr.) Quél. - on soil, under pine; J: 84, 61, 7, 13, 1, 6, 11, 16, phases 4-8, X 1994, X-XI 1995, X-XI 1996. 
Tricholoma saponaceum (Fr.) P. Kumm. var. saponaceum - on soil, under pine; J: 61, 7, 13, 1, 6, phases 5-6/7, X 1994, X 1995, IX-XI 1996, X-XI 1997.

Tricholoma saponaceum (Fr.) P. Kumm. var. squamosum (Cooke) Rea - on soil, under pine; J: 84, phase 4, X 1995; CzO: 5, 7, phase 9/10, IX 1994, X 1995, XI 1996, IX 1998.

Tubaria confragosa (Fr.) Harmaja - on fallen branch; J: 16, phase 8, IX 1995; E.

Tubaria furfuracea (Pers.) Gillet - on fallen twigs, on pieces of bark; J: 84, 11, 16, phases 4, 8, IX 1994, IX-X 1995, VI-VII, IX-XI 1996, VII, XI 1997.

Xeromphalina cornui (Quél.) J. Favre - on fallen needles of pine; J: 11, phase 8, IX-X 1994, IX 1995; CzO: 2, 5, 6, 7, 8, phase 9/10, IX 1994, IX 1995, VII 1996, VII, IX 1997.

\section{Atheliales}

Athelia decipiens (Höhn. \&t Litsch.) J. Erikss. - on fallen twigs of pine; CzO: 5, 7, 8, phase 9/10, VIII 1994, VI 1996.

Athelia epiphylla Pers. - on decayed log; J: 11, phase 8, X 1994; det. W. Wojewoda.

Leptosporomyces galzinii (Bourdot) Jülich - on fallen branches, on fallen cones of pine; J: 7, 13, 1, 6, 11, 16, phases 6-8, VI 1995, VI 1996; CzO: 2, 5, 6, 7, 8, phase 9/10, VI 1995; det. W. Wojewoda.

\section{Boletales}

Boletus edulis Bull. - on soil , under pine, birch, aspen; J: 67, 84, 61, 85, 13, 1, 6, 11, 16, phases 4-8, IX-X 1994, VI, VIII, IX-X 1995, VII-X 1996, VII 1997, VII 1998.

Boletus pinophilus Pilát \& Dermek - on soil, under pine; J: 1, 6, phase 6/7, VIII, X 1996, VII 1997.

Boletus reticulatus Schaeff. - on soil, under Betula, pine; J: 84, 1, phases 4, 6/7, VIII 1995, VIII 1996.

Chalciporus piperatus (Bull.) Bataille - on soil, under pine; J: 67, 84, 61, 85, 7, 13, 1, 6, 11, 16, phases 4-8, IX 1994 , VIII-X 1995, VII-XI 1996, VII 1998.

Chroogomphus rutilus (Schaeff.) O.K. Mill. - on soil, under pine; CzO: 5, phase 9/10, X 1995.

Coniophora arida (Fr.) P. Karst. - on fallen branches of pine; J: 11, phase 8, X 1994; CzO: 2, 5, 7, 8, phase 9/10, IX 1994, X 1995, VI, X 1996; det. W. Wojewoda.

Gyroporus castaneus (Bull.) Quél. - on soil; J: 84, 85, phases 4-5, VIII, X 1995, VIII 1996, VII 1997 ; R.

Gyroporus cyanescens (Bull.) Quél. - on soil; CzO: phase 9/10, VII 1997; R.

Hygrophoropsis aurantiaca (Wulfen) Maire - on soil; J: 6, phase 6/7, IX 1996; CzO: 5, 6, 7, phase 9/10, IX-X 1994, X-XI 1995, XI 1996.

Leccinum aurantiacum (Bull.) Gray - on soil, under aspen; J: 84, 85, 7, 1, 11, phases 4-8, IX 1994, VI, VIII-X 1995 , VII-IX 1996, VII 1997, VII 1998.

Leccinum scabrum (Bull.) Gray - on soil, under birch; J: 67, 84, 16, phases 4, 8, IX 1994, VIII, X 1995 , VIII 1996 , VII, IX 1997.

Paxillus involutus (Batsch) Fr. - on soil, under pine, birch, aspen; J: 67, 84, 61, 85, 7, 13, 1, 11, 16, phases 4-8, X 1994, IX-X 1995, VII-VIII, X-XI 1996, VII, XI 1997, VII 1998; CzO: 2, 5, 6, 7, 8, phase 9/10, IX-X 1994, X-XI 1995, VIII, X-XI 1996, XI 1997, VII 1998.

Rhizopogon luteolus Fr. \& Nordholm [ $=$ R. obtextus (Spring.) Rauschert $]$ - hypogeous, party visible on the soil surface; J: 67, 7, 6, phases 4, 6-6/7, IX 1994, X 1995, VIII 1996, XI 1997, IX 1998; det. M. Ławrynowicz.

Scleroderma bovista Fr. - on soil; J: near the plot no. 11, phase 8, IX 1997.

Scleroderma fuscum (Corda) E. Fischer. - on soil; J: 85, phase 5, X 1995; E.

Note. According to Legon et al. (2009) S. fuscum and S. bovista are synonyms; the species is mentioned as a separate one by Wojewoda (2003) and red-listed in Poland (WoJEwoda \& Kawrynowicz 2006).

Suillus bovinus (L.) Roussel - on soil, under pine; J: 13, 1, 6, phases 6-6/7, X 1995, XI 1996.

Suillus luteus (L.) Roussel - on soil, under pine; J: 67, 84, 61, 85, 7, 13, 1, 6, 11, phases 4-8, IX-X 1994, VIII-XI 1995, VII-XI 1996, VII 1998.

Suillus variegatus (Sw.) Kuntze - on soil, under pine; CzO: 7, phase 9/10, X 1996.

Tylopilus felleus (Bull.) P. Karst. - on soil; CzO: 5, 6, 8, phase 9/10, VIII 1995, VII 1997.

Xerocomus badius (Fr.) E.-J. Gilbert [= Boletus badius (Fr.) Fr.] - on soil, under pine; J: 7, 1, 6, phases 6-6/7, IX-X 1995, VIII, X 1996, VII 1998; CzO: 2, 5, 6, 7, 8, phase 9/10, IX-X 1994, X-XI 1995, X-XI 1996 , VII 1997.

Xerocomus chrysenteron (Bull.) Quél. [= Boletus chrysenteron Bull.] - on soil, under birch, pine; J: 85, phase 5, X 1995.

Xerocomus subtomentosus (L.) Quél. [= Boletus subtomentosus (L.) Quél.] - on soil, under birch, pine; J: 67, 84, 61, 85, phase 4-5, IX 1994, VII 1997, VII 1998. 


\section{Cantharellales}

Botryobasidium vagum (Berk. \& M.A. Curtis) D.P. Rogers - on fallen branches of pine; CzO: 2, 5, 7, phase 9/10, IX 1994, VI, IX-X 1995, VI 1996; R; det. W. Wojewoda.

Cantharellus cibarius Fr. - on soil, under pine; J: 16, phase 8, VI, IX-X 1994, VI, VIII-X 1995, VI-VIII, X-XI 1996; CzO: 2, 5, 6, 7, phase 9/10, X 1994, VI, IX-X 1995, VIII, X-XI 1996, VII 1997, VII 1998 ; I.

Tulasnella pallida Bres. - on stump of pine; J: 11, phase 8, X 1995; det. W. Wojewoda.

\section{Geastrales}

Geastrum quadrifidum Pers. - on soil; J: 11, 16, phase 8, VI, IX 1994; R.

Sphaerobolus stellatus Tode - on fallen twigs, on pieces of bark; J: 84, 7, 11, 16, phases 4, 6, 8, IX-X 1994, IX-X 1995.

\section{Gomphales}

Ramaria cf. abietina (Pers.) Quél. - on soil; J: 16, phase 8, IX 1994, IX 1995.

Ramaria eumorpha (P. Karst.) Corner - on soil; J: 67, 7, 13, 6, phases 4, 6-6/7, IX-X 1994, IX 1995, VIII, X 1996.

\section{Hymenochaetales}

Coltricia perennis (L.) Murril - on soil; J: 84, 61, 16, phases 4, 5, 8, IX 1994, X 1995, VI, X 1996, IX 1997; CzO: on forest path, phase 9/10, VII 1998.

Hymenochaete tabacina (Sowerby) Lév. - on fallen twigs of aspen; J: 11, 16, phase 8, IX 1994, VI, VIII 1995, VI, XI 1996; R; det. E. Parmasto.

Hyphodontia aspera (Fr.) J. Erikss. - on log and fallen branches of pine; J: 11, phase 8, VIII-IX 1995, CzO: 2, 8, phase 9/10, IX 1994, VIII, X 1995; det. W. Wojewoda.

Hyphodontia quercina (Pers.) J. Erikss. - on fallen branch of aspen; J: 16, phase 8, VI 1995; det. W. Wojewoda.

Hyphodontia subalutacea (P. Karst.) J. Erikss. - on fallen branches of pine; CzO: 6, 8, phase 9/10, IX 1994, X 1995, VI 1996.

Inonotus rheades (Pers.) Bondartsev \& Singer - on dead trunks of aspen; J: 11, 16, phase 8, VI-X 1994, VIII, X 1995, VI-VII, X-XI 1996; CzO: 5, phase 9/10, V 1996; V; rev. W. Wojewoda.

Phellinus punctatus (Fr.) Pilát - on dead trunks of aspen; J: 11, 16, phase 8, X 1994, XI 1996; rev. W. Wojewoda.

Rickenella fibula (Bull.) Raithelh. - on soil, among mosses; J: 67, 84, 61, 85, 7, 13, 1, 6, phases 4-6/7, IX-X 1994, IX-XI 1995, VII-XI 1996.

Schizopora paradoxa (Schrad.) Donk [= Hyphodontia paradoxa (Schrad.) E. Langer \& Vesterholt s.1.] - on dead trunk of aspen; J: 16, phase 8, X 1994.

Tubulicrinis subulatus (Bourdot \& Galzin) Donk - on decayed woody debris of aspen ; J: 11, phase 8, VI 1995; CzO: 2, phase 9/10, V 1996; det. W. Wojewoda.

\section{Polyporales}

Byssomerulius corium (Pers.) Parmasto - on decayed woody debris; J: 11, 16, phase 8, IX-X 1994, XI 1997; det. E. Parmasto.

Daedaleopsis confragosa (Bolton) J. Schröt. - on dead trunks and branches of aspen; J: 11, 16, phase 8, VIII-X 1994, X 1995, VIII-XI 1996.

Fomes fomentarius (L.) J.J. Kickx - on dead trunk of birch; J: 16, phase 8, 1994, 1995, 1996, IX 1997.

Gloeoporus taxicola (Pers.) Gilb. \& Ryvarden - on dead branches of pine; J: 11, phase 8, VIII 1995, CzO: 2, 7, phase 9/ 10, VIII 1994, VI 1995; R; rev. W. Wojewoda.

Hyphoderma setigerum (Fr.) Donk - on fallen twigs of aspen; J: 11, 16, phase 8, IX-X 1994, VI 1995; CzO: 8, phase9/10, IX 1994; det. W. Wojewoda.

Oligoporus alni (Niemelä \& Vampola) M. Piątek [= Postia subcaesia ss. Polish authors] - on log; J: 11, phase 8, IX-X 1994, X 1995, X 1996. See notes in WoJEwoda (2003; p. 474)).

Panus suavissimus (Fr.) Singer [= Lentinus suavissimus Fr.] - on fallen twigs of aspen; J: 16, phase 8, VI, IX 1994, IX 1995.

Phanerochaete sanguinea (Fr.) Pouzar - on fallen branches and logs of pine; J: 7, 1, 6, phases 6-6/7, X 1994, VI, X 1995; CzO: 2, 5, 8, phase 9/10, VIII 1994, VI, VIII, X 1995; det. W. Wojewoda.

Phlebia rufa (Pers.) M.P. Christ. - on stump of birch; J: 11, 16, phase 8, IX-X 1994, VI, VIII 1995, XI 1996; R; rev. W. Wojewoda.

Phlebiella pseudotsugae (Burt) K.H. Larss. \& Hjortstam - on rotting log of pine; CzO: 2, phase 9/10, V 1995; det. W. Wojewoda. 
Phlebiella sulphurea (Pers.) Ginns \& M.N.L. Lefebvre [= Phlebiella vaga (Fr.) P. Karst.] - on fallen branches, on pieces of bark; J: 11, phase 8, IX-X 1995; CzO: 2, 5, 6, 7, 8, phase 9/10, IX 1994, VI, VIII, IX-X 1995, VI 1996, IX 1997; det. E. Parmasto.

Polyporus ciliatus Fr. - on fallen branches; J: 85, 6, phases 5, 6/7, VI 1994, VI 1996.

Steccherinum fimbriatum (Pers.) J. Erikss. - on rotting wood; J: 16, phase 8, X 1994, VI, VIII 1995, V 1996; R. Trametes ochracea (Pers.) Gilb. \& Ryvarden [= Trametes zonatella Ryvarden] - on fallen branches; J: 16, phase 8, IX-X 1994.

Trichaptum fuscoviolaceum (Ehrenb.) Ryvarden - on log of pine; J: 7, phase 6, VI, IX-X 1994.

\section{Russulales}

Amylostereum laevigatum (Fr.) Boidin - on dead branches of Juniperus; J: 1, 11, 16, phases 6/7-8, X 1994, VI 1995; det. E. Parmasto.

Auriscalpium vulgare Gray - on buried cones of pine; J: 1, 6, 11, phases 6/7, 8, IX-X 1994, IX-X 1995, VII, IX, XI 1996, IX 1997; CzO: 2, 5, 6, 8, phase 9/10, VIII-IX 1994, IX, XI 1995.

Gloeocystidiellum porosum (Berk. \& M.A. Curt.) Donk - on fallen branches of aspen; J: 11, phase 8, IX-X 1994, VIII 1995; det. W. Wojewoda.

Lactarius helvus (Fr.) Fr. - on soil; J: 1, phase 6/7, IX 1997.

Lactarius hysginus (Fr.) Fr. - on soil; J: 6, phase 6/7, XI 1997; V.

Lactarius necator (Bull.) Pers. [= Lactarius turpis (Weinm.) Fr.] - on soil, under birch; J: 11, phase 8, VIII 1996.

Lactarius quieticolor Romagn. - on soil, under pine; J: 61, phase 5, X-XI 1995, VIII 1996, VII 1998.

Lactarius rufus (Scop.) Fr. - on soil, under pine; J: 7, 13, 1, 6, 11, phases 6-8, IX-X 1994, IX-XI 1995, VII-VIII, IX-X 1996; CzO: 2, 5, 7, 8, phase 9/10, IX 1994, X 1995, VIII 1996, IX 1997.

Lactarius tabidus Fr. [= Lactarius thejogalus (Bull.) Gray s. auct.] - on soil; CzO: 5, phase 9/10, IX 1994, X 1995. Lactarius torminosus (Schaeff.) Pers. - on soil, under birch; J: 11, 16, phase 8, IX-X 1994, X 1995, VII 1998.

Lactarius uvidus (Fr.) Fr. - on soil, under aspen; J: 85, 11, 16, phases 5, 8, X 1995.

Lactarius vietus (Fr.) Fr. - on soil, under birch; J: 84, phase 4, X 1995.

Peniophora cinerea (Pers.) Cooke - on fallen twigs of aspen; J: 11, phase 8, VI 1995.

Peniophora polygonia (Pers.) Bourdot \& Galzin - on fallen twigs of aspen; J: 11, 16, phase 8, VI, IX-X 1994, V-VI, X 1995, XI 1996; det. W. Wojewoda.

Russula amethystina Quél. - on soil, under pine; CzO: phase 9/10, XI 1997, VII, IX 1998.

Russula badia Quél. - on soil, under pine; CzO: 2, 5, 6, 7, 8, phase 9/10, IX-X 1994, IX-XI 1995, X 1996.

Russula clavipes Velen. [= Russula xerampelina (Schaeff.) Fr. var. elaeodes Bres., R. elaeodes (Bres.) Bon.] - on soil under birch, aspen J: 84, 85, 7, 11, 16, phases 4-6, 8, X 1994, VIII, X 1995, VII-VIII 1996, VII 1997, VII 1998; CzO: 5, phase 9/10, IX 1997.

Russula decolorans (Fr.) Fr. - on soil, under pine; CzO: 2, 5, 6, 7, 8, phase 9/10, VIII, X 1995, VII-X 1996, VII 1997, VII 1998.

Russula emetica (Schaeff.) Pers. - on soil, under pine; J: 84, phase 4, X 1995; CzO: 2, 5, 6, 7, IX-X 1995 , X 1996. Russula fragilis (Pers.) Fr. - on soil, under aspen, pine, among mosses; J: 67, 84, 85, 7, 11, 16, phases 4-6, 8, IX-X 1994, VIII-X 1995, VII-VIII, X 1996, VII 1997, VII 1998; CzO: 2, 5, phase 9/10, X 1995, X 1996.

Russula galochroa (Fr.) Fr. [= R. anatina Romagn.] - on soil, under birch, aspen; J: 84, 85, 11, 16, phases 4-5, 8, IX 1994, VIII, X 1995, VII-VIII 1996, VII 1997, VII 1998.

Russula cf. mustelina Fr. - on soil, under pine; J: 16, phase 8, IX-X 1994, VII 1996.

Russula nigricans (Bull.) Fr. - on soil; CzO: phase 9/10, IX 1998.

Russula paludosa Britzelm. - on soil, under pine; J: 16, phase 8, IX-X 1994, VIII 1995, VII 1997; CzO: 2, 5, 6, 7, 8, IX 1994, VI, VIII-X 1995, VII-VIII 1996, VII, IX 1997, VII 1998.

Russula subfoetens Wm.G. Sm. - on soil, under birch; J: 84, 85, phases 4-5, VIII, X 1995.

Russula turci Bres. s. Maire - on soil, under pine; CzO: 7, phase 9/10, X 1995.

Russula versicolor Jul. Schäff. - on soil, under birch; J: 16, phase 8, IX 1994.

Russula vesca Fr. - on soil; CzO: 5, 8, phase 9/10, X 1995, IX 1997.

Russula vinosa Lindblad - on soil, under pine, among mosses; CzO: 5, phase 9/10, VI, X 1995, VII 1996, VII 1997.

Russula cf. vinosobrunnea (Bres.) Romagn. - on soil; J: 85, phase 5, X 1995.

Russula xerampelina (Schaeff.) Fr. s.str. - on soil, under pine; CzO: 5, 7, 8, phase 9/10, X 1995.

Stereum hirsutum (Willd.) Gray - on fallen branches of birch; J: 11, 16, phase 8, IX-X 1994, IX-X 1995, X-XI 1996. 
Vesiculomyces citrinus (Pers.) E. Hagstr. [= Gloiothele citrina (Pers.) Ginns \& G.W. Freeman] - on woody debris; J: 11, phase 8, IX 1994, X 1995; det. W. Wojewoda.

\section{Thelephorales}

Sarcodon squamosus (Schaeff.) Quél. - on soil, under pine; J: 13, 1, 6, phases 6-6/7, IX-X 1994, X 1995, X-XI 1996.

Thelephora caryophyllea (Schaeff.) Pers. - on soil; J: 84, 1, 11, 16, phases 4, 6/7, 8, IX-X 1994, IX, XI 1995,VII 1997, VII, IX 1998; V.

Thelephora palmata (Scop.) Fr. - on soil (forest path); CzO: phase 9/10, VII 1997.

Thelephora terrestris Ehrh. - on soil, on woody debris; J: 67, 84, 61, 85, 7, 13, 1, 6, 11, phases 4-8, VI, IX-X 1994, VI, VIII-XI 1995, VI, VIII-XI 1996; CzO: 2, 5, 6, 7, 8, phase 9/10, IX 1994, IX 1995, IX 1996.

Agaricomycetes, incertae sedis

Peniophorella praetermissa (P. Karst.) K.-H. Larss. [= Hyphoderma praetermissum (P. Karst.) J. Erikss. \& Å. Strid] - on fallen branches of pine, aspen; J: 11, phase 8, IX 1994, VI 1995; det. W. Wojewoda.

Resinicium bicolor (Alb. \& Schwein.) Parmasto - on woody debris; J: 16, phase 8, VI 1995; det. W. Wojewoda. 


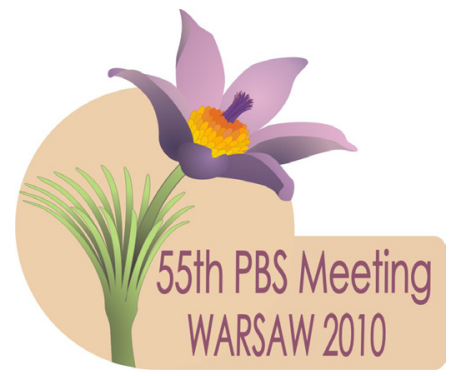

\title{
THE POLISH BOTANICAL SOCIETY
}

\author{
announces the \\ 55th MEETING OF THE \\ POLISH BOTANICAL SOCIETY \\ „Planta in vivo, in vitro et in silico" \\ September 6-12, 2010 \\ Warsaw University of Life Sciences-SGGW \\ 166 Nowoursynowska St., \\ 02-787 Warsaw, Poland
}

\section{Programme}

General Assembly (September 6), plenary sessions (September 7), session arranged by PBS sections (September 8-9), field sessions presenting the virtues and changes of Central and North-East Poland as well as of Southern Lithuania vegetation

\section{Organizer}

Warsaw Branch of Polish Botanical Society

\section{Coorganizers}

Warsaw University of Life Sciences-SGGW (WULS-SGGW):

Forestry Faculty: Forest Botany Department, Mycology and Forest Phytopathology Division; Agriculture and Biology Faculty: Department of Botany; Horticulture and Landscape Architecture Faculty: Department of Environment Protection, Ornamental Plants Department

\section{Warsaw University (WU)}

Biology Faculty: Institute of Botany, Botanical Garden

Forest Research Institute (FRI)

Botanical Garden Centre for Biological Diversity Conservation of Polish Academy of Sciences (BG CBDC PAS)

\section{Organizing Committee}

Jacek Zakrzewski, Katarzyna Marciszewska, Łukasz Chachulski, Wojciech Ciurzycki, Piotr Dobrzyński, Bożena Dubielecka, Kazimierz Dyguś, Małgorzata Falencka-Jabłońska, Mirosława Górecka, Magdalena Górska-Czekaj, Sławomir Janakowski, Józef Klocek, Monika Latkowska, Elżbieta Melon, Artur Obidziński, Małgorzata Pstrągowska, Piotr Sikorski, Mirosław Sobczak, Małgorzata Sułkowska, Andrzej Szczepkowski, Ewa Zaraś-Januszkiewicz

\section{Scientific Committee}

Jan J. Rybczyński, Maria Ławrynowicz, Elżbieta Bednarska, Urszula Bielczyk, Jacek Borowski, Maria Dynowska, Ludwik Frey, Jan Holeksa, Ewa Kępczyńska, Jan Kępczyński, Maria Lankosz-Mróz, Anna Mikuła, Dorota Nalepka, Elżbieta Romanowska, Anna Rusińska, Ewa Szczęśniak, Elżbieta WeryszkoChmielewska, Beata Zagórska-Marek

\section{Local Scientific Committe}

Grażyna Garbaczewska, Helena Kubicka, Aleksandra Łukaszewska, Katarzyna Marciszewska, Artur Obidziński, Jerzy Puchalski, Barbara Sudnik-Wójcikowska, Andrzej Szczepkowski, Hanna WerblanJakubiec, Czesław Wysocki, Stefan Zajączkowski, Jacek Zakrzewski

55th PBS Meeting Office

Katrzyna Marciszewska, Ph.D.

Forest Botany Division, Forestry Faculty Warsaw University of Life Sciences-SGGW

159 Nowoursynowska St., 02-776 Warsaw, Poland

E-mail: ptb.marciszewska@wl.sggw.pl

Tel. (+4822) 5938026 Fax. (+4822) 5938022

http:/www.zjazd55.ptb.waw.pl 